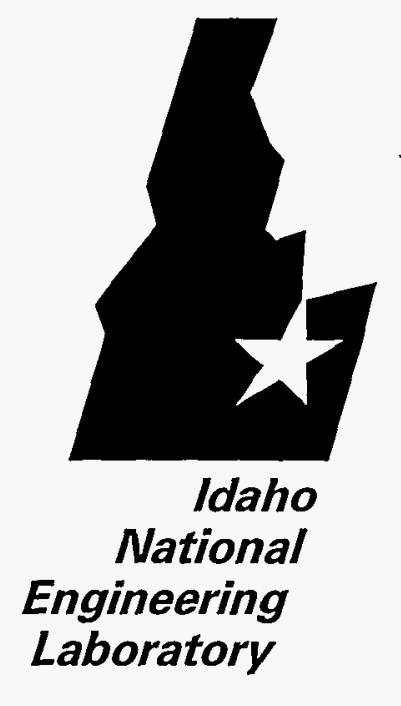

INEELIEXT-97-00977

September 1997

\title{
Feasibility Study for Early Removal of HEU from CPP-651-Phase II
}

Cari Vitale Smith

Roger Henry

Carl Milligan

Bob Harmon

John Peterson

Mary Alice Thom

Roy Campbell

Bruce Hendrix 


\section{DISCLAIMER}

This report was prepared as an account of work sponsored by an agency of the United States Government. Neither the United States Government nor any agency thereof, nor any of their employees, makes any warranty, express or implied, or assumes any legal liability or responsibility for the accuracy, completeness, or usefulness of any information, apparatus, product, or process disclosed, or represents that its use would not infringe privately owned rights. Reference herein to any specific commercial product, process, or service by trade name, trademark, manufacturer, or otherwise does not necessarily constitute or imply its endorsement, recommendation, or favoring by the United States Government or any agency thereof. The views and opinions of authors expressed herein do not necessarily state or reflect those of the United States Government or any agency thereof. 


\section{DISCLAMIEX}

Portions of this docament may be illegible in electronic imoge products. Images are produced from the best availabie original doevonem 


\section{SUMMARY}

This report develops and evaluates different strategies for early removal of SNM from the CPP-651 vault via comparisons of resource-loaded schedules and cost and risk information. Preliminary Phase I removal strategies (INEL/EXT-97 Rev-1) were developed in early 1997 via a systems engineering approach. This effort identified local HEU management concerns and national post cold war issues to help assure an integrated programmatic solution that benefits the DOE complex and the INEEL. Phase II maintained this systems engineering focus to analyze detailed schedules, identify critical path resource issues, and ultimately provide a recommended plan for early removal of the CPP-651 SNM. Provided current assumptions do not change, implementation of this proposed course of action will (a) expedite the consolidation of SNM across the DOE complex and at the INEEL, (b) promote disposition of about $2.4 \mathrm{MT}$ of HEU to LEU feed stock, and (c) improve local and offsite planning and communication. Overall costeffectiveness for the complex is assumed and can be validated as soon as the estimated receiver costs are verified.

Completion of Phase II has provided: (a) a resource-loaded base case, (b) options for expediting the removal of SNM from CPP-651 (the preferred option is identified), and (c) the tools and planning software to provide continued support for this program.

Removal of SNM from CPP-651 within the proposed 10-year window required developing a plan that integrated specific tasks to minimize risk, cost, time, receipt issues at receiver locations (i.e., Oak Ridge 10 SST shipments per year from the INEEL), ${ }^{2}$ and retain future operational flexibility to insure the greatest probability of success. Guided by these criteria, we produced our base case which is summarized by the following actions:

- Continue to collect missing data and resolve package certification issues

- Dry mill and blend denitrator product $\left(\mathrm{UO}_{3}\right)$ with depleted uranium $\left(\mathrm{UO}_{3}\right)$ in a sealed can to $<20 \%$ enrichment (LEU threshold) until the HEU blending site (e.g., SRS) has enough storage vault capacity to accept ICPP HEU (dry blending is terminated as soon as HEU shipments are made to the receiver)

- Ship $27 \mathrm{~kg}$ of Rocky Flats $\mathrm{HEU}\left(\mathrm{U}_{3} \mathrm{O}_{8}\right)$ to $\mathrm{SRS}$ as soon as possible

- Utilize ANL-W resources for timely storage and/or dispositioning of VYCOR Glass, ANL-E materials, and JANUS material.

a. IAEA programs were not considered in this study. 
The base case empties CPP-651 within the 10-year window with a high probability of success (low shipper/receiver risk) and requires no additional personnel. This plan is similar to that identified in Phase I as the preferred option, but it does not yield the schedule reduction (2001) that was believed to be possible in Phase I. Resource loading of the proposed plan demonstrated that the reduced schedule identified in Phase I could not be achieved with existing staff.

Systems engineering was used to develop and evaluate four options/strategies for accelerating removal of SNM (see Figure EX-1). A simplistic overview of the program activities for each option can be summarized as preparation, packaging/shipping, tasks outside CPP-651, and tasks inside CPP-651. There is a limit on how many personnel can work effectively in CPP-651 and similarly there is a limit to the number of personnel working on preparation tasks. Thus, selection of extra personnel was done in a strategic manner. The following strategies utilized incremental adjustments in resources in one or both of these areas to resolve critical path issues for expediting the removal of SNM from CPP-651. They are characterized as follows:

Option A-Base case plus transfer negotiation team (TNT):

A dedicated team of about four experienced personnel are formed to resolve shipper/receiver issues and assist with related preparation paperwork for all inventory items.

Option B-Ship-as-is plus TNT:

The TNT is implemented to resolve shipper/receiver issues, but none of the SNM is processed or conditioned at ICPP.

Option C-Base case plus TNT and a dedicated crew:

The TNT and nine additional ICPP personnel are added to the CPP-651 operations to produce the equivalent of four days of packaging operations per week.

Option D-Ship as-is-plus TNT and a dedicated crew:

The TNT and nine additional ICPP personnel are added to CPP-651 operations to produce the equivalent of four days of packaging operations per week.

The schedule impact, programmatic cost, and risk of these proposed options are summarized in Table EX-1 along with the referenced base case and the current funding. The current funding will not provide closure of CPP-651 until January 30, 2009. It also does not support conditioning of the denitrator product which further jeopardizes successful removal of this inventory item. Thus, all comparisons are made against the base case and not the current budget. Figure EX-2 presents a graphic display of the schedules. This data indicates that significant gains in shortening the schedule are possible if additional experienced staff can be allocated to the program or if the scope of work is reduced. 


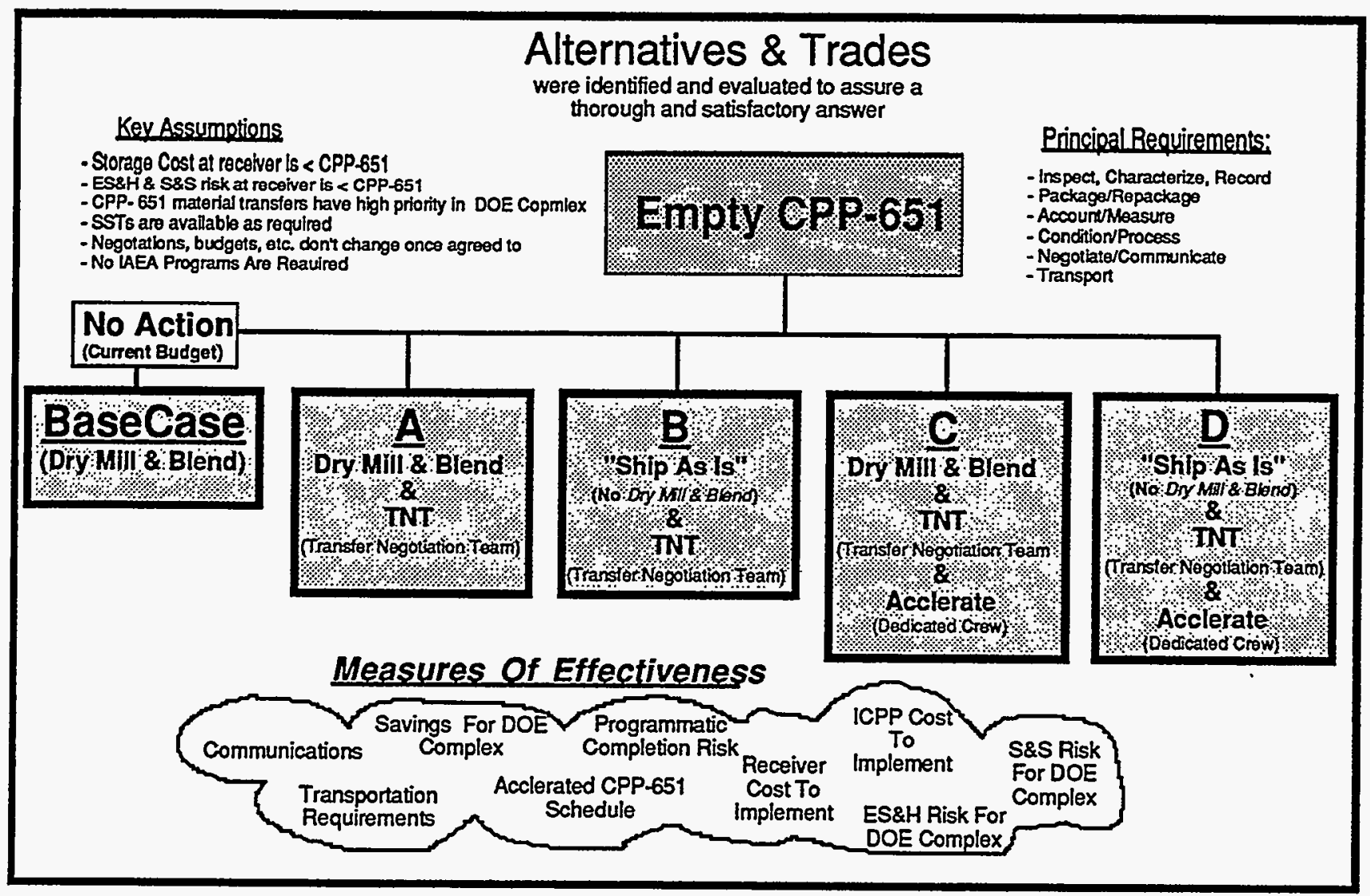

Figure EX-1. Development of alternate schedule.

Table EX-1. Schedule impact, costs, and risk of the proposed options.

\begin{tabular}{|c|c|c|c|c|c|c|c|c|c|}
\hline & $\begin{array}{c}\text { New } \\
\text { Staff } \\
\text { (FTEs) }\end{array}$ & $\begin{array}{c}\text { CPP } \\
\text { Safeguards } \\
\text { \& Security } \\
\text { Costs (\$ M) } \\
\text { Until } \\
9 / 11 / 06 \\
\text { (b) } \\
\end{array}$ & \begin{tabular}{|c|} 
Surveillance \\
$\&$ \\
Maintenance \\
Costs (\$M) \\
For CPP-651 \\
Until Empty \\
(c) \\
\end{tabular} & $\begin{array}{l}\text { Transfer } \\
\text { Cost To } \\
\text { Remove } \\
\text { Material } \\
\text { From CPP. } \\
651(\$ M) \\
\end{array}$ & \begin{tabular}{|c|} 
Total Cost - \\
Options Are \\
Benchmarked \\
Against Base \\
Case $(\$ \mathrm{M})$ \\
\end{tabular} & \begin{tabular}{|c|} 
Savings \\
(Base \\
Case \\
Cost \\
Minus \\
Option \\
Cost) \\
\end{tabular} & $\begin{array}{c}\text { Receiver } \\
\text { Acceptance } \\
\text { (10 Is HIGH } \\
\text { Pisk) } \\
\end{array}$ & $\begin{array}{c}\text { Completion } \\
\text { Date }\end{array}$ & $\begin{array}{c}\text { Reduced } \\
\text { Base Case } \\
\text { Schedule By } \\
\text { (1) Months } \\
\end{array}$ \\
\hline Current Budget (a) & 0 & $\$ 100.1$ & $\$ 6.3$ & $\$ 3.4$ & $\$ 109.7$ & $(\$ 19.0)$ & $10+$ & 30-Jan-09 & -29 \\
\hline \multicolumn{10}{|l|}{ (Ship As Is - Existing Staff) } \\
\hline Base Case & 0 & $\$ 79.0$ & $\$ 5.1$ & $\$ 6.6$ & $\$ 90.7$ & $\$ 0.0$ & 3 & $11-$ Sep-06 & 0 \\
\hline \multicolumn{10}{|l|}{ (Dry Blend - Existing Stafi) } \\
\hline Eption A & 4 & $\$ 76.0$ & $\$ 4.4$ & $\$ 8.6$ & $\$ 89.0$ & $\$ 1.7$ & 3 & 18-Jun-05 & 15 \\
\hline \multicolumn{10}{|l|}{ (Dry Bland + TNT) } \\
\hline Option B & 4 & $\$ 71.6$ & $\$ 3.5$ & $\$ 6.2$ & $\$ 81.3$ & $\$ 9.4$ & 10 & 2-Sep-03 & 37 \\
\hline \multicolumn{10}{|l|}{ (Shlp As IS + TNT) } \\
\hline Eption C & 13 & $\$ 71.6$ & $\$ 3.5$ & $\$ 10.3$ & $\$ 85.4$ & $\$ 5.3$ & 2 & 4-Sep-03 & 37 \\
\hline \multicolumn{10}{|l|}{ (Dry Bland + TNT + Crow) } \\
\hline Option D & 13 & $\$ 68.1$ & $\$ 2.8$ & $\$ 7.3$ & $\$ 78.2$ & $\$ 12.5$ & 9 & 27-Mar-02 & 54 \\
\hline \multicolumn{10}{|l|}{ (Ship As Is + TNT + Crew) } \\
\hline & & & & & & & & & \\
\hline (a) Costs for "current bu & et" do & not terminat & te until the fac & lity is empty & $(1-30-09)$ & & & & \\
\hline
\end{tabular}




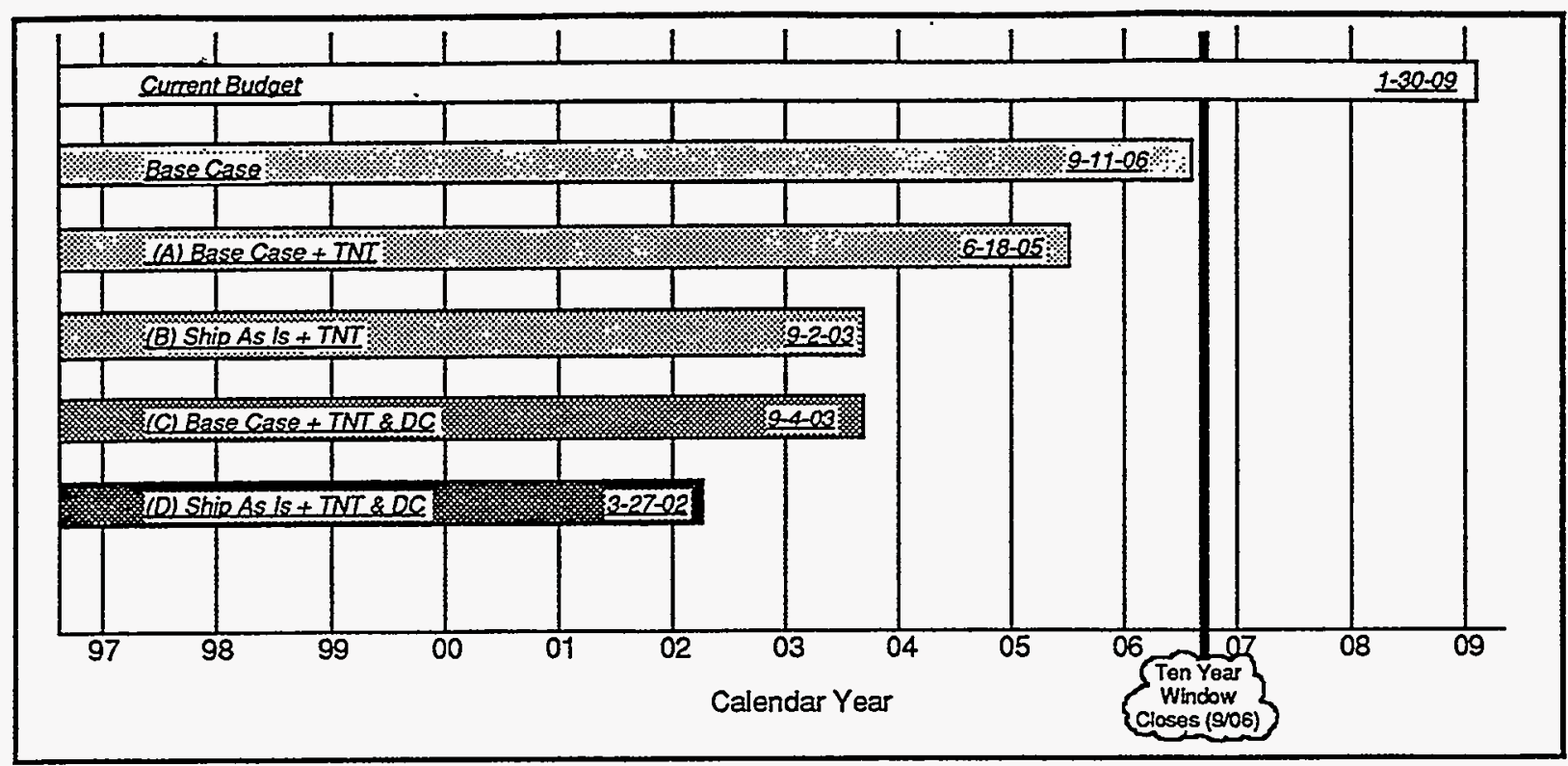

Figure EX-2. Schedule comparisons. 
Based on these results it appears that: (a) additional personnel are costeffective; Option A and Option C pay for the personnel and still save $\$ 1.7$ and $\$ 5.3 \mathrm{M}$ respectively and (b) ship-as-is saves the most time and money, but its probability of success is too low. Per DP's request to provide a successful ASAP schedule, the team concluded that Option $\mathrm{C}$ is to be the best choice.

Option C represents the best strategy for quickly removing SNM from CPP-651 because it will:

- $\quad$ Reduce the 10-year schedule by 37 months.

- Balance reliance of onsite and offsite resources and their transitioning process capabilities and budgets.

- Help assure success because the denitrator product is converted to a more user friendly form relative to storage and/or site-specific processing capabilities.

- Eliminate the utilization/restart of ICPP aqueous production purification systems.

- $\quad$ Require minimal ICPP conditioning (same as the base case) and only a small increase in funding. These expenditures $(\$ 2.7 \mathrm{M}$ for GPP construction tanks) are recovered and exceeded by reduced schedule.

- Produce incremental ES\&H and security risks that do not appear to be significant.

- Require minimal new dedicated staffing (13 FTEs) and their cost is recovered and exceeded by the savings that result from the reduced schedule.

- $\quad$ Provide a blend of synergistic ICPP operations that utilize a common operational area and concept (dry glovebox operations) rather than different processes for each inventory item.

When approved by DOE, these ICPP HEU management plans will become an integrated part of a much larger post cold war transition program to disposition excess (HEU) (proliferation reduction) and promote consolidation of SNM to fewer locations at the INEEL and across the DOE complex. The changes that have occurred across the DOE complex since the start of this study are significant and are likely to continue. Thus, the value of having this planning capability (resource data, offsite contacts, and the planning software) is strategic to success. Maintaining this capability will require periodic updating and publishing of the results, e.g., MMP. Ownership, funding, and control of this responsibility will be key to the continued planning success. Regularly scheduled communications/ contacts with the offsite receivers is another important success factor that is built 
into Option C. This information will also improve the remaining decisionmaking prior to finalizing commitments, schedules, and expending funds.

Successful early removal of SNM from CPP-651 will make this facility available for other support roles which (e.g., dispositioning of ${ }^{239} \mathrm{Pu}$ or storage ${ }^{233} \mathrm{U}$ ) should be evaluated as part of a national stewardship and materials management planning process. 


\section{ACKNOWLEDGMENTS}

The following people are recognized for their contribution to this study: T. L. Bridges, L. C. Lewis, B. J. Schrader, O. O. Gaddis, R. N. Wright, I . L. Walters, G. K. Kanemoto, E. P. Wagner, H. R. Lepage, J. P. Henschied, C. E. Stuart, D. W. Smith, D. J. Snow, R. L. Smith, D. C. Crawford, R. D. Haga, D. S. Swanson, E. L. Goldman, J. E. Kaylor, N. A. Chipman, R. A. Schiffern, B. L. Denning, E. L. Laible, D. R. Schilling, T. A. Mathews, K. R. Tuuri, and D. R. Bell. 
- 


\section{CONTENTS}

SUMMARY

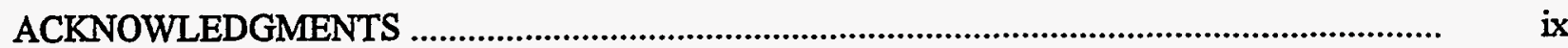

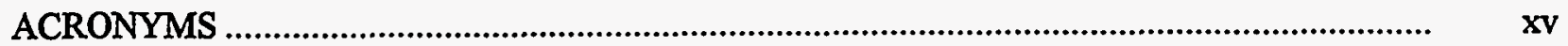

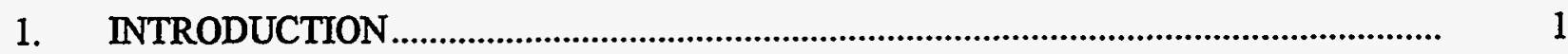

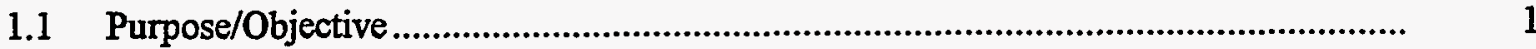

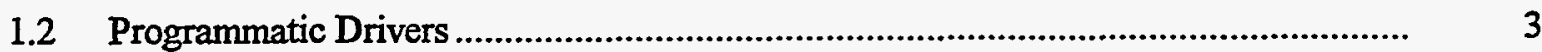

1.2.1 National Issues and Programs ..............................................................

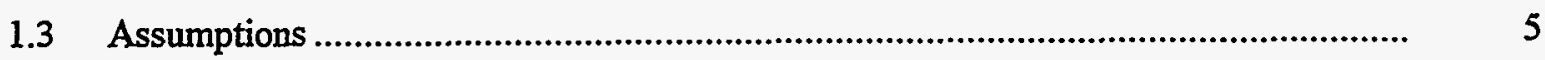

2. VALUATION CRITERIA AND METHODOLOGY .................................................. 8

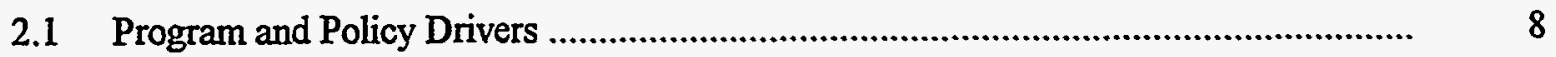

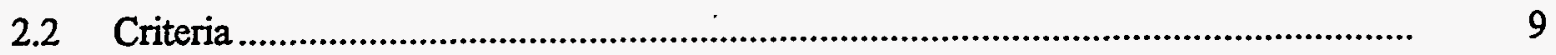

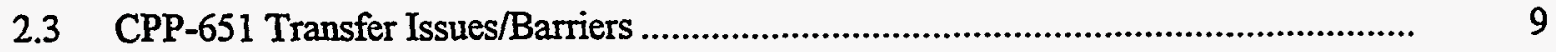

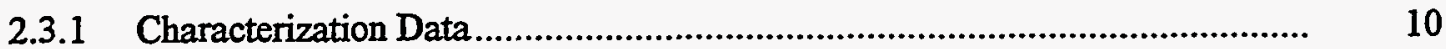

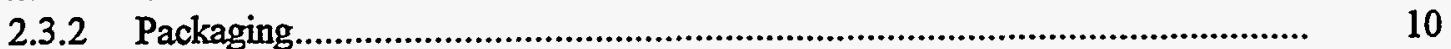

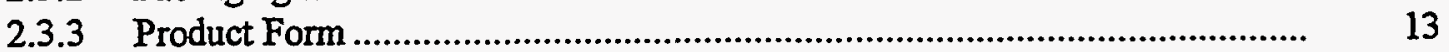

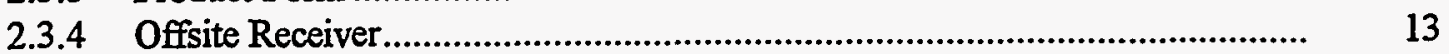

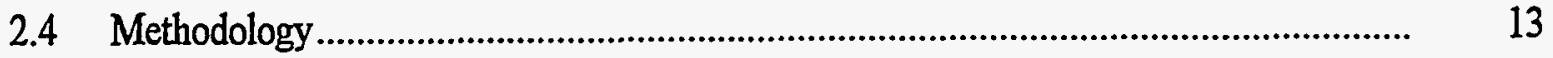

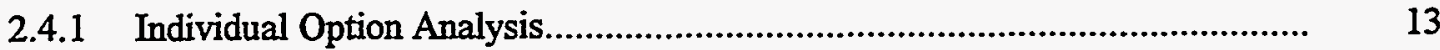

2.4.2 Integration of Options .................................................................... 15

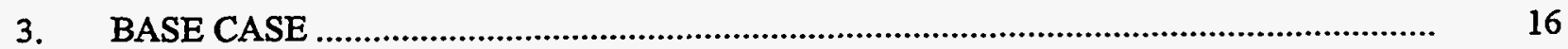

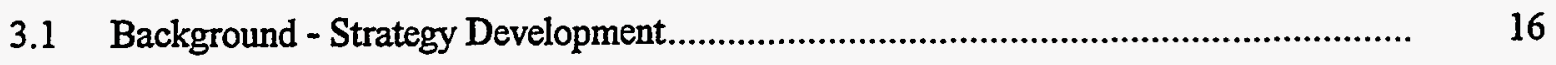

3.1.1 Post Cold War Operational Status ......................................................... 16

3.1.2 ICPP SNM Storage ......................................................................... 17

3.1.3 CPP-651 Material Management and Categorization ...................................... 23

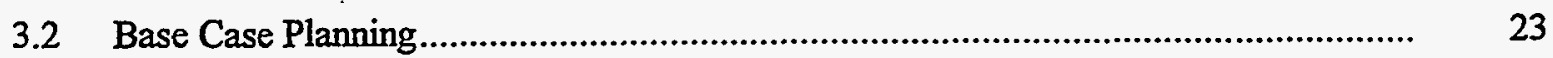

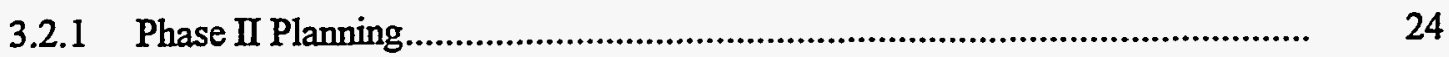

3.2.2 Resources, Costs, and Schedule ............................................................... 26

3.2.3 Integration Process ................................................................................ 28 


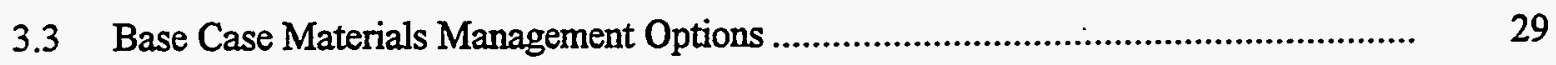

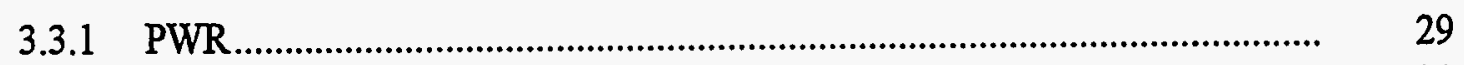

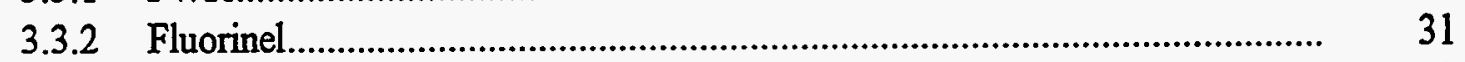

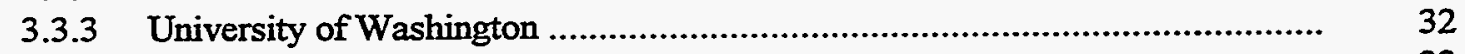

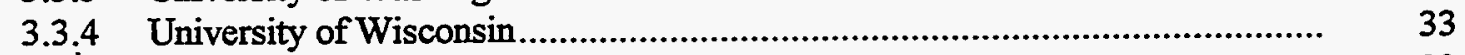

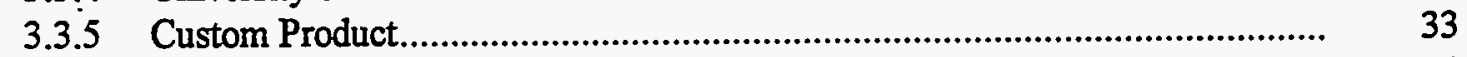

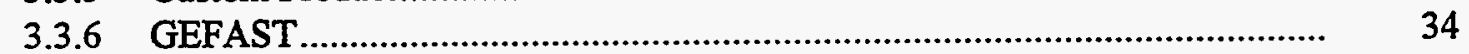

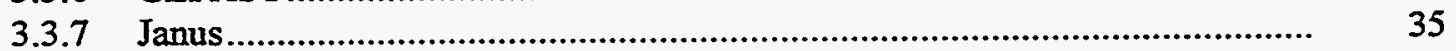

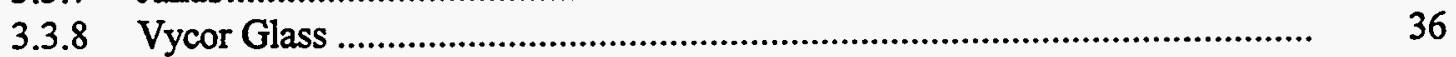

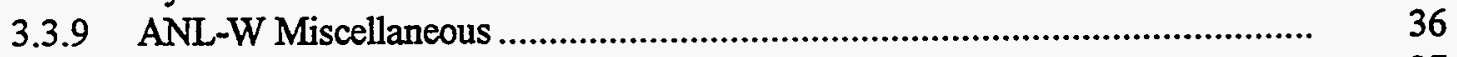

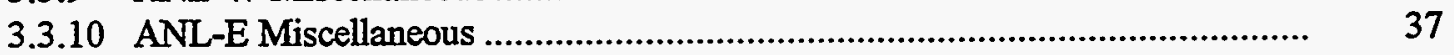

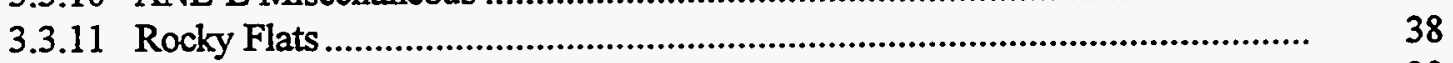

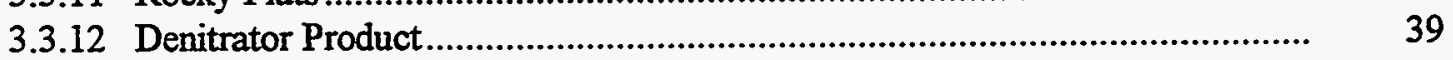

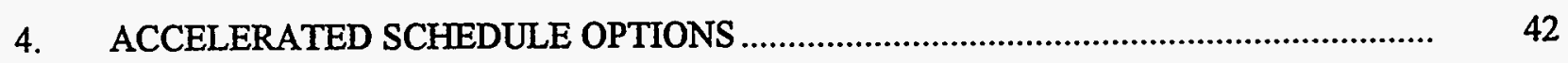

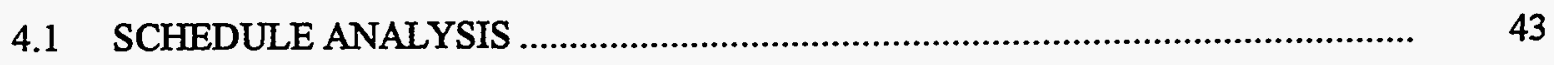

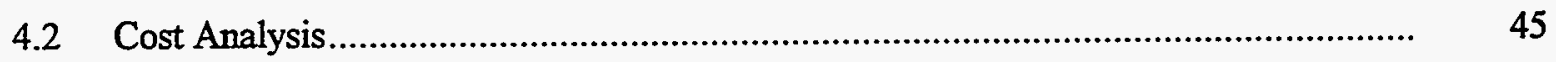

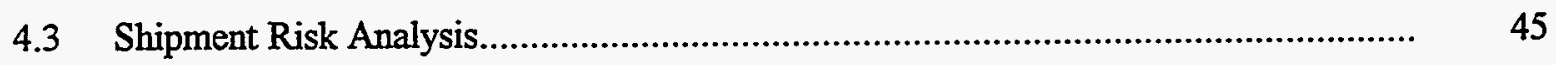

$4.4 \quad$ Proposed Accelerated Schedule ..................................................................... 57

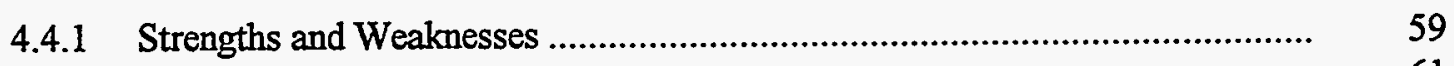

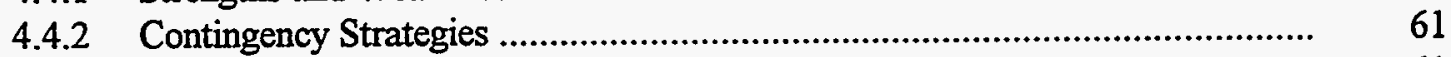

4.4.3 Future SNM Management Issues .......................................................... 61

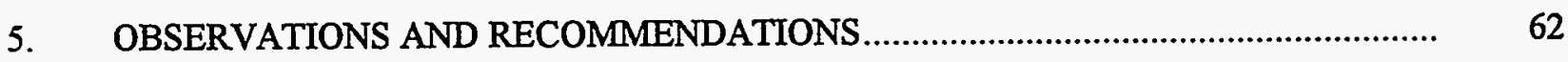

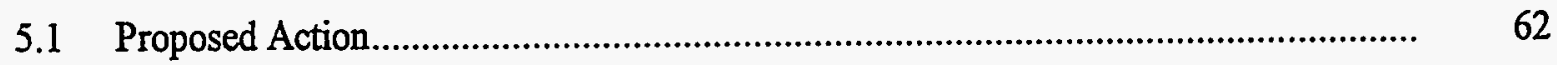

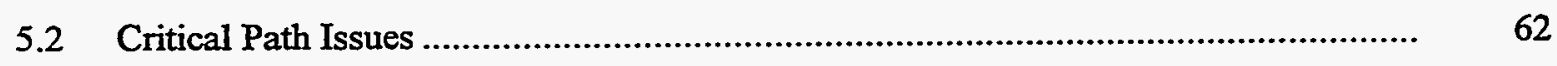

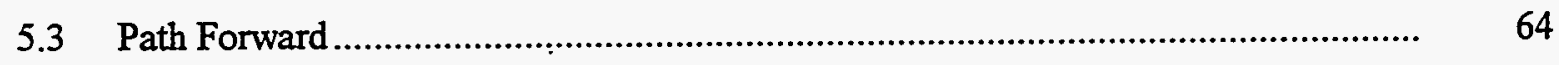

Appendix A-Cost Estimates, Schedules, and Flowsheets for CPP-651 Material Conditioning Options

Appendix B—Dry Blending Test and Evaluation: Development of a $\mathrm{UO}_{3}$ Grinding/Blending Process Using RM-2 Mill

Appendix C-Detailed Cost and Schedule Activities for Current Budget, Base Case, and Options A, B, C, and $\mathrm{D}$

Appendix D-Detailed Resource and Cost Reports for Current Budget, Base Case, and Options A, B, C, and D 


\section{FIGURES}

EX-1. Development of alternate schedule. ……………………................................................... v

EX-2. Schedule comparisons.................................................................................................. vi

1.2-1. The global perspective of excess HEU management strategy................................................

2.3-1. Shipping constraints for remaining CPP-651 inventory.................................................... 11

3.1-1. Locations, forms, and amounts of surplus highly enriched uranium, as of

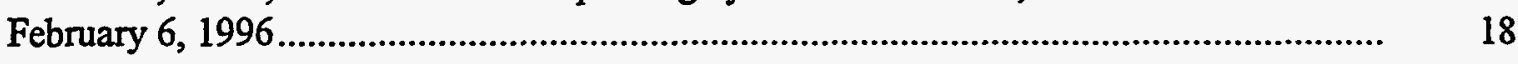

3.1-2. Savannah River Two Canyon operations 10-year plan....................................................... 19

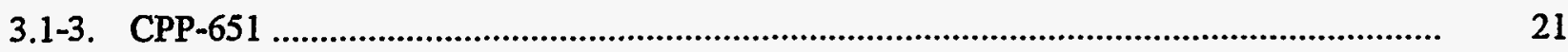

3.1-4. Plot plan of CPP-651..............................................................................................

4.0-1. Measures of effectiveness of the options to remove HEU from CPP-651 early .................... 44

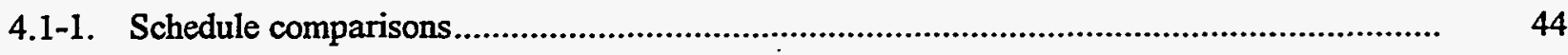

4.4-1. Overview of options and measure of effectiveness. ........................................................... 58

5.2.1. Programmatic overview of key conclusions. ........................................................................

5.3-1. Schedule for CPP-651 feasibility study - Phase II............................................................... 66

\section{TABLES}

EX-1. Schedule impact, costs, and risk of the proposed options................................................... v

2.3-1. Nuclear materials categorization of inventories (as of 9/30/96).......................................... 12

2.4-1. Material types, barriers and current issues........................................................................

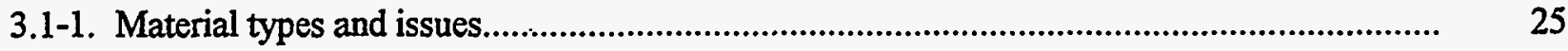

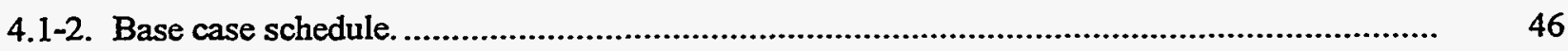

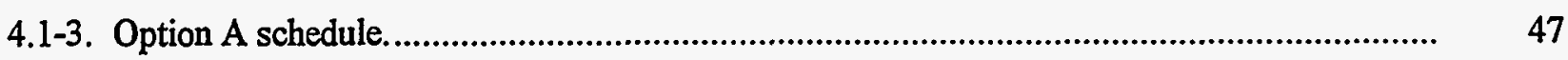

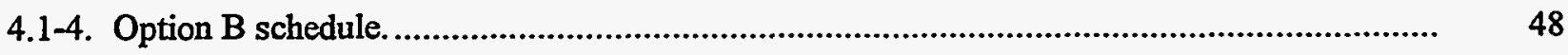

4.1-5. Option C schedule ........................................................................................................ 


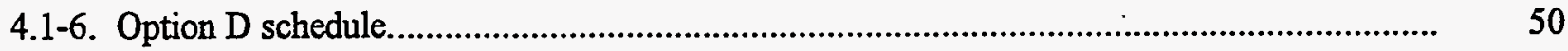

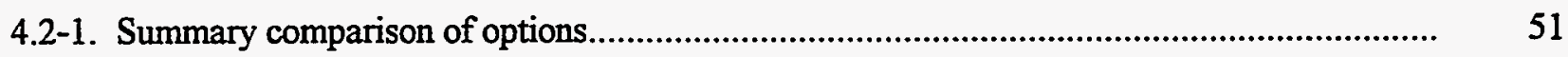

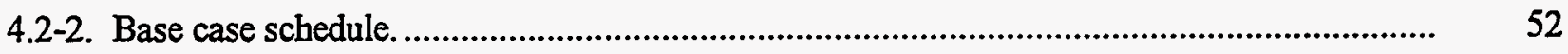

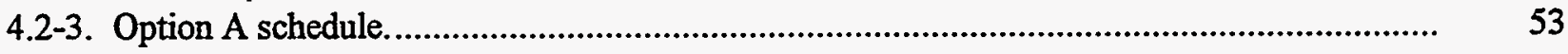

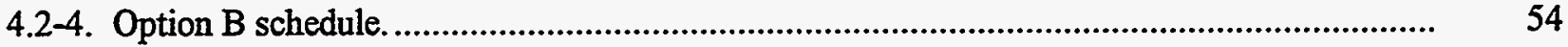

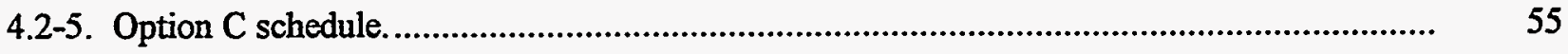

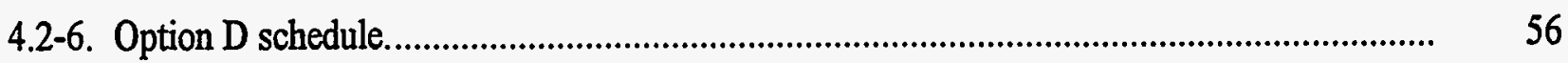




\section{ACRONYMS}

\begin{tabular}{|c|c|}
\hline AL & aluminum \\
\hline ANL-E & Argonne National Laboratory-East \\
\hline ANL-W & Argonne National Laboratory-West \\
\hline $\mathrm{B} \& W$ & Babcock and Wilcox \\
\hline BAPL & Bettis Atomic Power Laboratory \\
\hline CPP & Chemical Processing Plant \\
\hline CPP-651 & Unirradiated Fuel Storage Facility \\
\hline CSMO & Central Scrap Management Office \\
\hline DC & dedicated crew \\
\hline DOE & U.S. Department of Energy \\
\hline DOE-ID & U.S. Department of Energy, Idaho Operations \\
\hline DOT & Department of Transportation \\
\hline DP & Defense Program \\
\hline EA & environmental assessment \\
\hline EIS & environmental impact statement \\
\hline EM & Environmental Restoration and Waste Management \\
\hline $\mathrm{ES \& H}$ & environmental, safety, and health \\
\hline FAST & Fluorinel Dissolution Process and Fuel Storage \\
\hline FDP & Fluorinel Dissolution Process \\
\hline FTE & full-time employee \\
\hline FY & fiscal year \\
\hline GEFAST & a standard used in the Fast Facility \\
\hline HEU & high-enriched uranium \\
\hline IAEA & International Atomize Energy Agency \\
\hline
\end{tabular}




\begin{tabular}{|c|c|}
\hline ICPP & Idaho Chemical Processing Plant \\
\hline IFSF & Irradiated Fuel Storage Facility \\
\hline INEEL & Idaho National Engineering and Environmental Laboratory \\
\hline KAPL & Knolls Atomic Power Labs \\
\hline $\mathrm{kg}$ & kilogram \\
\hline LANL & Los Alamos National Laboratory \\
\hline LEU & low-enriched uranium \\
\hline LLW & low-level radioactive waste \\
\hline LMTTCO & Lockheed Martin Idaho Technologies Company \\
\hline LWBR & light water breeder reactor \\
\hline MBA & Material Balance Area \\
\hline MD & material dispositioning \\
\hline MMP & Materials Management Plan \\
\hline $\mathrm{mr} / \mathrm{hr}$ & millirem/hour \\
\hline MT & metric tons \\
\hline NE & nuclear energy \\
\hline NEPA & National Environmental Policy Act \\
\hline NFS & Nuclear Fuel Services \\
\hline NN & nuclear nonproliferation \\
\hline NR & Naval Reactors \\
\hline NRC & U.S. Nuclear Regulatory commission \\
\hline OR & Oak Ridge \\
\hline ORR & operational readiness review \\
\hline PO & policy office \\
\hline P\&T & packaging and transportation \\
\hline
\end{tabular}


PPU potential programmatic use

PWR pressurized water reactor

$\mathrm{R} \quad$ roentgen

R\&D Tesearch and development

RAL Remote Analytical Laboratory

RAMPAC Radioactive Materials Packaging

ROD Record of Decision

RW Civilian Radioactive Waste Management

S/R shipper/receiver

SNF spent nuclear fuel

SNM special nuclear material

SRS Savannah River Site

SST safe secure transport

TNT Transfer Negotiation Team

TRIGA Training, Research, Isotope Production Built by GA

TVA Tennessee Valley Authority

UFSF Unirradiated Fuel Storage Facility

U.S. United States

UNC United Nuclear Corporation

WAC waste acceptance criteria 


\section{Feasibility Study for Early Removal of HEU from CPP-651}

\section{INTRODUCTION}

A two-phase feasibility study was initiated in late 1996 to identify a way to expedite the removal of SNM from the CPP-651 vault. The first phase of this study provided preliminary information that appeared promising, but needed additional detailed planning and evaluation to validate the concepts and conclusions. The focus of Phase II was to provide the validation via resource-loaded schedules and more detailed cost estimates.

Section 1 describes the purpose and objectives of the Phase II tasks and the programmatic drivers that influence related CPP-651 high-enriched uranium (HEU) management issues. Section 2 identifies the evaluation criteria and methodology and the transfer issues and barriers preventing shipment. Section 3 provides site-specific background information for the CPP-651 facility and the Idaho National Engineering and Environmental Laboratory (INEEL) and describes the development of the basic material removal schedule, the proposed base case plan for removal of SNM, and the proposed HEU material management/shipping issues and strategies. Section 4 identifies the proposed options for accelerated removal of SNM and how they were evaluated via detailed scheduling, resource histograms, and cost analysis. Section 5 summarizes principal tasks for implementing this plan and other related HEU CPP-651 management issues that require continued planning efforts to assure successful implementation of this proposed early removal strategy.

\subsection{Purpose/Objective}

Defense Programs (DP) requested that SNM be removed from the CPP-651 vault as soon as feasible, but no later than 10 years. The base case schedule is shown in Table 1.1-1. The purpose of this report is to complete Phase II tasks and thereby provide DOE-ID with:

(a) A base case detailed schedule that confirms that CPP-651 can be emptied in 10 years or less (2006) with the existing resources and funds.

(b) An accelerated plan/schedule for early removal of all DP special nuclear material (SNM).

(c) The planning tools that will continue to provide detailed cost and schedule information for future CPP-651 management issues.

The objective of the Phase II effort was to confirm preliminary observations and strategies for the early removal of SNM via detailed resource loading, schedule building, and risk and cost analysis. In addition to early removal, the planning process also focused on achieving low risk for issues related to ES\&H, security, shipment of product, and identification of HEU management strategies that would significantly reduce costs for CPP-651, the INEEL, and the nation. Cost savings at the national level cannot be validated until shipper/receiver negotiations and related receiver costs are finalized. However, most cases appear to be cost-effective. 
Table 1.1-1. Base case schedule.

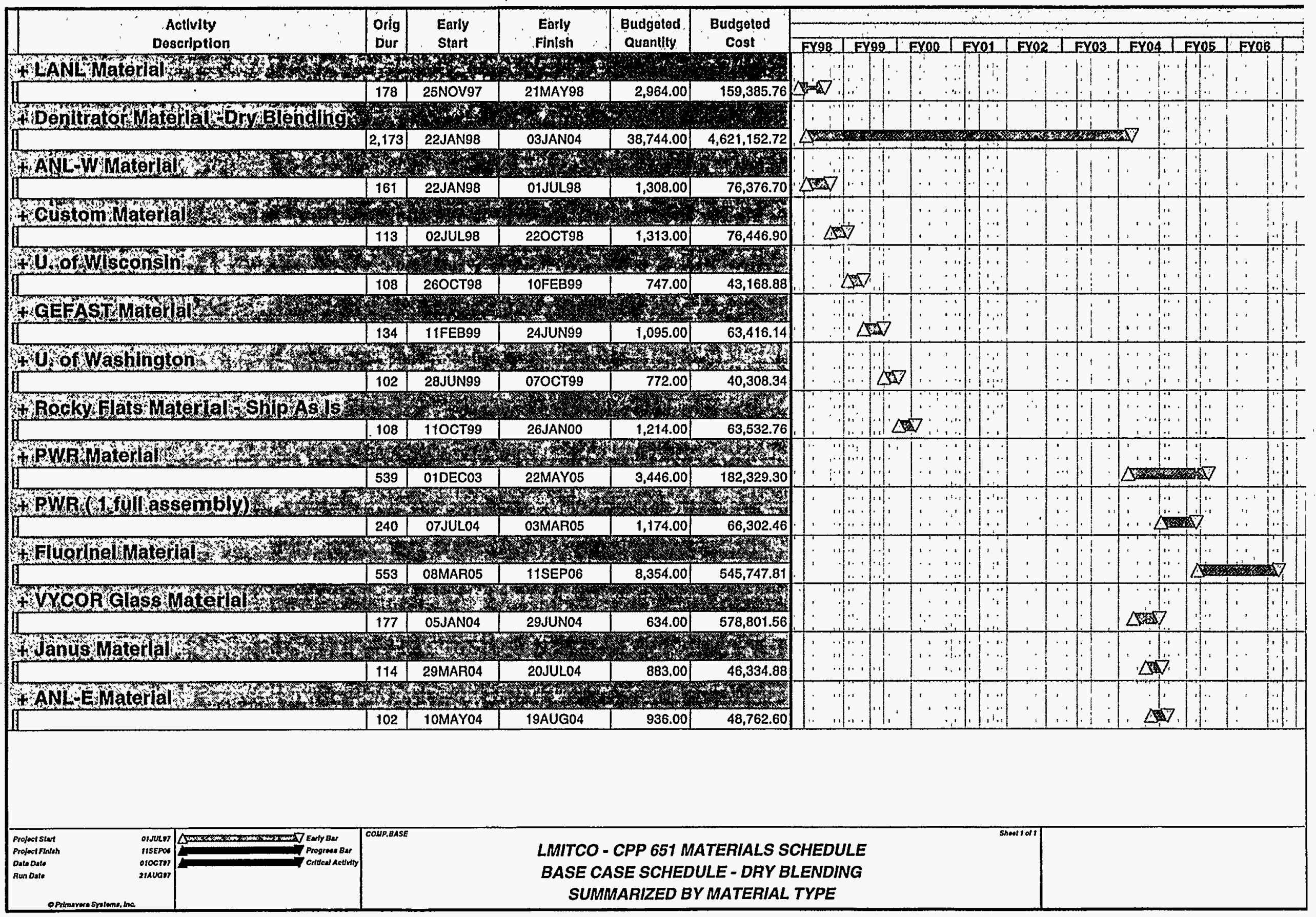


Phase II efforts utilized Phase I background information, goals, evaluation criteria, and management strategies and continued to develop in more detail the scope of HEU disposition activities. It identified programmatic assumptions that address known HEU management issues, developed summary level schedules and milestones, and addressed budget and resource requirements. Some of these related requirements, issues, and activities (national and local levels) are still evolving as the DOE complex continues to transition into the post cold war era (e.g., remediation of related HEU management vulnerabilities and disposition of excess HEU). This report addresses these issues as well as we currently understand them and formulates an initial strategy for implementation of the Phase II plan.

\subsection{Programmatic Drivers}

\subsubsection{National Issues and Programs}

The end of the cold war created a legacy of weapons-capable fissile material. Global stockpiles of this material threaten national and international security through potential proliferation of nuclear weapons and could result in environmental safety and health consequences if material is not properly stored, handled, and managed. Demonstrating a commitment to nonproliferation, the President of the United States (U.S.) announced on March 1, 1995, that approximately 200 metric tons $(t)$ of U.S. fissile material is excess to national security needs. Currently a total of approximately $174 \mathrm{t}$ of HEU have been declared excess to national security needs. Much of this material and the 500 metric tons of HEU purchased from Russia will be disposed via fabrication into low-enriched uranium (LEU) reactor fuel (see Figure 1.2-1).

Unirradiated and non-SNF nuclear materials consist primarily of fuel in active programs and HEU that has been declared excess to national security needs. Since many of these materials are weapons-usable materials, programmatic decisions have been made for managing excess HEU that reduce their proliferation threat. These decisions are documented in The Disposition of Surplus Highly Enriched Uranium Final Environmental Impact Statement DOE/EIS-0240, June 1996, which provides the programmatic driver for managing materials discussed in the LMITCO Material Management Plan (MMP). The preferred option in this Record of Decision (ROD) is to blend most (85\%) HEU down to low enrichment levels (<5\%) for use in commercial reactors; remaining HEU (estimated at $15 \%$ ) will be blended to $0.9 \%$ for disposal as low-level radioactive waste (LLW). Historically, DOE has authorized the use of some HEU for other programmatic uses, such as fuel for research reactors. A small fraction (about 10\%) of the $174 t$ recently declared excess has been reserved for such uses. Initially, HEU inventories must be identified and prioritized for down blending, including both weapons and nonweapons materials. Most surplus materials can be down blended efficiently. Some will be difficult to down blend for reactor fuel because of impurities or isotopic composition. However, the entire surplus inventory will be down blended for nonproliferation. Priority may be given to certain surplus materials to alleviate safety, environmental, and security concerns. The HEU inventory in CPP-651 is included in the $85 \%$ that will be down blended to LEU. None of the CPP-65 1 HEU was considered to be candidate material for an IAEA program. If feasible, addition of such a program would require new funding and additional time.

HEU from Lockheed Martin Idaho Technology Company (LMITCO) programs that meets receivers' criteria will be transferred to either the Oak Ridge Y-12 Plant (for recycle and treatment) or shipped to SRS for dilution to off-spec commercial reactor-grade LEU for irradiation in the TVA reactors. Some CPP-651 materials will require treatment prior to implementing proposed disposition options. Requirements to transfer HEU to Y-12 are found in the Environmental Assessment for the Proposed Interim Storage of Enriched Uranium Above The Maximum Historical Storage Level at Y-12 Oak Ridge, 


\section{- The Global Perspective Of Excess HEU Management Strategy}

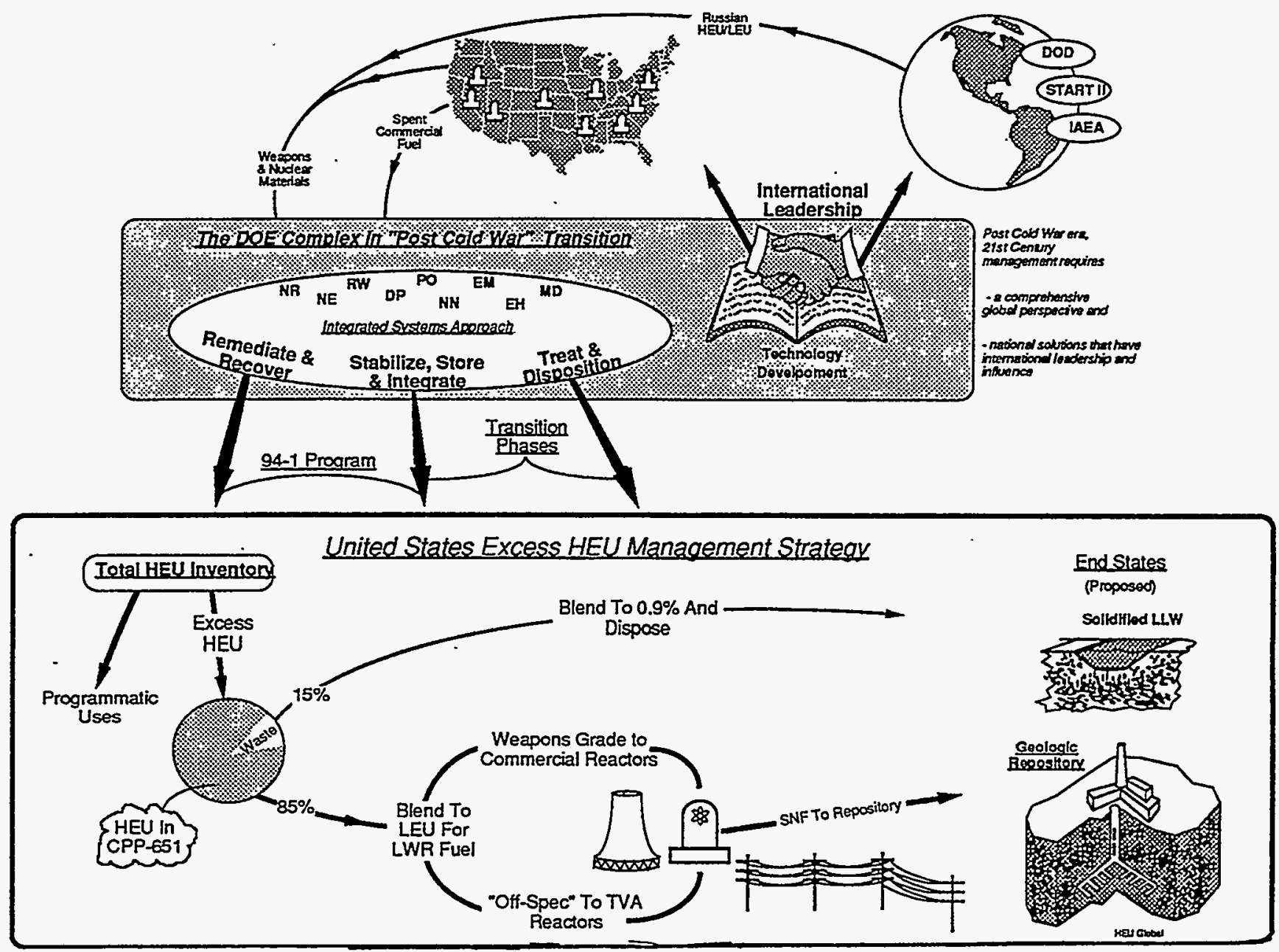

Figure 1.2-1. The global perspective of excess HEU management strategy. 
Tennessee (Y-12 EA) (DOE/EA-0929, September 1994). This environmental assessment (EA) states that the DOE will consolidate HEU from other DOE sites at $Y-12$. This also requires that the material to be shipped must be acceptable to the receiver. These receiver requirements are being modified to assure stability of product forms, receipt of product information that is important to dispositioning options, and other related accountability information to maintain high quality security programs.

The President's announcement concerning excess fissile materials signaled a change in national priorities and resulted in significant changes in missions of many DOE sites. DOE sites with historical missions of weapons production began the transition to downsized stockpile maintenance sites and/or environmental cleanup sites. In addition to excess weapons material taken from the stockpile, weapons site cleanup activities are expected to yield additional quantities of excess SNM materials. The impact of this transition is very significant.

For example, the amount of inventory that must be dispositioned exceeds any past experience. Dispositioning via dilution cannot occur in a timely manner at Oak Ridge alone. Thus, multiple dilution sites must be utilized to reduce HEU proliferation risk in a timely manner ( $<10$ years). This large inventory also presents new shipping issues in terms of volume (shipments / year), availability of SSTs, winter weather restrictions, and priority (who gets to ship first). All these new programmatic challenges come at a time when many of the management systems and product packages face significant aging and safety-related issues. These problems have been recently documented in the HEU Vulnerability Assessment. Collectively these issues have created a significant degree of uncertainty for processing and consolidating HEU throughout the DOE complex. As previously mentioned, much of this excess material has potential commercial value as nuclear reactor fuel. DOE recognized the need for increased coordination among affected sites and an integrated disposition process in order to reduce overall operation and management costs and to provide a timely return to the U.S. Treasury.

\subsection{Assumptions}

The following paragraphs provide a listing of assumptions and conditions that were made to bound the scope of this feasibility study.

(1) Uranium oxide $\left(\mathrm{U}_{3} \mathrm{O}_{8}\right.$ and $\left.\mathrm{UO}_{3}\right)$ and uranium metal are assumed to be acceptable physical forms for interim storage of $\mathrm{HEU}$.

(2) The study shall consider ICPP future mission activity from 1997 to 2035 (40 years) and will be integrated with other planning documents such as the EM 10-year plan, National SNF plan, etc.

(3) The remaining lifetime of CPP-651 is assumed to be 30 years (2025).

(4) It is assumed that the HEU EIS disposition strategy of dilution to $0.9 \%{ }^{235} \mathrm{U}$ will meet or exceed any federal repository WAC (waste acceptance criteria) for unirradiated fissile material.

(5) Removal of HEU from the INEEL is consistent with the intent of the agreement with the State of Idaho.

(6) HEU treatment processes at ICPP that require line item funding will be accelerated to help shorten the schedule and reduce costs. (No line items were identified that impact this report.) 
(7) Use and or restart of existing INEEL facilities and equipment to condition HEU for offsite transfer is consistent with the focus of the 94-1 Implementation Plan.

(8) Existing federal and state regulations will be enforced.

(9) Any waste generated from the ICPP HEU conditioning options will be processed via existing INEEL/ICPP systems.

(10) Recoverable HEU material will be declared to CSMO and will be shipped to a location designated by them.

(11) A near-term schedule has been negotiated with Y-12. Successful completion of negotiated transfers is assumed even though some degree of uncertainty remains. These operations are dependent upon Y-12's ability to receive and store material and the INEEL's ability to complete shipper/receiver ( $\mathrm{S} / \mathrm{R})$ agreements and secure sufficient funding and personnel to accomplish packaging and transportation (P\&T).

(12) The primary facility for managing inactive HEU at the INEEL is the Unirradiated Fuel Storage Facility (UFSF) (CPP-651). Fuel categories presently approved for storage in the unirradiated fuel storage facility are designated in LMITCO technical standard 4.8A1. Various types of materials are stored in specific containers and configurations for safety and control.

(13) HEU transport to Y-12 will be accomplished in approved vehicles using certified containers. A full SST shipment is assumed to be 40 to 48 drums per truck and will be determined by the transport index. This assumption is for 55-gallon DOT 6M drums; other size containers will dictate different loading limits.

(14) Combination of various HEU fuel materials being shipped in the same transport will be determined by transport index, container compatibility, drum sizes, and any other pertinent conditions.

(15) No DOT 6M drums will be returned from $\mathrm{Y}-12$ for re-use.

(16) The schedules for the base case and options assume funding will be made available to support projected activities and transfers.

(17) Startup of the ICPP RAL custom processing will require only a readiness assessment; completion of an operational readiness review is not factored in.

(18) SNM at other ICPP locations, such as the unirradiated light water breeder reactor (LWBR) fuel in CPP-749, is not included in the scope of this study.

(19) ICPP HEU oxides can be dry blended with LEU in a manner that will satisfy security- and safety-related concerns for interim storage. Final and complete blending if required will occur via aqueous operations at proposed DOE HEU dilution sites.

(20) Offsite shipments are any shipments outside of ICPP; this includes shipping to ANL-W. 
(21) If necessary, it will be possible to obtain state approval to ship in existing containers between CPP and Argonne National Laboratory-West (ANL-W). It is assumed this would be accomplished by temporarily closing the public access to the State highway between the facilities.

(22) HEU material shipped to ANL-W will be conditioned and returned to Y-12.

(23) Waste from ANL-W processing will be dispositioned via their management programs.

(24) Additional funding for offsite conditioning or storage is not included in the scope of this study except for the Vycor glass that is to be sent to ANL-W.

(25) SRS can accept HEU after the second quarter of 2002 and LEU as soon as ICPP can ship.

(26) The proposed dry blending strategy to achieve LEU status ( $<20 \%{ }^{235} \mathrm{U}$ enriched) is acceptable.

(27) Dry blended LEU can be charged to the SRS dilution train without unpackaging.

(28) Rocky Flats material can be shipped to SRS prior to 2000.

(29) Transfer of CPP-651 SNM to other sites does not increase security and ES\&H risks for the DOE complex.

(30) This study does not address receiver costs that may result at other facilities.

(31) None of the material in CPP-651 is or will be placed under an IAEA program.

(32) Parka fuel transfers from CPP-603 will not need to utilize the CPP-651 facility. Funding for Parka fuel transfers is assumed to come from DP.

(33) SNM material in CPP-651 that has potential program use is a small inventory that is assumed to be transferred to other customers before the end of the base case schedule. This material was not included in the scope of this study.

(34) Storage costs for LEU (dry blended denitrator product) are assumed to be very low and have not been included in this study.

(35) Specific security sampling and measurement issues cannot be addressed until a detailed milling and dry blending process design is developed. 


\section{EVALUATION CRITERIA AND METHODOLOGY}

The objective of the study was to develop a detailed resource-loaded plan for moving all SNM material out of CPP-651 as quickly as possible. The assumptions are that transfer of the material to another site is cost-effective and promotes reduced safety and proliferation risks. Each category of material in CPP-651 has its own set of properties and issues that impact the ability to ship it to another customer. These properties and issues along with a recommended strategy for getting material moved will be discussed in detail in Section 3. This section discusses evaluating proposed solutions on an individual basis and how individual solutions were integrated and evaluated to provide an optimized plan. This process employed the following principal steps for Phase I:

- Understand local and national programmatic and policy drivers at the shipping and receiving sites

- Establish criteria (such as cost, schedule, safety, and security) for evaluating options based on these drivers

- Analyze issues preventing materials from being shipped and establish general barrier categories

- Develop a set of preferred options for these general categories using criteria to rank order of preference

- Analyze materials individually; identify key issues; and establish preferred options

- Integrate individual options and evaluate each possible combination to select best proposal.

The process was expanded to include the following additional steps for Phase II:

- Review safety-related issues in more detail for each of the proposed strategies

- Negotiate commitments and schedule options with offsite receivers

- Identify resources and costs for proposed activities

- Develop conceptual related design information for any equipment or facility modification to enhance cost and schedule estimates

- Develop detailed schedules of different enveloping strategies

- Identify critical path issues in the detailed schedule and provide additional resources to improve the schedule

- Balance reduced schedule time with cost and probability of success.

\subsection{Program and Policy Drivers}

National programmatic HEU management drivers were previously discussed in Section 1.2. The Lockheed Martin Idaho Technologies Company Materials Management Plan has included these issues in 
developing plans to remove nuclear material from CPP-651. Requirements to transfer HEU to Y-12 are found in Environmental Assessment for the Proposed Interim Storage of Enriched Uranium Above The Maximum Historical Storage Level at Y-12 Oak Ridge, Tennessee. This environmental assessment (EA) states that the DOE intends to consolidate HEU from other DOE sites at Y-12. In addition, removal of all nuclear material from CPP-651 by 2006 is another DOE-ID directive and DOE Defense Programs mandate. Furthermore, the ROD from the Disposition of Surplus Highly Enriched Uranium Programmatic Environmental Impact Statement, has directed that the HEU be diluted to LEU to reduce its proliferation risk. Most of this diluted inventory will be fabricated into LEU fuel for commercial power reactors. Off-spec HEU will also be diluted into LEU feedstock for commercial reactor fuel (only TVA reactors would burn off-spec inventory). Other programmatic drivers would include compliance with the agreement signed with the State of Idaho and execution of all proposed shipping tasks in full compliance with all federal and state regulations and policies. Acceptable safety and environmental risks present other policy driven issues.

\subsection{Criteria}

Criteria fall into two categories: absolute requirements limiting conditions that must be satisfied by any proposed option, and desirable attributes that are used to help rank feasible options. In both Phase I and II of this study the absolute requirements are receiver acceptance, regulatory acceptance, and customer acceptance. Each proposed option must have a receiver willing to accept material. The process of preparing material and shipping it to the receiver must meet all regulatory requirements. Additionally, the plan must be acceptable to the customer (DOE) in terms of cost, schedule, and risk. Those options meeting this test of feasibility were then ranked according to desirable attribute criteria. Criteria used to rank options for each material were an extension of the basic objective. The ideal solution would move material as quickly as possible with lowest cost and risk. Key criteria developed in order of importance are:

- Environmental, safety, and health risk

- $\quad$ Security risk

- Political acceptance

- Supports accelerated schedule

- Cost

- Transportation risk .

- Risk of depending on other site to receive

- Existing capabilities

- Other (facilities, infrastructure, scale, packaging).

\subsection{CPP-651 Transfer Issues/Barriers}

Materials in CPP-651 were analyzed individually to determine issues preventing shipment. This was done during Phase I in a facilitated, interdisciplinary team meeting involving representatives from CPP-651 operations, criticality safety, transportation, security, plant operations, safety analysis, systems 
engineering, ICPP technical support, spent fuel, and representatives from ANL-W operations, engineering, and security. The team reviewed the inventory of materials and determined key issues preventing shipment. Issues around each material type are discussed in detail in Section 3. As shown in Figure 2.3-1, these issues were classified into the following primary categories:

- Characterization data or other information issues

- Packaging issues such as shipping containers, product containers, and certification papers

- Product form issues (such as concerning oxide, metal, fabricated fuel, scrap pieces, molds, and fission products radiation fields)

- Offsite receiver issues such as storage space, processing capability, schedules, funding, and remediation of vulnerability issues.

\subsubsection{Characterization Data}

A detailed inventory of the material stored in CPP-651 was performed in 1995. As part of the inventory radiation readings, characterization data and photographs were obtained. The CPP-651 material inventory is shown in Table 2.3-1. Computational analyses have been performed as part of Phase II to determine if some of the more difficult materials will meet the acceptance criteria for highly enriched uranium fuels into the Y-12 plant. This new information has been made available to the proposed receiving site (the $\mathrm{Y}-12$ plant) for review. In some cases the material meets the acceptance criteria and this will allow shipment and ship dates to be negotiated. However, some materials may require a variance in order to be accepted by the Y-12 plant. If the variance cannot be obtained, then some form of conditioning will be implemented to make the materials acceptable somewhere in the DOE complex.

\subsubsection{Packaging}

Phase I identified several materials that could not be shipped due to a range of packaging problems. The simplest examples are materials that are too long or otherwise won't fit into readily obtainable and certified shipping containers. Alternative shipping containers were identified that allow shipment without resizing material (i.e., cutting fuel, recanning in smaller cans).

A more complicated packaging issue exists for materials that must be repackaged because the current internal package (i.e., plastic bottle and/or plastic bag) doesn't meet the receivers' acceptance criteria. These materials must be repackaged unless the receivers' acceptance criteria can be renegotiated. Some materials in this category also have shipping container size issues and radiation level issues. These conditions also ultimately require repackaging. 


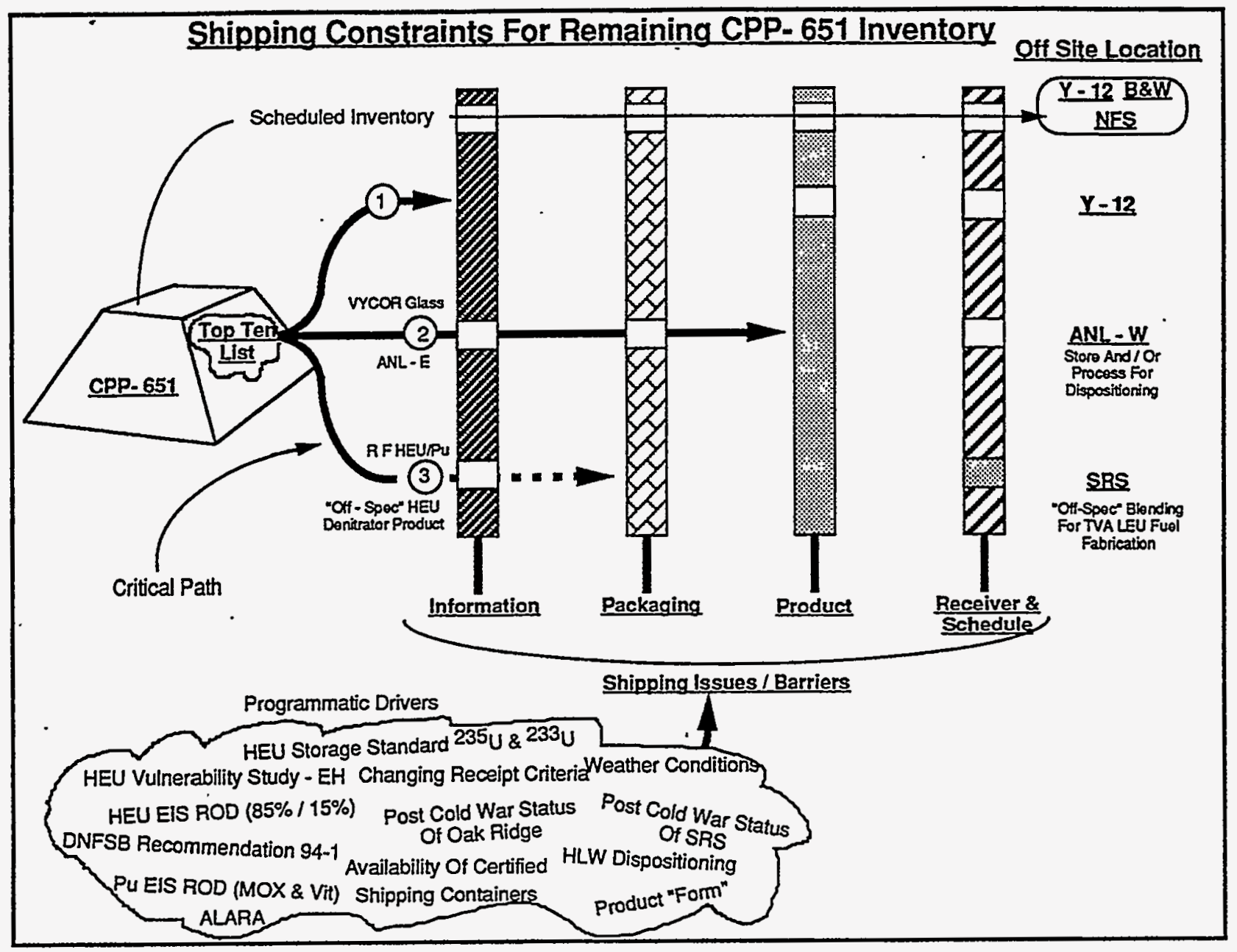

Figure 2.3-1. Shipping constraints for remaining CPP-651 inventory. 
Table 2.3-1. Nuclear materials categorization of inventories (as of 9/30/96).

\begin{tabular}{|c|c|c|c|c|}
\hline Description & Owner & Category & Sub-category & $\begin{array}{l}\text { Quantity } \\
\text { (kg U) }\end{array}$ \\
\hline$Y-12$ & DP & Inactive material & Potential Program Use & 4.494 \\
\hline Custom product reference samples & DP & Inactive material & Potential Program Use & 1.583 \\
\hline Denitrator product reference samples & DP & Inactive material & Potential Program use & 0.176 \\
\hline LANL & $\mathrm{DP}$ & Inactive material & Negotiated & 257.475 \\
\hline ANL-W & $\mathrm{DP}$ & Inactive material & Negotiated & 52.294 \\
\hline Fluorinel & DP & Inactive material & To Be Negotiated & 105.237 \\
\hline PWR & DP & Inactive material & To Be Negotiated & 86.461 \\
\hline University of Washington & $\mathrm{DP}$ & Inactive material & To Be Negotiated & 0.459 \\
\hline University of Wisconsin & DP & Inactive material & To Be Negotiated & 0.145 \\
\hline GEFAST & DP & Inactive material & To Be Negotiated & 1.100 \\
\hline Custom product & DP & Inactive material & To Be Negotiated & 82.416 \\
\hline Janus & $\mathrm{DP}$ & Inactive material & To Be Negotiated & 33.907 \\
\hline Vycor glass & DP & Inactive material & To Be Negotiated & 4.394 \\
\hline ANL-W and ANL-E & $\mathrm{DP}$ & Inactive material & To Be Negotiated & 2.185 \\
\hline Rocky Flats & DP & Inactive material & To Be Negotiated & 26.983 \\
\hline \multirow[t]{2}{*}{ Denitrator product } & DP & Inactive material & To Be Negotiated & $1,687.645$ \\
\hline & & & & $2,346.287$ \\
\hline
\end{tabular}

DP-Defense Program

Negotiated refers to surplus material that can be transferred to another location, has been listed on a scrap declaration, and has been accepted by the central Scrap Management Office (CSMO). In most cases the receiver has been identified or the contract is being bid. Schedules and packaging requirements are either known or being developed. 


\subsubsection{Product Form}

Some materials may end up being unacceptable to designated HEU receivers and will require some type of conditioning prior to shipment. This is the result of the abrupt halt to operations at the ICPP at the end of the cold war. These potentially difficult materials were sent to the ICPP because of its unique processing capabilities (e.g., custom dissolution in the multi-curie cell). Now that these process capabilities are shut down, it is not surprising that other sites are not anxious to accept these materials. Material with a very small inventory could be processed via lab-scale equipment in facilities like CPP-684 RAL (Remote Analytical Laboratory). Larger inventories are not feasible because the processing time is too long. Examples of material form issues are HEU with high plutonium concentration, metal alloys containing zirconium, broken glass with embedded uranium metal, and materials with high radiation levels.

\subsubsection{Offsite Receivers}

A series of issues deals with offsite receivers. In general, success of the plan is totally dependent on timely delivery of all material to each offsite receiver. Any single material that is delayed for any reason could potentially force CPP-651 to be operated longer than planned. This could significantly reduce or even eliminate anticipated cost savings. This puts the ICPP at risk of committing to a plan that may not be supported by other sites if their site-specific funding is reprioritized or other issues arise. Some concerns are related to previous issues discussed. There is a risk that actions taken to get characterization data, repackage materials, and resolve material form issues may end with the receiver rejecting material because their acceptance criteria has continued to change. Even if the receiver has agreed to receive a material, any of several programmatic issues may cause delays in shipments. These include receiver verification of contents prior to shipping (no surprises for receivers), new requirements for information, better accuracy and expanded measurement criteria, availability of safe secure transports ( SSTs), availability of storage space in vaults, and programmatic decisions that affect processing schedules. All these issues are further complicated by the relative priority of ICPP compared to other sites and labs shipping to these receivers and other high priority national programs such as dispositioning excess plutonium.

\subsection{Methodology}

\subsubsection{Individual Option Analysis}

The base case scenario was developed in the following manner. Phase I developed a set of management/shipment options for each inventory item in CPP-651 and these options were ranked based on judgments of team members as is shown in Table 2.4-1. The next step was to integrate the individual options into a program in order to identify those that generated maximum cost savings and satisfied the absolute requirements. Several assumptions were made that helped form the basis for evaluation:

- $\quad$ Because the HEU Disposition EIS specifies that designated good HEU will be transferred to Y-12 for down blending into commercial fuel, Y-12 should accept anything that they or a contracted fuel fabricator can process

- SRS is specified as a site for down blending off-spec HEU into TVA fuel. SRS or any other off-spec HEU down blending site should accept all off-spec HEU material as long as it can be handled by their existing/planned processes 
Table 2.4-1. Material types, barriers and current issues.

\begin{tabular}{|c|c|c|c|c|c|c|c|c|c|c|c|}
\hline & & Ship & pling & Barr & flers & & & & & & \\
\hline E & Material & 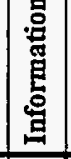 & 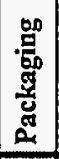 & 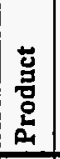 & 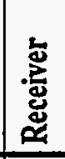 & Options - In Order & Receiver & $\begin{array}{l}\text { Cost } \\
\$ K\end{array}$ & $\begin{array}{l}\text { Schedule } \\
\text { Duration } \\
\text { Months }\end{array}$ & Risk & Comments \\
\hline $1 \mathrm{a}$ & PWR & & 整: & & & 1) Repackage and ship in 85 gal $6 M$ drums & B\&WINFS & 182 & 18 & Low & Waiting for CSMO to award contract \\
\hline & Plates & & int & & & 2) Certify Spert boxes and ship & B\&W/NFS & 90 & 18 & Med & Spert boxes not acceptable \\
\hline $1 \mathrm{~b}$ & PWR & & Entots & & & 1) Certify box it is in and ship & B\&WINFS & 66 & 8 & Low & Waiting for CSMO to award contract \\
\hline & Assembly & & 3 & & & 2) Get certified B\&W box and ship & B\&WINFS & 65 & 8 & Med & Assembly will not fit in B\&W boxes \\
\hline 2 & Fluorinel & & 4 & & & 1) Get longer inner containers \& drums, ship & B\&WINFS & 546 & 18 & Low & Waiting for CSMO to award contract \\
\hline & & & $\because$ & & & 2) Cut long material and ship in $6 \mathrm{M}$ drums & B\&WINFS & 613 & 21 & Med & No need to cut to fit drums \\
\hline & & & $\because$ & & & 2) Get certified B\&W box and ship & B\&WINFS & 296 & 21 & Med & Drums are easier to obtain than boxes \\
\hline 3 & Univ. of & 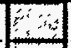 & & & & 1) Repackage and ship to SRS & SRS & 40 & 4 & Low & \\
\hline & Wash. & 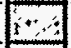 & & & & 2) Repackage and ship to $Y-12$ & $Y-12$ & 40 & 4 & Med & Does not meet $Y-12$ acceptance criteria \\
\hline & & 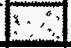 & & & & 3) ICPP stabilization to oxide, ship & $\mathrm{Y}-12$ & \begin{tabular}{l|l}
56 \\
\end{tabular} & 5 & Med & Added cost to process at ICPP \\
\hline 4 & Univ. of & & & & & 1) Repackage and ship to $Y-12$ & $\mathrm{Y}-12$ & 43 & 4 & Low & $\gamma-12$ has agreed to accept material \\
\hline & Wisc. & & & & & 2) Repackage and ship to SRS & SRS & 43 & 4 & Med & \\
\hline & & & & & & 3) ICPP stabilization to oxide, ship & $\mathrm{Y}-12$ & 54 & 5 & Med & Added cost to process at ICPP \\
\hline 5 & Custom & & 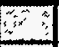 & & & 1) Repackage into 6M's and DC-1's & $\mathrm{Y}-12$ & 76 & 4 & Low & \\
\hline & & & 20 & & & 2) Repackage 4 cans into smaller cans, ship all in 6M's & $\mathrm{Y}-12$ & 75 & 8 & Med & Assumes repackaging glovebox available \\
\hline & & & 6 & & & 3) Dry Blend 4 cans, repackage, ship all in 6M's & $\mathrm{Y}-12 / \mathrm{SRS}$ & 145 & 8 & Med & Assumes dry blending process available \\
\hline 6 & GEFAST & & 21 & & & 1) Repackage into $6 \mathrm{M}$ 's and a UN1A2 & $Y-12$ & 63 & 5 & Low & \\
\hline & & & 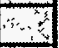 & & & 2) Repackage 1 can into smaller cans, ship all in 6M's & $Y-12$ & 103 & 9 & Med & Assumes repackaging glovebox available \\
\hline & & & 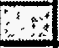 & & & 3) Dry Blend 1 can, repackage, ship all in 6M's & $\mathrm{Y}-12$ & 107 & 9 & Med & Assumes dry blending process available \\
\hline 7 & Janus & 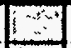 & & 02 & $\therefore$ & 1) Ship in current drum to ANL-W & ANL-W & 46 & 4 & Low & Requires NEPA and DP approval \\
\hline & & 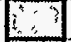 & & a & 3 & 2) Repackage, ship to $Y-12$ & $Y-12$ & 49 & 4 & Low & Does not meet $Y-12$ acceptance criteria \\
\hline & & in & & $\because$ & $\therefore$ & 3) ICPP stabilization to oxide, ship & $\mathrm{Y}-12$ & 309 & 20 & Med & Added cost to process at ICPP \\
\hline 8 & VYCOR & & & 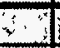 & +4 & 1) Ship in current drum to ANL-W for processing & ANL-W & 579 & 6 & Low & ANL-W has developed process \\
\hline & Glass & & & 3 & 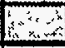 & 2) ICPP stabilization to oxide, ship & $\mathrm{Y}-12$ & 241 & 19 & Med & Added cost to process at ICPP \\
\hline 9 & ANL-W & 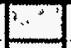 & & & & 1) Repackage and ship to $Y-12$ & $Y-12$ & 76 & 6 & Low & Y-12 has agreed to accept material \\
\hline & & & & & & 2) Ship in current drum to ANL-W & ANL-W & 71 & 6 & Low & Requires NEPA and DP approval \\
\hline & & & & & & 3) ICPP stabilization to oxide, ship & $\mathrm{Y}-12$ & 114 & 8 & Med & Added cost to process at ICPP \\
\hline 10 & ANL-E & & & & & 1) Ship in current drum to ANL-W & ANL-W & 49 & 4 & Low & Requires NEPA and DP approval \\
\hline & & & & & & 2) ICPP stabilization to oxide, ship & $Y-12$ & 95 & 6 & Med & Added cost to process at ICPP \\
\hline & & $7=$ & & & & 3) Repackage and ship to $Y-12$ & $\mathrm{Y}-12$ & 52 & 4 & Med & Does not meet $Y-12$ acceptance criteria \\
\hline 11 & Rocky & & & & 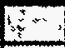 & 1) Repackage and ship as HEU to SRS & SRS & 64 & 4 & Low & \\
\hline & Flats & & & $\because \because$ & E. & 2) ICPP stabilization to oxide, ship as liquid in RAL & $Y-12$ & 234 & 14 & Med & Added cost to process at ICPP \\
\hline & & & & $\therefore$ & ris & 3) ICPP stabilization to oxide, ship as liquid in new bldg. & $\mathrm{Y}-12$ & 605 & 15 & Med & Assumes new process bldg. constructed \\
\hline & & & & in & 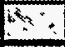 & 4) Dry Blend to $<20 \%$, repackage, ship & SRS & 414 & 15 & Med & Plutonium in material creates problems \\
\hline 12 & Denitrator & & 2 & 3 & X: & 1) Dry Blend to $<20 \%$, repackage, ship & SRS & 4621 & 72 & Low & Fabricate/install dry blend process \\
\hline & & & 8 & 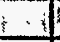 & $b+x$ & 2) Repackage and ship as HEU to SRS & SRS & 1679 & 36 & Med & Large risk of slipping schedule \\
\hline & & & & - & $\cdots$ & 3) ICPP stabilization to oxide, ship as liquid in new bldg. & SRS & 11,554 & 53 & Med & Construct new process building \\
\hline & & & $\therefore$ & $\therefore$ & $\therefore x^{*}$ & 4) ICPP stabilization to oxide, ship as liquid in 637,601 . & SRS & 4,559 & 52 & Med & Added cost to process at ICPP \\
\hline & & & & - & $\therefore=$ & 5)Repackage in smaller cans in CPP-651, ship to SRS & SRS & 2159 & 38 & Med & Fabricate/install repackaging glovebox \\
\hline$\perp$ & - & نت & Sh: & - & read & lenotes a shioping barriar & - & & & & $-\quad-$ \\
\hline
\end{tabular}


- If Y-12, ANL-W, and SRS have excess capacity in their storage facilities, there is little or no additional cost to the complex (DP) to store Idaho materials in their facilities while waiting for processing

- All material in CPP-651 must, as a minimum, be repackaged into certified drums for transport

- Because plans are already in place to repackage and transport these materials within the next 10 years, there is no new additional cost for repackaging drums sooner unless expediting removal is less efficient or requires additional drums.

\subsubsection{Integration of Options}

The final step in developing the Phase I plan was integration of options for individual materials into an overall cost-effective strategy. For example, the denitrator product is the single largest item in the CPP-651 inventory (see Table 2.3-1). The decision to mill and blend with depleted uranium to reduce enrichment is more complicated than the ship-as-is option, but produces a more user friendly product that could be received earlier by SRS. Milling and blending also helped eliminate package size problems, provided for the removal of unwanted plastic material, and reduced high radiation fields for each product can. Aqueous blending will occur via SRS's off-spec blending program and the ICPP dry blend strategy is only proposed as an interim storage mode. Once it was decided to use ICPP operations to dry blend the denitrator product, then inventory remaining was examined to see if any other oxides could utilize this process and avoid implementing another process. In this case, it was decided that the Rocky Flats material may also be considered. However, this strategy is not the preferred option because of the Pu-related contamination control issues for the Rocky Flats inventory. This theme was repeated for other inventory items in an attempt to minimize processing requirements. Since most individual inventory items represent small amounts of HEU, processing them through production-sized equipment via special procedures was usually not cost-effective at any site. Thus, many of these options defaulted to lab-scale operations. Another factor that influenced integration was the INEEL ownership or control of the proposed resolution. If the options were equal relative to cost and risk, then options that provided more local control were selected. By starting with the largest inventories with the most difficult material issues and working back through the other materials, decisions were made to alter options on smaller inventories to take advantage of actions planned for more difficult issues. In many cases, overall cost or schedule risk for an individual material could be reduced. The net result of this process was the base case schedule (see Table 1.1-1) that confirmed the CPP- 651 vault could be emptied in less than 10 years. 


\section{BASE CASE}

The following subsections discuss background information and the development of the base case planning scenario. This process was required to (a) demonstrate that the 10-year window could be met and (b) develop enough detailed information to be able to identify the critical path resource issues and better understand how to accelerate the schedule.

\subsection{Background to Strategy Development}

Uranium inventories in CPP-651 and stored in vaults across the DOE complex are enriched in the isotopes ${ }^{235} \mathrm{U}$ or ${ }^{233} \mathrm{U}$. These include HEU having a ${ }^{235} \mathrm{U}$ content of greater than $20 \%$ by weight or a ${ }^{233} \mathrm{U}$ content greater than $12 \%$ by weight or mixtures of the two isotopes. Other HEU inventories include large quantities of relatively pure weapons-grade material, HEU recovered from recycle of irradiated reactor fuel, and additional enriched ${ }^{233} \mathrm{U}$.

In the defense nuclear complex, HEU has had two primary purposes-for weapons components and as fuel for material production and Naval Nuclear Propulsion reactors. DOE facilities have also provided support services for a wide range of domestic and foreign research reactor programs. Defense-related HEU activities have traditionally centered at the Oak Ridge Y-12 Plant, which is expected to retain interim support for weapon dismantlement, uranium processing and storage, and programs for disposition and use of the fuel value of enriched materials. HEU materials that are directly addressed by the 94-1 program are stored at other sites where conversion and packaging of inventories from former missions are important to overall plans for safe facility restart, operation, and shutdown.

As with plutonium, the U.S. holds large quantities of HEU that are now excess to national security needs. Unlike plutonium, however, this HEU can be isotopically diluted with natural or depleted uranium to produce a material (less than $20 \%$ enriched in ${ }^{235} \mathrm{U}$ ) that is substantially more resistant to re-enrichment and use in weapons. Thus, near- and long-term stabilization goals emphasize benefits of dilution to lowenriched uranium (LEU) for commercial reactor fuel (see Figure 1.2-1).

DOE's support for long-term management of enriched uranium is influenced by the large quantity of HEU included in the 200 metric tons (MT) of U.S. weapons-grade fissile material that was declared excess to national security needs and up to $500 \mathrm{MT}$ of excess weapons-grade HEU, down blended to LEU, from Russia. Quantities described in the 94-1 program are small compared to these huge process and storage streams, and must be evaluated in the context of the larger program.

Most ${ }^{235} \mathrm{U}$ materials have never been irradiated and contain essentially no ${ }^{236} \mathrm{U}$ or ${ }^{232} \mathrm{U}$. However, a significant quantity of HEU was recovered by reprocessing HEU fuels from research, production, and Naval reactors. The different isotope composition of this reactor grade HEU affects its potential uses and storage requirements. ${ }^{236} \mathrm{U}$ is a mild nuclear poison that affects production in new fuel and the decay daughters of ${ }^{232} \mathrm{U}$ produce an increased radiation hazard during handling and storage.

\subsubsection{Post Cold War Operational Status}

The Office of Fissile Material Dispositioning has prepared A Surplus HEU Disposition Environmental Impact Statement (DOE/EIS-0240, June 1996), that describes expected environmental impacts of down blending surplus HEU to destroy its weapons capability. The EIS describes various alternatives for blending surplus HEU with low-assay uranium to achieve an LEU product suitable for feed stock for commercial fuel fabrication $(<5 \%)$ and well below the weapons-usable enrichment $20 \%$ assay. 
Four potential down blending sites were identified by DOE in the EIS: Two are DOE sites: the Y-12 Plant in Oak Ridge, Tennessee; and the Savannah River Site (SRS) in Aiken, South Carolina. The other two are commercial facilities: Nuclear Fuel Services (NFS) in Erwin, Tennessee; and Babcock and Wilcox (B\&W) in Lynchburg, Virginia.

The Oak Ridge, Tennessee, Y-12 Plant has long been designated as the DOE lead site for managing uranium inventories. It has now been established as lead laboratory for surplus HEU disposition and has been charged with providing options for safe, secure, and environmentally sound management and disposition of surplus HEU. This surplus HEU is currently stored at many sites across the DOE weapons complex (see Figure 3.1-1). The location, general form, and amount of surplus material at various DOE sites is thoroughly documented.

The Savannah River (Westinghouse) Site (SRS) also has the capability to manage uranium inventories. SRS can process AL/HEU materials in their large two canyon operation. Funding for Savannah River is proposed to be cut by 300 million dollars (25\% of the total budget) by October 1997 and the Savannah River Site will have a reduction in work force of about 4,000 people. This layoff will impact the sites current 10-year plan by possibly creating the need to consolidate their two canyon operation to one (F-Canyon). If only F-Canyon is open, then plutonium operations would probably be performed first followed by off-spec uranium operations. The startup date (2002) for uranium dilution operations will then be delayed at least two to three years (see Figure 3.1-2).

ANL-W is a nonprofit research laboratory operated by the University of Chicago for the Department of Energy. ANL-W is located about 35 miles west of Idaho Falls, Idaho, on the INEEL. Research at ANL-W is typically focused on large-scale nuclear facility testing and development. ANL-W is currently committed to a three year campaign to process ANL-W material through their electrorefiner. Following completion of the ANL-W material campaign in 2000 , the electrorefiner can potentially be used to process other material such as CPP-651 HEU. ANL-W has tested a magnetic separator that is capable of separating the uranium from broken Vycor glass molds. This dry process separation can be used for processing both CPP-651 and ANL-W inventories of Vycor glass molds. ANL-W also has vault space and warehouse space available to potentially store small inventories of CPP-651 material.

\subsubsection{ICPP SNM Storage}

The purpose of the Unirradiated Fuel Storage Facility (CPP-651) is to provide safe and secure storage for a variety of unirradiated and slightly irradiated fuel materials for subsequent processing or shipment to other facilities for use. Each type of material is handled and stored under specifically approved criteria. A complete listing of CPP-651 inventory is given in Table 2.3-1. Other unirradiated and slightly irradiated materials are stored at other ICPP locations such as CPP-749, CPP-603. Manager of the SNM in these facilities utilizes similar resources and their resource demands have been integrated with the CPP651 study in that possible interfaces with Parka transfers were evaluated. Since ICPP's mission no longer includes production scale reprocessing, the material stored in the CPP-651 vault must be relocated to other facilities for storage or conditioning. Potential receivers such as Y-12, SRS, and ANL-W have been identified to manage and process the Defense Program SNM currently stored in CPP-651. 


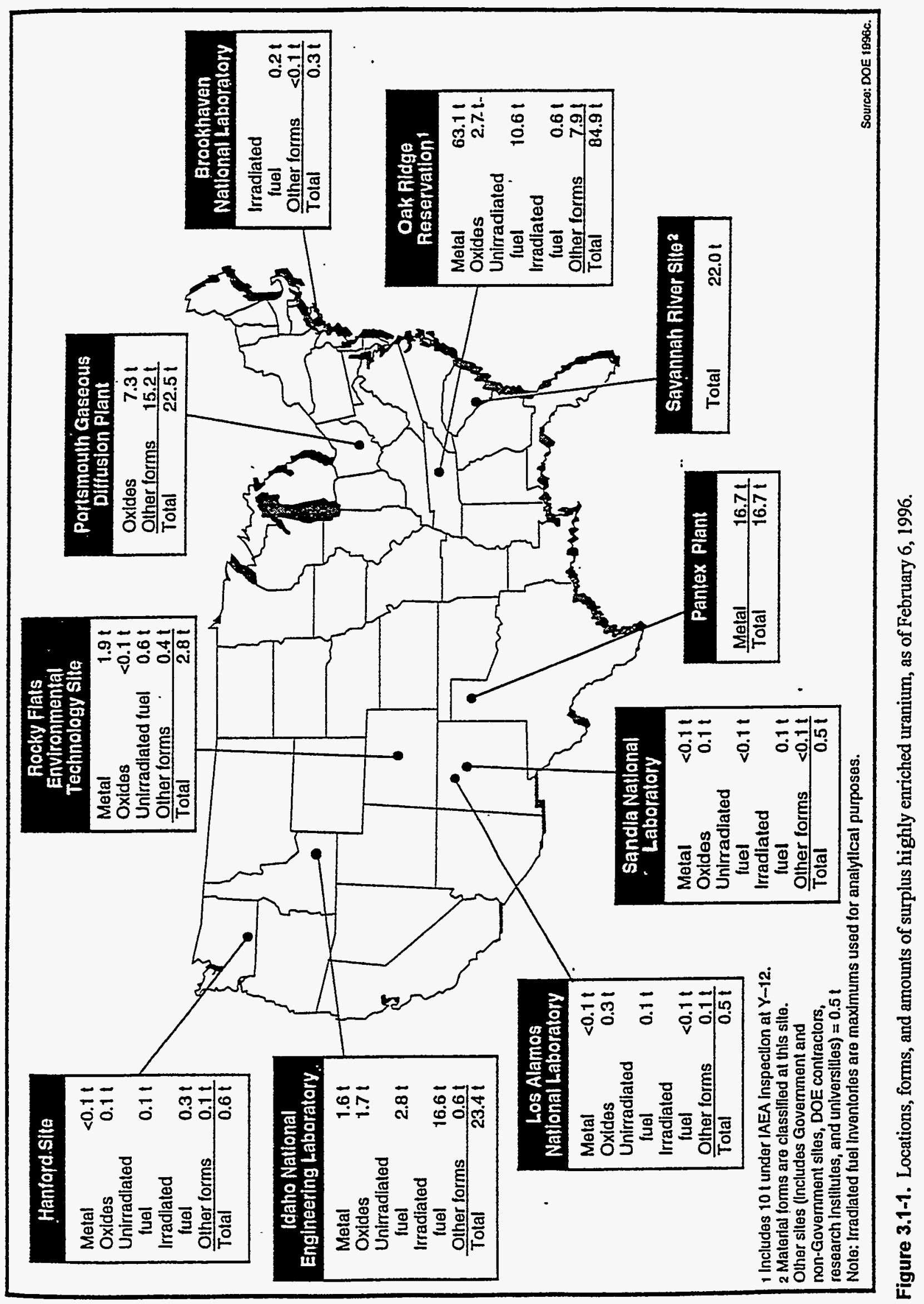


SRS Material Stabilization Phased Canyon Strategy

with F-Canyon Purex Through March 2000 (Inoludes Existing RF SSC, Scrub Alloy, Fluorides, and Table 6.2-1 SNF)

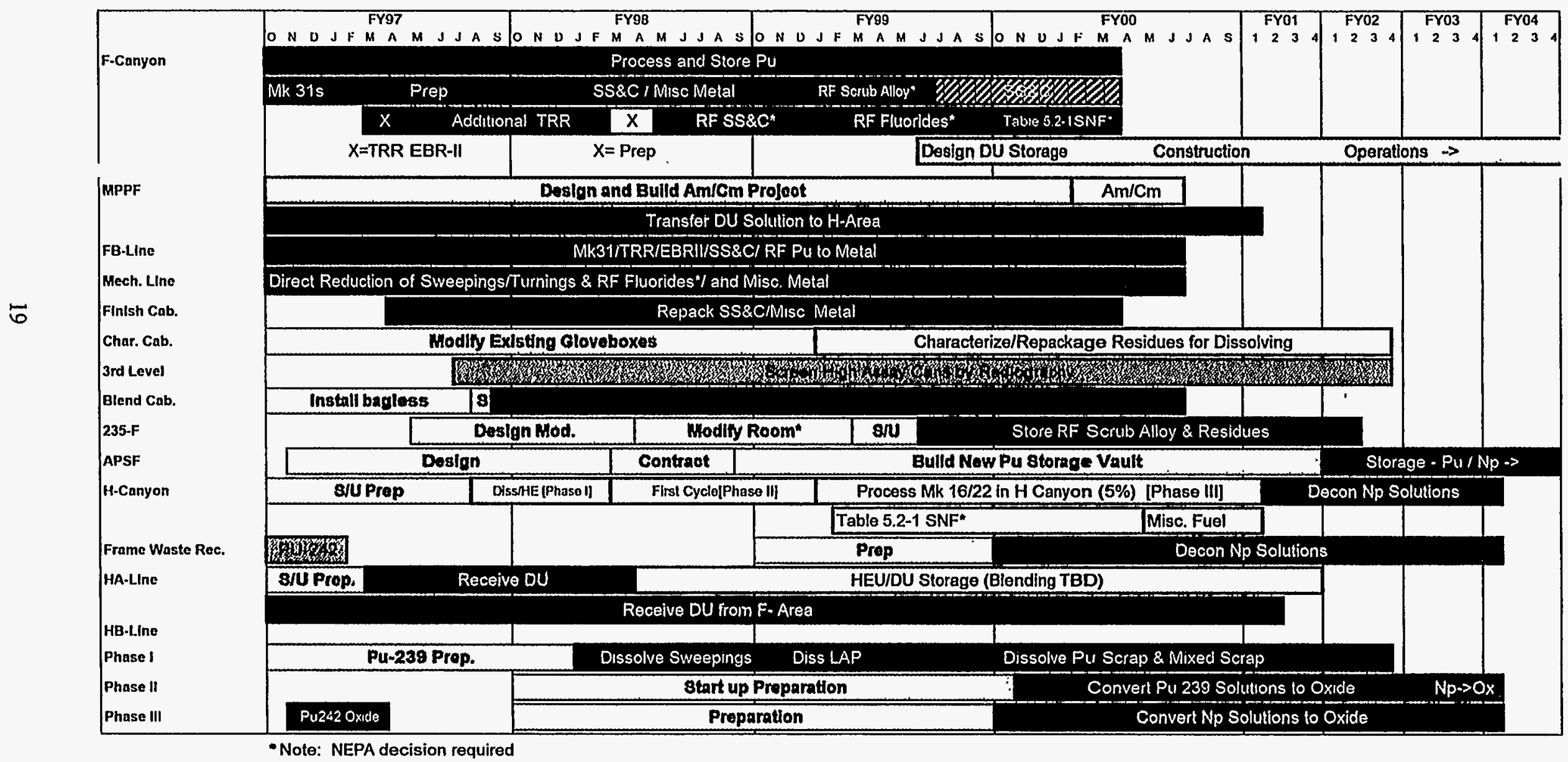

Figure 3.1-2. Savannah River Two Canyon operations 10-year plan. 
CPP-651 is the primary facility for managing inactive HEU at the INEEL. CPP-651 (see Figure 3.1-3) was originally designed for storage of unirradiated fuel materials brought to the ICPP for custom processing. Capacity was later increased to include interim storage of the $\mathrm{UO}_{3}$ product from ICPP processing operations. As shown in Figure 3.1-4, CPP-651 is a two-compartment inner-vault building approximately 42 feet wide by 45 feet long, surrounded by a reinforced concrete outer shell. The inner vault building is divided into two separate areas-the north and south vaults. Each vault is accessible from the receiving area only. Material in approved shipping or storage packages may be stored by transport index in the North Vault. The North Vault storage area is 25 feet long and 19 feet wide. The South Vault is used to store a wide variety of fissile materials. The outer shell provides a 20 foot wide interior receiving area on the west end for use in receiving and preparing material shipments. Additional storage for ICPP product containers is in storage wells located in the annulus between the facility outer walls and the North and South Vaults. The annulus has 100 storage wells and each well can hold seven containers in a linear array. Shipping and storage packages may also be stored in the north annulus above the storage wells.

The CPP-651 storage facility is not a processing facility, but related repackaging and inspection operations do occur within the facility. Some fuel elements, bundles, and packaged materials are stored in specially designed racks or cabinets that provide geometrically favorable constraints and/or nuclear poison. Other materials are maintained in approved storage packages, principally DOT- or DOE-approved shipping packages. Fuel categories presently approved for storage in the unirradiated fuel storage facility are designated in Table 2.3-1. CPP- 651 has a safety limit of $1,500 \mathrm{~kg}^{235} \mathrm{U}$ in the south vault and $1,500 \mathrm{~kg}$ ${ }^{235} \mathrm{U}$ in the north vault. The actual CPP-651 capacity is physically dependent upon the fuel package configuration; the available space may be filled to capacity before the kilogram limit is reached.

The other two SNM storage locations at ICPP include CPP-603 and CPP-749. The Irradiated Fuel Storage Facility (IFSF) is a nuclear fuel storage facility located in the Fuel Receiving Storage Facility (CPP-603) at the Idaho Chemical Processing Plant (ICPP). The IFSF was constructed at ICPP to provide safe storage for fuels that are potentially chemically reactive with water or industrially hazardous when exposed to the environment. Initially three graphite-based fuels were approved for storage at IFSF: Rovertype fuels, Peach Bottom Core I, and Fort St. Vrain. Several nongraphite fuels such as BER-II and TRIGA were added to the list of fuels approved for storage in the IFSF. The fuel storage area in IFSF contains the carbon steel storage rack that provides both spacing and support for 636 fuel storage canisters, each of which is 18 inches in diameter and 11 feet long. The Dry Fuel Storage Facility (CPP-749) provides storage for chemically reactive fuels that require long term storage and cannot be stored in the CPP-603 basin water. The underground fuel storage area is located within the confines of the ICPP security fence and north of CPP-603, the fuel basin. The storage area covers an area approximately 400 feet by 600 feet. Within that area are underground storage vaults for Peach Bottom fuel and Fermi I Blanket fuel. The vaults are approximately 20 feet deep by 30 inches in diameter. The storage vaults are sealed for containment, security, and inventory control of the spent fuel by welding a steel plate on the top of each vault. 


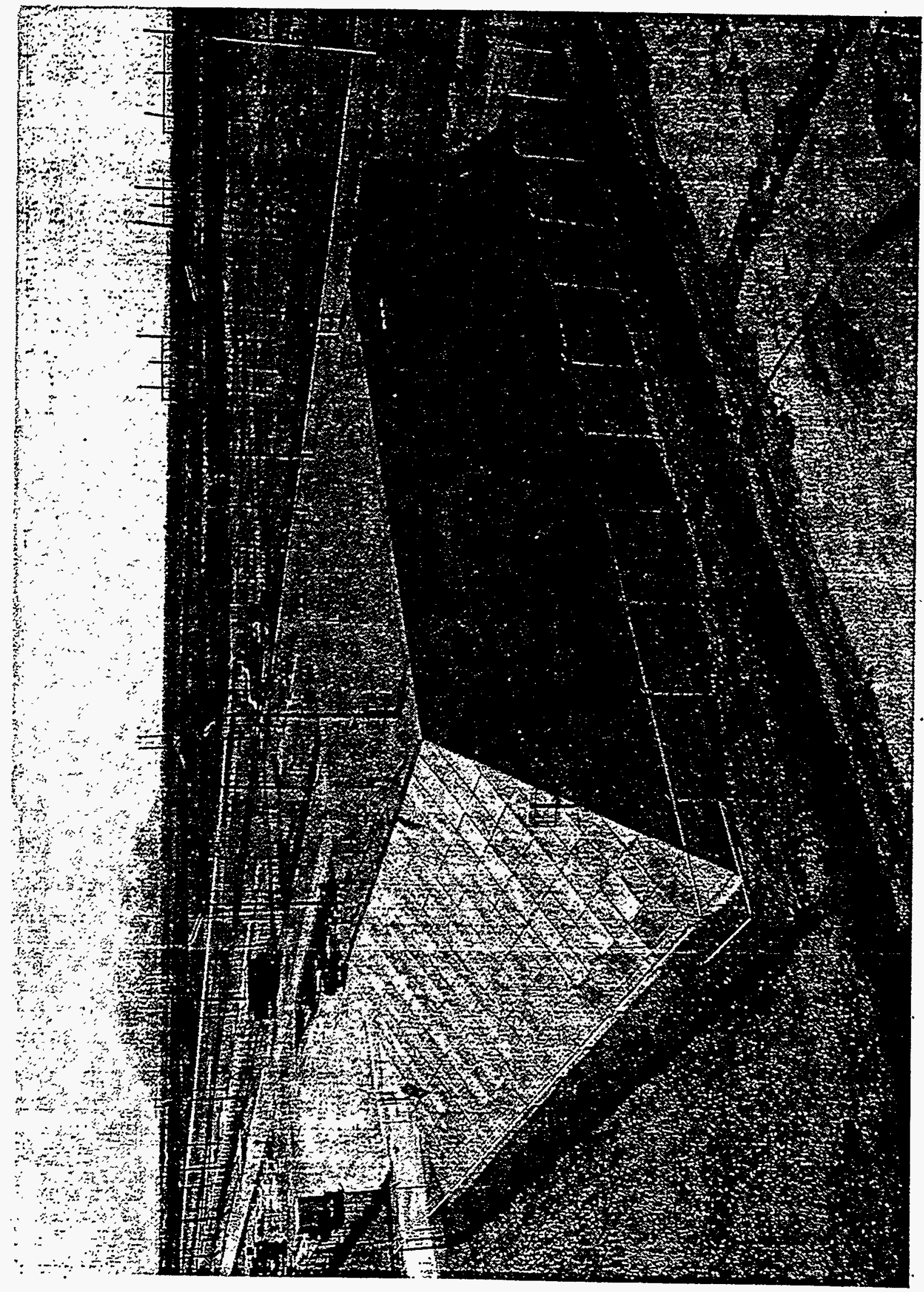




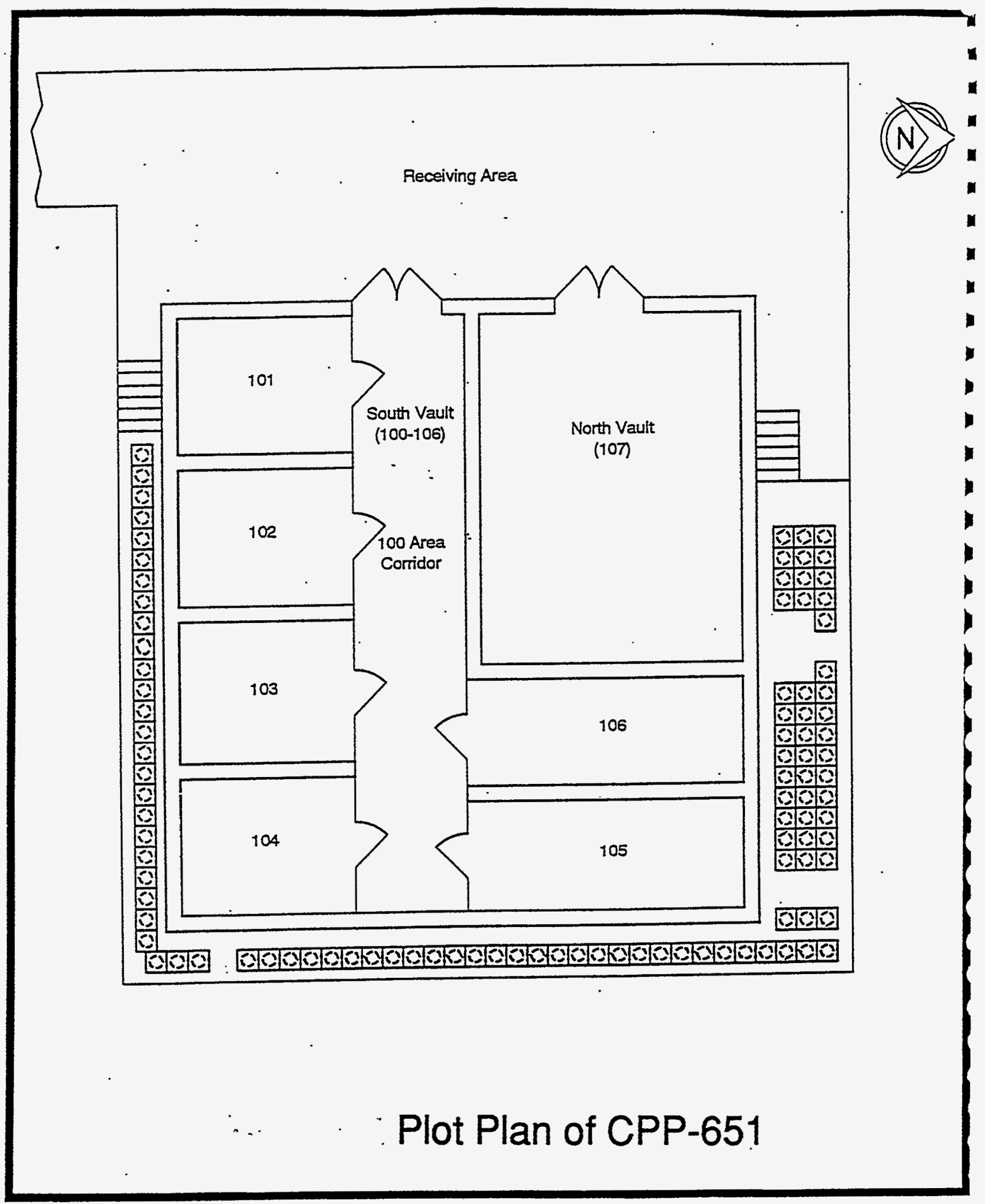

Figure 3.1-4. Plot plan of CPP-651. 


\subsubsection{CPP-651 Material Management and Categorization}

DP has mandated this facility be empty by 2006 and will be secured in stable standby condition. The unused capacity of CPP-651 is available for new missions. The LMTCO Materials Management Plan addresses plans in place to remove all nuclear material from CPP-651. Table 1.1-1 shows the base case schedule for SNM removal by 2006.

Materials in CPP-651 are categorized in the MMP by disposition status. In this study, a subset of these materials were further categorized as being a problem or difficult. Each of these are summarized in the following sections.

3.1.3.1 MMP Categorization. Nuclear materials at the INEEL exist in many forms and varying quantities. Each type of material in CPP-651 is handled and stored under specifically approved criteria. Stored materials include fluorinel, PWR, Rocky Flats scrap, ANL scrap, LANL scrap, ICPP denitrator product and product samples, uranium solutions, and miscellaneous fissile material stored in drums. The complete inventory is given in Table 2.3-1.

Material located in CPP-651 is categorized as inactive and has been divided into three management subcategories according to proposed disposition paths and options.

- Potential Programmatic Use is material with an optional program need and is being held in reserve pending the outcome of departmental decisions.

- Negotiated refers to surplus material that can be transferred to another location, has been listed on a scrap declaration, and has been accepted by the CSMO. In most cases the receiver has been identified or a contract will be bid. Schedules and packaging requirements are either known or being developed.

- To Be Negotiated consists of surplus material that has not yet been submitted to the CSMO, or material that has not been accepted for transfer pending resolution of issues.

Material categorization in the MMP was done in order to identify current status of the path forward, while maintaining focus on ultimate disposition of materials. Each kind of material was analyzed individually to determine general information and any issues relative to shipment. Based on the above assumptions, the preferred baseline option for each material type was established to be simply repackage and ship to appropriate site if possible.

3.1.3.2 Material Management. Material that had potential programmatic use was not addressed in this report. Fluorinel/PWR material is listed as negotiated but was still included in our list because it has a packaging issue to resolve. All to be negotiated material and the fluorinel/PWR were the HEU inventory items in CPP-65I that do not have a complete and funded disposition plan to another site. These 10 materials are fluorinel/PWR, University of Washington and University of Wisconsin, GEFAST, custom product, Janus, Vycor glass, ANL-W, ANL-E, Rocky Flats, and denitrator product. Table 3.1-1 summarizes each material, the initial shipping barriers identified in Phase I and the current status as far as resolution of barriers and proposed receivers per the baseline option. 


\subsection{Base Case Planning}

\subsubsection{Phase II Planning}

The primary goal of Phase II was to plan and schedule the sequence of material removal activities and take into account not only the schedule of each individual activity, but the potential impact that the activity schedule can have on the material removal schedule as a whole. The Phase II activities focused on identifying and integrating the resources and costs associated with removal of the material from CPP-651. The planning portion consisted of the following main activities:

- Establish project objectives and scope of work

- Delineate project organization/team

- Define the work

- Determine the timing/sequence

- Establish resource requirements/availability

- Establish a cost budget

- Evaluate/analyze the schedule

- List alternatives for shortening schedule.

Define and create a target schedule.

Primavera Project Planner software was used to create the basic material removal schedule with activities, resources, and cost account structure. The planning portion of the Primavera Project Planner software is used to define and coordinate specific activities and work tasks, prepare work schedules, assign and allocate resources to competing activities, and develop an acceptable budget. The Primavera Project Planner software can also be used to:

- Track work in progress and actual costs

- Compare schedule and cost data to baseline

- Use the baseline to guide your decision

- Update and modify the current project with realistic data

- Analyze and evaluate performance

- Recommend action and re-forecast

- Communicate project goals. 
Table 3.1-1. Material types and issues.

\begin{tabular}{|c|c|c|c|c|c|c|c|}
\hline \multirow[b]{2}{*}{$\underset{\Phi}{ \pm}$} & \multirow[b]{2}{*}{ Material } & \multicolumn{4}{|c|}{ Shipping Barriers } & \multirow[b]{2}{*}{$\begin{array}{c}\text { Composition/ } \\
\text { Form }\end{array}$} & \multirow[b]{2}{*}{ Current Status } \\
\hline & & 을 & 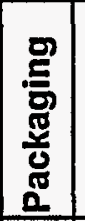 & むั & 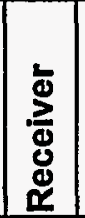 & & \\
\hline $1 \mathrm{a}$ & PWR Plates & & \% & & & $\begin{array}{l}\text { ceramic uranium- } \\
\text { zirconium fuel } \\
\text { plates }\end{array}$ & $\begin{array}{l}\text { The cut pieces of fuel that are contaminated will be bagged } \\
\text { and sealed and then placed within an aluminum container } \\
\text { prior to being placed within the } 2 R \text { inner container. This } \\
\text { procedure will eliminate the packaging barrier. }\end{array}$ \\
\hline $1 b$ & PWR Assembly & & 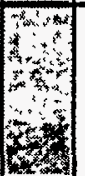 & & & $\begin{array}{l}\text { ceramic uranium- } \\
\text { zirconium } \\
\text { subassembly }\end{array}$ & $\begin{array}{l}\text { Upon issuance of a "certificate to ship" from Bettis, the PWR } \\
\text { assembly can be shipped, as an intact fuel element, in its } \\
\text { existing box as long as it is the only item on the truck. This } \\
\text { procedure will eliminate the packaging barrier. }\end{array}$ \\
\hline 2 & Fluorinel & & (3) & & & $\begin{array}{l}\text { zirconium clad } \\
\text { fuels }\end{array}$ & $\begin{array}{l}\text { The Fluorinel fuel pieces that are extra long will be placed in } \\
\text { a } 72 \text { inch long } 2 R \text { container which will then fit inside a } 110 \\
\text { gallon } 6 \mathrm{M} \text { drum. The use of a longer but narrower } 2 R \\
\text { container and DOT-6M } 110 \text { drum eliminates the packaging } \\
\text { barrier. }\end{array}$ \\
\hline 3 & Univ. of Wash. & 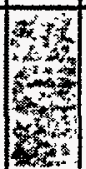 & & & & Aluminum fuel & $\begin{array}{l}\text { The calculations showed that the slightly irradiated material } \\
\text { does not meet the } Y-12 \text { acceptance criteria. Both the } \\
\text { unirradiated and irradiated Univ. of Wash. material will be } \\
\text { sent to SRS. Information collection is complete. }\end{array}$ \\
\hline 4 & Univ. of Wisc. & & & & & $\begin{array}{l}\text { Aluminum fuel } \\
\text { plates }\end{array}$ & No barriers. Paperwork in progress to send to $Y-12$. \\
\hline 5 & Custom & & 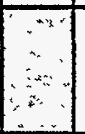 & & & Uranium Oxide & $\begin{array}{l}\text { The four oversized cans will be repackaged and shipped in } \\
\text { DC-1 shipping containers. These larger inside diameter } \\
\text { drums will eliminate the packaging barrier. }\end{array}$ \\
\hline 6 & GEFAST & & 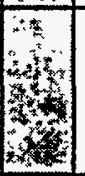 & & & $\begin{array}{l}\text { Zirconium \& } \\
\text { Uranium Oxide }\end{array}$ & $\begin{array}{l}\text { The oversized can contains less than } 350 \text { grams of uranium } \\
\text { and therefore can be shipped in a larger diameter } 35 \text { gallon } \\
\text { DOT UN1A2 shipping drum. This eliminates the packaging } \\
\text { barrier. }\end{array}$ \\
\hline 7 & Janus & 3tet & & 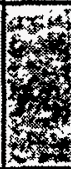 & (6) & $\begin{array}{l}\text { Stainless steel } \\
\text { clad uranium foils }\end{array}$ & $\begin{array}{l}\text { Based on which assumptions are used, the calculations } \\
\text { showed that the slightly irradiated material may or may not } \\
\text { meet the } Y-12 \text { acceptance criteria. Since there is no } \\
\text { metallurgical bonding the material will be sent to ANL-W. }\end{array}$ \\
\hline 8 & VYcoR Glass & & & tots & 6e & $\begin{array}{l}\text { Metal \& oxide in } \\
\text { broken glass } \\
\text { molds }\end{array}$ & $\begin{array}{l}\text { The VYCOR glass will be sent to ANL-W to separate the HEU } \\
\text { from the broken glass. They can process this material in its } \\
\text { current form which eliminates our barriers. }\end{array}$ \\
\hline 9 & ANL-W & Sistion & & & & $\begin{array}{l}\text { Scrap metal and } \\
\text { oxide }\end{array}$ & No barriers. Paperwork in progress to send to $\mathrm{Y}-12$. \\
\hline 10 & ANL-E & 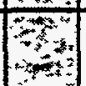 & & & & $\begin{array}{l}\text { Scrap metal and } \\
\text { oxide }\end{array}$ & $\begin{array}{l}\text { The ANL-E material along with the characterization data will } \\
\text { be sent to ANL-W. information collection is complete. }\end{array}$ \\
\hline 11 & Rocky Flats & & & +2 & 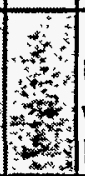 & $\begin{array}{l}\text { Uranium Oxide } \\
\text { with . } 2 \% \\
\text { Plutonium }\end{array}$ & $\begin{array}{l}\text { Since there will only be } 15 \text { drums with a total of } 30 \text { cans of } \\
\text { material, SRS will accept this material as soon as they are } \\
\text { able to provide some vault space. This eliminates our } \\
\text { barriers. }\end{array}$ \\
\hline 12 & Denitrator & & 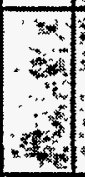 & 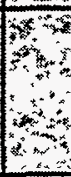 & $\sum_{1}$ & Uranium Oxide & $\begin{array}{l}\text { This material will be dry blended so that it can be shipped or } \\
\text { stored somewhere else as LEU until SRS has available vault } \\
\text { space. At that time the material will be shipped "as is" in DC-1 } \\
\text { shipping containers. This eliminates our barriers. }\end{array}$ \\
\hline & & & & & & & \\
\hline & & & & & & as & Deamer \\
\hline
\end{tabular}




\subsubsection{Resources, Costs, and Schedule}

The tasks or operations associated with removing each material from CPP-651 were grouped into three main functional areas-Receiver Process, Conditioning Process, and Packaging/Transportation Process. Team members were assigned to these three functional areas based on their areas of expertise. Each team resolved the issues, defined resources, developed schedules and costs for the functions within their assigned areas; and provided resource data to the master schedule. Durations and man-hours were allocated for each task based on past experience by knowledgeable personnel.

Resource data sheets were developed as a means to define the functions associated with removal of each material and to record the associated resources, duration, and costs. The main functions identified on the data sheet were preparations, conditioning, and shipment. Subcategories under these functions included project definition, procurement, documentation, procedures, plans, training, certification of readiness, operations, material repackaging and product shipment. The personnel resources identified included plant system engineers, facility fuels engineers, design engineers, technical support engineers, criticality safety engineers, safety analysis engineers, environmental engineers, radiological engineers, radiological technicians, quality engineers, quality inspectors, fuel handling foreman, fuel handling operators, analytical laboratory engineers, analytical laboratory technicians, security operations, procedure writers, trainers, transportation coordinators, administrative assistants, crafts foremen, crafts operators, and project managers. Additional costs were included for subcontract labor, equipment, facilities, and materials necessary for completion of the removal project.

3.2.2.1 Receiver Process Team. The receiver process team initiated negotiations with offsite receivers, determined acceptance criteria, discussed inventory issues, and resolved programmatic issues to determine overall programmatic direction. The receiver process team included spent fuel personnel who are familiar with complex-wide capabilities and issues, security personnel who are responsible for controlling and monitoring accountable nuclear material (NM) transfer to, from, and within the INEEL; and operations personnel who are familiar with the procedures and capabilities of CPP-651.

The receiver process team provided offsite receivers with characterization data on the materials in CPP-651 so that shipper/receiver agreements could start to be negotiated. The team determined that as a minimum the shipper/receiver agreements should include the following information: (1) types and forms of material to be shipped, (2) the period of time for which the shipper/receiver agreement will be in effect, (3) how the materials will be prepared and packaged for shipment, (4) documentation to be provided by the shipper prior to, with, and after the shipment, (5) measurement methods to be used by the shipper, (6) measurement methods to be used by the receiver, (7) how limits of error for accountability measurements will be calculated for accountability measurements required by the shipper/receiver agreement, (8) what acceptance/rejection criteria will be used for confirmatory measurements, (9) what documentation will be provided to the shipper by the receiver both after receipt and after measurement of the materials, (10) documentation of any deviations from DOE policy granted in accordance with DOE Order 5630.11A that apply to shipment covered by the agreement, (11) provisions for periodic review of the agreement, and (12) requirements for change control of revisions to the agreement. The receiver may want to make additional transfer checks or measurements beyond those included in the shipper/receiver agreement as a means to provide other checks. Additionally, the shipper/receiver agreements should include an outline of the process to be used for resolution of significant shipper/receiver differences.

Meetings were held with SRS and OR Y-12 to generate an understanding of our HEU storage issues, to discuss overall programmatic goals, and to help develop a spirit of ownership relative to the management of special nuclear material (SNM) throughout the Department of Energy (DOE) complex. Site-specific 
receiving and processing issues such as shipper/receiver agreements, onsite observation of characterizations and packaging, measurement requirements, and shipping schedules were discussed. SRS cannot formally respond to a request to receive HEU from ICPP until a conceptual study is completed. The conceptual study would be initiated by a formal request from DOE-ID to DOE-SR. The conceptual study would assess the technical feasibility and allow SRS to develop their procedures, schedules, and costs before formally committing to receive the HEU from ICPP.

3.2.2.2 Conditioning Process Team. The conditioning process team concentrated their effort on developing the processes required to put materials in a form that is acceptable to offsite receivers. The team discussed processing options for the PWR subassembly, the denitrator product, and the Rocky Flats material.

The conditioning team looked at various cutting processes for the C2S2 PWR subassembly. Prior to finalizing the cutting process the team determined that the PWR subassembly could be shipped, as an intact fuel element, in its existing box.

The conditioning team looked at several options for processing the Rocky Flats material such as dissolution, dilution, and dry blending. The Rocky Flats material requires conditioning because it does not meet the criteria for Y-12 acceptance due to the plutonium content. The conditioning team developed flowsheets and costs for the following Rocky Flats material processing options:

- $\quad$ Send as-is, in DOT-6M drums

- Dissolve, dilute, extract, and send as liquid using RAL

- Dissolve, dilute, extract, and send as liquid using a new process facility

- Dry blend in the North Vault of CPP-651 using a new glovebox within a new containment structure that includes a ventilation and filter system.

The flowsheets and the associated cost and schedule data are in Appendix A.

The conditioning team also looked at several options for processing the denitrator product such as dissolution, dilution, and dry blending. The denitrator product requires conditioning because it does not meet the criteria for $\mathrm{Y}-12$ acceptance due to the high ${ }^{232} \mathrm{U}$ content. Radiation levels have grown in since extraction and have created a handling issue of worker exposure.

The conditioning team developed flowsheets and costs for the following denitrator product processing options:

- Send as-is, in larger diameter drums

- Dry blend in the North Vault of CPP-651 using a new glovebox within a new containment structure that includes a ventilation and filter system

- Dissolve, dilute, and send as liquid using CPP-601 and CPP-627

- Dissolve, dilute, and send as liquid using a new process facility 


\section{- Repackage into smaller containers and then ship in DOT-6M drums.}

The flowsheets and associated costs and durations for each of these options are included in Appendix A of this report.

Milling and blending is one of the proposed options for diluting the denitrator product to less than $20 \%$ enrichment. This dilution will convert the HEU to LEU and eliminate the need to store the material in a vault while waiting at SRS for aqueous processing. Safety and security issues exist that must be addressed prior to accepting dry blending as an interim storage form. The main concern is from a proliferation standpoint. An expert analysis was performed of the relative difficulty of separating the HEU from the blended product. The details of the test and the results of the analysis are discussed in Appendix B. In general, these results look very promising and no show stopper issues were identified.

3.2.2.3 Packaging and Transportation Team. The packaging and transportation team obtained characterization data and identified resources that were required for packaging and transportation of the material in CPP-651. They provided interpretation of regulatory information and requirements pertinent to the packaging and transportation of materials to and from the INEEL. Members of the P\&T team have experience with transporting radioactive materials. They have consulted with programs to identify requirements for shipment; assisted in locating the appropriate containers required to ship, identify and contract a transport company to meet requirements of the shipment; ensured packages are transported without damage and delivered to the appropriate locations; managed records to track the shipment; and developed transportation plans. They typically determine the mode of transportation based upon size, weight, cost, destination, and specific regulatory requirements.

During Phase $\Pi$ the $P \& T$ team researched available packaging containers and requirements and details of packaging containers of currently stored material. P\&T has access to shipping containers located at other DOE laboratories and in radioactive materials packagings (RAMPAC), which is a storage and retrieval database of shipping packaging certified for the transport of radioactive materials. Shipping containers listed in the database are certified by the U.S. Nuclear Regulatory Commission (NRC) and DOE. RAMPAC is the only tool available to radioactive material shippers that contains and reports packaging information from all three U.S. agencies (DOE, NRC, DOT) and the international Atomic Energy Agency (IAEA). RAMPAC contains information on over 2,000 radioactive material shipping containers.

\subsubsection{Integration Process}

The goal of integrating the various options was to take a systems approach and attempt to optimize the overall plan. By examining the most difficult, highest risk issues first, a plan evolved to leverage options selected for more difficult problems. This process was iterative and was based on judgments about relative difficulties and risks with each material.

Clearly the most difficult problem is the denitrator product because of volume, radiation level, and the size of the product cans (won't fit into a 6-M drum). This material is also complicated in that it is offspec HEU (high in ${ }^{232} \mathrm{U}$ and ${ }^{236} \mathrm{U}$ ) and must be sent to an off-spec HEU dilution site such as $\mathrm{SRS}$. The team felt that there would be significant schedule risk if it were planned to send this material as HEU to SRS. Radiation levels may cause an acceptance issue, but more importantly, the HEU shipment would be dependent on SRS starting their HEU blending process and creating storage space in their vault. At best, they could receive material starting in 2002, but it could be as late as 2006 or 2007 as it is currently an unfunded part of their HEU dilution program. By establishing a repackaging capability that includes 
milling and dry blending with DU, it is possible to down blend material to LEU, reduce radiation levels, and ensure internal packages are acceptable to SRS. Material could then be shipped to SRS as soon as ICPP is ready to ship. Thus, the schedule risk is under direct control of ICPP management. Furthermore, if for some reason an off-spec HEU dilution site cannot receive this inventory in the next 10 years, it would still be removed from the CPP-651 vault and stored in a warehouse because it would no longer be HEU. Other materials needing repackaging due to container size can also be included in this campaign such as the custom product samples.

Rocky Flats material is the next biggest problem due to the volume and difficulty associated with plutonium. Initially, the team felt that the best plan would be to down blend Rocky Flats material by dissolution and dilution so that it could also be shipped to SRS for off-spec blending. However, the plutonium contamination ( 1 to 2 grams of $\mathrm{Pu}$ per 1,000 grams of $U$ ) eliminated it from being a good candidate for the dry blending process. Thus, it was concluded that the best option was to send this as HEU to SRS where it would become part of the HEU off-spec dilution program. Shipment to SRS is a possibility because of sufficient storage space and the $\mathrm{Pu}$ would be removed prior to blending with the $\mathrm{DU}$. The backup option is to dissolve the material in RAL and remove the $\mathrm{Pu}$ and ship liquid uranium nitrate to Oak Ridge for conversion to uranium oxide. The RAL facility is capable of processing and handling this volume of material in their hot cell which minimizes cost. A batch-wise process would be established to avoid exceeding any critical mass processing issues.

Y-12 and SRS will not accept the Vycor glass containing HEU. Thus, it is necessary to separate the metal from the glass before it would be accepted. The only viable option other than wet lab-scale processing at the ICPP is to send this material to ANL-W and fund implementation of their magnetic separation process. Working with ANL-W opens the door for them to potentially receive some other low volume, but difficult to place, materials such as the ANL-E explosion scrap and the Janus material.

Utilization of other ICPP dry storage facilities such as CPP-603 IFSF and CPP-749 simply to expedite the removal of SNM from the vault was considered, but programmatic and security issues eliminated this idea from further consideration.

\subsection{Base Case Materials Management Options}

Sections 3.3.1 through 3.3.12 list the DP-owned, CPP-651 HEU materials that have no complete disposition plan. A description of material is included with proposed options, estimated cost and schedule, disposition barriers, and a brief description of selected priorities. See Appendix A for detailed calculations of costs and schedules.

\subsubsection{PWR}

\subsubsection{PWR Plates.}

Material Description-Pressurized water reactor (PWR) fuel is a ternary oxide fuel consisting of a calciastabilized (ceramic) uranium-zirconium material $\left(\mathrm{UO}_{2}-\mathrm{ZrO}_{2}-\mathrm{CaO}\right)$, clad in Zircalloy. There are a total of 905 PWR plates. 854 plates are PWR Core 2, Seed 1 type fuel, and 51 plates are PWR Core 2, Seed 2 type fuel. All plates are cut and have smearable contamination ranging from $<10 \mathrm{dpm} / \mathrm{cm}^{2} \mu$ on the PWR Core 2 Seed 1 fuel to $250 \mathrm{dpm} / 100 \mathrm{~cm}^{2} \mu$ on the PWR Core 2 Seed 2 fuel. The PWR Core 2 Seed 2 plates are currently stored in three $6 \mathrm{M}$ drums. The PWR Core 2 Seed 1 plates are currently stored in six SPERT boxes. 
Issues-A shipping schedule cannot be finalized for this material until the contractor for the reprocessing facility has been selected and receipt criteria established. The accuracy and validations of the accountability measurements required by the receiver will be a key factor in the negotiated schedule. Negotiations with the designated contractor will commence as soon as directed by CSMO.

Packaging-The proposed plan is to repackage the 905 PWR fuel plates into 44 certified 85-gallon DOT 6M drums. The PWR Core 2 Seed 1 plates and the PWR Core 2 Seed 2 plates will be separated into 44 bundles of between 13 to 21 pieces, assayed, and bagged in polyethylene sleeve sealed with duct tape. Each of the 44 bundles will be placed in an aluminum can that is sealed with duct tape. Silicone rubber impact absorbers will be positioned in the bottom and top of each shipping drum $2 \mathrm{R}$ inner container to center the aluminum can and provide cushioning for the fuel. The aluminum can is placed in the $2 R$ container so that it rests on top of the silicone rubber impact absorbers. Silicone rubber impact absorbers are added on top of the can up to the top of the $2 \mathrm{R}$ container. The $2 \mathrm{R}$ container is closed and then placed in the 85-gallon drum which is then sealed for shipping.

Disposition-The 44 certified 85-gallon DOT 6M drums loaded with PWR fuel will be shipped to a designated contractor when a contract has been awarded by the CSMO.

Base Case Cost and Duration-A firm schedule will be developed with the contractor once the selection of the contractor has been made. Preliminary estimates indicate that it will take approximately $11 / 2$ years for planning and preparations, repackaging, and shipment of all items. The resource-loaded, base case schedule shows the following cost and duration:

\section{Cost: $\quad \$ 182.3 \mathrm{~K} \quad$ Duration: $1 \frac{1}{2}$ years}

Priority/Justification - This material was submitted and approved by CSMO under Scrap Declaration ID-93-04. Since the original submittal, additional material that was held for potential programmatic use (PPU) has been added to this declaration. In the near future, that declaration number will be canceled and the PWR materials will be put on a FY 1998 scrap declaration number and remaining fluorinel items will also be declared separately. This is being done at the request of the CSMO.

Assumptions

- The packaging plan is acceptable the material will not need to be separated and/or resorted by type prior to repackaging

- The certified 85-gallon DOT-6M drums are acceptable.

\subsubsection{PWR Subassembly}

Material Description-Pressurized water reactor (PWR) fuel is a ternary oxide fuel consisting of a calciastabilized (ceramic) uranium-zirconium material $\left(\mathrm{UO}_{2}-\mathrm{ZrO}_{2}-\mathrm{CaO}\right)$, clad in Zircalloy. The fuel is a PWR Core 2 Seed 2 subassembly. The subassembly is approximately 105 inches long and is currently stored in a metal box.

Issues-The PWR C2S2 fuel subassembly is too long for available drums. A shipping schedule cannot be finalized for this material until the contractor for the reprocessing facility has been selected and receipt criteria established. Negotiations with the designated contractor will commence as soon as practical for criteria identification. 
Packaging-The safety analysis states that the design of the PWR subassembly is inherently safe. Upon issuance of a certificate to ship from Bettis, the PWR subassembly can be shipped, as an intact fuel element, in its existing box. The only criteria is that it is the only item loaded on the truck.

Disposition-The PWR Subassembly will be shipped in its current box to a designated contractor when a contract has been awarded by the CSMO.

Base Case Cost and Duration-A firm schedule will be developed with the contractor once the selection of the contractor has been made. Preliminary estimates indicate that it will take approximately eight months for planning and preparations, inventory, and shipment of the assembly. The resource-loaded, base case schedule shows the following cost and duration:

\section{Cost: $\$ 66.3 \mathrm{~K} \quad$ Duration: 8 months}

Priority/Justification-This material was submitted and approved by CSMO under Scrap Declaration ID-93-04. Since the original submittal, additional material that was held for potential programmatic use (PPU) has been added to this declaration. In the near future, that declaration number will be canceled and the PWR materials will be put on a FY 1998 scrap declaration number and remaining fluorinel items will also be declared separately. This is being done at the request of CSMO.

Assumption

- The packaging plan is acceptable the material can be shipped as is in its existing container.

\subsubsection{Fluorinel}

Material Description-Fluorinel material is zirconium-clad fuel of various compositions. These materials were intended to be used for research and development (R\&D) as part of the prototype work on the new Fluorinel Dissolution Process for zirconium fuels. Fluorinel is an acronym for fluoride dissolution at the INEEL. Fluorinel scrap is currently stored in drums and cabinets in CPP-651.

Issues-Several pieces of fluorinel material are too long for the typical $6 \mathrm{M}$ drums used at ICPP. A shipping schedule cannot be finalized for this material until the contractor for the reprocessing facility has been selected and receipt criteria established. The accuracy and validations of the accountability measurements required by the receiver will be a key factor in the negotiated schedule. Negotiations with the designated contractor will commence as soon as practical for criteria identification

Packaging-The proposed plan is to repackage the fluorinel fuel into 21110 -gallon, DOT-6M shipping packages with a 72 -inch long $2 \mathrm{R}$ inner container; five 110-gallon, DOT-6M shipping packages with a 58-inch long $2 \mathrm{R}$ inner container; four 55-gallon, DOT-6M shipping packages with a 23-inch long $2 \mathrm{R}$ inner container; and 60 85-gallon, DOT-6M shipping packages with a 43-inch long 2R inner container.

Disposition-The certified 110-, 85-, and 55-gallon DOT 6M drums loaded with fluorinel fuel will be shipped to a designated contractor when a contract has been awarded by the CSMO.

Base Case Cost and Duration-A firm schedule will be developed with the contractor once the selection of the contractor has been made. Preliminary estimates indicate that it will take approximately $1 \frac{1}{2}$ years for planning and preparation, repackaging, and shipment of all items. The resource-loaded, base case schedule shows the following cost and duration: 


\section{Cost: $\$ 546 \mathrm{~K} \quad$ Duration: $1 \frac{1}{2}$ years}

Justification/Other-This material was submitted and approved by CSMO under Scrap Declaration ID-93-04. Since the original submittal, additional material that was held for potential programmatic use (PPU) has been added to this declaration. In the near future, that declaration number will be canceled and the fluorinel material will be put on a FY 1998 scrap declaration number. The remaining PWR items will also be declared separately. This is being done at the request of the CSMO.

\section{Assumptions}

- The packaging plan is acceptable-the material will not need to be separated and/or resorted by type prior to repackaging

- The certified 110-, 85-, and 55-gallon DOT-6M drums are acceptable.

\subsubsection{University of Washington}

Material Description-The University of Washington fuel is in an aluminum alloy form with an argonaut core and aluminum cladding. The fuel consists of 30 plates and one can containing cut fuel pieces and scraps. The plates are uncut and free of surface contamination. Eleven of the fuel plates are unirradiated and the remaining 19 are slightly irradiated. The slightly irradiated fuel plates contain quantities of plutonium.

Issues-The 19 slightly irradiated fuel elements contain concentrations of $\mathrm{Pu}-239$ and $\mathrm{Pu}-240$ in the milligram range. The irradiated fuel elements do not meet the alpha activity hazard ratio criteria or the gamma activity criteria and therefore would not meet the acceptance criteria for highly enriched fuels into the $\mathrm{Y}-12$ plant.

Packaging-The proposed plan is to repackage the University of Washington fuel (both irradiated and unirradiated) into one certified 85-gallon DOT-6M drum.

Disposition-The one certified 85-gallon DOT-6M drum will be sent to Savannah River for off-spec blending.

Base Case Cost and Duration-Preliminary estimates indicate that it will take approximately four months for planning and preparation, repackaging, and shipment of all items. The resource-loaded, base case schedule shows the following cost and duration:

\section{Cost: $\$ 40.3 \mathrm{~K} \quad$ Duration: 4 months}

Priority/Justification-Scrap Declaration ID-94-03 has been submitted for this material. The irradiated material has been rejected by CSMO and therefore will not be sent to Oak Ridge, Y-12 Plant.

\section{Assumptions}

- The Y-12 plant will not accept the irradiated material

- Savannah River will accept both the unirradiated and irradiated material 
- The packaging plan is acceptable- the material will not need to be separated and/or resorted by type prior to repackaging

- The certified 85-gallon DOT-6M drum is acceptable.

\subsubsection{University of Wisconsin}

Material Description-The University of Wisconsin is MTR-type fuel manufactured by General Electric. The fuel consists of 10 plates made in an aluminum alloy form with aluminum cladding. The plates are uncut and free of surface contamination.

Issues-None. The only reason this material has not been shipped is because it is on the same scrap declaration as the University of Washington fuel.

Packaging-The proposed plan is to repackage the University of Wisconsin fuel into one certified 85-gallon DOT-6M drum.

Disposition-The one certified 85-gallon DOT-6M drum will be sent to the Oak Ridge Y-12 plant.

Base Case Cost and Duration-Preliminary estimates indicate that it will take approximately four months for planning and preparations, repackaging, and shipment of all items. The resource-loaded, base case schedule shows the following cost and duration:

\section{Cost: $\$ 43.2 \mathrm{~K} \quad$ Duration: 4 months}

Priority/Justification-Scrap Declaration ID-94-03 has been submitted for this material. Once this material has been accepted under a scrap declaration, it can be shipped in one certified 85-gallon DOT-6M drum to Y-12 for potential processing and/or storage. Shipment will be coordinated with the custom product and GEFAST.

Assumptions

- The Y-12 plant will accept this material

- The packaging plan is acceptable

- The certified 85-gallon DOT-6M drum is acceptable.

\subsubsection{Custom Product}

Material Description-The custom product is uranium trioxide $\left(\mathrm{UO}_{3}\right)$ powder, a high grade uranium oxide product obtained from reprocessing SNF at ICPP. The powder is contained in 18 cans and four bottles.

Issues-Four bottles of this material do not fit in the typical 2R inner containers for DOT-6M drums. The accuracy and validation of the accountability measurements required by the receiver will be a key factor in the negotiated schedule. 
Packaging-The proposed plan is to repackage the 18 cans of custom product into nine certified 55-gallon DOT-6M drums and to repackage the four bottles of custom product into four certified DC-1 shipping packages.

Disposition-The nine certified 55-gallon DOT-6M drums and the four certified DC-1 shipping packages containing the custom product will be sent to the Oak Ridge Y-12 plant.

Base Case Cost and Duration-Preliminary estimates indicate that it will take approximately four months for planning and preparations, repackaging, and shipment of all items. The resource-loaded, base case schedule shows the following cost and duration:

\section{Cost: $\quad \$ 76.4 \mathrm{~K} \quad$ Duration: 4 months}

Priority/Justification-This material has been accepted by CSMO under scrap declaration ID-97-07. Shipment will be coordinated with the GEFAST and University of Wisconsin materials.

\section{Assumptions}

- The Y-12 plant will accept the nine DOT-6M drums and the four DC-1 shipping packages of material

- The packaging plan is acceptable

- The certified 55-gallon DOT-6M drums and the certified DC-1 drums are acceptable.

\subsubsection{GEFAST}

Material Description-GEFAST consists of five containers of zirconium oxide and uranium oxide powder. Four of the containers are made of stainless steel pipe 4.5 " outside diameter with a 5 " bolted flange opening at the top. The fifth container is a large metal can 8 " in diameter and 10 " tall.

Issues-Scrap Declaration ID-94-03 has been submitted. A firm shipping schedule can be determined for this material once it is accepted under Scrap Declaration ID-94-03.

Packaging-The proposed plan is to ship the four smaller, stainless steel containers in four 55-gallon DOT-6M drums and to ship the single, large metal can in one 35-gallon DOT UN1A2 drum.

Disposition-The five drums containing GEFAST will be sent to the Oak Ridge Y-12 plant. This transfer is expected to be coordinated with the custom product and University of Wisconsin materials.

Base Case Cost and Duration-Preliminary estimates indicate that it will take approximately five months for planning and preparations, repackaging, and shipment of all items. The resource-loaded, base case schedule shows the following cost and duration:

\section{Cost: $\$ 63.4 \mathrm{~K} \quad$ Duration: 5 months}

Priority/Justification-Before a shipping schedule can be finalized, this material must be negotiated under a scrap declaration. Shipment will be coordinated with the custom product and University of Wisconsin materials. 


\section{Assumptions}

- The Y-12 plant will accept this material

- The packaging plan is acceptable

- The certified 55-gallon DOT-6M drums and the 35-gallon DOT UN1A2 drum are acceptable.

\subsubsection{Janus}

Material Description-Janus is stainless steel-clad enriched uranium foils, known as Janus Reactor High Flux Converter Foils. The stainless steel is not metallurgically bonded to the uranium and should separate rather easily. This material has been slightly irradiated in the Janus Reactor. There are 34 foils with standardized dimensions of 39 inches long, 4 inches wide, and 0.037 inch thick $(0.021$ inch of uranium and 0.08 inch of cladding). The 34 foils are contained in three $6 \mathrm{M}$ drums.

Issues-Janus was previously rejected by the CSMO because the radiation level was too high ( $5 \mathrm{R}$ per hour). Additional inspections were completed in September 1996. The drum inspected indicated $180 \mathrm{mR}$ beta and $60 \mathrm{mR}$ gamma. Additional analysis appears to indicate that the slightly irradiated JANUS fuel plates meet all the Y-12, acceptance criteria depending on which burnup basis is used in the calculations. The analysis has been sent to $Y-12$ for review and comment. If the material is acceptable to $Y-12$, then the scrap declaration will be resubmitted to $\mathrm{Y}-12$. If the scrap declaration is rejected, the material could be sent to Argonne West pending DP's concurrence. If material is sent to ANL-W, DP would still own the material and may need to pay ANL-W for storage and/or processing/stabilization.

Packaging-Janus can be shipped in three, 110-gallon DOT-6M drums.

Disposition-The three drums containing Janus will be sent to the Oak Ridge Y-12 plant assuming that the plates meet Y-12's acceptance criteria. If the material does not meet their acceptance criteria, then the material will be sent to ANL-W.

Base Case Cost and Duration-Preliminary estimates indicate that it will take approximately four months to complete preparations, transfer documentation, inventory of material, and shipment to ANL-W. The material will not have to be repackaged if it is sent to ANL-W because it can be shipped in the drums that it is currently stored in. The resource-loaded, base case schedule shows the following cost and duration:

\section{Cost: $\quad \$ 46.3 \mathrm{~K} \quad$ Duration: 4 months}

Priority/Justification-A scrap declaration has been submitted for this material. Once this material has been accepted under a scrap declaration, it can be shipped to $Y-12$ for potential processing and/or storage. If the material is not accepted under the scrap declaration, it will be sent to ANL-W for potential processing and/or storage. If the material is sent to ANL-W it will still be owned by DP. Funds may need to be provided to ANL-W for storage and/or processing/stabilization.

\section{Assumptions}

- Argonne West will accept the three drums of material if it is rejected by Y-12

- The Y-12 plant will accept the three drums of material 
- The packaging plan is acceptable

- The certified 110-gallon DOT-6M drums are acceptable for shipment to Y-12

- The noncertified 110-gallon DOT-6M drums are acceptable to send as is on the back roads to ANL-W.

\subsubsection{Vycor Glass}

Material Description-This material is broken pieces of glass molds used to manufacture fuel at ANL-W. The glass pieces retain small amounts of the fuel that was being molded. The glass must be processed to remove the small amount of uranium.

Issues-This material has been rejected by CSMO because it is glass. This material does not meet the security termination criteria and therefore cannot be written off the books as waste.

Packaging-The Vycor Glass will not be repackaged; it will be shipped in the drums where it is currently stored.

Disposition-Send to ANL-W for dry processing through their magnetic separator. After separation of the uranium from the glass, ANL-W will be responsible for sending the uranium to Y-12 and for disposing the glass.

Base Case Cost and Duration-Preliminary estimates indicate that it will take approximately six months to complete preparations, transfer documentation, inventory of material, and shipment to ANL-W. The material will not have to be repackaged if it is sent to ANL-W because it can be shipped in the drums that it is currently stored in. The resource-loaded, base case schedule shows the following cost and duration:

Cost: $\$ 578.8 \mathrm{~K}$

Duration: 6 months

Priority/Justification-ANL-W has approximately 40 cans of Vycor glass, as compared to our 400 cans. ANL-W has not found a way to acceptably dispose their material. They stated that their only option was to dry process to separate uranium from glass. ANL-W has purchased a magnetic separator, but would need funding to help design, set up, test, and operate equipment. If material is sent to ANL-W, DP would still own the material and may need to pay ANL-W for storage and/or processing/stabilization.

\section{Assumptions}

- The Argonne West plant will accept the ten drums of material

- The packaging plan is acceptable

- The noncertified $17 \mathrm{H}$ drums are acceptable to send as is on the back roads to ANL-W.

\subsubsection{ANL-W}

Material Description-ANL-W material consists of 48 cans of EBR-II scrap metal and oxide. 
Issues-Reevaluation of the characterization of the material has been performed with ANL-W and it has been determined that this material is from the same source as the other ANL-W Miscellaneous (EBR-II) material currently stored in CPP-651. This other ANL-W material has been accepted by the CSMO under scrap declaration ID-93-17. The scrap declaration will be revised to add the additional cans.

Packaging - This material will be divided into two shipments. Twenty eight of the cans will be packaged in 13 55-gallon, certified DOT-6M drums and shipped to the Y-12 plant in FY 1998. The remaining 20 cans will be packaged in approximately 1055 -gallon, certified DOT-6M drums and shipped to the Y-12 plant at a later date.

Disposition- Once this material has been accepted under a scrap declaration it will be sent to the Y-12 plant.

Base Case Cost and Duration - Preliminary estimates indicate that it will take approximately five months for planning and preparations, repackaging, and shipment of all items. The resource-loaded, base case schedule shows the following cost and duration:

\section{Cost: $\quad \$ 76.4 \mathrm{~K} \quad$ Duration: 5 months}

Priority/Justification-Before a shipping schedule can be finalized, this material must be negotiated under a scrap declaration. Shipment will be coordinated with the Custom product, GEFAST, and University of Wisconsin materials.

\section{Assumptions}

- The Y-12 plant will accept this material

- The packaging plan is acceptable

- The certified 55-gallon DOT-6M drums are acceptable.

\subsubsection{ANL-E Miscellaneous}

Material Description-ANL-E Miscellaneous is comprised of hot cell experimental scrap collected following the custom processing explosion.

Issues-Argonine stated that they could potentially process this material in their electrorefiner. They currently lack NEPA approval to do this. They are committed to process certain material through their electrorefiner for the next two years. The earliest that they could process this material (assuming they could get NEPA approval) would be in 2000 . They have vault space to store this material; therefore it could be sent to them prior to 2000 . If material is sent to ANL-W, DP would still own it and may need to pay ANL-W for storage and/or processing/stabilization.

Packaging-The ANL-E material will be repackaged into two, 55-gallon DOT-6M drums and shipped to ANL-W.

Disposition-Once the data package is complete, the material will be shipped in two 55-gallon, DOT-6M drums to ANL-W for processing through their electorefiner. The recovered uranium will then be sent to the Y-12 plant. 
Base Case Cost and Duration-Preliminary estimates indicate that it will take approximately four months to complete preparations, transfer documentation, inventory material, and ship to ANL-W. The material will not have to be repackaged if it is sent to ANL-W because it can be shipped in the drums that it is currently stored in. The resource-loaded, base case schedule shows the following cost and duration:

$$
\text { Cost: } \quad \$ 48.8 \mathrm{~K} \quad \text { Duration: } \quad 4 \text { months }
$$

Priority/Justification-The material sent to ANL-W will still be owned by DP. Funds may need to be provided to ANL-W for storage and/or processing/stabilization.

\section{Assumptions}

- The Argonne West plant will accept the two drums of material.

- The packaging plan is acceptable

- The certified 55-gallon, DOT 6M drums are acceptable.

\subsubsection{Rocky Flats}

Material Description-Rocky Flats has $\mathrm{U}_{3} \mathrm{O}_{8}$ powder contaminated with plutonium. This material contains a total of $27 \mathrm{kilograms}$ of uranium and a total of 56 grams of plutonium. There are 30 cans ( 4 inches in diameter and 9.5 inches tall) of this material and they each contain 1 to 2 grams of plutonium.

Issues-This material has been rejected under Scrap Declaration ID-93-16 due to the plutonium content. In order to send this material to Y-12, the material must be processed to separate the plutonium from the uranium oxide. Returning this material to Rocky Flats is not a viable option because they have no processing capabilities. Savannah River (SRS) is capable of taking it, but since it is HEU, it would need to be stored in a vault until their canyon operation is ready to process this material. SRS has very little vault space available until 2001 when they are planning to operate both of their canyons, or until 2005 if only one canyon is allowed to operate.

Note-The ship-as-is option was selected for the base case scenario. See Appendix A for costs and duration of the various conditioning options for the Rocky Flats material.

Packaging-The proposed plan is to repackage the Rocky Flats material in the existing containers into 15 ( 2 cans per drum) certified 55-gallon DOT-6M drums.

Disposition-The 15 certified 55-gallon DOT-6M drums will be sent to the Savannah River plant.

Base Case Cost and Duration-Preliminary estimates indicate that it will take approximately four months for planning and preparations, repackaging, and shipment of all items to Savannah River. The resourceloaded, base case schedule shows the following cost and duration:

Cost: $\$ 63.5 \mathrm{~K}$

Duration: 4 months

Priority/Justification-The ship-as-is option is the simplest for ICPP as far as repackaging and shipping but it is also dependent on operation of the SRS canyons. Material cannot be sent to SRS as HEU until 
space is made available in their vault by either processing or relocating the material currently stored in their vault.

\section{Assumptions}

- This material cannot be sent to SRS as HEU until they make space available in their vault either by operation of their canyons or relocation of material.

- SRS costs are not factored into this option.

\subsubsection{Denitrator Product}

Material-This denitrator product is $\mathrm{UO}_{3}$ obtained from Navy fuel dissolved in the fluorinel dissolution process (FDP) at ICPP. This item contains a significant quantity of enriched uranium, $1,700 \mathrm{~kg}$. This material contains approximately 50 parts per billion ${ }^{232} U$.

Issues-This material does not meet the criteria for $Y-12$ acceptance because the ${ }^{232} U$ content of this material is too high. Radiation levels have grown in since extraction and have created a handling issue of worker exposure. Savannah River (SRS) is capable of processing this material in their off-spec HEU dilution program however, since it is HEU, it would need to be stored in a vault until their canyon operation is ready to process this material. SRS has very little vault space available until 2002 when they are planning to operate both of their canyons, or until 2005 if only one canyon is allowed to operate. Furthermore, it is not clear if the funding will be made available to process this inventory. The current storage containers for the denitrator product do not fit in the $2 \mathrm{R}$ inner containers for the DOT-6M shipping containers. In order to send the denitrator product to SRS it will need to be either repackaged into a larger DOT shipping container or repackaged into a smaller storage container that will fit in a DOT-6M shipping container.

Note-The proposed best plan is a combination of two options: to dry blend the denitrator product with DU or LEU (option 2) and ship to SRS. These operations will continue until SRS has vault space to receive HEU. At that time dry blending will be stopped and HEU shipment in DC-1 shipping packages (optionl) will proceed. See Appendix A for costs and duration of the various other conditioning options for the denitrator product.

Packaging-The proposed plan is to package the denitrator product with depleted uranium, in a new container, dry blend in a mill, and then place in a $2 \mathrm{R}$ inner container for a 110 -gallon DOT-6M drum. A total of 552 new containers will be used. It is assumed that 24110 -gallon, DOT-6M drums can be loaded onto one commercial carrier per shipment; therefore it will take 23 shipments to transfer all of the dry blended denitrator product to Savannah River. When SRS has vault space available the dry blending operations will discontinue and then the Denitrator Product will be repackaged into certified 109-gallon Oak Ridge, Y-12 Model DC-1 shipping packages and sent to SRS via a SST. Ninety six DC-1 drums will be purchased and they will be reused in order to send the remaining denitrator product containers to Savannah River.

Disposition-The certified 110-gallon DOT-6M shipping packages (552 maximum) will be used for the dry blending operations to send the material to the Savannah River plant. The certified 109-gallon Oak Ridge, Y-12 Model DC-1 shipping packages will be used for the ship-as-is scenario to send the material to the Savannah River plant. Approximately 7 DC-1 shipping packages can be loaded onto one SST, therefore it will require a maximum of 40 SST shipments to transfer the material to Savannah River. 
Base Case Cost and Duration-Preliminary estimates indicate that it will take approximately six years to design, procure, construct, test and operate the dry blend process including the time for planning and preparations, repackaging, and shipment of all items using the dry blending option to Savannah River. The resource-loaded, base case schedule shows the following cost and duration:
Cost:
$\$ 4,621 \mathrm{~K}$
Duration:
6 years

Preliminary estimates indicate that it will take approximately three years to obtain DC-1 shipping packages, and complete planning and preparations, repackaging, and shipment of all items using the shipas-is option to Savannah River. The resource-loaded, ship-as-is schedule using the transfer negotiations team shows the following cost and duration:
Cost:
$\$ 1,668 \mathrm{~K}$
Duration:
3 years

Priority/Justification-The proposed process creates a dilute, dry product that could be shipped to SRS as a nonweapons grade material. This would eliminate the necessity to store the product in the HEU vault at SRS, thereby reducing costs and allowing the INEEL to move the material sooner.

\section{Assumptions}

- The dry blending process is an alternative to aqueous processing of the denitrator product.

- Each can of denitrator product will be diluted with depleted uranium to less than $20 \%$ enrichment or approximately a 5 to 1 dilution. The volume will therefore grow by a factor of about 6 .

- Contact radiation level readings range from $3 \mathrm{mr} / \mathrm{hr}$ to $900 \mathrm{mr} / \mathrm{hr}$. The majority are in the 100 to $200 \mathrm{mr} / \mathrm{hr}$ range and only 14 of the 276 bottles are at $500 \mathrm{mr} / \mathrm{hr}$ or greater.

- The process will be designed for the 100 to $200 \mathrm{mr} / \mathrm{hr}$ material. The higher levels will be handled/processed on a case by case basis.

- The dry blended denitrator product will be contained within dissolvable cans that are compatible with the SRS dissolution process.

- This material cannot be sent to SRS as HEU (ship-as-is) until space is made available in their vault by either processing or relocating the material currently stored in their vault.

- The 5.25 inch outside diameter of the 2.85 liter metal can is too large to fit inside a $2 \mathrm{R}$ inner container of a DOT- $6 \mathrm{M}$ drum. The inside dimensions of a $2 \mathrm{R}$ inner container for a 55-gallon DOT-6M drum is 5.05 inch inside diameter and 23 inches long.

- The Oak Ridge Y-12, model DC-1 shipping package has a larger inside diameter than the DOT-6M drums.

- The SARP for the DC-1 shipping packaged will need to be revised and approved prior to using it to ship our denitrator product or our custom product. 
- Seven DC-1 shipping packages will be allowed per SST. It will take 40 shipments to transfer this material to Savannah River.

- Savannah River will not store the material in the DC-1 shipping packages. They will remove the denitrator product containers and then return the empty DC-1 shipping packages to ICPP for repackaging.

- Ninety six DC-1 shipping packages will be adequate to allow for efficient cycling of shipping packages for repackaging, shipment, unloading, and return.

- Security sampling/measurement issues have not all been addressed. 


\section{ACCLERATED SCHEDULE OPTIONS}

Four different accelerated schedules (Options A, B, C, and D) were developed and analyzed to provide a suite of choices that incrementally evaluated the interaction of cost, shipping risk, and reduced schedule time. These accelerated schedules were developed via a system engineering methodology and an in-depth analysis of the base case. This analysis identified the critical path issues and how they could be improved. From a national programmatic perspective it includes understanding the shipper and receiver limitations and interactions. At the local level, the shipper (ICPP) picture simplifies to preparations for making the transfer (paper work and conditioning) and the hands-on tasks related to the actual material packaging and transfer to an SST. The receiver has very similar preparation paper work and the tasks related to unloading and storing the inventory (receiver related tasks were not resource-loaded on this schedule). All the tasks in the base case fall into the general categories of preparation, packaging/shipping, tasks outside CPP-651, and tasks inside CPP-651.

Examination of the base case information indicated there are two fundamental ways to reduce the schedule: (a) increase staff and (b) decrease scope (i.e., decrease or eliminate any material conditioning operations) and ship-as-is. Current staffing levels are adequate to support the base case which will empty the CPP-651 vault in less than 10 years. However, it is clear that this level of staffing reflects the effects of down sizing and does not produce the optimum or accelerated results. Additional personnel can reduce the time related to: (a) preparation of paper work and negotiations with the receiver (b) conditioning of material for packaging and (c) the repackaging and transfer operations. It should be noted if additional experienced staff can be allocated to the shipper program it may also require some additional staff at the receiver site to fully realize the benefits. Obviously there is a limit on how many personnel can work effectively inside CPP-651 and similarly there is a limit of effectiveness of personnel working on the preparation related tasks. Thus, the selection of extra personnel was done in a strategic manner.

The first increment of new staff (4 FTEs) was provided to just focus on preparation paper work and receiver negotiations. This group is referred to as the Transfer Negotiations Team (TNT) and included the following areas of expertise: security, accountability/measurements, transportation, facility manager. The team is utilized for a period of about four to five years depending on the option. The next increment of staff (9 FTEs) provided additional crew for only those preparation tasks inside CPP-651 that were significant in duration (e.g., denitrator product). These personnel would be completely dedicated to accelerating tasks inside CPP-651 and are referred to as new dedicated crew (DC). The DC is utilized for a period of about two to four years. The DC included five operators, one foreman, a radiological technician, one materials accountability person and a security guard. The impact of the additional crew equated to increasing from two to four days of conditioning or packaging activities per week. The option of eliminating all material conditioning will obviously reduce the schedule and cost. However, it also presents the highest risk for never removing the material from CPP-651, i.e., the material would have been transferred by now if a receiver would have taken it.

The impacts of implementing the previously discussed ideas for reducing the schedule, such as (a) increase staff and (b) ship-as-is were evaluated by developing the following options and comparing them to the base case:

- Base Case: Existing crew and dry blending

The denitrator product is milled and dry blended with DU to produce LEU and thereby assure its removal from CPP-651. No new staff is required. The 10-year schedule is shortened by a few months 
- Option A-Base case plus transfer negotiation team (TNT)

A dedicated team of about four experienced personnel are formed to resolve shipper/receiver issues and assist with related preparation paperwork for all inventory items. The schedule is shortened; cost is increased; and shipper/receiver issues are improved (this assumes that the receiver sites retain staffing levels to make these negotiations productive).

- Option B-Ship as-is plus TNT

None of the SNM is processed or conditioned at ICPP. The schedule is shortened; overall cost is reduced; but uncertainty of shipment is very high for material that requires offsite processing such as the denitrator product (off-spec HEU).

- Option C-Base case plus TNT and a dedicated crew

Nine ICPP personnel (operators, foreman, radiological technician, and security) are added to the CPP-651 operations to produce the equivalent of four days of packaging operations per week. The critical path issues inside CPP-65l are shortened; cost is increased; and shipper/receiver issues are improved.

- Option D-Ship as-is plus TNT and a dedicated crew

Nine ICPP personnel are added to the CPP-651 operations to produce the equivalent of four days of packaging operations per week. The schedule is shortened to primarily CPP-651 repackaging operations because no conditioning is proposed. The direct transfer cost is greater than Option B because of the extra personnel, but it is less than Option $\mathrm{C}$ because there is no cost for milling and dry blending. However, like Case B, the shipper/receiver issues are high enough that the inventory may never be removed in the allotted 10 -year period.

Figure 4.0-1 presents a summary overview of the system engineering approach used in developing and analyzing the above options. The various measures of effectiveness for each option are discussed in the following subsections.

\subsection{Schedule Analysis}

An important schedule consideration is whether operations at ICPP can support any of the proposed accelerated schedules. Discussions with operations management at ICPP indicate that the level of effort is well within current capacity. For example, current capacity for repackaging drums at CPP-651 is about four packages per day or the equivalent of approximately 400 drums per year. The total number of packages (drums and boxes), excluding the large volume of denitrator product, is a combination of 111 drums and 56 boxes. Level-loaded over a three to five year period, this is well within current capacity. The denitrator product could be processed in a three to four month campaign using trained operators coming off the Rover project. Figure 4.1-1 summarizes the schedule impacts for each of the above options and the base case. More detailed summary level schedules for each option are shown in 


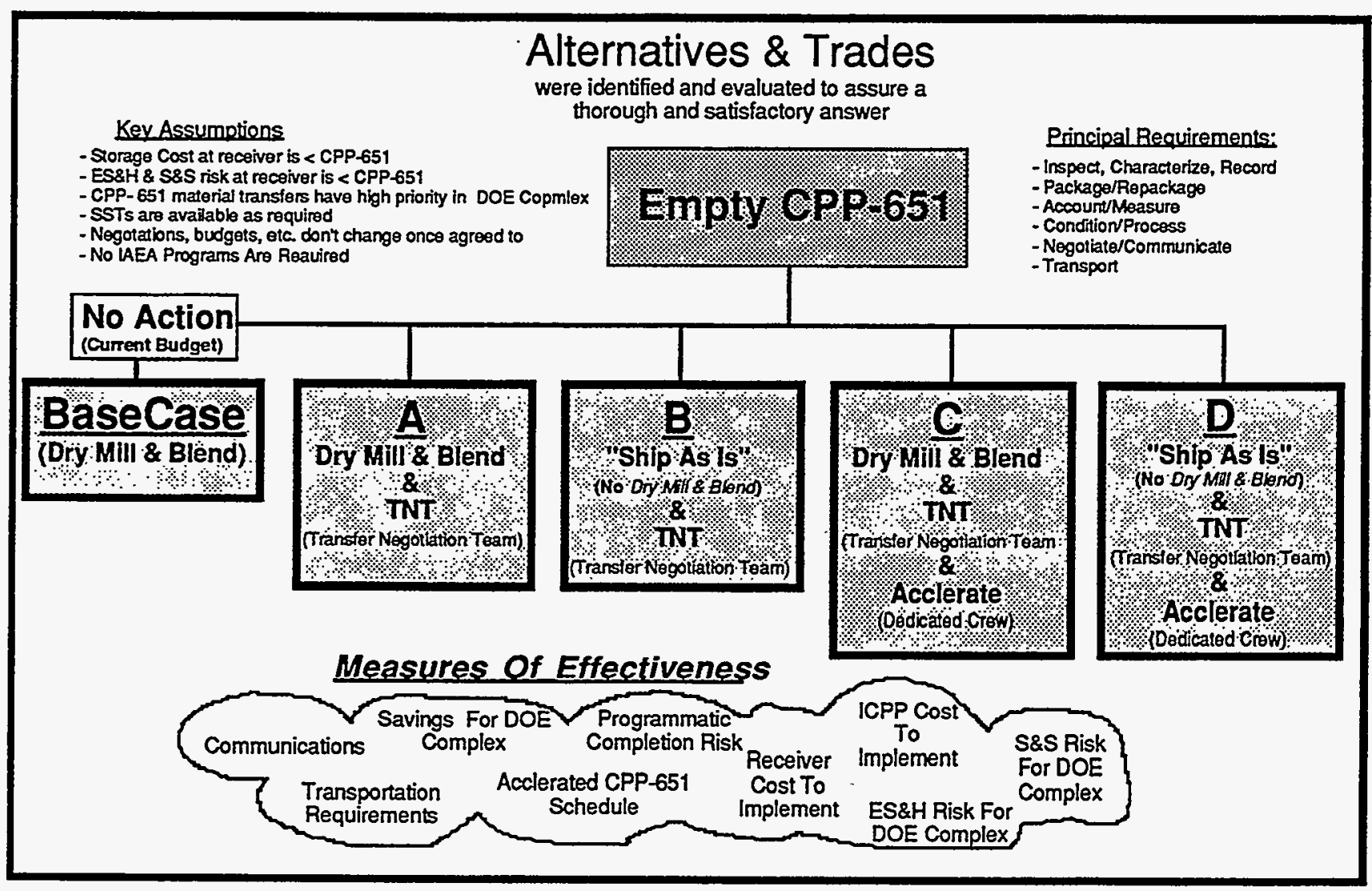

Figure 4.0-1. Measures of effectiveness of the options to remove HEU from CPP-651 early.

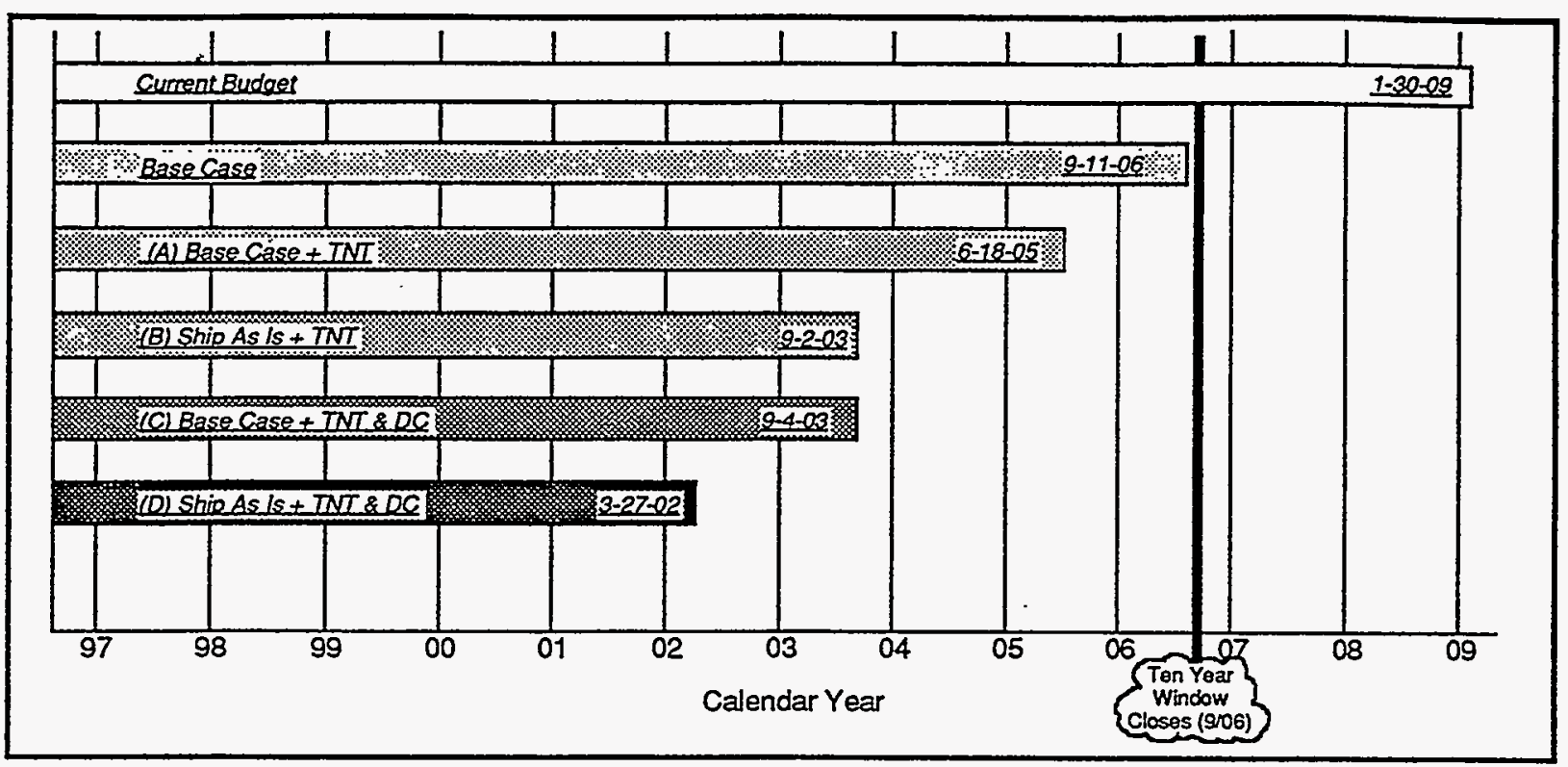

Figure 4.1-1. Schedule comparisons. 
Tables 4.1-1 through 4.1-5 (additional detail can be found in Appendix C). As expected option D reduces the schedule the most because it retains the benefits of less work scope and the positive impact of additional staff. However, it also assumes that an offsite HEU dilution site can begin to receive the HEU as early as June 2001. If SRS is the selected site, this shipment date could slip to October 2001 which would add three to four months to this schedule. The maximum schedule impact of adding staff to the base case is a reduction of about 36 months and the maximum impact of reduced conditioning (i.e., ship-as-is) is about 21 months. Since the base case intends to ship HEU as soon as a receiver can be identified, the 21 month savings represents a maximum value because HEU that is shipped without milling and dry blending will reduce this projected savings.

\subsection{Cost Analysis}

Cost analysis requires the following assumptions: (1) each material will be moved within 10 years, (2) the cost to move material sooner is only marginally higher than waiting to move later, (3) the total (direct and indirect) estimated cost of maintaining CPP-651 is $\$ 2.4 \mathrm{M}$ per year. In simple terms, at an estimated savings of $\$ 2.4$ million per year, a plan that moves material out of CPP-651 sooner would generate \$2.4 million in savings for every year reduced from the schedule. Table 4.2-1 summarizes the total cost for each of the options, the base case, and the current budget. Since the life cycle cost of the current budget is $\$ 19 \mathrm{M}$ more than the base case and does not empty CPP-651 until January 30, 2009, all of the options were compared to the base case cost and schedule. Tables 4.2-2 through 4.2-6 (additional detail can be found in Appendix D) provide the annual cost profiles for only those costs related to the transfer operations (fourth column of Table 4.2-1). The savings realized by each option result from reduced time to complete the work and reduced scope of work. Shorter completion times save an estimated $\$ 2.4 \mathrm{M}$ per year for each year the facility is emptied ahead of the 10-year schedule (9-06). The savings realized by reducing the scope of work (ship-as-is) is revealed by comparing the transfer cost values in Table 4.2-1 for those options that include dry blending and those that don't, i.e., A with B (\$2.4 M) and C with $\mathrm{D}(\$ 3.0 \mathrm{M})$. The difference in total program savings increase to $\$ 7.7 \mathrm{M}$ between Options $\mathrm{A}$ and $\mathrm{B}$ and $\$ 7.2 \mathrm{M}$ between Options $\mathrm{C}$ and $\mathrm{D}$.

The cost of adding the TNT to the base case (option A) is about $\$ 2.0 \mathrm{M}$. These additional personnel will reduce the base case by 15 months, which pays for their cost and produces an estimated savings of $\$ 1.7 \mathrm{M}$. The cost of adding the $\mathrm{DC}$ to Option $\mathrm{A}$ is $3.8 \mathrm{M}$ ( $\$ 850,000$ per year plus $\$ 300,000$ for the initial training and worker qualifications). This reduces the base case schedule by another 22 months which pays for the $\mathrm{DC}$ and produces an additional savings of about $\$ 3.6 \mathrm{M}$. Thus, the cost of increased staff is recovered in all of the options.

No attempts have been made to level the cost profiles because the main interest was to identify the fastest possible schedule. The level funding profile is more of an issue for the options that include milling and dry blending because of the procurement and installation of equipment needed to support these operations in CPP-651. While the funding isn't very level, it should be noted that the total cost is not a very significant part of the total ICPP budget and therefore should not present any real funding issue. Furthermore, the capital expenditures for milling and dry blending are accomplished via GPP tasks and do not require line item funding.

\subsection{Shipment Risk Analysis}

There is a risk of not being able to complete the transfers associated with each of the proposed options. Since most of the related issues that determine this risk are directly associated with post cold war 


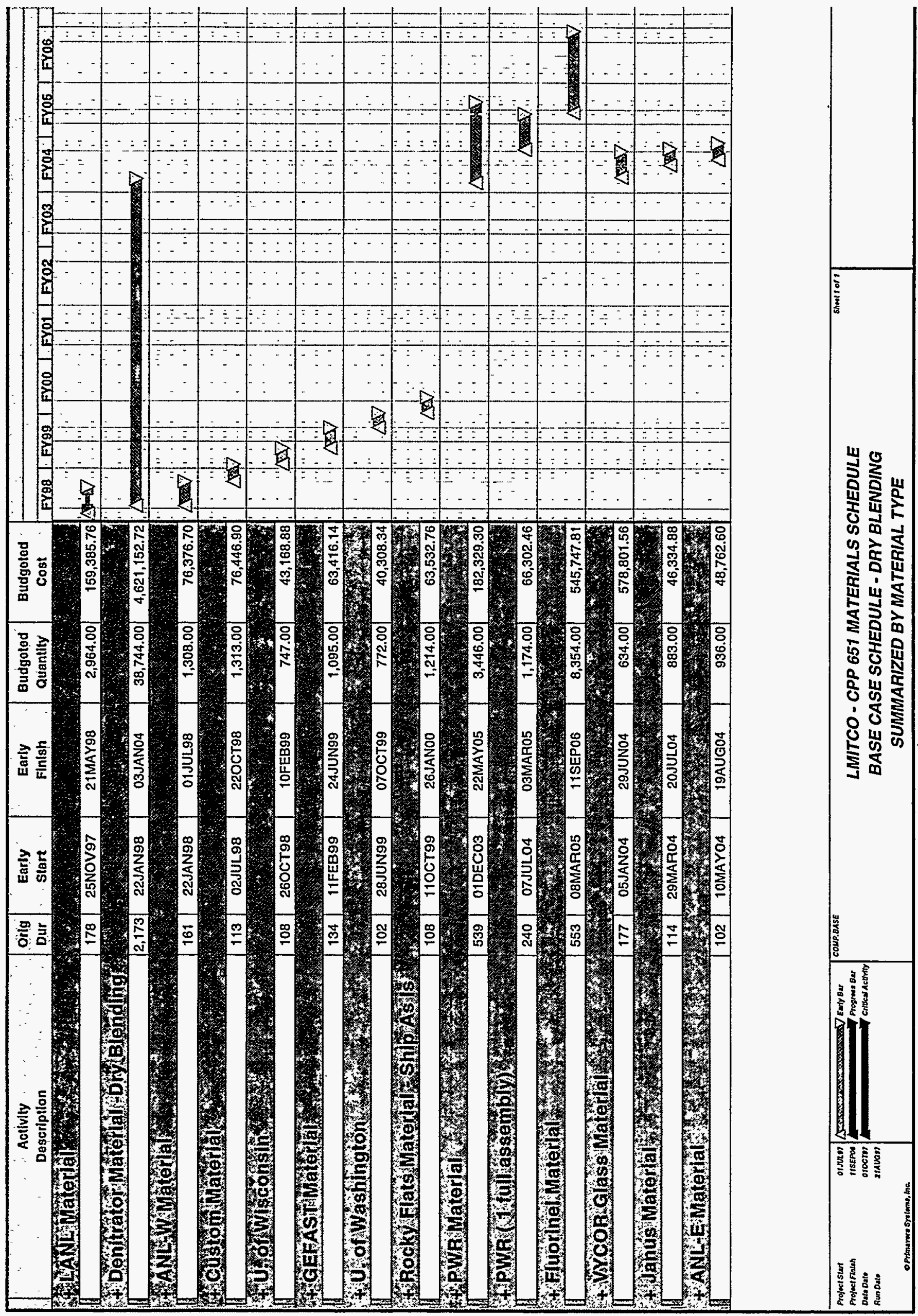


Table 4.1-2. Option A schedule.

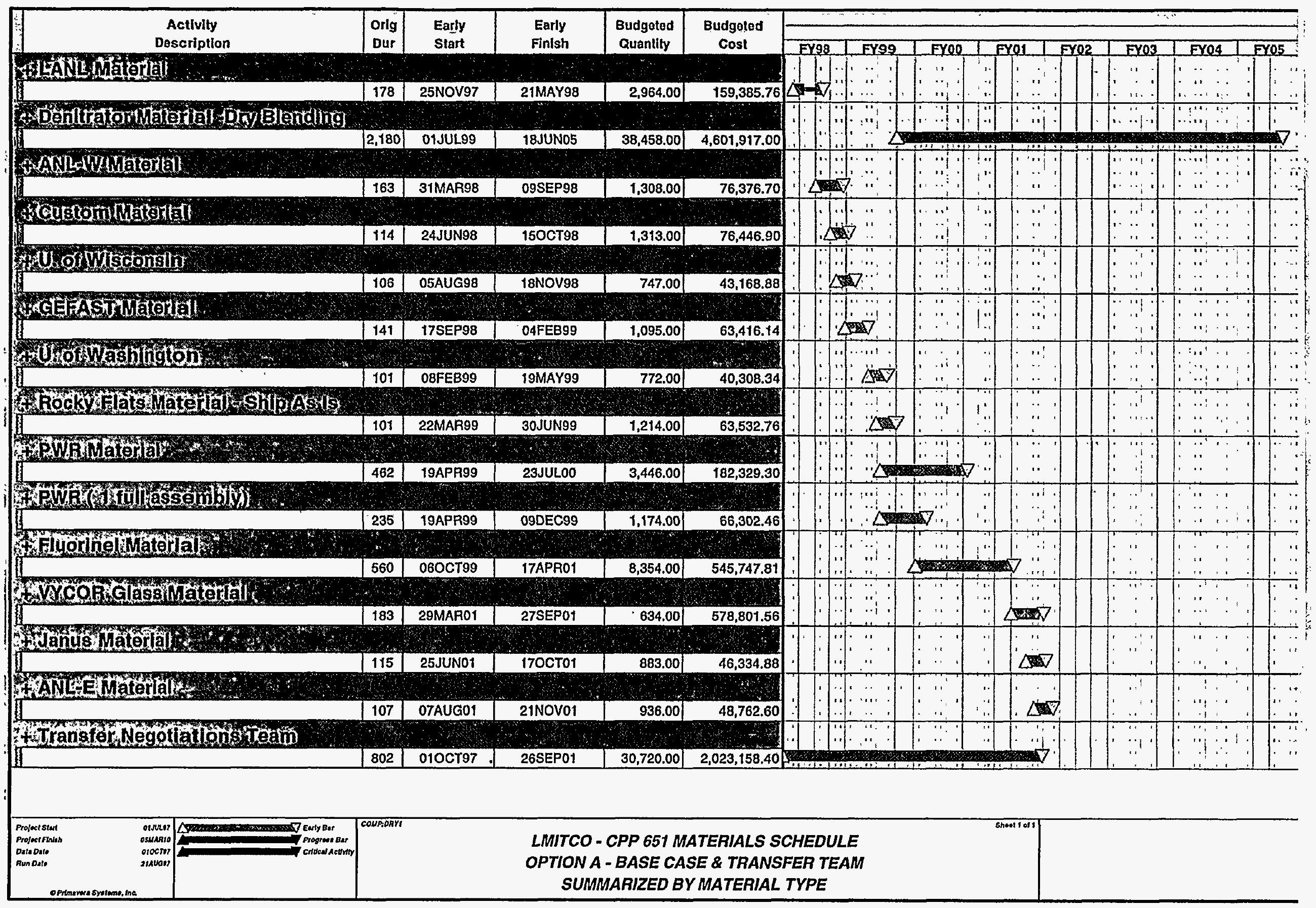


Table 4.1-3. Option B schedule.

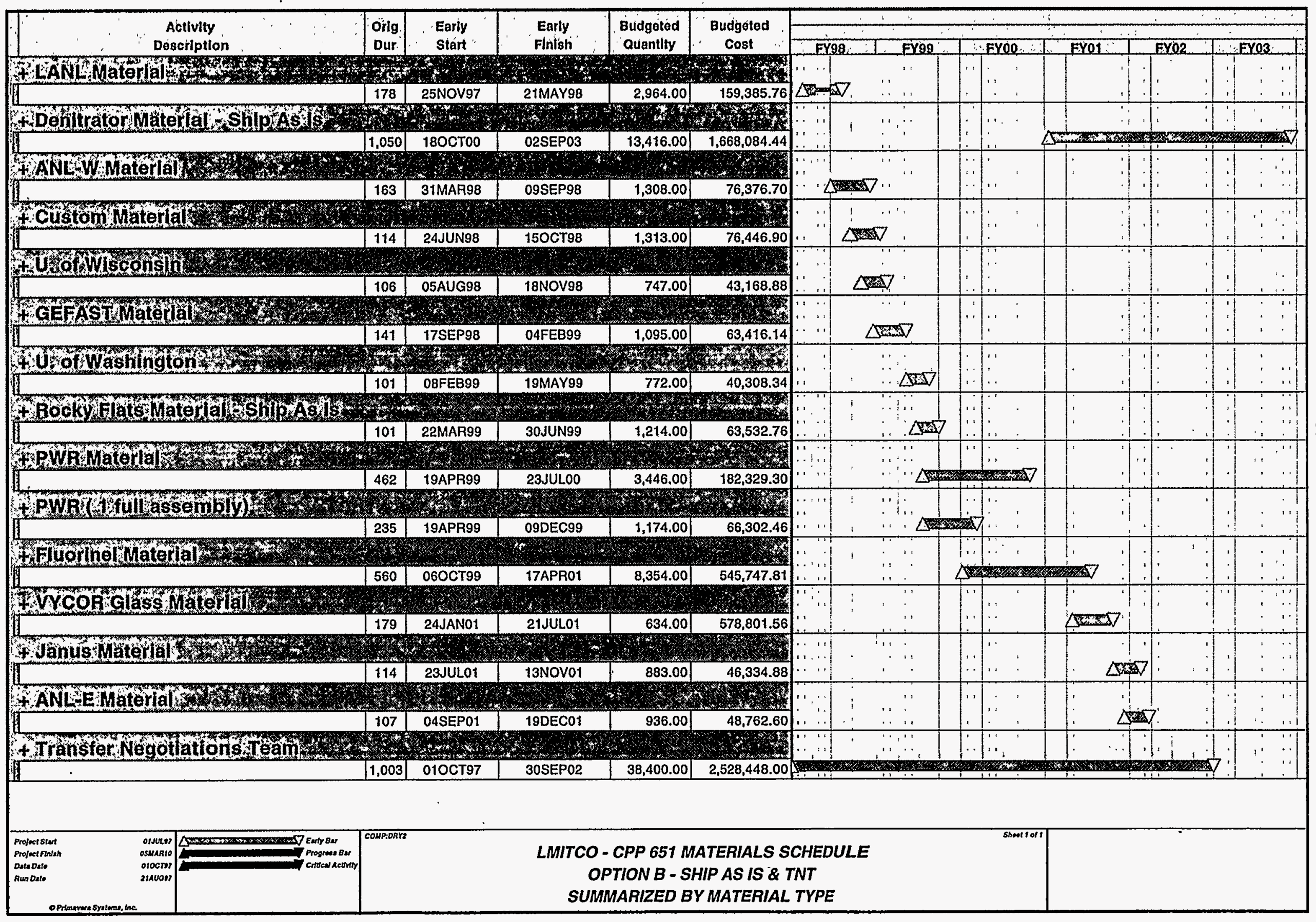


Table 4.1-5. Option D schedule.

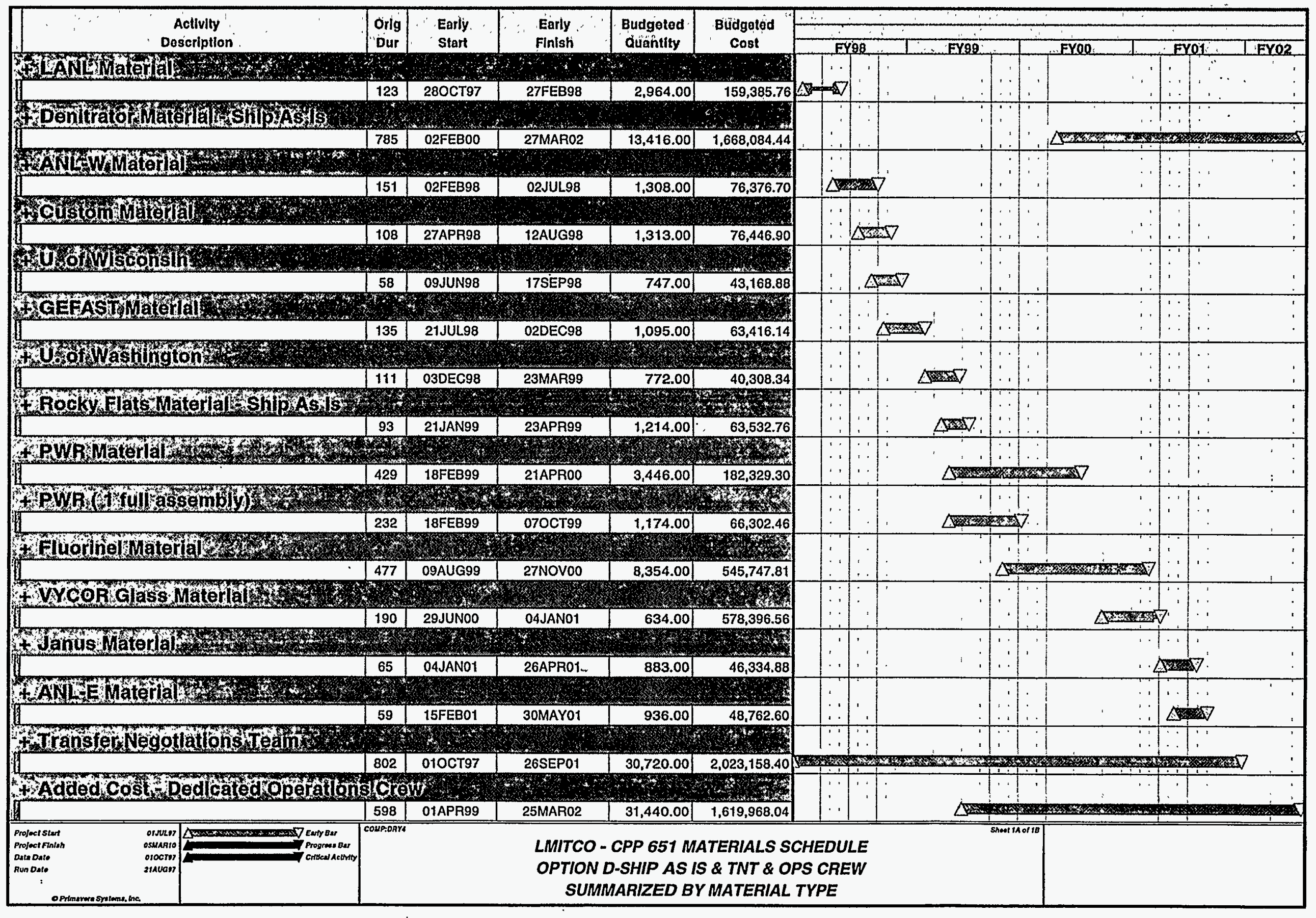




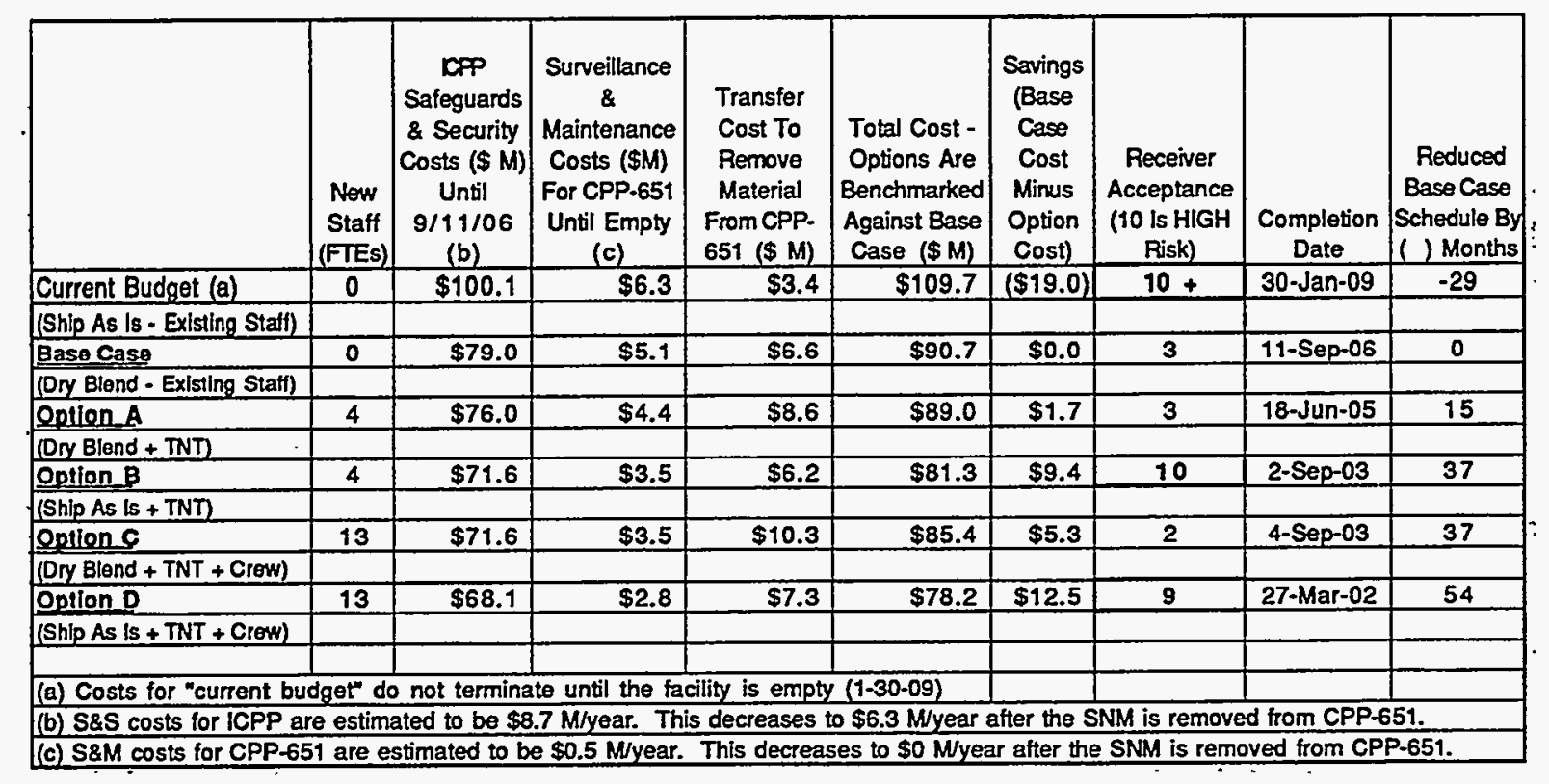

Table 4.2-1. Summary comparison of options. 
Table 4.2-2. Base case schedule.

\begin{tabular}{ccc} 
LMITCO - CPP 651 MATERIAL SCHEDULE & PRIMAVERA PROJECT PLANNER & BASE CASE SCHEDULE - DRY BLENDING \\
$\begin{array}{c}\text { REPORT DATE 05AUG97 RUN NO. } 482 \\
13: 01\end{array}$ & COST LOADING REPORT & START DATE 01JUL97 \\
FIN DATE 11SEP06 \\
Cosi Loading - Summary by Cost Account & TOTAL USAGE FOR YEAR & DATA DATE 01OCT97 PAGE NO. 1 \\
\hline
\end{tabular}

\begin{tabular}{|c|c|c|c|c|c|c|c|c|c|c|c|}
\hline ACCOUNT & ACCOUNT. TITLE & $\begin{array}{r}F Y \\
1998 \\
\end{array}$ & $\begin{array}{r}F Y \\
1999 \\
\end{array}$ & $\begin{array}{r}F Y \\
2000 \\
\end{array}$ & $\begin{array}{r}F Y \\
2001 \\
\end{array}$ & $\begin{array}{r}F Y \\
2002 \\
\end{array}$ & $\begin{array}{r}F Y \\
2003 \\
\end{array}$ & $\begin{array}{r}F Y \\
2004 \\
\end{array}$ & $\begin{array}{r}F Y \\
2005 \\
\end{array}$ & $\begin{array}{r}F Y \\
2006 \\
\end{array}$ & TOTAL \\
\hline 12100 & LANL Material & 159386 & & & & & & & & & 159386 \\
\hline 12101 & Fluorinel Material & & & & & & & & 62088 & 483660 & 545748 \\
\hline 121010 & VYCOR Glass Material & & & & & & & 578802 & & & 578802 \\
\hline 121011 & ANL-W Material & 76377 & & & & & & & & & 76377 \\
\hline 121012 & ANL-E Material & & & & & & & 48763 & & & 48763 \\
\hline 121013 & Rocky Flats Option 1 (As Is) & & & 63533 & & & & & & & 63533 \\
\hline 121018 & Denitrator Option 2 (Dry Blend) & 320259 & 1182927 & 1345679 & 600851 & 532630 & 544723 & 94084 & & & 4621153 \\
\hline 12103 & PWR (6 SPERT Boxes) & & & & & & & 41717 & 140612 & & 182329 \\
\hline 12104 & PWR (1 full assembly) & & & & & & & 20113 & 46189 & & 66302 \\
\hline 12105 & $U$ of Washington & & 24859 & 15449 & & & & & & & 40308 \\
\hline 12106 & $U$ of Wisconsin & & 43169 & & & & & & & & 43169 \\
\hline 12107 & Custom Product Material & 34830 & 41616 & & & & & & & & 76447 \\
\hline 12108 & GFAST - AWF-1 & & 63416 & & & & & & & & 63416 \\
\hline 12109 & JANUS Material & & & & & & & 46335 & & & 46335 \\
\hline & REPORT TOTAL & 590852 & 1355988 & 1424661 & 600851 & 532630 & 544723 & 829813 & 248890 & 483660 & 6612067 \\
\hline
\end{tabular}


Table 4.2-3. Option A schedule.

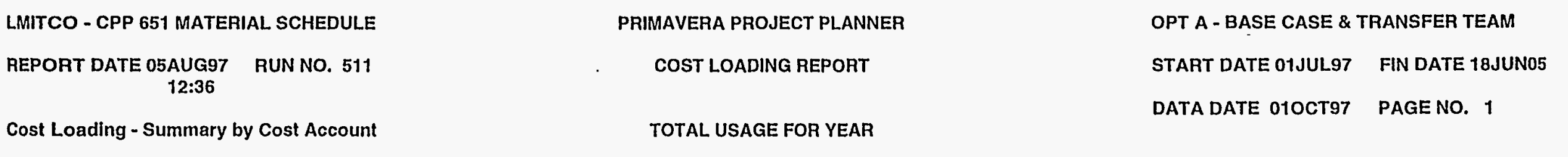

\begin{tabular}{|c|c|c|c|c|c|c|c|c|c|c|}
\hline ACCOUNT & ACCOUNT TITLE & $\begin{array}{r}F Y \\
1998 \\
\end{array}$ & $\begin{array}{r}F Y \\
1999\end{array}$ & $\begin{array}{r}F Y \\
2000 \\
\end{array}$ & $\begin{array}{r}F Y \\
2001 \\
\end{array}$ & $\begin{array}{r}F Y \\
2002 \\
\end{array}$ & $\begin{array}{r}F Y \\
2003 \\
\end{array}$ & $\begin{array}{r}F Y \\
2004\end{array}$ & $\begin{array}{r}F Y \\
2005\end{array}$ & TOTAL \\
\hline $\begin{array}{l}12100 \\
12101 \\
121010 \\
121011 \\
121012 \\
121013 \\
121018 \\
12103 \\
12104 \\
12105 \\
12106 \\
12107 \\
12108 \\
12109 \\
12110\end{array}$ & $\begin{array}{l}\text { LANL Material } \\
\text { Fluorinel Material } \\
\text { VYCOR Glass Material } \\
\text { ANL-W Material } \\
\text { ANL-E Material } \\
\text { Rocky Flats Option } 1 \text { (As Is) } \\
\text { Denitrator Option } 2 \text { (Dry Blend) } \\
\text { PWR (6 SPERT Boxes) } \\
\text { PWR (1 full assembly) } \\
\text { U of Washington } \\
\text { U of Wisconsin } \\
\text { Custom Product Material } \\
\text { GFAST - AWF-1 } \\
\text { JANUS Material } \\
\text { Transfer Negotiations Team }\end{array}$ & $\begin{array}{r}10388 \\
36341 \\
1199 \\
507051\end{array}$ & $\begin{array}{r}63533 \\
111527 \\
12317 \\
34395 \\
40308 \\
32781 \\
40106 \\
62218 \\
509574\end{array}$ & $\begin{array}{r}415967 \\
170013 \\
31907\end{array}$ & $\begin{array}{r}310527 \\
578802 \\
10233 \\
1987991\end{array}$ & $\begin{array}{r}38530 \\
668520 \\
16532\end{array}$ & 546878 & 540551 & 330483 & $\begin{array}{r}159386 \\
545748 \\
578802 \\
76377 \\
48763 \\
63533 \\
4601917 \\
182329 \\
66302 \\
40308 \\
43169 \\
76447 \\
63416 \\
46335 \\
2023158\end{array}$ \\
\hline & REPORT TOTAL & 790740 & 906759 & 1357635 & 3419361 & 723582 & 546878 & 540551 & 330483 & 8615990 \\
\hline
\end{tabular}


Table 4.2-4. Option B schedule.

\begin{tabular}{ccc} 
LMITCO - CPP 651 MATERIAL SCHEDULE & PRIMAVERA PROJECT PLANNER & OPT B - SHIP AS IS \& TRANSFER TEAM \\
$\begin{array}{c}\text { REPORT DATE 05AUG97 } \\
-12: 30\end{array}$ & RUN NO. 462 & COST LOADING REPORT \\
Cost Loading - Summary by Cost Account & TOTAL USAGE FOR YEAR & DATA DATE 01OCT97 PAGE NO. 1 \\
\hline
\end{tabular}

\begin{tabular}{|c|c|c|c|c|c|c|c|c|}
\hline ACCOUNT & ACCOUNT TITLE & $\begin{array}{r}F Y \\
1998 \\
\end{array}$ & $\begin{array}{r}F Y \\
1999 \\
\end{array}$ & $\begin{array}{r}F Y \\
2000 \\
\end{array}$ & $\begin{array}{r}F Y \\
2001 \\
\end{array}$ & $\begin{array}{r}F Y \\
2002 \\
\end{array}$ & $\begin{array}{r}F Y \\
2003 \\
\end{array}$ & TOTAL \\
\hline 12100 & LANL Material & 159386 & & & & & & 159386 \\
\hline 12101 & Fluorinel Material & & & 235221 & 310527 & & & 545748 \\
\hline 121010 & VYCOR Glass Material & & & & 578802 & & & 578802 \\
\hline 121011 & ANL-W Material & 76377 & & & & & & 76377 \\
\hline 121012 & ANL-E Material & & & & 2712 & 46051 & & 48763 \\
\hline 121013 & Rocky Flats Option 1 (As is) & & 63533 & & & & & 63533 \\
\hline 121017 & Denitrator Option 1 (As Is) & & & & 692190 & 625066 & 350828 & 1668084 \\
\hline 12103 & PWA (6 SPERT Boxes) & & 12317 & 170013 & & & & 182329 \\
\hline 12104 & PWR (1 full assembly) & & 34395 & 31907 & & & & 66302 \\
\hline 12105 & $\mathrm{U}$ of Washington & & 40308 & & & & & 40308 \\
\hline 12106 & $\mathrm{U}$ of Wisconsin & 10388 & 32781 & & & & & 43169 \\
\hline 12107 & Custom Product Material & 36341 & 40106 & & & & & 76447 \\
\hline 12108 & GFAST - AWF-1 & 1199 & 62218 & & & & & 63416 \\
\hline 12109 & JANUS Material & & & & 19402 & 26933 & & 46335 \\
\hline \multirow[t]{2}{*}{12110} & Transfer Negotiations Team & 506698 & 509219 & 504177 & 504177 & 504177 & & 2528448 \\
\hline & REPORT TOTAL & 790388 & 794877 & 941317 & 2107810 & 1202227 & 350828 & 6187446 \\
\hline
\end{tabular}


Table 4.2-5. Option C schedule.

LMITCO - CPP 651 MATERIAL SCHEDULE

REPORT DATE 05AUG97 RUN NO. 505

$$
\text { 13:11 }
$$

Cost Loading - Summary by Cost Account
PRIMAVERA PROJECT PLANNER

COST LOADING REPORT

TOTAL USAGE FOR YEAR
OPT C - BASE CASE \& TNT \& DED. CREW

START DATE 01JUL97

FIN DATE 04SEP03

DATA DATE $010 \mathrm{CT} 97$ PAGE NO. 1

\begin{tabular}{|c|c|c|c|c|c|c|c|c|}
\hline ACCOUNT & ACCOUNT TITLE & $\begin{array}{r}F Y \\
1998 \\
\end{array}$ & $\begin{array}{r}F Y \\
1999 \\
\end{array}$ & $\begin{array}{r}F Y \\
2000 \\
\end{array}$ & $\begin{array}{r}F Y \\
2001 \\
\end{array}$ & $\begin{array}{r}F Y \\
2002 \\
\end{array}$ & $\begin{array}{r}F Y \\
2003 \\
\end{array}$ & TOTAL \\
\hline 12100 & LANL Material & 159386 & & & & & & 159386 \\
\hline 12101 & Fluorinel Material & & 4386 & 361659 & 179703 & & & 545748 \\
\hline 121010 & VYCOR Glass Material & & & & 578802 & & & 578802 \\
\hline 121011 & ANL-W Material & 76377 & & & & & & 76377 \\
\hline 121012 & ANL-E Material & & & & 48763 & & & 48763 \\
\hline 121013 & Rocky Flats Option 1 (As Is) & & 63533 & & & & & 63533 \\
\hline 121018 & Denitrator Option 2 (Dry Blend) & & 321522 & 1171058 & 1350829 & 858160 & 900348 & 4601917 \\
\hline 12103 & PWR (6 SPERT Boxes) & & 21007 & 161323 & & & & 182329 \\
\hline 12104 & PWR (1 full assembly) & & 46462 & 19841 & & & & 66302 \\
\hline 12105 & U of Washington & & 40308 & & & & & 40308 \\
\hline 12106 & U of Wisconsin & 43169 & & & & & & 43169 \\
\hline 12107 & Custom Product Material & 76447 & & & & & & 76447 \\
\hline 12108 & GFAST - AWF-1 & 12248 & 51168 & & & & & 63416 \\
\hline 12109 & JANUS Material & & & & 46335 & & & 46335 \\
\hline \multirow{3}{*}{$\begin{array}{l}12110 \\
12111\end{array}$} & Transfer Negoliations Team & 507051 & 629105 & 683826 & 502006 & & & 2321987 \\
\hline & Dedicated Operations Crew & & & 467303 & 508386 & 280405 & 79373 & 1335468 \\
\hline & REPORT TOTAL & 874678 & 1177490 & 2865010 & 3214823 & 1138565 & 979721 & 10250286 \\
\hline
\end{tabular}


Table 4.2-6. Option D schedule.

LMITCO - CPP 651 MATERIAL SCHEDULE

REPORT DATE $05 A U G 97$ RUN NO. 465

$13: 15$

Cost Loading - Summary by Cost Account
PRIMAVERA PROJECT PLANNER

COST LOADING REPORT

TOTAL USAGE FOR YEAR
OPT D - SHIP AS IS \& TNT \& DED. CAEW

START DATE 01JUL97 FIN DATE 27MAR02

DATA DATE $010 \mathrm{CT} 97$ PAGE NO. 1

\begin{tabular}{|c|c|c|c|c|c|c|c|}
\hline ACCOUNT & ACCOUNT TITLE & $\begin{array}{r}F Y \\
1998 \\
\end{array}$ & $\begin{array}{r}F Y \\
1999 \\
\end{array}$ & $\begin{array}{r}F Y \\
2000 \\
\end{array}$ & $\begin{array}{r}F Y \\
2001 \\
\end{array}$ & $\begin{array}{r}F Y \\
2002 \\
\end{array}$ & TOTAL \\
\hline & ' & & & & & & \\
\hline 12100 & LANL Material & 159386 & & & & & 159386 \\
\hline 12101 & Fluorinel Material & & 4386 & 361659 & 179703 & & 545748 \\
\hline 121010 & VYCOA Glass Material & & & 7457 & 570940 & & 578397 \\
\hline 121011 & ANL-W Material & 76377 & & & & & 76377 \\
\hline 121012 & ANL-E Material & & & & 48763 & & 48763 \\
\hline 121013 & Rocky Flats Option 1 (As Is) & & 63533 & & & & 63533 \\
\hline 121017 & Denitrator Option 1 (As Is) & & & 440019 & 897354 & 330711 & 1668084 \\
\hline 12103 & PWR (6 SPERT Boxes) & & 21007 & 161323 & & & 182329 \\
\hline 12104 & PWR (1 full assembly) & & 46462 & 19841 & & & 66302 \\
\hline 12105 & $\mathrm{U}$ of Washington & & 40308 & & & & 40308 \\
\hline 12106 & $\mathrm{U}$ of Wisconsin & 43169 & & & & & 43169 \\
\hline 12107 & Custom Product Material & 76447 & & & & & 76447 \\
\hline 12108 & GFAST - AWF- 1 & 12248 & 51168 & & & & 63416 \\
\hline 12109 & JANUS Material & & & & 46335 & & 46335 \\
\hline 12110 & Transfer Negotiations Team & 507051 & 808402 & 504528 & 502006 & & 2321987 \\
\hline \multirow[t]{2}{*}{12111} & Dedicated Operations Crew & & 15870 & 452260 & 340538 & 512471 & 1321139 \\
\hline & REPORT TOTAL & 874678 & 1051135 & 1947087 & 2585639 & 843182 & 7301720 \\
\hline
\end{tabular}


transition conditions it is nearly impossible to assess this risk in a totally objective manner. Site-specific budgets, processing capabilities, accountability requirements, characterization requirements, storage capacities, staffing levels, IAEA programs, unfunded mandates and the like continue to change the planning horizon. Nevertheless the task team has made a subjective determination of this risk factor for each option which is based on the collective experience of the team. Several general observations were agreed upon:

- The more user friendly the package the better the chance that it will be shipped

- Changes will continue and are likely to become more restrictive as the DOE complex ages

- Site budgets are not likely to increase in the near term and will probably decrease with time

- Processing capability (personnel, equipment and facilities) are not being maintained per the DNFSB's Recommendation 94-1

- Future EIS RODs and licensing issues for repositories could significantly change SNM management strategies and related facilities/infrastructure.

The strategic planning response to this uncertain future forced the selection of options that (a) retained as much local control as possible, and (b) produced user friendly packaged products. Thus, the collective effect of this general situation lead the team to conclude that the risk of ever shipping material like the denitrator product without conditioning (reduce its radiation level and/or its attractiveness level) was be too great to accept. Accordingly, high risk values were assigned to Options B and D. B is slightly worse than $\mathrm{D}$ because the program runs longer and is therefore subject to more change.

\subsection{Proposed Accelerated Schedule}

Figure 4.4-1 presents a summary overview of the options and a subjective measure of their effectiveness. Per DP's request to provide the schedule ASAP, it is concluded that Option $C$ should be selected because it provides the best balance of accelerated schedule, reduced cost, and probability of success. The strategy developed is designed to expedite (a) removal of material currently in CPP-651, (b) disposition of its excess off-spec HEU, and (c) consolidation of SNM to fewer locations at the INEEL and across the DOE complex. The result is a cost savings to the complex due to lower INEEL security costs. This assumes that the storage cost at the receiver site does not equal or exceed the cost of storage at ICPP. This assumption appears to be true for most inventory items. However, preliminary discussions indicate that there are scenarios for the denitrator product where the storage costs could be as high as $\$ 6.0 \mathrm{M}$ per year if the total cost was allocated to this material. Thus, the cost savings for the DOE complex cannot be validated at this time without additional study. The possibility of even greater savings may be realized by making CPP-651 available for new missions which may avoid or delay capital outlays for upgrading old facilities or constructing new capacity.

The proposed accelerated schedule implements the base case strategy with 13 additional personnel to expedite all phases of operations. The principal tasks include the actions: (1) collect data and resolve transportation packaging issue. These actions are currently underway and should take care of about half of the problem materials; (2) mill and dry blend the denitrator product with LEU to less than $20 \%$ enrichment and ship to an off-spec HEU dilution site such as SRS. Terminate dry milling and blending as soon as any off-spec HEU dilution site has vault storage space to receive HEU shipments. Products that have simple packaging problems (such as custom product and GEFAST) can also take advantage of the glovebox 


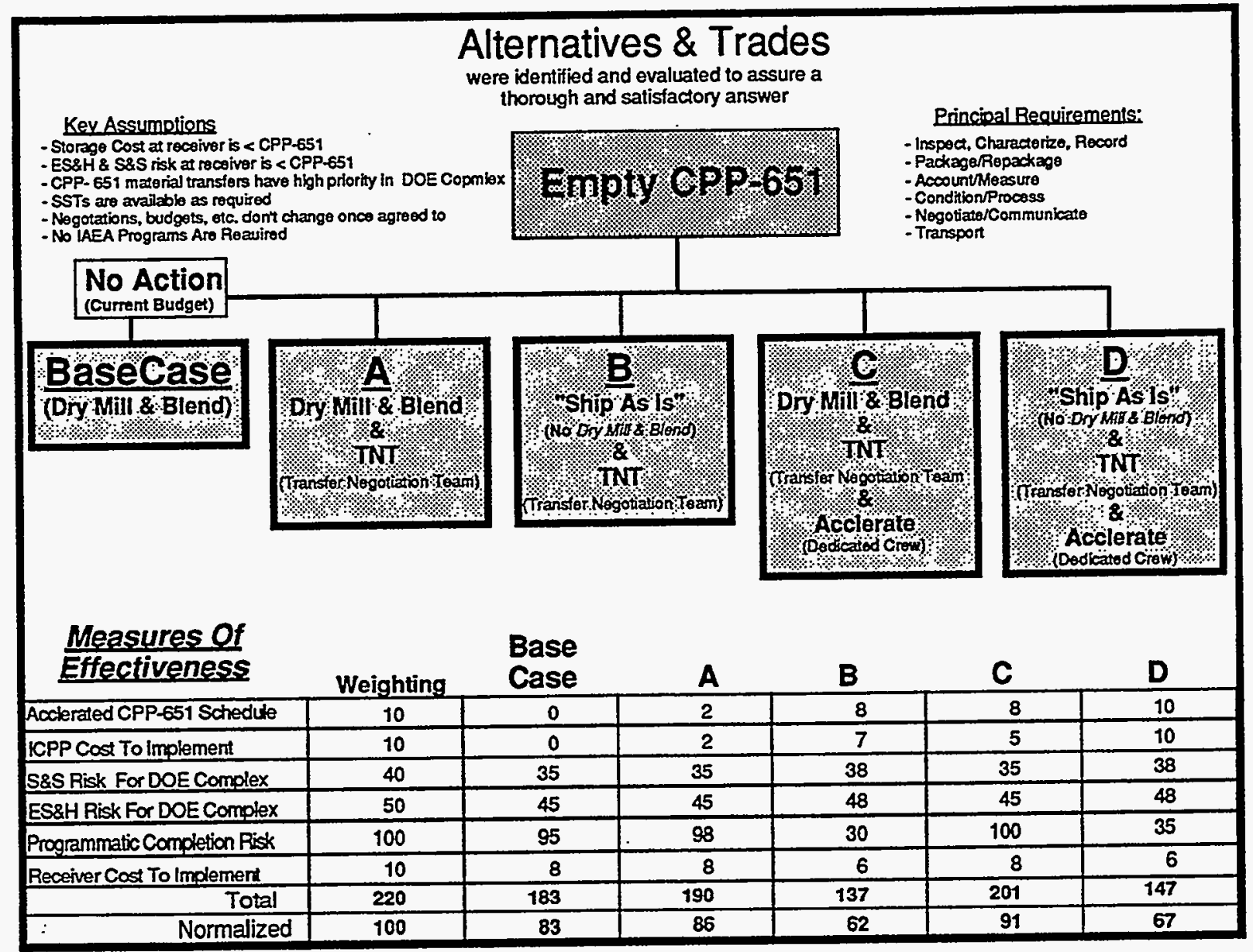

Figure 4.4-1. Overview of options and measure of effectiveness. 
repackaging system; (3) transfer Rocky Flats material to SRS as soon as possible; and (4) utilize ANL-W resources for timely storage and/or dispositioning Vycor glass, ANL-E material, and Janus material.

The key to accelerating the schedule is recognizing that the major volumes of material and the most difficult repackaging issues lie squarely with the denitrator product. Extra personnel can significantly expedite this process and also shorten the PWR and Fluorinel packaging efforts. Because the Rocky Flats inventory is small and requires significantly less storage space, it can be sent to SRS long before the denitrator product. This leaves Vycor glass as the next most troublesome material to deal with. By working with ANL-W, this material can also be moved. At this point subtraction of materials that already are being moved along with those that will likely be resolved by providing data or packaging leaves about six drums (one of University of Washington, two of ANL-E, and three of Janus). ANL-W has already indicated that they would accept a few drums for future processing to allow early completion of material removal from CPP-651.

\subsubsection{Strengths and Weaknesses}

The key elements of success for the proposed strategy are: extra dedicated personnel (13 FTEs, TNT, and DC), centralization of efforts at CPP-651, a mill and dry blending process that is accomplished in a sealed can, and continuous offsite negotiations with all receivers to resolve any issues as soon as they are identified.

Using a new glovebox facility in CPP-651 to repackage, mill, and dry blend the denitrator product into a more user friendly form provides the following advantages:

- Eliminates need to provide additional security.

- The process can be designed to fit easily into the 475 square feet available in the North Vault.

- The process can be designed to operate safely and efficiently within a low cost, temporary, self-contained Perma Con structure with a shielded glovebox and a portable ventilation system.

- Eliminates the need to create a new material balance area (MBA) for staging material and drum.

- The CPP-651 annulus provides shielding for the material until it is removed for blending and milling.

- Eliminates intra-site shipments.

- $\quad$ Makes repackaging of the custom product more viable.

- Makes use of an existing facility with minimal changes to safety analysis documentation, technical standards, and operating procedures.

- Minimizes reliance on offsite resources by allowing material to be stored somewhere besides CPP-651, LEU will not require vault type security. This means that we are not depending entirely on SRS to complete their canyon operations and empty out their HEU vault. 
- Repackaging the milled and blended material provides opportunity to package it in containers that can be put directly into the SRS dissolver (no plastic bags or bottles).

Using ANL-W for storage, processing, and disposition of materials provides the following advantages:

- A capability to remove Vycor glass from CPP-651 as early as the year 2000.

- Allows Vycor glass to be processed with similar material for removal of uranium.

- The glass separation process allows ANL-W to establish a capability that they can use to solve their own Vycor glass problem.

- Use of ANL-W simplifies material transfer issues.

- $\quad$ Reduces need to set up small lab-scale dissolutions at CPP. will:

Option C represents the best overall strategy for quickly removing SNM from CPP-651 because it

- $\quad$ Reduces the 10 -year schedule by 37 months

- Balance reliance of onsite and offsite resources and their transitioning process capabilities and budgets

- Help assure success because the denitrator product is converted to a form that is more user friendly relative to storage and/or site specific processing capabilities

- Eliminate the utilization/restart of ICPP aqueous production purification systems

- Require minimal ICPP conditioning and funding (same as the base case). These expenditures ( $\$ 2.7 \mathrm{M}$ for new construction) are recovered and exceeded by reduced schedule (no operations in the out years saves about $\$ 5 \mathrm{M}$ )

- Produce incremental ES\&H and security risks that do not appear to be significant

- Require minimal new dedicated staffing (13 FTEs) and their cost is recovered and exceeded by the savings that result from the reduced schedule

- Provide a blend of synergistic ICPP operations that utilize a common operational area and concept (dry glovebox operations) rather than different processes for each inventory item.

The main weakness of the proposed strategy is the additional funding (personnel and the dry blending equipment) relative to the current funding level. As noted earlier the procurement and installation of dry blending equipment do increase funding levels above what has been required in the past.

Another weakness of the proposed strategy is uncertainty of utilizing ANL-W and SRS to store, process, and disposition materials. Firm commitments from the DOE field offices for these sites will be 
needed to ensure they can support this strategy. We are unsure if DP will need to fund ANL-W to process and/or store the DP material. ANL-W receives the majority of its funding from NE.

\subsubsection{Contingency Strategies}

The critical path issue for the proposed strategy is the probability/risk of the offsite receivers ever accepting or having room in their vaults to accept any of these materials, e.g., SRS needs room for the denitrator product and Rocky Flats HEU. This issue is resolved for the denitrator product by blending this material to less than $20 \%$ enrichment. This allows material to be accepted at another HEU dilution site as soon as the LEU is ready to ship and allows it to be stored in a warehouse rather than a SNM vault if the offsite receiver has no HEU storage space. In general if the proposed offsite receiver cannot receive the material this will require ICPP to condition that inventory via some lab scale process (see backup options identified in Table 2.4-1). This will be more time consuming and costly.

\subsubsection{Future SNM Management Issues}

Removal of SNM from CPP-651 will reduce the number of SNM vaults at the INEEL and reduce related costs. However, this does not necessarily imply that CPP-651 does not have a continued costeffective role to play in the DOE complex. An overall complex-wide SNM storage strategy needs to be developed to assess the best use of post cold war SNM storage facilities. This type of study was initiated in The Integrated Facility Plan for the 94-1 Implementation Plan but the results have not yet been utilized to develop complex-wide facility planning strategies. The recent HEU vulnerability assessment has underscored safety-related risks of continuing to operate first generation SNM facilities throughout the complex. If HEU can be diluted fast enough, the need for new storage facilities and some related safety issues will be reduced. Under these circumstances, utilization of CPP-651 as an interim storage facility may help promote retirement of a higher risk facility at another site that may be scheduled for significant upgrade activity and thereby save money. The disposition of excess $\mathrm{Pu}$ and the storage of ${ }^{233} \mathrm{U}$ present other circumstances where CPP-65I may provide a cost-effective role. The 3019 Building at Oak Ridge has been identified in the HEU vulnerability assessment and significant funding is anticipated to correct facility deficiencies. Relocating and storing this material in CPP-651 or any other newer facility in the $\mathrm{DOE}$ complex may prove to be much more cost-effective and would consolidate all ${ }^{233} \mathrm{U}$ for dispositioning and/or medical isotope production. 


\section{OBSERVATIONS AND RECOMMENDATIONS}

\subsection{Proposed Action}

The recommended plan to empty CPP-651 can be divided into three general functions:

- Obtain commitments from receivers

- Process/condition HEU to remove unwanted waste materials, i.e., utilize ANL-W resources for timely storage and/or dispositioning of Vycor glass, ANL-E, and JANUS; SRS for offspec denitrator product, Rock Flats, and University of Washington material

- Repackage and condition off-spec denitrator product to provide a more user friendly condition, i.e., mill and dry blend denitrator (with $\mathrm{UO}_{3}$ ) to less than $20 \%$ enrichment and ship to SRS to serve as feed stock in their off-spec blending program for fabrication of TVA fuel.

These actions represent the best plan for removing SNM from CPP-651 because they will:

- $\quad$ Reduce the 10 -year schedule by 37 months

- Balance reliance of onsite and offsite resources and their transitioning process capabilities and budgets

- Assure shipping dates for dry blended uranium oxide because the product is in a form that is more user friendly relative to storage and/or site-specific processing capabilities

- Not require utilization of ICPP aqueous production purification systems

- Require minimal ICPP conditioning and funding (same as the base case). These expenditures (\$2.7M for new construction) are recovered and exceeded by reduced schedule (no operations in the out years saves about $\$ 5 \mathrm{M}$ )

- Require minimal new dedicated staffing (13 FTEs) and their cost is recovered and exceeded by the savings that result from the reduced schedule

- Produce incremental ES\&H and security risks that do not appear to be significant

- Provide a blend of synergistic ICPP operations that utilize a common operational area and concept (dry glovebox operations) rather than different processes for each inventory item.

\subsection{Critical Path Issues}

Figure 5.2-1 summarizes in a programmatic overview the efforts of this task team and the key conclusions that have been developed. Action is absolutely necessary relative to programmatic direction and funding if the identified benefits and savings are to be realized. The critical path issues for accelerated removal of SNM from CPP-651 include:

- Immediate funding to support the proposed program changes 


\section{Removal of SNM From CPP. 651}

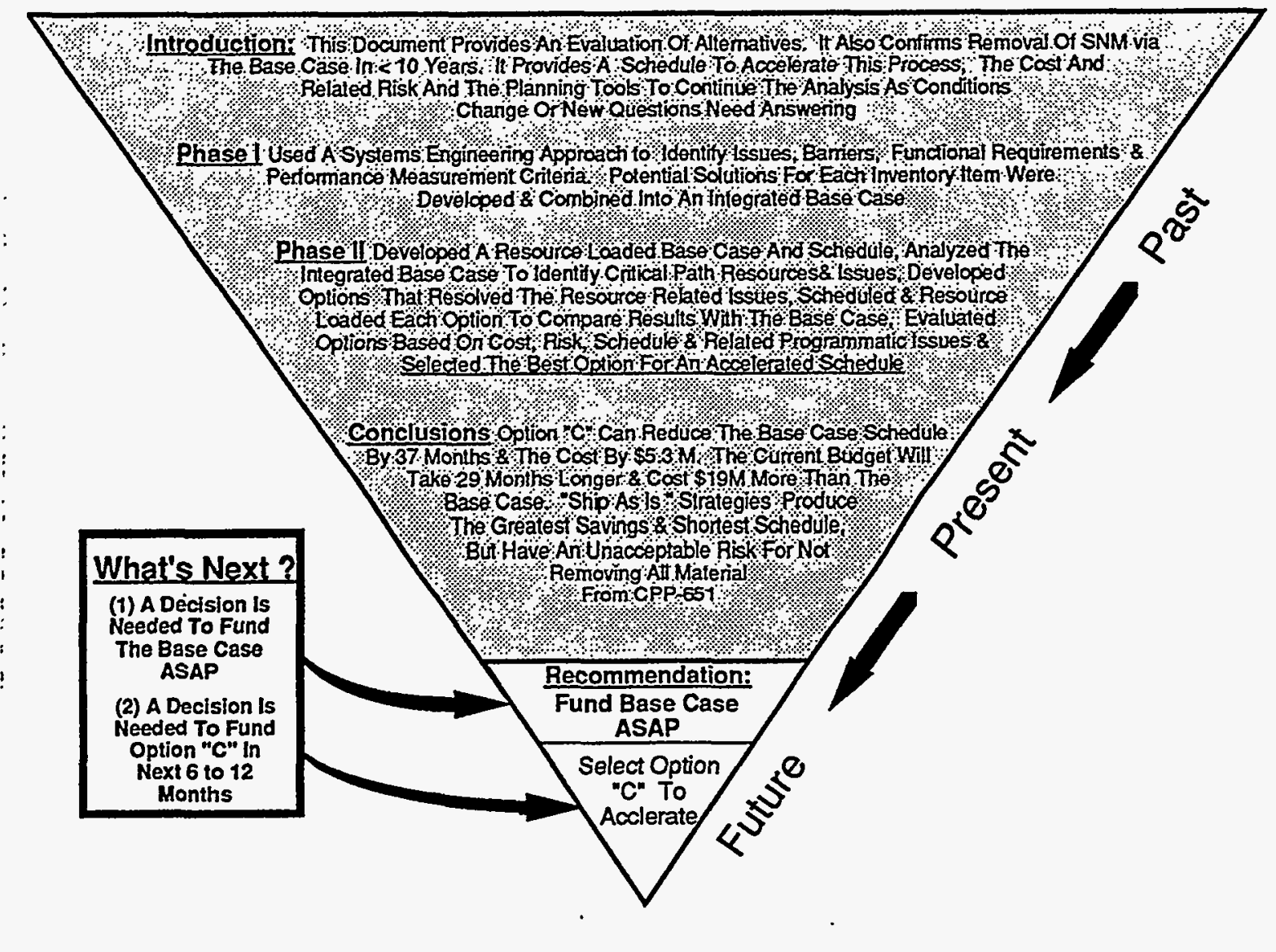

Figure 5.2.1 Programmatic overview of key conclusions. : 
- Continued regular and aggressive communications with offsite receivers

- Implementation of extra staff

- Implementation of the proposed milling and dry blending process.

The largest single inventory item and the most difficult to ship is the denitrator product. If denitrator material does not get into the off-spec dilution program, then the only remaining option in DOE's HEU management strategy is dilution to $0.9 \%$ for disposal. This will require an aqueous blending process that would be expensive and time consuming if initiated at ICPP as a one-time stand-alone program. DOE's current focus is on dispositioning HEU that has a value added capability (sales to LEU fuel fabricators). Thus, dispositioning of denitrator product via dilution to $0.9 \%$ on or before 2006 is unlikely. The proposed plan of dry blending to $<20 \%$ enrichment would provide a fall back position of at least not requiring vault storage for this material, because it would not be classified as SNM. Dry blending to less than $20 \%$ also simplifies receipt issues at SRS or any other site and promotes delivery prior to initiation of the off-spec dilution program. Shipping HEU to SRS in the near term requires vault space that is unavailable until their processing has emptied enough room in the vault (2001 for a two canyon operation and 2005 for a one canyon operation). Storage with unirradiated HWR fuel is under consideration and will continue to be evaluated. This may provide an earlier shipping date that could reduce or eliminate milling and dry blending.

Plutonium in the Rocky Flats material makes it difficult to get it into the HEU dispositioning cycle via $Y-12$. The SRS program will remove the Pu prior to TVA fuel fabrication. If for some reason SRS cannot take the material, we know of no other site at this time willing to receive it. However, dissolution and removal of the Pu via RAL operations would allow material to be removed from CPP-65I and shipped to Oak Ridge, but as previously mentioned this will take longer and cost more than the proposed action.

\subsection{Path Forward}

Publishing this report completes the Phase I and Phase II tasks and deliverables that are shown on the schedule in Figure 5.3-1. A conceptual strategy and contingency options have been developed to resolve local and national issues that are related to HEU management in CPP-651.

Thus, DOE-HQ approval and funding for these Phase II tasks should be initiated as soon as possible to at least implement the base case and if possible the accelerated schedule and its related tasks. This is very important for timely completion of ICPP actions that will integrate with various offsite processing capabilities and schedules. When approved by DOE, these ICPP HEU management plans well become an integrated part of a much larger post cold war transition program to disposition excess (HEU) (proliferation reduction) and promote consolidation of SNM to fewer locations at the INEL and across the DOE complex. The changes that have occurred across the DOE complex since the start of this study are significant and are likely to continue. Thus, the value of having this planning capability (resource data, offsite contacts and the planning software) is strategic to success. Maintaining this capability will require periodic updating and publication of the results. Ownership, funding, and control of this responsibility will be key to the continued planning success. Regular scheduled communications/contacts with the offsite receivers is another important success factor that is built into Option $C$. This information will also improve the remaining decisionmaking prior to finalizing commitments, schedules, and expending funds. 
Successful early removal of SNM from CPP-651 will make this facility available for other support roles (e.g., dispositioning of ${ }^{239} \mathrm{Pu}$ or ${ }^{233} \mathrm{U}$ ) that should be evaluated as part of a national stewardship and materials management planning process. 


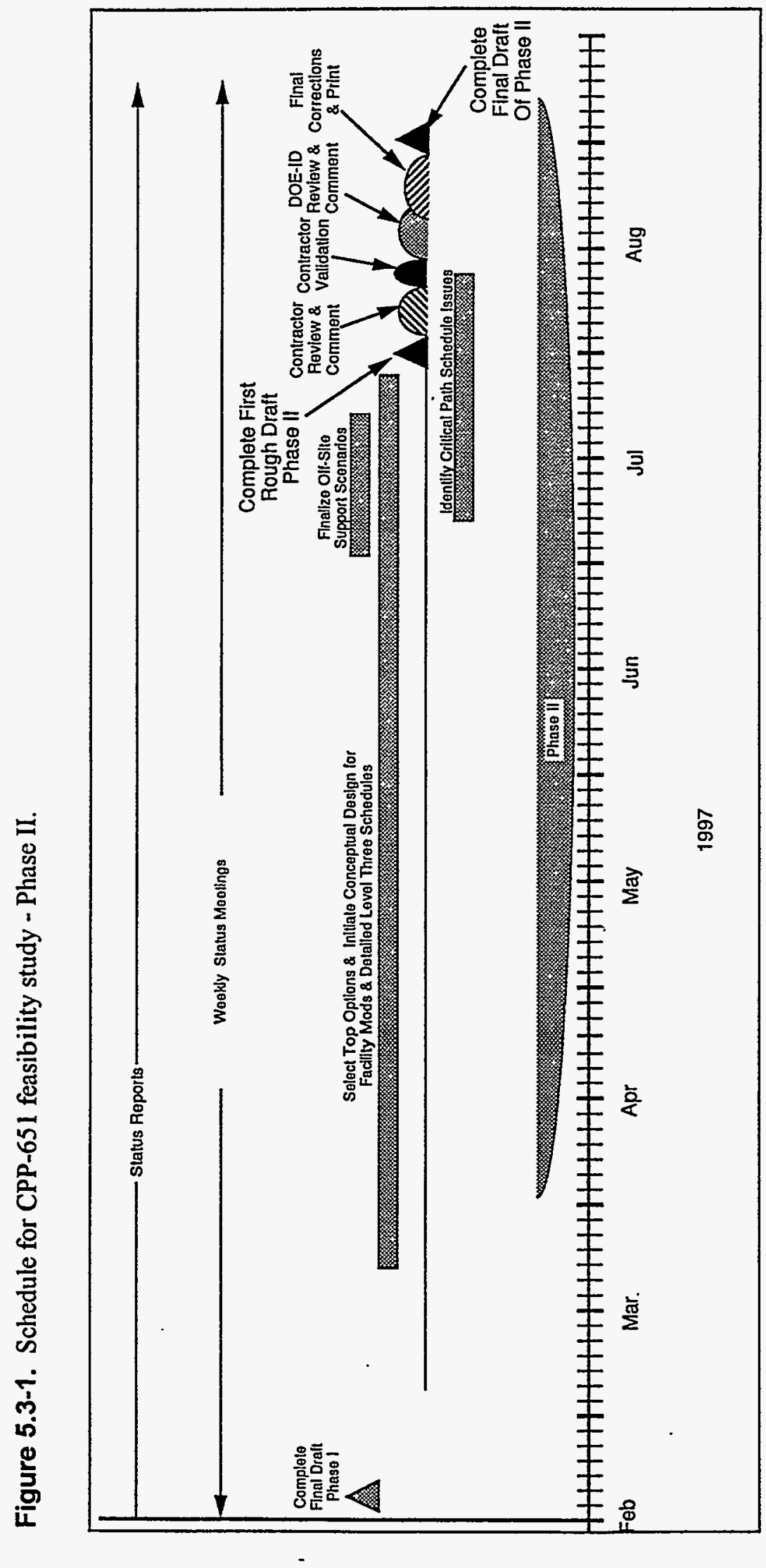




\section{Appendix A}

Cost Estimates, Schedules and Flowsheets

for

CPP-651 Material Conditioning Options 


\section{Attachment A \\ Cost Estimates, Schedules and Flowsheets for CPP-651 Material Conditioning Options}

\section{PWR PLATES}

Option 1 (Order drums, repackage, ship to B\&W/NFS)

Cost

Cost to Procure Drum(s) $=\$ \mathbf{6 , 0 0 0}$

Cost to Design \& fabricate $2 R$ inner containers $=\$ 29,600$

Cost for Planning and preparations $=\$ \mathbf{2 6 , 5 0 0}$

Cost for Procedure Preparation = assume $\mathbf{\$ 1 5 , 5 0 0}$

Cost to Repackage in CPP-651 and Ship

$\$ 34,500+(\$ 1500 /$ drum $\times 47$ drum $)=\$ 104,700$

Total Cost for Option 1 (Base Case) =

$\$ 6,000+\$ 29,600+\$ 26,500+\$ 15,500+104,700=\underline{\$ 182,300}$

Schedule: $\quad 4$ months to procure containers and drums

9 months for planning \& preparations

2 months to develop procedures and QA drums

3 months to repackage and ship

\section{Total Duration for Option 1 (Base Case) $=\underline{\underline{18 \text { months }}}$}

Comments: The Primavera generated Base Case detailed resources, cost data and scheduled activities for this option is shown in Appendix $C$ and $D$ of this report. 


\section{PWR PLATES}

Option 2 (Obtain certification of SPERT boxes, ship, as-is to B\&W/NFS)

Cost

Cost to Certify SPERT boxes:

Assume certification costs $\$ 3000$ per box

$$
\$ 3,000 \times 6=\$ 18,000
$$

Cost for Planning and preparations $=\$ \mathbf{2 3 , 3 0 0}$

Cost for Procedure Preparation = assume \$15,500

Cost to inventory material in CPP-651

$\$ 3500$ per Spert box $\times 6$ boxes $=\$ \mathbf{2 1 , 0 0 0}$

Cost to perform radiation surveys, QA boxes, and remove from CPP-651

Assume $\$ 2000$ per box

$$
\$ 2,000 \times 6 \text { boxes }=\$ 12,000
$$

Total Cost for Option $2=$

$$
\$ 18,000+\$ 23,300+\$ 15,500+\$ 21,000+\$ 12,000=\underline{\mathbf{\$ 8 9 , 8 0 0}}
$$

Schedule: $\quad 6$ months to certify SPERT boxes

9 months for planning \& preparations

$21 / 2$ months to develop procedures and QA drums

2 weeks to inventory and ship

$$
\text { Total Duration for Option } 2=\underline{\underline{18 \text { months }}}
$$

Comments: The Packaging and Transportation team determined that the Spert boxes were not an acceptable shipping package. No detailed cost estimates were performed for this option.

\section{PWR PLATES}

Option 3 (Manage as Spent Fuel) No cost estimate was performed for this option. 


\section{PWR Assembly}

Option 1 (Certify the box the assembly is currently in, ship to B\&W or NFS)

Cost:

Cost to Certify existing box $=\mathbf{\$ 8 , 5 0 0}$

Cost for Planning and preparations $=\$ \mathbf{2 3 , 3 0 0}$

Cost for Procedure Preparation $=\mathbf{\$ 1 5 , 5 0 0}$

Cost to inventory assembly in CPP $-651=\$ \mathbf{1 0 , 1 0 0}$

Cost to perform radiation surveys, $\mathrm{QA}$ box, and ship $=\mathbf{\$ 8 , 9 0 0}$

Total Cost for Option 1 (Base Case) = $\$ 8,500+\$ 23,300+\$ 15,500+\$ 10,100+\$ 8,900=\underline{\$ 66,300}$

Schedule: 5 months to obtain certification

1 month for planning and preparations

2 months to develop procedures and QA drums

1 week to inventory and ship

Total Duration for Option 1 (Base Case) $=\underline{\underline{8 \text { months }}}$

Comments: The Primavera generated Base Case detailed resources, cost data and scheduled activities for this option is shown in Appendix C and D of this report.

PWR Assembly

Option 2 (Obtain certified B\&W box, package into B\&W box, ship to B\&W or NFS)

Cost

* Assume fuel assembly will fit in B\&W box without being cut.

* Assume that the repackaging and shipping of $1 \mathrm{~B} \& \mathrm{~W}$ box is equivalent to the repackaging and shipping of 4 drums.

Cost for Planning and preparations $=\$ \mathbf{2 3 , 3 0 0}$

Cost for Procedure Preparation $=\mathbf{\$ 1 5 , 5 0 0}$

Cost to inventory assembly in CPP- $651=\mathbf{\$ 1 0 , 1 0 0}$

Cost to perform radiation surveys and QA box $=\$ \mathbf{8 , 9 0 0}$

Cost to Repackage in CPP-651 and Ship $=\$ \mathbf{7 , 5 0 0}$

Total Cost for Option $2=$

$\$ 23,300+\$ 15,500+\$ 10,100+\$ 8,900+\$ 7,500=\underline{\underline{\$ 65,300}}$ 
Schedule: $\quad 4$ months to negotiate use of $B \& W$ box

1 month for planning and preparations

2 months to develop procedures and QA drums

1 week to inventory

1 month to repackage and ship

\section{Total Duration for Option $2=\underline{\underline{8 \text { months }}}$}

Comments: The Packaging and Transportation team determined that the PWR Assembly would not fit in a B\&W box without being cut. No detailed cost estimates were performed for this option.

\section{PWR Assembly \\ Option 3 (Cut assembly to fit a certified shipping package)}

Comments: The Packaging and Transportation team determined that the PWR Assembly could be shipped in its current storage package therefore no cutting would be required. No detailed cost estimates were performed for this option.

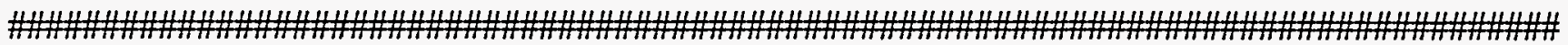

Fluorinel

Option 1 (Obtain longer 2R inner containers and certified $6 \mathrm{M}$ drums, package into $6 \mathrm{M}$ drums, ship to B\&W or NFS)

* Assume that the repackaging and shipping of $1 \mathrm{~B} \& W$ box is equivalent to the repackaging and shipping of 4 drums, therefore a total of 220,110 -gallon, $6 \mathrm{M}$ drums are needed.

Cost

Cost to Procure $2 \mathrm{R}$ inner containers and Drum(s) $=\$ \mathbf{1 4 8 , 0 0 0}$

Cost to Design \& fabricate $2 R$ inner containers $=\$ 29,600$

Cost for Planning and preparations $=\$ \mathbf{4 5 , 6 0 0}$

Cost for Procedure Preparation $=\$ \$ 30,000$

Cost to Repackage in CPP-651 and Ship

$\$ 28,000+(1200 /$ drum $\times 220$ drums $)=\$ 292,800$

Total Cost for Option 1 (Base Case) =

$\$ 148,000+\$ 29,600+\$ 45,600+\$ 30,000+\$ 292,800=\underline{\$ \mathbf{5 4 6 , 0 0 0}}$ 
Schedule: $\quad 6$ months to procure 110 gallon, $6 \mathrm{M}$ drum

4 months for planning and preparations

2 months to develop procedures and QA drums

6 months to repackage and ship

\section{Total Duration for Option 1 (Base Case) $=\underline{\underline{18} \text { months }}$}

Comments: The Primavera generated Base Case detailed resources, cost data and scheduled activities for this option is shown in Appendix C and D of this report.

\section{Fluorinel}

Option 2 (Obtain certified 6M drums, cut material to fit into 6M drums, package into 6M drums, ship to B\&W or NFS)

* Assume it will take $55 \mathrm{~B} \& \mathrm{~W}$ boxes to hold all of this Fluorinel material

* Assume that the repackaging and shipping of $1 \mathrm{~B} \& \mathrm{~W}$ box is equivalent to the repackaging and shipping of 4 drums, therefore a total of 220,110 -gallon, $6 \mathrm{M}$ drums are needed.

* Assume that cutting can be done using glovebags, in CPP-651

Cost

Cost to Procure Drum(s)

$\$ 1,200$ per 110 gallon drum $\times 220$ drums $=\$ \mathbf{2 6 4 , 0 0 0}$

Cost for Planning and preparations $=\$ \mathbf{4 6 , 0 0 0}$

Cost to cut material to fit into $6 \mathrm{M}$ drums

assume time to cut fuel is equivalent to repackaging and shipping every fourth drum or $1 / 4$ the cost to repackage \& ship

$[\$ 11,900+(940 /$ drum $\times 220$ drums $)] \times 1 / 4=\$ \mathbf{5 4 , 6 7 5}$

Cost for Procedure Preparation $=\mathbf{\$ 3 0 , 0 0 0}$

Cost to Repackage in CPP-651 and Ship

$\$ 11,900+(940 /$ drum $\times 220$ drums $)=\$ 218,700$

Total Cost for Option $2=$

$\$ 264,000+\$ 46,000+\$ 54,675+\$ 30,000+\$ 218,700=\underline{\underline{613,375}}$ 
Schedule: 6 months to procure 110 gallon, $6 \mathrm{M}$ drum

4 months for planning and preparations

1 month to develop procedures and QA drums

5 months to cut

5 months to repackage and ship

\section{Total Duration for Option $2=\underline{\underline{21} \text { months }}$}

Comments: The Packaging and Transportation team determined that extra long $2 \mathrm{R}$ inner containers and $6 \mathrm{M}$ drums could be fabricated that could contain the long pieces of Fluorinel material therefore no cutting would be required. No detailed cost estimates were performed for this option.

\section{Fluorinel}

Option 3 (Obtain certified B\&W boxes, package into B\&W boxes, ship to B\&W or NFS)

* Assume it will take $55 \mathrm{~B} \& \mathrm{~W}$ boxes to hold all of this Fluorinel material

Cost

Cost for Procedure Preparation $=$ assume $\mathbf{\$ 3 0 , 0 0 0}$

Cost for Planning and preparations $=\$ \mathbf{4 5 , 6 0 0}$

Cost to perform radiation surveys and inspect boxes in CPP-651

Assume $\$ 500$ per box

$\$ 500 \times 55$ boxes $=\$ 27,500$

Cost to Repackage in CPP-651 and Ship

$\$ 3500$ per B\&W box $\times 55$ boxes $=\$ 192,500$

Total Cost for Option $3=$

$\$ 30,000+\$ 45,600+\$ 27,500+\$ 192,500=\underline{\$ \mathbf{2 9 5 , 6 0 0}}$

Schedule: $\quad 3$ months to negotiate use of $B \& W$ boxes

2 months to develop procedures and QA drums

4 months for planning and preparations

12 months to repackage and ship

\section{Total Duration for Option $3=\underline{\underline{21} \text { months }}$}

Comments: The Packaging and Transportation team determined that extra long $2 \mathrm{R}$ inner containers and $6 \mathrm{M}$ drums could be fabricated that could contain the long pieces of Fluorinel material therefore no $\mathrm{B} \& \mathrm{~W}$ boxes were needed. No detailed cost estimates were performed for this option.

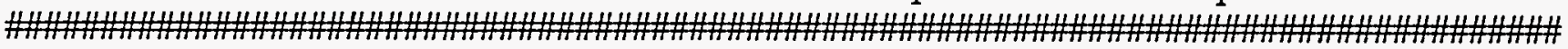




\section{University of Washington}

Qption 1 \& 2 (Repackage and ship to either SRS or Y-12)

Cost:

Cost for Planning and preparations $=\$ \mathbf{1 0 , 6 0 0}$

Cost for Procedure Preparation $\mathbf{= \$ 1 5 , 5 0 0}$

Cost to perform radiation surveys, inspect and QA drum

Assume $\$ 2200$ per drum

$\$ 2,200 \times 1$ drum $=\$ 2,200$

Cost to Repackage in CPP-651 and Ship

$\$ 11,000+(1000 /$ drum $\times 1$ drum $)=\$ 12,000$

\section{Total Cost for Option 1 (Base Case) \& $2=$}

$$
\$ 10,600+\$ 15,500+\$ 2,200+\$ 12,000=\underline{\mathbf{\$ 4 0 , 3 0 0}}
$$

Schedule: 2 months for planning and preparations

2 months to develop procedures and QA drums

1 day to ship

\section{Total Duration for Option 1 (Base Case) \& $2=\underline{\underline{4 \text { months }}}$}

Comments: The characterization data showed that the material did not meet the Y-12 acceptance criteria therefore the material will be sent to SRS. The Primavera generated Base Case detailed resources, cost data and scheduled activities for option 1 is shown in Appendix C and D of this report.

\section{University of Washington}

Option 3 (CPP Stabilization to Uranium Oxide, repackage and ship to Y-12)

Assumed a small lab scale set-up is used that consists of a 10 liter dissolver. The dissolver can process approximately 50 grams of uranium per batch. Assumed the waste is disposed of via the PEW system. The University of Washington Aluminum Clad Plates contain approximately 460 grams of Uranium.

Cost:

Dissolution of this material (460 grams uranium) will require 10 batches through the dissolver.

Estimated time - 2 people full time for three weeks.

Cost to stabilize: 2 people $\times 40 \mathrm{hrs} / \mathrm{wk}$. $\times 3$ wks $\times \$ 67 / \mathrm{hr}=\$ 16,080$

Total Cost for Option 3 to stabilize, repackage and ship to Y-12= $\$ 40,300$ (see option $1 \& 2$ ) $+\$ 16,080=\underline{\mathbf{\$ 5 6 , 3 8 0}}$ 
Schedule: $\quad 3$ weeks to stabilize material

2 months for planning and preparations

2 months to develop procedures and QA drums

1 day to ship

Total Duration for Option $3=\underline{\underline{5 \text { months }}}$

Comments: No detailed cost estimates were performed for this option.

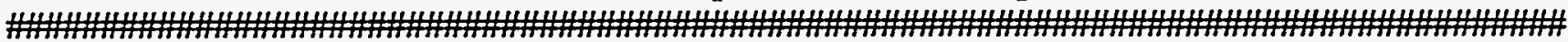

University of Wisconsin

Option 1 \& 2 (Repackage and ship to either $\mathrm{Y}-12$ or SRS)

Cost:

Cost for Planning and preparations $=\$ \mathbf{1 0 , 5 0 0}$

Cost for Procedure Preparation = assume \$15,500 .

Cost to perform radiation surveys, inspect and QA drum

Assume $\$ 2200$ per drum

$\$ 2,200 \times 1$ drum $=\$ 2,200$

Cost to Repackage in CPP-651 and Ship

$\$ 14,000+(1000 /$ drum $\times 1$ drum $)=\$ \mathbf{1 5 , 0 0 0}$

Total Cost for Option 1 (Base Case) \& $2=$

$$
\$ 10,500+\$ 15,500+\$ 2,200+\$ 15,000=\underline{\$ 43,200}
$$

Schedule: 2 months for planning and preparations

2 months to develop procedures and QA drums

1 day to ship

Total Duration for Option 1 (Base Case) \& $2=\underline{\underline{4 \text { months }}}$

Comments: The material meets the Y-12 acceptance criteria therefore the material will be sent to Y12. The Primavera generated Base Case detailed resources, cost data and scheduled activities for option 1 is shown in Appendix C and D of this report. 


\section{University of Wisconsin}

Option 3 (ICPP Stabilization to Uranium Oxide, order drums, repackage, ship to Y12)

Assumed a small lab scale set-up is used that consists of a 10 liter dissolver. The dissolver can process approximately 50 grams of uranium per batch. Assumed the waste is disposed of via the PEW system. The University of Wisconsin Aluminum Clad Plates contain approximately 150 grams of Uranium.

Cost:

Dissolution of this material (150 grams uranium) will require 3 batches through the dissolver. Estimated time - 2 people full time for two weeks.

Cost to stabilize: 2 people $\times 40 \mathrm{hrs} / \mathrm{wk}$. $\times 2$ wks $\times \$ 67 / \mathrm{hr}=\$ \mathbf{1 0 , 7 2 0}$

Total Cost Option 3 to stabilize, order drums, repackage, ship to Y-12= $\$ 43,200$ (see option $1 \& 2$ ) $+\$ 10,720=\underline{\$ \mathbf{5 3 , 9 2 0}}$

Schedule: $\quad 2$ weeks to stabilize material

2 months for planning and preparations

2 months to develop procedures and QA drums

1 day to ship

Total Duration for Option $3=\underline{\underline{5 \text { months }}}$

Comments: No detailed cost estimates were performed for this option.

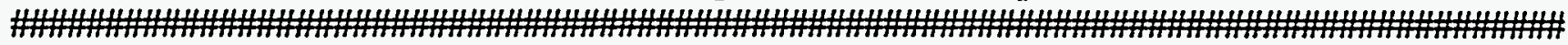

Custom Product

Option 1 (Order seven 6M drums, repackage small bottles into 6M drums, borrow four DC-1 shipping packages from $Y-12$, repackage 4 large bottles into DC-1's, ship to Y-12.)

Cost:

Cost to Procure Drum(s)

$\$ 600$ per 55 gallon drum $\times 7$ drums $=\$ 4200$

Cost for Planning and preparations $=\mathbf{\$ 2 0 , 2 0 0}$

Cost for Procedure Preparation $=\$ \mathbf{\$ 1 5 , 5 0 0}$

Cost to Repackage 11 drums in CPP-651 and Ship

$\$ 20,000+(1500 /$ drum $\times 11$ drums $)=\$ 36,500$

Total Cost for Option 1 (Base Case) =

$$
\$ 4,200+\$ 20,200+\$ 15,500+\$ 36,500=\underline{\$ 76,400}
$$


Schedule: $\quad 11 / 2$ months for planning and preparations

2 months to develop procedures and QA drums

2 weeks to ship

Total Duration for Option 1 (Base Case) $=\underline{\underline{4 \text { months }}}$

Comments: The material meets the Y-12 acceptance criteria therefore the material will be sent to Y12. The Primavera generated Base Case detailed resources, cost data and scheduled activities for this option is shown in Appendix C and D of this report.

\section{Custom Product}

Option 2 (Order drums, repackage 7 drums in CPP-651, repackage 4 bottles in CPP651 , ship to $\mathrm{Y}-12$ )

Cost:

Cost to Procure Drum(s)

$\$ 600$ per 55 gallon drum $\times 11$ drums $=\$ 6600$

Cost for Planning and preparations $=\$ \mathbf{2 0 , 2 0 0}$

Cost for Procedure Preparation $=\$ \mathbf{\$ 1 5 , 5 0 0}$

Cost to Repackage 7 drums of the 11 in CPP-651 and Ship

$\$ 11,900+(940 /$ drum $\times 7$ drums $)=\$ 18,480$

Cost to Repackage the 4 large bottles into smaller bottles in CPP-651 and ship

assumes process initiation costs are incurred within the denitrator product estimate

1 Technical Shift Engineer at $\$ 65 /$ hour

1 Radcon Technician at $\$ 49 /$ hour

1 Supervisor at $\$ 52 /$ hour

3 Operators at $\$ 52 /$ hour

8 hours worth of work in a 10 hour shift. Work 410 hour shifts per week. Estimate repackaging 15 big bottles of HEU per day. Will repackage one big bottle every $1 / 2$ hour. Repackaging a total of 4 big bottles of Custom Product.

1 day (to repackage 4 bottles at 15 bottles per day) $\times 10 \mathrm{hrs} /$ day $=10$ hours

$(\$ 65 / \mathrm{hr} \times 10 \mathrm{hrs})+(\$ 49 / \mathrm{hr} \times 10 \mathrm{hrs})+(\$ 52 \times 4 \times 10$ hours $)=$

$$
\$ 650+\$ 490+\$ 2080=\$ 3,220
$$

Guards on average have cost $\$ 80,000$ per month (assume $\$ 5,000$ per day)

Assume we need 2 days $=\$ 10,000$ 
Cost to repackage \& ship each drum in CPP-651:

10 hour days at 15 drums per day $=.67$ hours per drum

3 Operators $=.67$ laborhrs $/$ drum $\times 3 \times \$ 52 / \mathrm{hr}=\$ 110 / \mathrm{drum}$

2 Foreman $/$ Supervisor $=.67$ laborhrs $/$ drum $\times 2 \times \$ 52 / \mathrm{hr}=\$ 70 /$ drum

1 Engineer $/$ Scientist $=.67$ laborhrs $/$ drum $\times \$ 67 / \mathrm{hr}=\quad \$ 50 / \mathrm{drum}$

1 Radcon Tech. $=.67$ laborhrs $/$ drum $\times \$ 49 / \mathrm{hr}=\$ 40 / \mathrm{drum}$ Total $\$ 270 /$ drum $\times 4$ drums $=\$ \mathbf{1 , 0 8 0}$

Total Cost for Option $2=$ $\$ 6,600+\$ 20,200+\$ 15,500+\$ 18,480+\$ 3,220+\$ 10,000+\$ 1,080=\underline{\mathbf{\$ 7 5 , 0 8 0}}$

Schedule: $\quad 4$ months to procure a 55 gallon, $6 \mathrm{M}$ drums

$11 / 2$ months for planning and preparations

2 months to develop procedures and QA drums

1 week to repackage in CPP-651

1 week to ship

Total Duration for Option $2=\underline{\underline{8 \text { months }}}$

Comments: No detailed cost estimates were performed for this option. The Primavera generated detailed resources, cost data and scheduled activities for repackaging the Denitrator Product and installing the glovebox is shown as option 5 for the Denitrator Product in this appendix.

\section{Custom Product}

Qption 3 (Order drums, repackage 7 drums in CPP-651 and ship to Y-12; dry-blend remaining 4 bottles to less than $20 \%$ enrichment, repackage into 40 smaller cans which will be shipped in $206 \mathrm{M}$ drums to SRS.)

- Assumed a 5 to 1 dilution is used to reduce the enrichment to less than $20 \%$.

Cost:

Cost to Procure Drum(s)

$\$ 600$ per 55 gallon drum $\times 27$ drums $=\$ 16,200$

Cost for Planning and preparations $=\$ \mathbf{2 0 , 2 0 0}$

Cost for Procedure Preparation $=\mathbf{\$ 1 5 , 5 0 0}$

Cost to Repackage 7 drums of the 20 in CPP-651 and Ship to Y-12

$\$ 11,900+(940 /$ drum $\times 7$ drums $)=\$ \mathbf{1 8 , 4 8 0}$ 
Dry blend 4 large bottles into 40 small cans ( 2 per drum) in CPP-651 and ship to SRS assumes process initiation costs are incurred within the denitrator product estimate

1 Technical Shift Engineer at $\$ 65 /$ hour

1 Radcon Technician at $\$ 49 /$ hour

1 Supervisor at $\$ 52 /$ hour

3 Operators at $\$ 52 /$ hour

8 hours worth of work in a 10 hour shift. Work 410 hour shifts per week. Estimate repackaging 15 big bottles of HEU per day. Will repackage one big bottle every $1 / 2$ hour.

Blending and repackaging a total of 4 big bottles of Custom Product to fit into $206 \mathrm{M}$ drums.

3 days (to repackage 4 bottles at 15 new bottles per day) $\times 10 \mathrm{hrs} /$ day $=30$ hours

$(\$ 65 / \mathrm{hr} \times 30 \mathrm{hrs})+(\$ 49 / \mathrm{hr} \times 30 \mathrm{hrs})+(\$ 52 \times 4 \times 30$ hours $)=$

$$
\$ 1,950+\$ 1,470+\$ 6,240=\$ 9,660
$$

Guards on average have cost $\$ 80,000$ per month (assume $\$ 5,000$ per day) Assume we need 6 days $=\$ \mathbf{\$ 3 0 , 0 0 0}$

Cost to repackage \& ship each drum in CPP-651:

10 hour days at 15 drums per day $=.67$ hours per drum

3 Operators $=.67$ laborhrs $/$ drum $\times 3 \times \$ 52 / \mathrm{hr}=\$ 110 /$ drum

2 Foreman/Supervisor $=.67$ laborhrs $/$ drum $\times 2 \times \$ 52 / \mathrm{hr}=\$ 70 / \mathrm{drum}$

1 Engineer $/$ Scientist $=.67$ laborhrs $/$ drum $\times \$ 67 / \mathrm{hr}=\quad \$ 50 / \mathrm{drum}$

1 Radcon Tech $=.67 \mathrm{laborhrs} / \mathrm{drum} \times \$ 49 / \mathrm{hr}=\quad \$ 40 / \mathrm{drum}$

Total

$\$ 270 /$ drum $\times 20$ drums $=\$ 5,400$

Cost for Decontamination and Accountability $=\quad \mathbf{\$ 3 0 , 0 0 0}$

Total Cost for Option $3=\$ 16,200+\$ 20,200+\$ 15,500+\$ 18,480+\$ 9,660$

$+\$ 30,000+\$ 5,400+\$ 30,000=\underline{\$ 145,440}$

Schedule: $\quad 4$ months to procure a 55 gallon, $6 \mathrm{M}$ drums

$11 / 2$ months for planning and preparations

2 months to develop procedures and QA drums

2 weeks to dry blend and repackage in CPP-651

I week to ship

\section{Total Duration for Option $3=\underline{\underline{8} \text { months }}$}

Comments: No detailed cost estimates were performed for this option. The Primavera generated detailed resources, cost data and scheduled activities for dry blending the Denitrator Product is shown as option 1 for the Denitrator Product in this appendix.

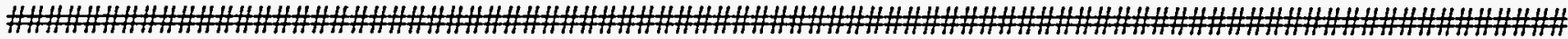




\section{GEFAST}

Option 1 (Repackage 4 cans into 6M drums in CPP-651 and ship to Y-12)

Cost:

Cost for Planning and preparations $=\$ \mathbf{8 , 5 0 0}$

Cost for Procedure Preparation = assume \$14,000

Cost to perform radiation surveys, inspect and QA drum

Assume $\$ 1200$ per drum

$\$ 1,200 \times 4$ drum $=\$ 4,800$

Cost to Repackage 4 drums in CPP-651 and Ship

$\$ 9,500+(1000 /$ drum $\times 4$ drums $)=\$ 13,500$

\section{Total Cost for Option 1 (Base Case) for GEFAST}

$$
\$ 8,500+\$ 14,000+\$ 4,800+\$ 13,500=\underline{\$ 40,800}
$$

Schedule: 2 months for planning and preparations

2 months to develop procedures and QA drums

1 week to load and ship drums

Total Duration for Option 1 (Base Case), GEFAST = $\underline{\underline{5} \text { months }}$

\section{GEFAST - AWF-1}

Option 1 (Purchase one UN1A2 drum; repackage 1 large can into UN1A2 drum in CPP-651 and ship to Y-12)

Cost:

Cost to Procure one UN1A2 drum $\$ 900$ per UN1A2 drum $\times 1$ drum $=\$ 900$

Cost for Planning and preparations $=\$ 4,300$

Cost for Procedure Preparation = assume \$14,000

Cost to Repackage 1 UN1A2 drum in CPP-651 and Ship

$\$ 11,900+(940 /$ drum $\times 1$ drums $)=\$ 3,400$

Total Cost Option 1 (Base Case) for GEFAST-AWF-1

$$
\$ 900+4,300+\$ 14,000+\$ 3,400=\underline{\$ 22,600}
$$


Schedule: $\quad 2$ month for planning and preparations

2 months to develop procedures and QA drums

1 months to procure \& load UN1A2 drum

Total Duration for Option 1 (Base Case), GEFAST AWF-1 = 5 months

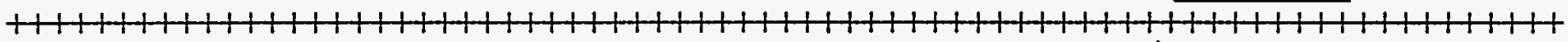

Total Cost Option 1 (Base Case) for GEFAST \& GEFAST-AWF-1

$\$ 40,800+\$ 22,600=\underline{\$ 63,400}$

\section{Total Duration for Option 1 (Base Case) for GEFAST \& GEFAST AWF-1}

$=\underline{\underline{\text { months }}}$

Comments: The material meets the Y-12 acceptance criteria therefore the material will be sent to Y12. The Primavera generated Base Case detailed resources, cost data and scheduled activities for this option is shown in Appendix C and D of this report.

\section{GEFAST - AWF-1}

Option 2 (Re-can 1 can into 3 smaller cans in CPP-651, repackage 3 cans into $36 \mathrm{M}$ drums in CPP-651, ship to Y-12)

Cost:

Cost for Planning and preparations $=\$ 4,300$

Cost for Procedure Preparation = assume \$14,000

Re-can 1 large can into smaller cans in CPP-651

Cost to Repackage the 1 large can in CPP-651 and ship

assumes process initiation costs are incurred within the denitrator product estimate

1 Technical Shift Engineer at $\$ 65 /$ hour

1 Radcon Technician at $\$ 49 /$ hour

1 Supervisor at $\$ 52 /$ hour

3 Operators at $\$ 52 /$ hour

8 hours worth of work in a 10 hour shift. Work 410 hour shifts per week. Estimate

repackaging 15 big bottles of HEU per day. Will repackage one big bottle every $1 / 2$ hour.

Repackaging 1 big can of GEFAST.

1 day (to repackage 1 can at 15 bottles per day) $\times 10 \mathrm{hrs} /$ day $=10$ hours

$(\$ 65 / \mathrm{hr} \times 10 \mathrm{hrs})+(\$ 49 / \mathrm{hr} \times 10 \mathrm{hrs})+(\$ 52 \times 4 \times 10$ hours $)=$

$$
\$ 650+\$ 490+\$ 2080=\$ \mathbf{3 , 2 2 0}
$$

Guards on average have cost $\$ 80,000$ per month (assume $\$ 5,000$ per day)

Assume we need 2 days $=\$ \mathbf{1 0 , 0 0 0}$ 
Cost to repackage \& ship each drum in CPP-651:

10 hour days at 15 drums per day $=.67$ hours per drum

3 Operators $=.67 \mathrm{laborhrs} / \mathrm{drum} \times 3 \times \$ 52 / \mathrm{hr}=$

2 Foreman $/$ Supervisor $=.67$ laborhrs $/$ drum $\times 2 \times \$ 52 / \mathrm{hr}=$

1 Engineer $/$ Scientist $=.67$ laborhrs $/$ drum $\times \$ 67 / \mathrm{hr}=$

1 Radcon Tech. $=.67$ laborhrs $/ \mathrm{drum} \times \$ 49 / \mathrm{hr}=$

Total

$\$ 110 /$ drum

$\$ 70 /$ drum

$\$ 50 /$ drum

$\$ 40 /$ drum

$\$ 270 /$ drum $\times 3$ drums $=\$ 810$

Decontamination and Accountability $=$

$\$ 30,000$

Total Cost for Option 2 for GEFAST-AWF-1 =

$\$ 4,300+\$ 14,000+\$ 3,220+\$ 10,000+\$ 810+\$ 30,000=\underline{\underline{\$ 62,330}}$

Total Cost for GEFAST (Option 1) + GEFAST-AWF-1 (Option 2) =

$\$ 40,800+62,330=\$ 103,130$

Schedule: $\quad 4$ months to procure a 55 gallon, $6 \mathrm{M}$ drums

$21 / 2$ months for planning and preparations

2 months to develop procedures and QA drums

1 week to load and ship drums

1 week to repackage in CPP-651

Total Duration for Option 2 for GEFAST-AWF-1 = 2 months

* Duration for GEFAST option 1 can be done concurrently.

Comments: No detailed cost estimates were performed for this option. The Primavera generated detailed resources, cost data and scheduled activities for repackaging the Denitrator Product is shown as option 5 for the Denitrator Product in this appendix.

GEFAST - AWF-1

Option 3 (Dry-blend 1 can to less than 20\% enrichment, repackage into 10 cans which will be shipped in $56 \mathrm{M}$ drums to SRS.)

Cost:

Cost to Procure Drum(s)

$\$ 600$ per 55 gallon drum $\times 5$ drums $=\$ 3,000$

Cost for Planning and preparations $=\$ 4,300$

Cost for Procedure Preparation = assume \$14,000

Dry blend 1 large can into 10 cans ( 2 per drum) in CPP-651 and ship to SRS assumes process initiation costs are incurred within the denitrator product estimate

1 Technical Shift Engineer at \$65/hour

1 Radcon Technician at $\$ 49 /$ hour

1 Supervisor at $\$ 52 /$ hour

3 Operators at $\$ 52 /$ hour 
8 hours worth of work in a 10 hour shift. Work 410 hour shifts per week. Estimate repackaging 15 big bottles of HEU per day. Will repackage one big bottle every $1 / 2$ hour. Blending and repackaging 1 big can of GEFAST to fit into $56 \mathrm{M}$ drums.

1 day (to repackage 1 can at 15 new cans per day) $\times 10 \mathrm{hrs} /$ day $=10$ hours

$(\$ 65 / \mathrm{hr} \times 10 \mathrm{hrs})+(\$ 49 / \mathrm{hr} \times 10 \mathrm{hrs})+(\$ 52 \times 4 \times 10$ hours $)=$

$$
\$ 650+\$ 490+\$ 2,080=\$ 3,220
$$

Guards on average have cost $\$ 80,000$ per month (assume $\$ 5,000$ per day)

$$
\text { Assume we need } 2 \text { days }=\$ \mathbf{\$ 1 0 , 0 0 0}
$$

Cost to repackage \& ship each drum in CPP-651:

10 hours day at 15 drums per day $=.67$ hours per drum

3 Operators $=.67$ laborhrs $/$ drum $\times 3 \times \$ 52 / \mathrm{hr}=\$ 110 / \mathrm{drum}$

2 Foreman/Supervisor $=.67$ laborhrs $/$ drum $\times 2 \times \$ 52 / \mathrm{hr}=\$ 70 /$ drum

1 Engineer $/$ Scientist $=.67 \mathrm{laborhrs} / \mathrm{drum} \times \$ 67 / \mathrm{hr}=\$ 50 / \mathrm{drum}$

1 Radcon Tech $=.67$ laborhrs $/$ drum $\times \$ 49 / \mathrm{hr}=\quad \$ 40 / \mathrm{drum}$

Total

Decontamination and Accountability $=$
$\$ 270 /$ drum $\times 5$ drums $=\$ 1,350$

$\$ 30,000$

Total Cost for Option 3 for GEFAST-AWF-1 =

$\$ 3,000+\$ 4,300+\$ 14,000+\$ 3,220+\$ 10,000+\$ 1,350+\$ 30,000=\underline{\mathbf{\$ 6 5 , 8 7 0}}$

Total Cost for GEFAST (Option 1) + GEFAST-AWF-1 (Option 3) =

$\$ 40,800+65,870=\$ 106,670$

Schedule: $\quad 4$ months to procure a 55 gallon, $6 \mathrm{M}$ drums

$21 / 2$ months for planning and preparations

2 months to develop procedures and QA drums

1 week to load and ship drums

2 weeks to repackage in CPP-651

Total Duration for Option 3 for GEFAST-AWF-1 = 9 months

* Duration for GEFAST option 1 can be done concurrently.

Comments: No detailed cost estimates were performed for this option. The Primavera generated Base Case detailed resources, cost data and scheduled activities for dry blending the Denitrator Product is shown as option 1 for the Denitrator Product in this appendix.

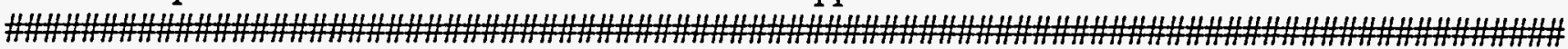




\section{Janus}

Option 1 (Ship in current drum to ANL-W)

Cost:

Cost for Planning and preparations $=\$ \mathbf{1 5 , 2 0 0}$

Cost for Procedure Preparation $=\mathbf{\$ 1 5 , 5 0 0}$

Cost to perform radiation surveys, inspect and QA drum

Assume $\$ 1200$ per drum

$\$ 1,200 \times 3$ drums $=\$ 3,600$

Cost to Ship to ANL-W $=\mathbf{\$ 1 2 , 0 0 0}$

Total Cost for Option 1 (Base Case) $=$

$$
\$ 15,200+15,500+\$ 3,600+\$ 12,000=\underline{\mathbf{\$ 4 6 , 3 0 0}}
$$

Schedule: $\quad 11 / 2$ months for planning and preparations

2 months to develop procedures and QA drums

1 week to ship

Total Duration for Option 1 (Base Case) $=\underline{\underline{4 \text { months }}}$

Comments: The material does not meet the Y-12 acceptance criteria therefore the material will be sent to ANL-W. The Primavera generated Base Case detailed resources, cost data and scheduled activities for this option is shown in Appendix $\mathrm{C}$ and $\mathrm{D}$ of this report.

\section{Janus}

Option 2 (Repackage, ship to Y-12)

Cost:

Cost for Planning and preparations $=\$ 15,200$

Cost for Procedure Preparation $=\mathbf{\$ 1 5 , 5 0 0}$

Cost to perform radiation surveys, inspect and QA drum Assume $\$ 1200$ per drum

$\$ 1,200 \times 3$ drums $=\$ 3,600$

Cost to Repackage in CPP-651 and Ship

$\$ 11,900+(940 /$ drum $\times 3$ drum $)=\$ 14,720$

Total Cost for Option $2=\$ 15,200+\$ 15,500+\$ 3,600+\$ 14,720=\underline{\mathbf{\$ 4 9 , 0 2 0}}$ 
Schedule: $\quad 11 / 2$ months for planning and preparations

2 months to develop procedures and QA drums

1 week to ship

Total Duration for Option $2=\underline{\underline{4 \text { months }}}$

Comments: The characterization data showed that the material did not meet the Y-12 acceptance criteria therefore the material will be sent to ANL-W. No detailed cost estimates were performed for this option.

Janus

Option 3 (ICPP Stabilization to Uranium Oxide, order drums, repackage, ship to Y-12)

Assumed a small lab scale set-up is used that consists of a 10 liter dissolver. The dissolver can process approximately 50 grams of uranium per batch. Assumed the waste is disposed of via the PEW system. The Janus material consists of stainless steel clad plates.

Cost:

Dissolution of this material (34,000 grams uranium) will require 680 batches through an electrolytic dissolver. Estimated time 2 people full time for 1 year.

Cost: 2 people $\times 1920$ hours $/ \mathrm{yr} \times \$ 67 / \mathrm{hr}=\$ \mathbf{2 6 0 , 0 0 0}$

Total Cost for Option 3 to stabilize, order drums, repackage, ship to Y-12= $\$ 49,020($ see option 2$)+\$ 260,000=\underline{\mathbf{\$ 3 0 9 , 0 2 0}}$

Schedule: 12 months weeks to stabilize material 4 months to procure a 110 gallon, $6 \mathrm{M}$ drum

$11 / 2$ months for planning and preparations

2 months to develop procedures and QA drums

1 week to ship

\section{Total Duration for Option $3=\underline{\underline{20} \text { months }}$}

Comments: No detailed cost estimates were performed for this option. The Primavera generated detailed resources, cost data and scheduled activities for dissolution of the Denitrator Product is shown as option 3 and 4 for the Denitrator Product in this appendix.

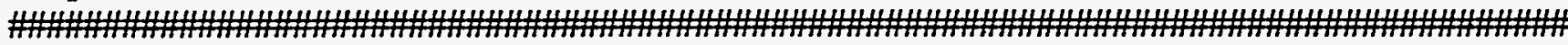


Vycor Glass:

Option 1 (Send to ANL-W, provide funds to ANL-W for dry processing using their magnetic separator)

The Vycor glass will be shipped to Argonne in the drums that it is currently stored in. Each drum will contain approximately 24 cans of Vycor glass.

Cost:

Cost for Planning and preparations $=\$ 4,900$

Cost to perform radiation surveys, inspect and QA drum

Assume $\$ 1,200$ per drum

$\$ 1,200 \times 10$ drums $=\$ 12,000$

Cost to inventory and Ship to ANL-W $=\mathbf{\$ 1 6 , 9 0 0}$

Argonne plans on removing the uranium from the Vycor glass by using a magnetic separation process. Argonne has already purchased and tested the magnetic separator. Assuming budget was provided to them in 1998, the Vycor glass could be shipped from ICPP to Argonne-West in 2000.

Listed below are the estimated costs for Argonne to set up the process for the Vycor glass.

2 operators -6 months time

glovebox purchase and installation

engineering design \& support - 4 months

training \& start-up

safety documentation \& procedures

overhead -HP's, Radiation Safety, NDA, MC\&A, etc.

Total
$\$ 150,000$

$\$ 150,000$

$\$ 75,000$

$\$ 65,000$

$\$ 30,000$

$\$ 75,000$

$\$ 545,000$

\section{Total Cost for Option 1 (Base Case) =}

$$
\$ 4,900+\$ 12,000+\$ 16,900+\$ 545,000=\underline{\mathbf{\$ 5 7 8 , 8 0 0}}
$$

Schedule: $\quad 4$ months for planning and preparations

2 months to develop inventory procedure and QA drums

1 week to inventory and ship

\section{Total Duration for Option 1 (Base Case) $=\underline{6 \text { months }}$}

Comments: The Primavera generated Base Case detailed resources, cost data and scheduled activities for this option is shown in Appendix $C$ and D of this report. 


\section{Vycor Glass:}

Option 2 (Stabilize to uranium oxide, then repackage and send to $\mathrm{Y}-12$

Cost:

Cost for Planning and preparations $=\$ 4,900$

Cost to perform radiation surveys, inspect and QA drum

Assume $\$ 1,200$ per drum

$\$ 1,200 \times 10$ drums $=\$ 12,000$

Dissolution of this material (5,500 grams uranium) will require 110 batches through the dissolver. Estimated time 2 people full time for 9 months.

Cost: 2 people $\times 160 \mathrm{hrs} / \mathrm{mo} \times 9 \mathrm{mo} \times \$ 67 / \mathrm{hr}=\$ \mathbf{2 0 0 , 0 0 0}$.

Cost to dispose of glass, assume $\$ 800$ per drum

$\$ 800 \times 10$ drums $=\$ 8,000$

Cost to package and ship to $\mathrm{Y}-12=\mathbf{\$ 1 6 , 5 0 0}$

Total Cost for Option 2 to stabilize, repackage, ship to $\mathrm{Y}-12=$

$\$ 4,900+\$ 12,000+\$ 200,000+\$ 8,000+\$ 16,500=\underline{\mathbf{\$ 2 4 1 , 4 0 0}}$

Schedule: $\quad 9$ months weeks to stabilize material

4 months to procure a 55 gallon, $6 \mathrm{M}$ drum

4 months for planning and preparations

2 months to develop inventory procedure and QA drums

1 week to package and ship

Total Duration for Option $2=19$ months

Comments: No detailed cost estimates were performed for this option. The Primavera generated detailed resources, cost data and scheduled activities for dissolution of the Denitrator Product is shown as option 3 and 4 for the Denitrator Product in this appendix.

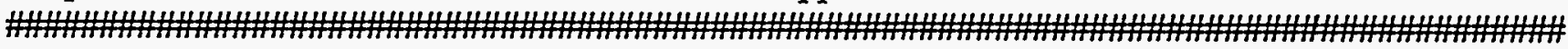

ANL-W EBR-II Scrap

Option 1 (Repackage material, ship to Y-12)

Cost:

Cost for Planning and preparations $=\$ 4,000$

Cost for Procedure Preparation $=\mathbf{\$ 1 2 , 0 0 0}$

Cost to perform radiation surveys, inspect and QA drum

Assume $\$ 1,200$ per drum

$\$ 1,200 \times 20$ drums $=\$ 24,000$ 
Cost to Repackage in CPP-651 and Ship

$\$ 12,400+(1200 /$ drum $\times 20$ drum $)=\$ 36,400$

\section{Total Cost for Option 1 (Base Case) =}

$$
\$ 4,000+\$ 12,000+\$ 24,000+\$ 36,400=\underline{\$ 76,400}
$$

Schedule:

4 months for planning and preparations

2 months to develop procedure and QA drums

1 week to package and ship

\section{Total Duration for Option 1 (Base Case) $=\underline{\underline{6 \text { months }}}$}

Comments: The Primavera generated Base Case detailed resources, cost data and scheduled activities for this option is shown in Appendix C and D of this report.

\section{ANL-W EBR-II Scrap \\ Option 2 (Ship to ANL-W)}

Cost:

Cost for Planning and preparations $=\$ \mathbf{4 , 0 0 0}$

Cost for Procedure Preparation $=\mathbf{\$ 1 2 , 0 0 0}$

Cost to perform radiation surveys, inspect and QA drum

Assume $\$ 1,200$ per drum

$$
\$ 1,200 \times 20 \text { drums }=\$ 24,000
$$

Cost to Ship to ANL-W

$\$ 11,900+(940 /$ drum $\times 20$ drum $)=\$ 30,700$

Total Cost for Option $2=\$ 4,000+\$ 12,000+\$ 24,000+\$ 30,700=\underline{\$ 70,700}$

Schedule: $\quad 4$ months for planning and preparations

2 months to develop procedure and QA drums

1 week to inventory and ship

\section{Total Duration for Option $2=\underline{\underline{6 \text { months }}}$}

Comments: The characterization data showed that the material did meet the Y-12 acceptance criteria therefore the material will not be sent to ANL-W. No detailed cost estimates were performed for this option. 


\section{ANL-W EBR-II Scrap \\ Option 3 (ICPP Stabilization to Uranium Oxide, repackage, ship to Y-12)}

Assumed a small lab scale set-up is used that consists of a 10 liter dissolver. The dissolver can process approximately 50 grams of uranium per batch. Assumed the waste is disposed of via the PEW system. The ANL-W EBR-II scrap contains approximately 1,000 grams of Uranium.

Cost:

Dissolution of this material (1,000 grams uranium) will require 20 batches through the dissolver.

Estimated time - 2 people full time for two months.

Cost to stabilize: 2 people $\times 40 \mathrm{hrs} / \mathrm{wk}$. $\times 8 \mathrm{wks} \times \$ 67 / \mathrm{hr}=\$ \mathbf{4 2 , 8 8 0}$

Total Cost for Option 3 stabilize, order drums, repackage, ship to Y-12= $\$ 70,700$ (see option 2$)+\$ 42,880=\underline{\$ 113,580}$

Schedule: $\quad 8$ weeks to stabilize material

4 months for planning and preparations

2 months to develop procedure and QA drums

1 week to inventory and ship

\section{Total Duration for Option $3=\underline{\underline{8 \text { months }}}$}

Comments: No detailed cost estimates were performed for this option. The Primavera generated detailed resources, cost data and scheduled activities for dissolution of the Denitrator Product is shown as option 3 and 4 for the Denitrator Product in this appendix.

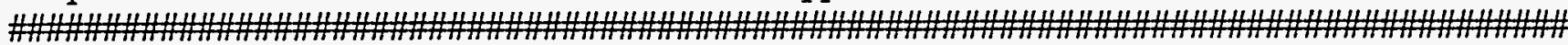

ANL-E Hot Cell Explosion Scrap

Option 1 (Ship to ANL-W)

Cost:

Cost for Planning and preparations $=\$ \mathbf{1 8 , 0 0 0}$

Cost for Procedure Preparation $=\$ \mathbf{\$ 1 5 , 5 0 0}$

Cost to perform radiation surveys, inspect and $\mathrm{QA}$ drum $=\mathbf{\$ 3 , 8 0 0}$

Cost to Ship to ANL-W $=\mathbf{\$ 1 1 , 5 0 0}$

Total Cost for Option 1 (Base Case) =

$\$ 18,000+\$ 15,500+\$ 3,800+\$ 11,500=\underline{\mathbf{\$ 4 8 , 8 0 0}}$ 
Schedule: 2 months for planning and preparations

2 months to develop procedure and QA drums

1 week to inventory and ship

\title{
Total Duration for Option 1 (Base Case) $=\underline{\underline{4 \text { months }}}$
}

Comments: The Primavera generated Base Case detailed resources, cost data and scheduled activities for this option is shown in Appendix C and D of this report.

\section{ANL-E Hot Cell Explosion Scrap \\ Option 2 (ICPP Stabilization to Uranium Oxide, repackage, ship to Y-12)}

Assumed a small lab scale set-up is used that consists of a 10 liter dissolver. The dissolver can process approximately 50 grams of uranium per batch. Assumed the waste is disposed of via the PEW system. The ANL-E Hot Cell Explosion scrap contains approximately 1,000 grams of uranium.

Cost:

Dissolution of this material (1000 grams uranium) will require 20 batches through the dissolver. Estimated time - 2 people full time for two months.

Cost to stabilize: 2 people $\times 40 \mathrm{hrs} / \mathrm{wk}$. $\times 8 \mathrm{wks} \times \$ 67 / \mathrm{hr}=\$ 42,880$

Total Cost for Option 2 to stabilize, repackage, ship to $\mathrm{Y}-12=$ $\$ 52,020$ (see option 3) $+\$ 42,880=\underline{\$ 94,900}$

Schedule: $\quad 8$ weeks to stabilize material

2 months for planning and preparations

2 months to develop procedure and QA drums

1 week to repackage and ship

\section{Total Duration for Option $2=\underline{\underline{6 \text { months }}}$}

Comments: No detailed cost estimates were performed for this option. The Primavera generated detailed resources, cost data and scheduled activities for dissolution of the Denitrator Product is shown as option 3 and 4 for the Denitrator Product in this appendix.

\author{
ANL-E Hot Cell Explosion Scrap \\ Option 3 (Repackage and ship to Y-12) \\ Cost: \\ Cost for Planning and preparations $=\$ \mathbf{1 8 , 0 0 0}$ \\ Cost for Procedure Preparation $=\mathbf{\$ 1 5 , 5 0 0}$
}


Cost to perform radiation surveys, inspect and QA drum $=\$ \mathbf{3 , 8 0 0}$

Cost to repackage and ship to $\mathrm{Y}-12=\$ 14,720$

\section{Total Cost for Option $3=$}

$$
\$ 18,000+\$ 15,500+\$ 3,800+\$ 14,720=\underline{\mathbf{5 2 , 0 2 0}}
$$

Schedule: $\quad 2$ months for planning and preparations

2 months to develop procedure and QA drums

1 week to repackage and ship

\section{Total Duration for Option $3=\underline{\underline{4 \text { months }}}$}

Comments: The characterization data showed that the material did not meet the Y-12 acceptance criteria therefore the material will be sent to ANL-W. No detailed cost estimates were performed for this option.

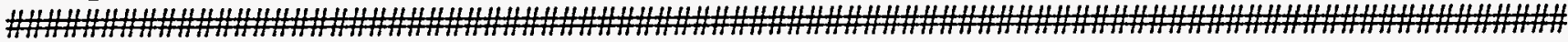

Rocky Flats

Option 1 (Repackage and ship as HEU to SRS)

Cost:

Cost for planning and preparations (Project Definition and S\&S plans) $=\$ 16,344$

Cost to QA drums $=\$ \$ 3,186$

Cost for Procedure Preparation and Training $=\mathbf{\$ 1 9 , 8 0 0}$

Cost to Repackage in CPP-651 and Ship $=\$ \mathbf{2 4 , 2 0 3}$

Total Cost for Option $1=\$ 16,344+\$ 3,186+\$ 19,800+\$ 24,203=\underline{\underline{\mathbf{6 3 3}, 533}}$

Schedule: $\quad 2$ months for planning and preparations

2 months to develop procedures, train and QA drums

1 week to repackage and ship

Total Duration for Option $1=\underline{\underline{4 \text { months }}}$

Comments: See attached Primavera generated detailed resources, cost data and scheduled activities for this option. 


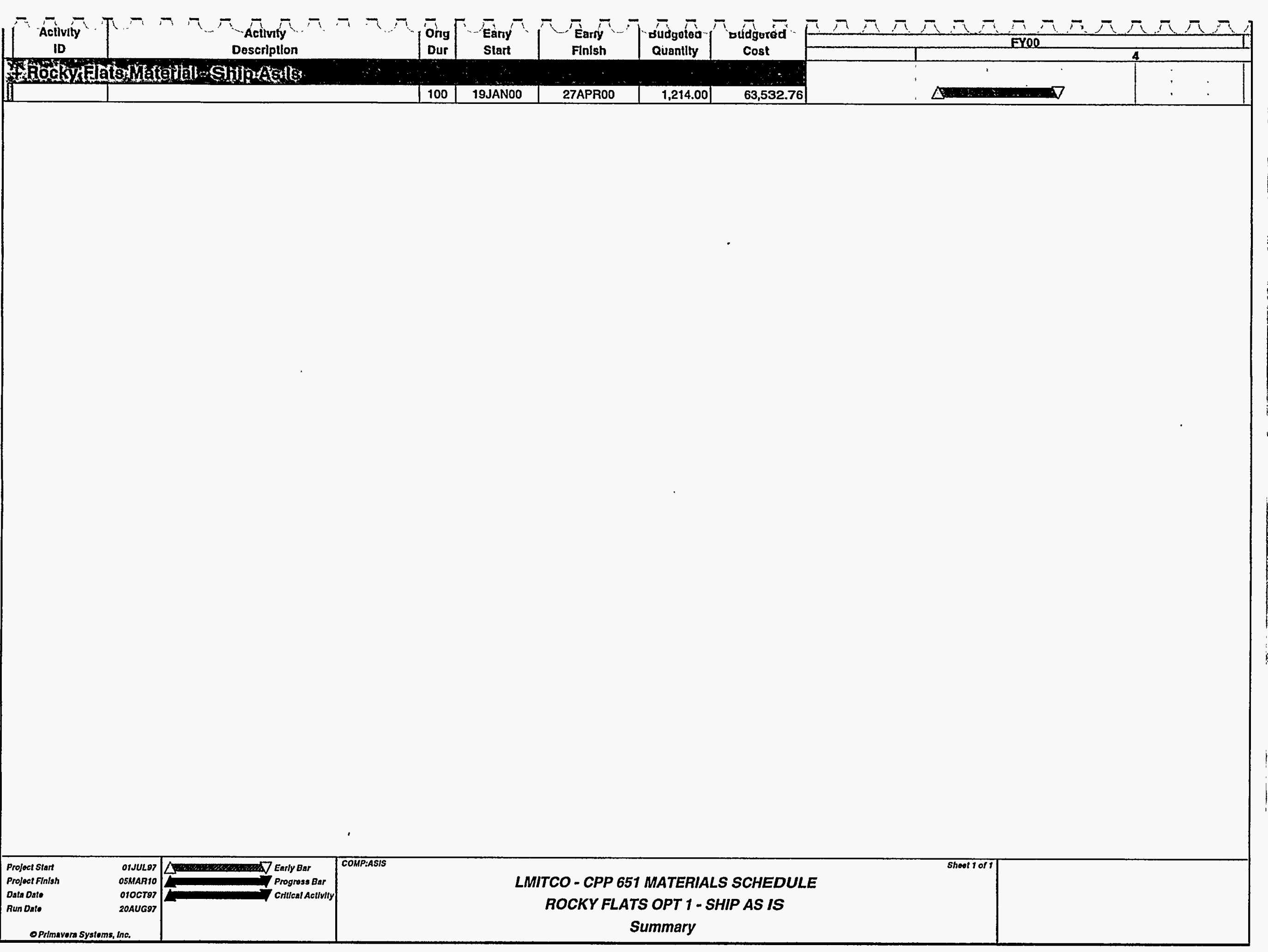




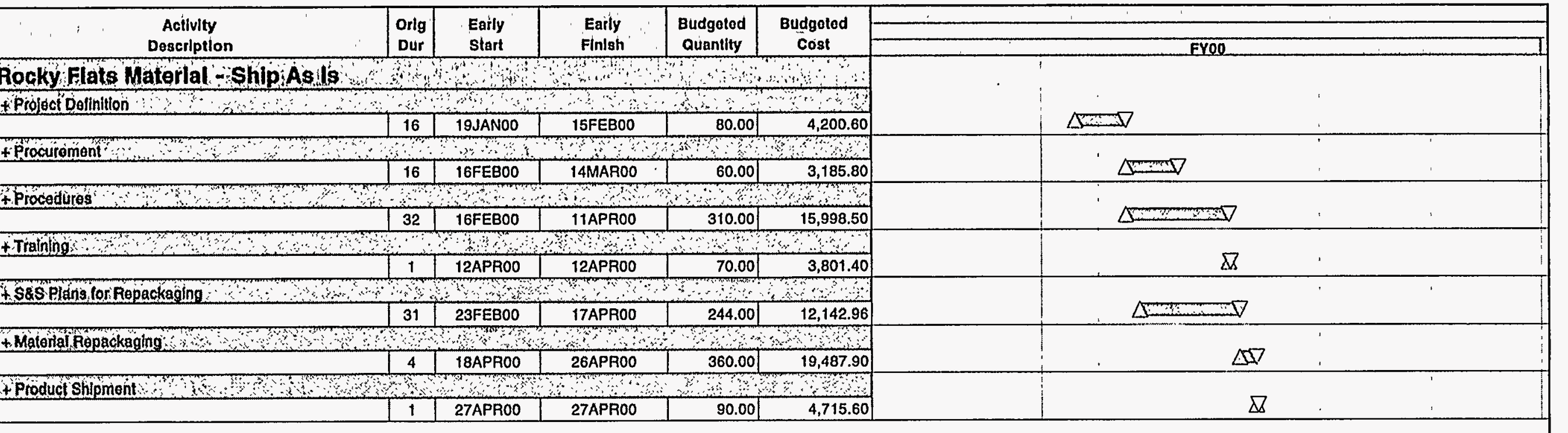


PRIMAVERA PROJECT PLANNER

16:46

st load by resource type
COST LOADING REPORT

RUN NO. 487

TOTAL USAGE FOR YEAR
CURRENT FUNDING -SHIP AS IS SCENARIO

START DATE 01JUL97 FIN DATE 30JAN09

DATA DATE $010 \mathrm{CT} 97$ PAGE NO. 1

\begin{tabular}{llrr}
\hline & & & \\
ESOURCE & RESOURCE DESCRIPTION & $\mathbf{2 0 0 0}$ & TOTAL \\
\hline & & & \\
341E140 & Radiological Engineer & 1216 & 1216 \\
342T050 & Radiological Technician & 1975 & 1975 \\
420E110 & Quality Engineer & 513 & 513 \\
420T060 & Quality Inspector & 1538 & 1538 \\
280P170 & Transporation Coordinator & 2708 & 2708 \\
110E130 & Other/Technical Engineer & 781 & 781 \\
112M010 & CPP 651 Operations Foreman & 1038 & 1038 \\
112R040 & CPP 651 Fuel Operators & 14008 & 14008 \\
113E080 & Facility Fuel Engineer & 13281 & 13281 \\
130P130 & Trainer & 1500 & 1500 \\
152P160 & Procedure Writer & 4128 & 4128 \\
221E010 & Technical Safety Engineer (TSE) & 709 & 709 \\
432E130 & Plant Systems Engineer & 1207 & 1207 \\
100E130 & Security Operations & 604 & 604 \\
120P170 & Safeguards \& Accountability & 16421 & 16421 \\
520R080 & Equipment Operator & 1906 & 1906 \\
\hline & REPORT TOTAL & 63533 & 63533
\end{tabular}




\begin{tabular}{|c|c|c|c|}
\hline RESOURCE & RESOURCE DESCRIPTION & $\begin{array}{r}F Y \\
2000 \\
\end{array}$ & TOTAL \\
\hline $1341 \mathrm{E} 140$ & Radioloqical Enqineer & 36 & 36 \\
\hline 1342T050 & Radiological Technician & 70 & 70 \\
\hline 1420E110 & Quality Engineer & 26 & 26 \\
\hline 1420T060 & Quality Inspector & 40 & 40 \\
\hline $3280 \mathrm{P} 170$ & Transporation Coordinator & 108 & 108 \\
\hline $4110 \mathrm{E} 130$ & Other/Technical Engineer & 30 & 30 \\
\hline $5100 \mathrm{M} 6$ & Direct Purchases & & \\
\hline $5100 M 8$ & Subcontracts & & \\
\hline $5112 \mathrm{M} 010$ & CPP 651 Operations Foreman & 108 & 108 \\
\hline $5112 R 040$ & CPP 651 Fuel Operators & 690 & 690 \\
\hline 5113E080 & Facility Fuel Engineer & 528 & 528 \\
\hline $5122 \mathrm{E} 130$ & Design Engineer & & \\
\hline $5130 P 130$ & Trainer & 66 & 66 \\
\hline $5152 P 160$ & Procedure Writer & 216 & 216 \\
\hline 5213R040 & CPP 602 Fuel Operators & & \\
\hline $5221 E 010$ & Technical Safety Engineer (TSE) & 26 & 26 \\
\hline $5432 E_{130}$ & Plant Systems Engineer & 40 & 40 \\
\hline $6100 \mathrm{E} 130$ & Security Operations & 26 & 26 \\
\hline $6120 P 170$ & Safeguards \& Accountability & 602 & 602 \\
\hline $6520 \mathrm{C040}$ & Machinist & & \\
\hline $6520 C 110$ & Welder & & \\
\hline $6520 \mathrm{M} 010$ & Craft Foreman & & \\
\hline \multirow[t]{2}{*}{ 6520R080 } & Equipment Operator & 90 & 90 \\
\hline & REPORT TOTAL & 2703 & 2703 \\
\hline
\end{tabular}




\section{Rocky Flats}

Option 2 (Stabilize to oxide and extract in RAL, ship as liquid to $\mathrm{Y}-12$ )

Cost:

Cost for planning and preparations (Project Definition and S\&S plans) $=\$ \mathbf{5 3 , 4 7 6}$

Cost for Documentation (SAR, etc. $)=\$ \mathbf{8 0 , 9 5 5}$

Cost for Procedure Preparation and Training $=\$ \mathbf{3 3 , 5 0 0}$

Cost to Repackage in CPP-651 and Ship $=\$ 66,498$

Total Cost for Option $2=\$ 53,476+\$ 80,955+\$ 33,500+\$ 66,498=\underline{\mathbf{\$ 2 3 4 , 4 2 9}}$

Schedule: $\quad 7$ months for planning and preparations

6 months for documentation, procedures and training

1 month to repackage and ship

Total Duration for Option $2=\underline{\underline{14} \text { months }}$

Comments: See attached Primavera generated detailed resources, cost data and scheduled activities for this option. 


\section{SHILITIDVH DNILSIX' DNISA GIOOIT

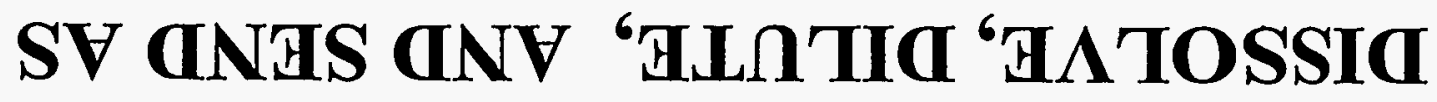
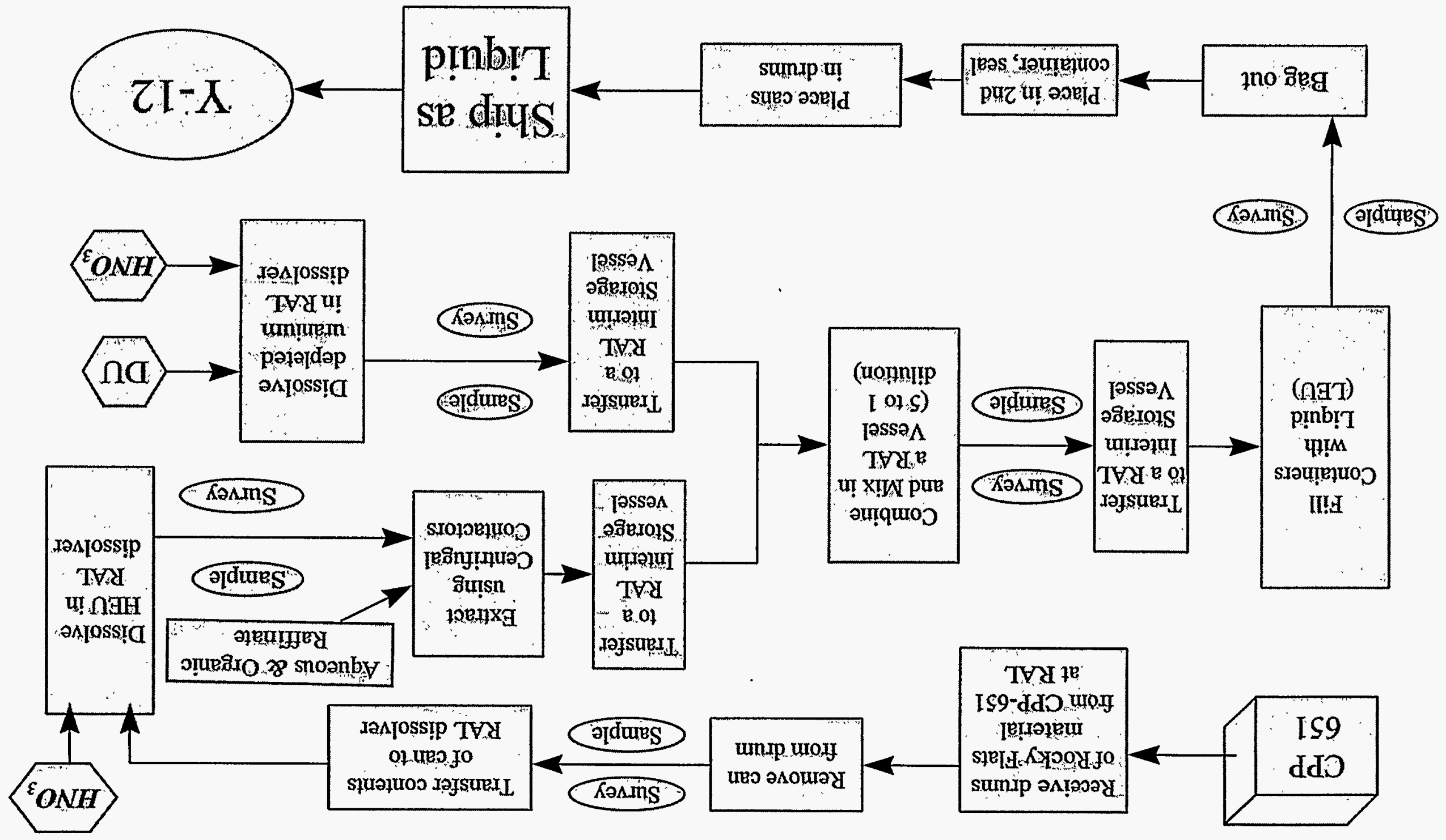


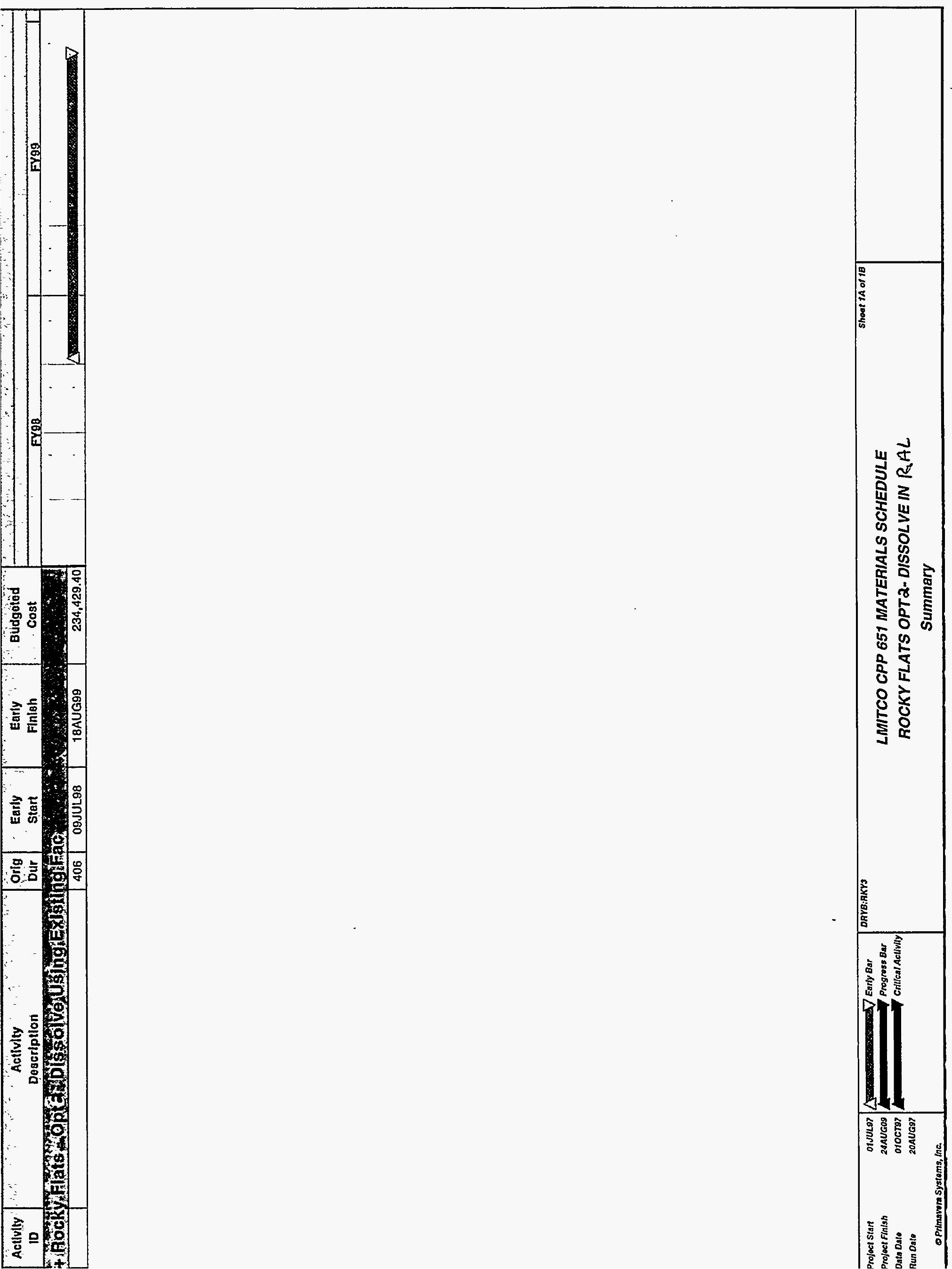




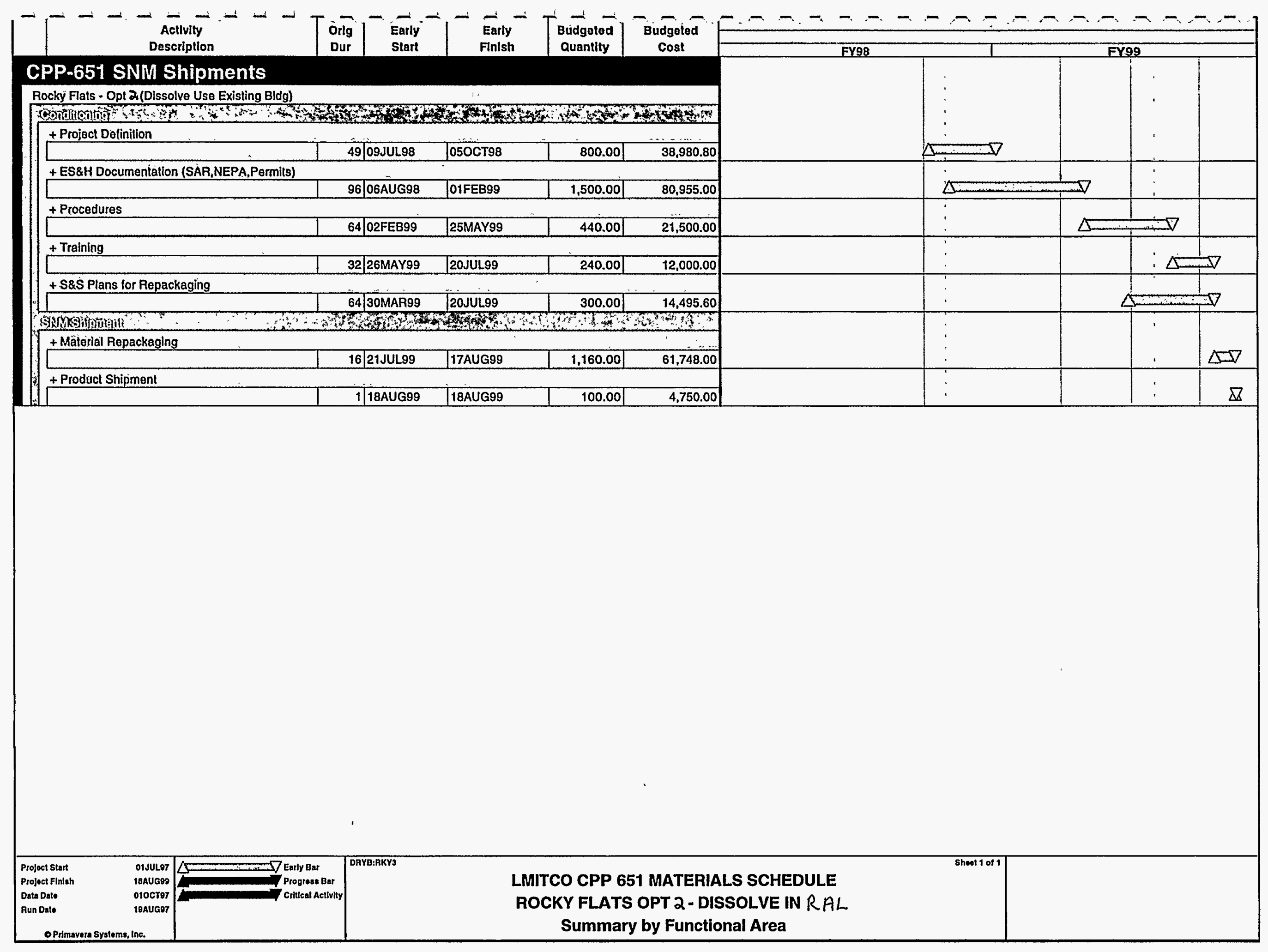




\section{LMITCO}

REPORT DATE 19AUG97 RUN NO. 328

16:16

Costs by Resource by Material Type
PRIMAVERA PROJECT PLANNER

COST LOADING REPORT

TOTAL USAGE FOR YEAR
CPP 651 Rocky Flats Matl Opt 2

START DATE 01JUL97 FIN DATE 18AUG99

DATA DATE 010 TT97 PAGE NO. 1

\begin{tabular}{|c|c|c|c|c|}
\hline RESOURCE & RESOURCE DESCRIPTION & $\begin{array}{r}F Y \\
1998 \\
\end{array}$ & $\begin{array}{r}F Y \\
1999\end{array}$ & TOTAL \\
\hline $1341 \mathrm{E} 140$ & Radiological Engineer & 5813 & 1188 & 7000 \\
\hline 1342 T050 & Radiological Technician & 5813 & 10064 & 15876 \\
\hline 1420E110 & Quality Engineer & & 1000 & 1000 \\
\hline $1710 \mathrm{P} 170$ & Environmental Engineer & 4448 & 9327 & 13775 \\
\hline $3280 \mathrm{P} 170$ & Transporation Coordinator & 1000 & 500 & 1500 \\
\hline 4110 E010 & Safety Analyst & 8073 & 16927 & 25000 \\
\hline $4110 \mathrm{E} 120$ & Criticality Safety Engineer & 8073 & 16927 & 25000 \\
\hline $4110 \mathrm{E} 130$ & Other/Technical Engineer & & 6000 & 6000 \\
\hline 41E1R010 & RAL Technician & 5813 & 188 & 6000 \\
\hline $5110 \mathrm{M020}$ & Fuel Manager & 5548 & 11632 & 17180 \\
\hline $5112 R 040$ & CPP 651 Fuel Operators & & 11000 & 11000 \\
\hline 5113E080 & Facility Fuel Engineer & 6813 & 32921 & 39733 \\
\hline $5130 \mathrm{P} 130$ & Trainer & & 5000 & 5000 \\
\hline $5152 P 160$ & Procedure Writer & & 3600 & 3600 \\
\hline 5213R040 & CPP 602 Fuel Operators & & 16602 & 16602 \\
\hline $5221 \mathrm{E} 010$ & Technical Safety Engineer (TSE) & & 1000 & 1000 \\
\hline $6100 E 130$ & Security Operations & & 2700 & 2700 \\
\hline $6120 P 170$ & Safeguards \& Accountability & 12688 & 20976 & 33664 \\
\hline $6520 \mathrm{MO} 10$ & Craft Foreman & & 2000 & 2000 \\
\hline \multirow[t]{2}{*}{$6520 R 080$} & Equipment Operator & & 800 & 800 \\
\hline & REPOAT TOTAL & 64079 & 170350 & 234429 \\
\hline
\end{tabular}




\begin{tabular}{|c|c|c|c|c|c|}
\hline ESOURCE & RESOURCE DESCRIPTION & $\begin{array}{r}F Y \\
1997 \\
\end{array}$ & $\begin{array}{r}F Y \\
1998\end{array}$ & $\begin{array}{r}F Y \\
1999 \\
\end{array}$ & TOTAL \\
\hline 341E140 & Radlological Engineer & & 116 & 24 & 140 \\
\hline З42T050 & Radiological Technician & & 116 & 204 & 320 \\
\hline $420 \mathrm{E} 110$ & Quality Engineer & & & 20 & 20 \\
\hline $710 \mathrm{P} 170$ & Environmental Engineer & & 81 & 169 & 250 \\
\hline $3280 P 170$ & Transporation Coordinator & & 20 & 10 & 30 \\
\hline $1110 E 010$ & Safety Analyst & & 161 & 339 & 500 \\
\hline $1110 \mathrm{E} 120$ & Criticality Safety Engineer & & 161 & 339 & 500 \\
\hline $1110 \mathrm{E} 130$ & Other/Technical Engineer & & & 120 & 120 \\
\hline IIE1R010 & RAL Technician & & 116 & 4 & 120 \\
\hline$\$ 110 \mathrm{M} 020$ & Fuel Manager & & 81 & 169 & 250 \\
\hline$\$ 112 R 040$ & CPP 651 Fuel Operators & & & 220 & 220 \\
\hline $1113 E 080$ & Facility Fuel Engineer & & 136 & 584 & 720 \\
\hline $130 P 130$ & Trainer & & & 100 & 100 \\
\hline $152 P 160$ & Procedure Writer & & & 80 & 80 \\
\hline $213 R 040$ & CPP 602 Fuel Operators & & & 320 & 320 \\
\hline ¿221E010 & Technical Safety Engineer (TSE) & & & 20 & 20 \\
\hline $100 E 130$ & Security Operations & & & 60 & 60 \\
\hline \multirow{4}{*}{$\begin{array}{l}520 \mathrm{P} 170 \\
520 \mathrm{AO} 080\end{array}$} & Safeguards \& Accountability & & 274 & 436 & 710 \\
\hline & \multirow{3}{*}{$\begin{array}{l}\text { Craft Foreman } \\
\text { Equipment Operator } \\
\text { REPORT TOTAL. }\end{array}$} & & & 40 & 40 \\
\hline & & & & 20 & 20 \\
\hline & & & 1263 & 3277 & $\mathbf{4 5 4 0}$ \\
\hline
\end{tabular}




\section{Rocky Flats}

Option 3 (Stabilize to oxide and extract in a new building, ship as liquid to Y-12)

Cost:

Cost for planning and preparations (Project Definition and $S \& S$ plans) $=\$ 47,800$

Cost for procurement $=\$ \mathbf{3 0 7 , 9 0 0}$

Cost for Documentation (SAR, etc.) $=\mathbf{\$ 5 0 , 0 0 0}$

Cost for Procedure Preparation and Training $=\$ \mathbf{\$ 1 9 0 , 3 0 0}$

Cost to package in CPP-651 and Ship $=\$ \mathbf{9 9 , 5 0 0}$

Total Cost for Option $3=$

$\$ 47,800+\$ 307,900+\$ 50,000+\$ 190,300+\$ 9,500=\underline{\underline{\$ 605,500}}$

Schedule: $\quad 8$ months for planning, preparations and procurement

6 months for documentation, procedures and training

1 weeks to repackage and ship

Total Duration for Option $3=\underline{\underline{15} \text { months }}$

Comments: See attached Primavera generated detailed resources, cost data and scheduled activities for this option. 


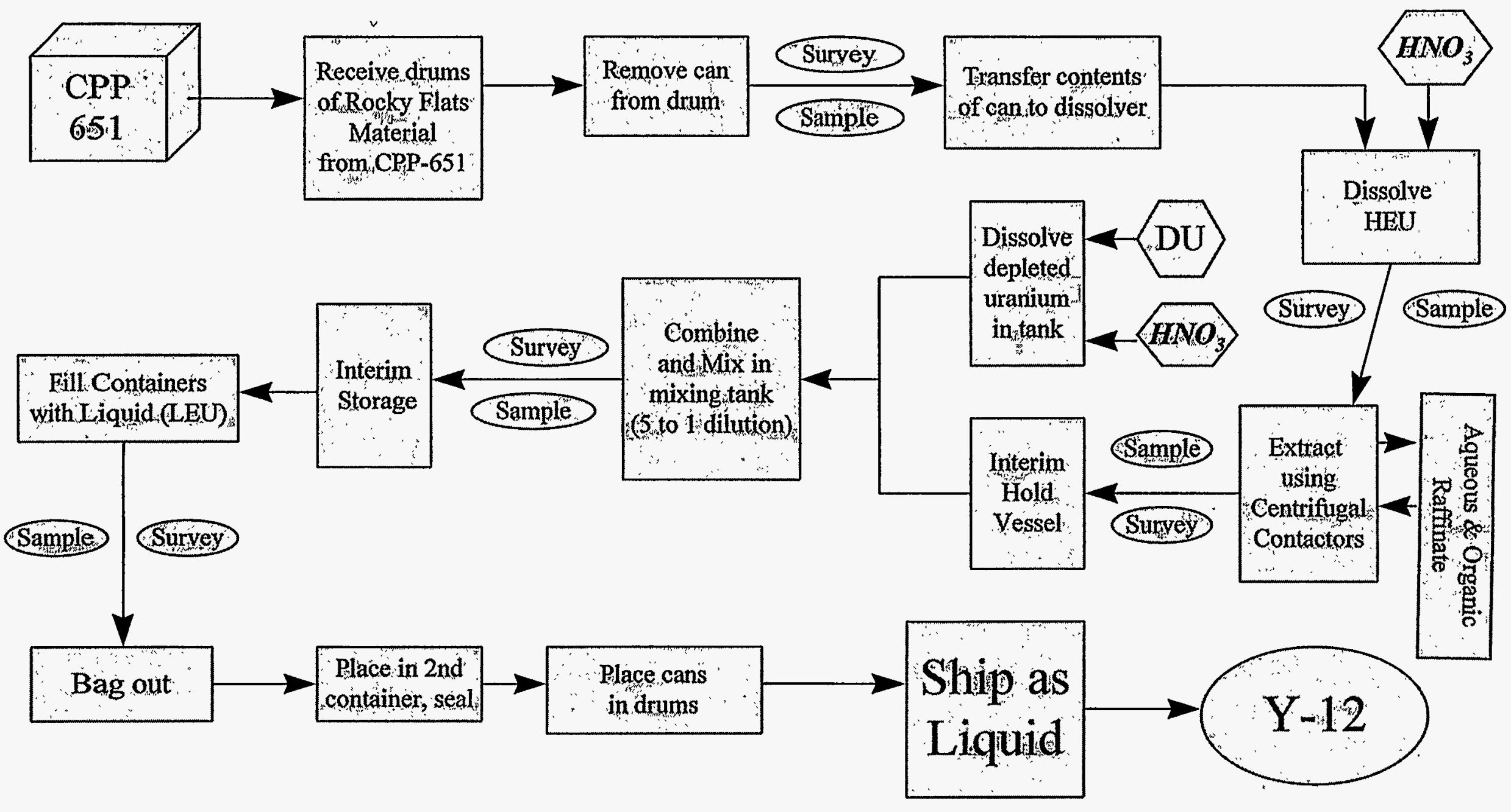

\section{DISSOLVE, EXTRACT, DILUTE, AND SEND AS LIQUID USING NEW FACILITY}




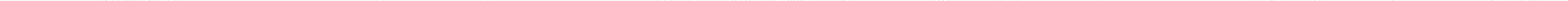




\begin{tabular}{|c|c|c|c|c|}
\hline ESOURCE & RESOURCE DESCRIPTION & $\begin{array}{r}F Y \\
1998 \\
\end{array}$ & $\begin{array}{r}F Y \\
1999 \\
\end{array}$ & TOTAL \\
\hline $341 \mathrm{E} 140$ & Radiological Engineer & 120 & 20 & 140 \\
\hline 342 T050 & Radiological Technician & 120 & 400 & 520 \\
\hline 420E110 & Quality Engineer & 16 & 44 & 60 \\
\hline 420T060 & Quality Inspector & & 10 & 10 \\
\hline $280 P 170$ & Transporation Coordinator & 20 & 44 & 64 \\
\hline 110E010 & Safety Analyst & 161 & 339 & 500 \\
\hline $10 E 120$ & Criticality Safety Engineer & 161 & 339 & 500 \\
\hline $10 E 130$ & Other/Technical Engineer & & 120 & 120 \\
\hline IE1R010 & RAL Technician & 120 & & 120 \\
\hline 100M6 & Direct Purchases & & & \\
\hline $112 \mathrm{R0} 040$ & CPP 651 Fuel Operators & & 2180 & 2180 \\
\hline $5113 E 080$ & Facility Fuel Engineer & 173 & 928 & 1100 \\
\hline $5130 \mathrm{P} 130$ & Trainer & & 100 & 100 \\
\hline $5152 P 160$ & Procedure Writer & & 80 & 80 \\
\hline $5221 E 010$ & Technical Safety Engineer (TSE) & & 20 & 20 \\
\hline $3432 E 130$ & Plant Systems Engineer & & 20 & 20 \\
\hline $3100 \mathrm{E} 130$ & Security Operations & & 60 & 60 \\
\hline$\$ 120 \mathrm{P} 170$ & Safeguards \& Accountability & 200 & 300 & 500 \\
\hline $520 \mathrm{M010}$ & Craft Foreman & & 40 & 40 \\
\hline \multirow[t]{2}{*}{$3520 R 080$} & \multirow{2}{*}{$\begin{array}{l}\text { Equipment Operator } \\
\text { REPORT TOTAL }\end{array}$} & & 50 & 50 \\
\hline & & 1092 & 5092 & 6184 \\
\hline
\end{tabular}


COST LOADING REPORT

START DATE 01JUL97 FIN DATE 24AUG09 09:21

Costs by Resource by Material Type
TOTAL USAGE FOR YEAR

\begin{tabular}{|c|c|c|c|c|}
\hline RESOURCE & RESOURCE DESCRIPTION & $\begin{array}{r}F Y \\
1998 \\
\end{array}$ & $\begin{array}{r}F Y \\
1999 \\
\end{array}$ & TOTAL \\
\hline 1341E140 & Radiological Engineer & 6000 & 1000 & 7000 \\
\hline 1342T050 & Radiological Technician & 6000 & 20000 & 26000 \\
\hline $1420 \mathrm{E} 110$ & Quality Engineer & 813 & 2188 & 3000 \\
\hline 1420T060 & Quality Inspector & & 500 & 500 \\
\hline $3280 \mathrm{P} 170$ & Transporation Coordinator & 1000 & 2200 & 3200 \\
\hline $4110 E 010$ & Safety Analyst & 8073 & 16927 & 25000 \\
\hline $4110 \mathrm{E} 120$ & Criticality Safety Engineer & 8073 & 16927 & 25000 \\
\hline $4110 \mathrm{E} 130$ & Other/Technical Engineer & & 6000 & 6000 \\
\hline 41E1R010 & RAL Technician & 6000 & & 6000 \\
\hline $5100 \mathrm{M} 6$ & Direct Purchases & 121875 & 178125 & 300000 \\
\hline $5112 R 040$ & CPP 651 Fuel Operators & & 109000 & 109000 \\
\hline $5113 E 080$ & Facility Fuel Engineer & 8625 & 46375 & 55000 \\
\hline $5130 P 130$ & Trainer & & 5000 & 5000 \\
\hline $5152 P 160$ & Procedure Writer & & 3600 & 3600 \\
\hline 5221E010 & Technical Safety Engineer (TSE) & & 1000 & 1000 \\
\hline 5432E130 & Plant Systems Engineer & & 1000 & 1000 \\
\hline $6100 E 130$ & Security Operations & & 2700 & 2700 \\
\hline $6120 P 170$ & Safeguards \& Accountability & 9000 & 13500 & 22500 \\
\hline 6520M010 & Craft Foreman & & 2000 & 2000 \\
\hline \multirow[t]{2}{*}{ 6520R080 } & Equipment Operator & & 2000 & 2000 \\
\hline & REPORT TOTAL & & 430042 & 605500 \\
\hline
\end{tabular}




\section{Rocky Flats}

Option 4 (Dry blend to less than 20\% enrichment, repackage, ship to SRS)

- Assumed a 5 to 1 dilution is used to reduce the enrichment to less than $20 \%$.

- Assumes process initiation costs are incurred within the denitrator product estimate

Cost:

Revise Procedures - 8 weeks

2 people $\times \$ 65 /$ hour $\times 10 \mathrm{hr} /$ day $\times 16$ days $/ \mathrm{mo} \times 2 \mathrm{mo}=$

$\$ 41,600$

Revise SAR and Technical Standards - OSA - 36 weeks

1 person $\times \$ 65 / \mathrm{hr} \times 40 \mathrm{hr} / \mathrm{wk} \times 36$ weeks $=$

$\$ 93,600$

Cost to Procure Drum(s)

up-front $=\quad \$ 135,200$

$\$ 600$ per 55 gallon drum $\times 150$ drums $=\$ 90,000$

Cost for Planning and preparations $=\$ \mathbf{3 5 , 7 0 0}$

Dry blend 30 bottles into 150 cans ( 1 per drum) in CPP-651 and ship to SRS

assumes process initiation costs are incurred within the denitrator product estimate

1 Technical Shift Engineer at $\$ 65 /$ hour

1 Radcon Technician at $\$ 49 /$ hour

1 Supervisor at $\$ 52 /$ hour

3 Operators at $\$ 52 /$ hour

8 hours worth of work in a 10 hour shift. Work 410 hour shifts per week. Estimate repackaging 15 bottles of HEU per day. Will repackage one bottle every $1 / 2$ hour. Blending and repackaging a total of 30 bottles of Rocky Flats material to fit into $1506 \mathrm{M}$ drums of LEU.

10 days (to repackage 4 bottles at 15 new bottles per day) $\times 10$ hrs/day $=100$ hours

$(\$ 65 / \mathrm{hr} \times 100 \mathrm{hrs})+(\$ 49 / \mathrm{hr} \times 100 \mathrm{hrs})+(\$ 52 \times 4 \times 100$ hours $)=$

$$
\$ 6,500+\$ 4,900+\$ 20,800=\$ 32,200
$$

Guards on average have cost $\$ 80,000$ per month (assume $\$ 5,000$ per day)

Assume we need 10 days $=\mathbf{\$ 5 0 , 0 0 0}$

Cost to repackage \& ship each drum in CPP-651:

10 hour days at 15 drums per day $=.67$ hours per drum

3 Operators $=.67$ laborhrs $/$ drum $\times 3 \times \$ 52 / \mathrm{hr}=\$ 110 / \mathrm{drum}$

2 Foreman/Supervisor $=.67$ laborhrs $/$ drum $\times 2 \times \$ 52 / \mathrm{hr}=\$ 70 / \mathrm{drum}$

1 Engineer $/$ Scientist $=.67 \mathrm{laborhrs} / \mathrm{drum} \times \$ 67 / \mathrm{hr}=\quad \$ 50 / \mathrm{drum}$

1 Radcon Tech $=.67$ laborhrs $/ \mathrm{drum} \times \$ 49 / \mathrm{hr}=\quad \$ 40 / \mathrm{drum}$

Total

$\$ 270 /$ drum $\times 150$ drums $=\$ \mathbf{4 0 , 5 0 0}$ 
Total Cost for Option $4=\$ 135,200+\$ 90,000+\$ 35,700+\$ 32,200+\$ 50,000$ $+\$ 40,500+\$ 30,000=\underline{\$ 413,600}$

Schedule: $\quad 6$ months to procure 55 gallon, $6 \mathrm{M}$ drums

6 months for planning, SAR changes and preparations

2 months to develop procedures and QA drums

2 weeks to dry blend and repackage in CPP-651

1 week to ship

\section{Total Duration for Option $4=\underline{\underline{15} \text { months }}$}

Comments: No detailed cost estimates were performed for this option. The Primavera generated detailed resources, cost data and scheduled activities for dry blending the Denitrator Product is shown as option 1 for the Denitrator Product in this appendix.

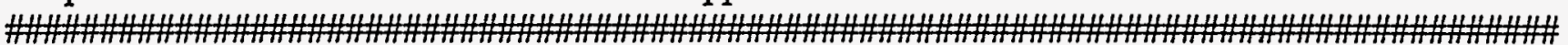

Denitrator Product

Option 1 (Dry Blend to less than 20\%, repackage and ship to SRS)

Cost:

Cost for planning and preparations (Project Definition and S\&S plans) $=\$ \mathbf{1 , 0 3 2 , 8 9 5}$

Cost for procurement $=\$ \mathbf{1 , 8 0 8 , 0 0 0}$

Cost for ES\&H documentation $(\mathrm{SAR})=\mathbf{\$ 2 5 7 , 1 5 4}$

Cost for Procedure Preparation and Training $=\mathbf{\$ 8 4 , 5 0 0}$

Cost to Dry Blend, Repackage and Ship $=\$ \mathbf{\$ 1 , 4 3 8 , 6 0 3}$

\section{Total Cost for Option $1=$}

$$
\$ 1,032,895+\$ 1,808,000+\$ 257,154+\$ 84,500+\$ 1,438,603=\underline{\mathbf{\$ 4 , 6 2 1 , 1 5 2}}
$$

Schedule: $\quad 26$ months for planning, SAR changes and preparations

6 months for procurement

8 months to develop procedures and train

32 months to dry blend, repackage and ship

\section{Total Duration for Option $1=\underline{\underline{72} \text { months (6 years) }}$}

Comments: See attached Primavera generated detailed resources, cost data and scheduled activities for this option. 


\section{Denitrator Product - Option 1}

\section{Assumption to Mill and Dry Blend}

Each can (drum) of product will result in 5 cans (drums) of blended product. Therefore the volume will grow by a factor of 5 .

This process will be contained within an enclosure which has a self contained ventilation and filter system. The enclosure will be similar to the personal containment (Permacon) structures that have been used at ICPP.

The enclosure will be placed within the CPP-651, North vault.

Shielding will be incorporated in the design of the process and the enclosure.

One can of Denitrator product will be processed per 12 hour shift.

Dry Blended Denitrator Product will be contained within dissolvable cans.

It will take approximately $2 \frac{1}{2}$ years to process all ( 276 cans) of the material.

The Rocky Flats material will not be dry blended. 


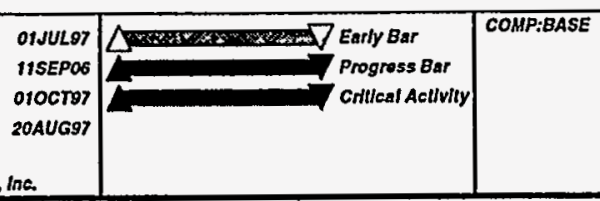

LMITCO - CPP 651 MATERIALS SCHEDULE DENITRATOR OPT 1 - DRY BLENDING Summary 


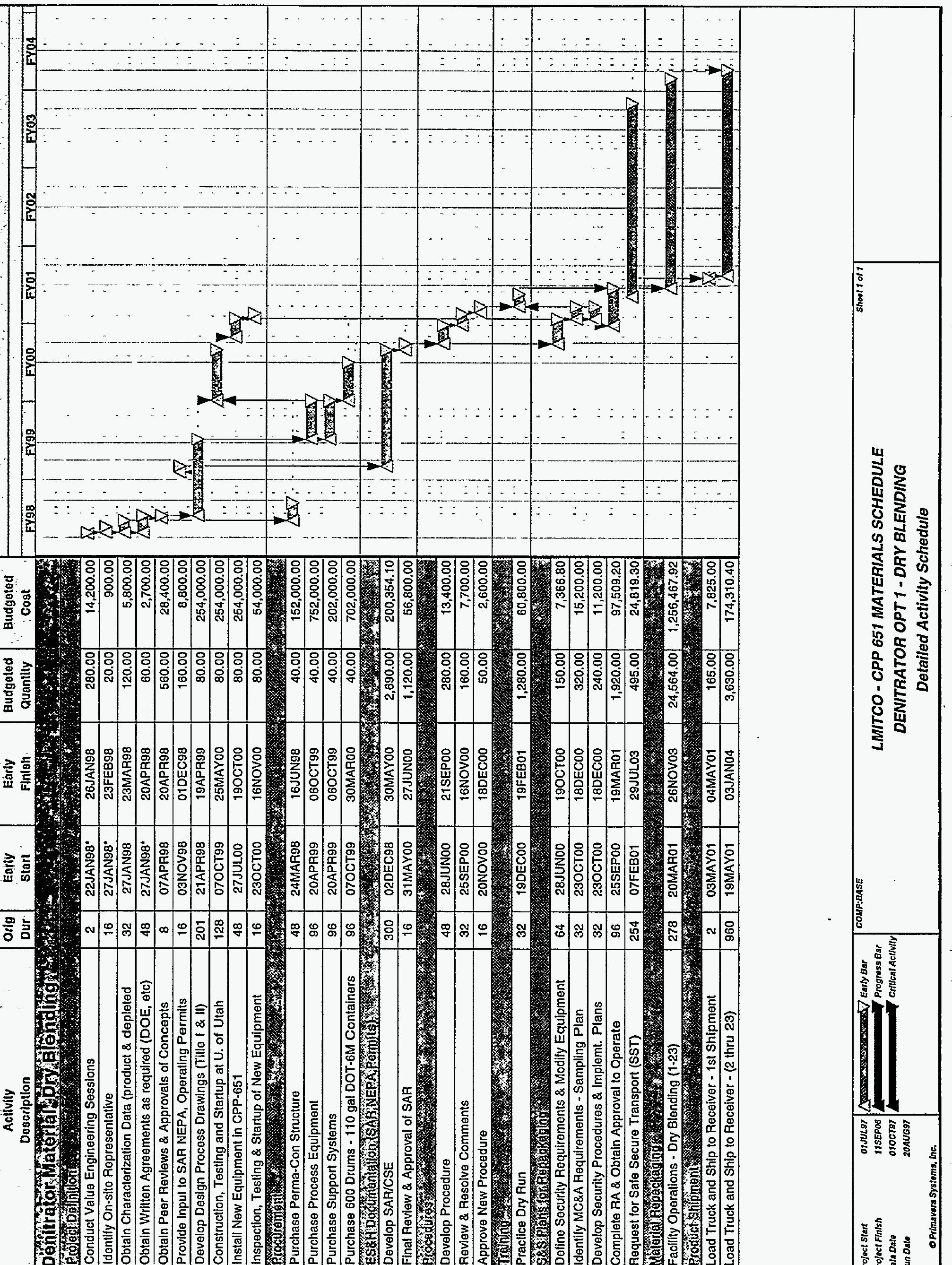


LMITCO - CPP 651 MATERIAL SCHEDULE

REPORT DATE 20AUG97 RUN NO. 486

10:27
PRIMAVERA PROJECT PLANNER

COST LOADING REPORT

TOTAL USAGE FOR YEAR
BASE CASE SCHEDULE - DAY BLENDING

START DATE 01JUL97 FIN DATE 11SEP06

DATA DATE $010 \mathrm{CT} 97$ PAGE NO. 1

\begin{tabular}{|c|c|c|c|c|c|c|c|c|c|}
\hline RESOURCE & RESOURCE DESCRIPTION & $\begin{array}{r}F Y \\
1998 \\
\end{array}$ & $\begin{array}{r}F Y \\
1999 \\
\end{array}$ & $\begin{array}{r}F Y \\
2000 \\
\end{array}$ & $\begin{array}{r}F Y \\
2001 \\
\end{array}$ & $\begin{array}{r}F Y \\
2002 \\
\end{array}$ & $\begin{array}{r}F Y \\
2003 \\
\end{array}$ & $\begin{array}{r}F Y \\
2004 \\
\end{array}$ & TOTAL \\
\hline $1341 E 140$ & Radiological Engineer & 4000 & & 4581 & 14748 & 6099 & 6280 & 1027 & 36734 \\
\hline 1342T050 & Radiological Technician & & & & 27799 & 50137 & 51626 & 8439 & 138000 \\
\hline 1420E110 & Quality Engineer & 4000 & 1938 & 5354 & 4708 & & & & 16000 \\
\hline $1710 \mathrm{P} 170$ & Environmental Engineer & 4000 & 11257 & 11440 & 3833 & & & & 30530 \\
\hline $3280 E 130$ & Transportation Engineer & & & 167 & 3833 & & & & 4000 \\
\hline $3280 \mathrm{P} 170$ & Transporation Coordinator & 3000 & & 6000 & 12700 & 22451 & 20985 & 3275 & 68412 \\
\hline 4110 E010 & Safety Analyst & 3000 & 78277 & 65504 & & & & & 146781 \\
\hline $4110 \mathrm{E} 120$ & Criticality Safety Engineer & 3000 & 13119 & 14308 & & & & & 30427 \\
\hline 4110E130 & Other/Technical Engineer & 4831 & 2169 & 11167 & 8833 & & & & 27000 \\
\hline 41E1R010 & RAL Technician & 1000 & & & 16679 & 30082 & 30976 & 5063 & 83800 \\
\hline 41E1S010 & RAL Engineer & & & & 13560 & 10027 & 10325 & 1688 & 35600 \\
\hline $5100 \mathrm{M} 4$ & Construction Purchases & & & 437500 & 112500 & & & & 550000 \\
\hline $5100 \mathrm{M} 8$ & Subcontracts & 264428 & 1055885 & 729688 & & & & & 2050000 \\
\hline $5110 \mathrm{MO} 020$ & Fuel Manager & 4200 & 14345 & 14904 & 6067 & & & & 39516 \\
\hline $5112 \mathrm{G} 050$ & Administration Support & & & 2019 & 8056 & & & & 10075 \\
\hline $5112 \mathrm{M} 010$ & CPP 651 Operations Foreman & & & 167 & 34724 & 56204 & 57749 & 9845 & 158689 \\
\hline $5112 \mathrm{RO} 40$ & CPP 651 Fuel Operators & 3000 & & 7150 & 143750 & 229785 & 235966 & 40672 & 660323 \\
\hline 5113E070 & Fuel Supervisor & & & 200 & 4600 & & & & 4800 \\
\hline 5113E080 & Facility Fuel Engineer & 5000 & 3938 & 9229 & 77726 & 58501 & 59990 & 10616 & 225000 \\
\hline 5122E130 & Design Engineer & 3000 & 2000 & 5625 & 375 & & & & 11000 \\
\hline $5130 \mathrm{P} 130$ & Trainer & 3000 & & 4125 & 16875 & & & & 24000 \\
\hline $5152 \mathrm{P} 160$ & Procedure Writer & & & 3713 & 1688 & & & & 5400 \\
\hline $5213 R 040$ & CPP 602 Fuel Operators & 900 & & 113 & 15188 & & & & 16200 \\
\hline 5221E010 & Technical Safety Engineer (TSE) & & & 292 & 4708 & & & & 5000 \\
\hline $5432 E 130$ & Plant Systems Engineer & & & 167 & 3833 & & & & 4000 \\
\hline $6100 \mathrm{E} 130$ & Security Operations & 2700 & & 5325 & 8175 & & & & 16200 \\
\hline $6120 P 170$ & Safeguards \& Accountability & 7200 & & 5732 & 47016 & 51778 & 53260 & 8888 & 173874 \\
\hline $6520 C 020$ & Electrician & & & 422 & 97 & & & & 519 \\
\hline 6520M010 & Craft Foreman & & & 403 & 2140 & 4182 & 4182 & 1089 & 11996 \\
\hline 6520R080 & Equipment Operator & & & & 6550 & 13383 & 13383 & 3483 & 36800 \\
\hline \multirow[t]{2}{*}{ 6520T070 } & Instrument Technician & & & 387 & 89 & & & & 476 \\
\hline & REPORT TOTAL & 320259 & 1182927 & 1345679 & 600851 & 532630 & 544723 & 94084 & 4621153 \\
\hline
\end{tabular}


TOTAL USAGE FOR YEAR

DATA DATE $010 \mathrm{CT} 97$ PAGENO. 1

\begin{tabular}{|c|c|c|c|c|c|c|c|c|c|}
\hline ESOURCE & RESOURCE DESCAIPTION & $\begin{array}{r}F Y \\
1998 \\
\end{array}$ & $\begin{array}{r}F Y \\
1999 \\
\end{array}$ & $\begin{array}{r}F Y \\
2000 \\
\end{array}$ & $\begin{array}{r}F Y \\
2001 \\
\end{array}$ & $\begin{array}{r}F Y \\
2002 \\
\end{array}$ & $\begin{array}{r}F Y \\
2003 \\
\end{array}$ & $\begin{array}{r}F Y \\
2004 \\
\end{array}$ & TOTAL \\
\hline $341 E 140$ & Radiological Engineer & 125 & 40 & 110 & 246 & 100 & 103 & 38 & 762 \\
\hline $342 T 050$ & Radiological Technician & 370 & 70 & 50 & 556 & 1003 & 1033 & 209 & 3290 \\
\hline $420 \mathrm{E} 110$ & Quality Engineer & 100 & 79 & 117 & 94 & & & 26 & 416 \\
\hline 20T060 & Quality Inspector & 40 & 40 & 30 & & & & 60 & 170 \\
\hline 710P170 & Environmental Engineer & 80 & 208 & 215 & 77 & & & & 580 \\
\hline $280 \mathrm{E} 130$ & Transportation Engineer & & & 3 & 77 & & & & 80 \\
\hline $280 P 170$ & Transporation Coordinator & 182 & 112 & 194 & 253 & 448 & 419 & 199 & 1807 \\
\hline $110 \mathrm{E} 010$ & Safety Analyst & 60 & 1002 & 868 & & & & & 1930 \\
\hline 110E120 & Criticality Safety Engineer & 60 & 168 & 212 & & & & & 440 \\
\hline 110E130 & Other/Technical Engineer & 307 & 113 & 233 & 177 & & & 73 & 903 \\
\hline E1R010 & RAL Technician & 20 & & & 334 & 602 & 620 & 101 & 1676 \\
\hline E1S010 & RAL Engineer & & & & 271 & 201 & 207 & 34 & 712 \\
\hline $100 \mathrm{M} 4$ & Construction Purchases & & & & & & & & \\
\hline 100M6 & Direct Purchases & & & & & & & & \\
\hline 100M8 & Subcontracts & & & & & & & & \\
\hline $110 \mathrm{M} 020$ & Fuel Manager & 60 & 208 & 215 & 87 & & & & 570 \\
\hline $112 \mathrm{G} 050$ & Administration Support & & & 41 & 199 & & & & 240 \\
\hline $112 \mathrm{M} 010$ & CPP 651 Operations Foreman & 400 & 130 & 53 & 674 & 1086 & 1116 & 291 & 3750 \\
\hline $112 R 040$ & CPP 651 Fuel Operators & 1740 & 720 & 533 & 2825 & 4429 & 4548 & 1308 & 16104 \\
\hline 13E070 & Fuel Supenvisor & & & 3 & 77 & & & & 80 \\
\hline | 13E080 & Facility Fuel Engineer & 848 & 743 & 467 & 1555 & 1170 & 1200 & 822 & 6804 \\
\hline |22E130 & Design Engineer & 60 & 40 & 113 & 8 & & & 131 & 351 \\
\hline $130 P 130$ & Trainer & 120 & 120 & 113 & 338 & & & 81 & 771 \\
\hline 152P160 & Procedure Writer & 194 & 341 & 184 & 38 & & & 281 & 1037 \\
\hline $213 R 040$ & CPP 602 Fuel Operators & 20 & & 3 & 338 & & & & 360 \\
\hline 221E010 & Technical Safety Engineer (TSE) & 20 & 40 & 16 & 94 & & & 21 & 191 \\
\hline 132E130 & Plant Systems Engineer & 60 & 60 & 23 & 77 & & & 40 & 260 \\
\hline 100E130 & Security Operations & 80 & 40 & 128 & 182 & & & 21 & 451 \\
\hline 20P170 & Safeguards \& Accountability & 1013 & 369 & 485 & 970 & 1045 & 1074 & 1265 & 6220 \\
\hline $320 C 020$ & Electrician & & & 8 & 2 & & & & 10 \\
\hline 5200040 & Machinist & & & & & & & 131 & 131 \\
\hline $520 C 110$ & Welder & & & & & & & 65 & 65 \\
\hline \multirow{4}{*}{$\begin{array}{l}20 \mathrm{M} 010 \\
\text { 220R080 } \\
520 \mathrm{TO} 070\end{array}$} & Craft Foreman & & & 8 & 43 & 84 & 84 & 64 & 283 \\
\hline & Equipment Operator & 100 & 110 & 60 & 164 & 335 & 335 & 187 & 1290 \\
\hline & Instrument Technician & & & 8 & 2 & & & & 10 \\
\hline & REPORT TOTAL & 6058 & $\overline{4753}$ & 4494 & 9752 & 10501 & 10737 & 5448 & 51744 \\
\hline
\end{tabular}




\section{Denitrator Product}

Qption 2(Repackage into DC-1's and ship as HEU to SRS)

Cost:

Cost for planning and preparations (Project Definition and S\&S plans) $=\$ \mathbf{2 8 , 9 3 0}$

Cost to procure drums $=\$ \$ 986,832$

Cost for Procedure Preparation and Training $=\$ 26,904$

Cost to Repackage in CPP-651 and Ship $=\$ 636,765$

Total Cost for Option $2=\$ 28,930+\$ 986,832+\$ 26,904+\$ 636,765=\underline{\mathbf{\$ 1 , 6 7 9 , 4 3 1}}$

Schedule: $\quad 8$ months for planning, SAR changes and preparations

13 months for procurement

5 months to develop procedures and training

10 months to repackage and ship

Total Duration for Option $2=\underline{\underline{36} \text { months }}$

Comments: See attached Primavera generated detailed resources, cost data and scheduled activities for this option. 


\section{Ship as is - Special Drum}
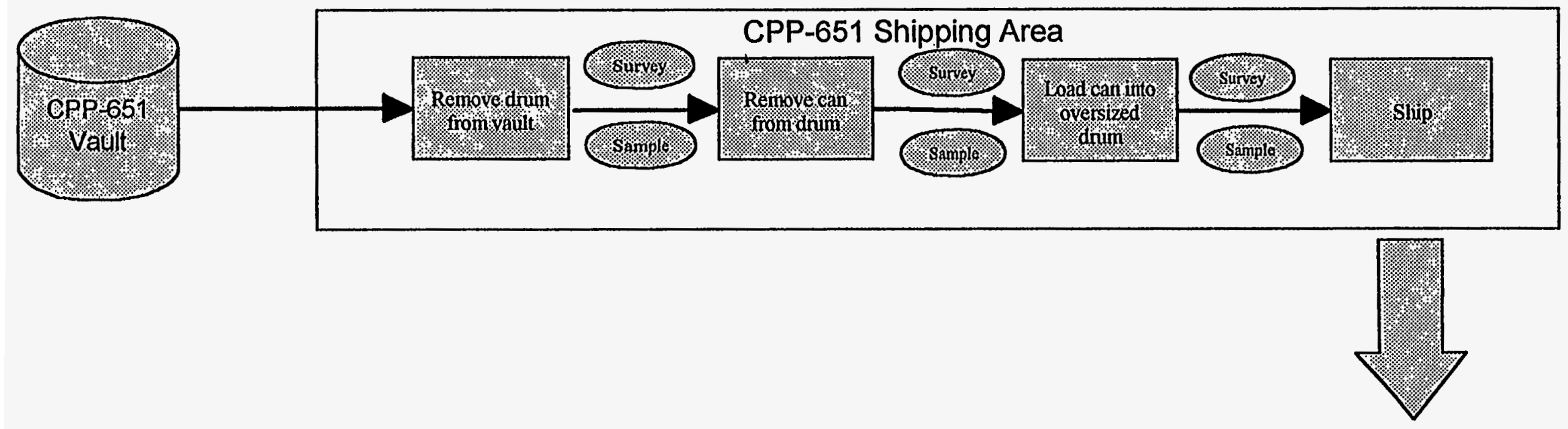

SRS

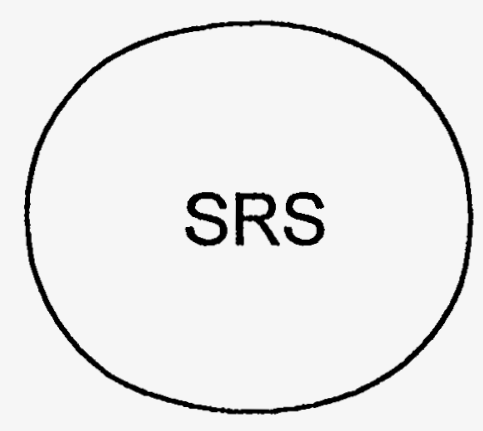




\section{Denitrator Product - Option 2}

\section{Assumption to Send As Is in Larger Diameter Drums}

The 276 containers of Denitrator product would be transferred to drums in CPP-651.

DOT DC-1 shipping drums will be used following completion and approval of changes to the DC-1 SARP.

Assuming 2 drums can be packaged per day and operators will work 2, 10 hour days per week; it will require approximately 18 months to package the product into drums and ship. This time can be accelerated if a dedicated crew is added.

Assuming 7 drums per truck. It will require 40 SST shipments to ship this material to Savannah River. 


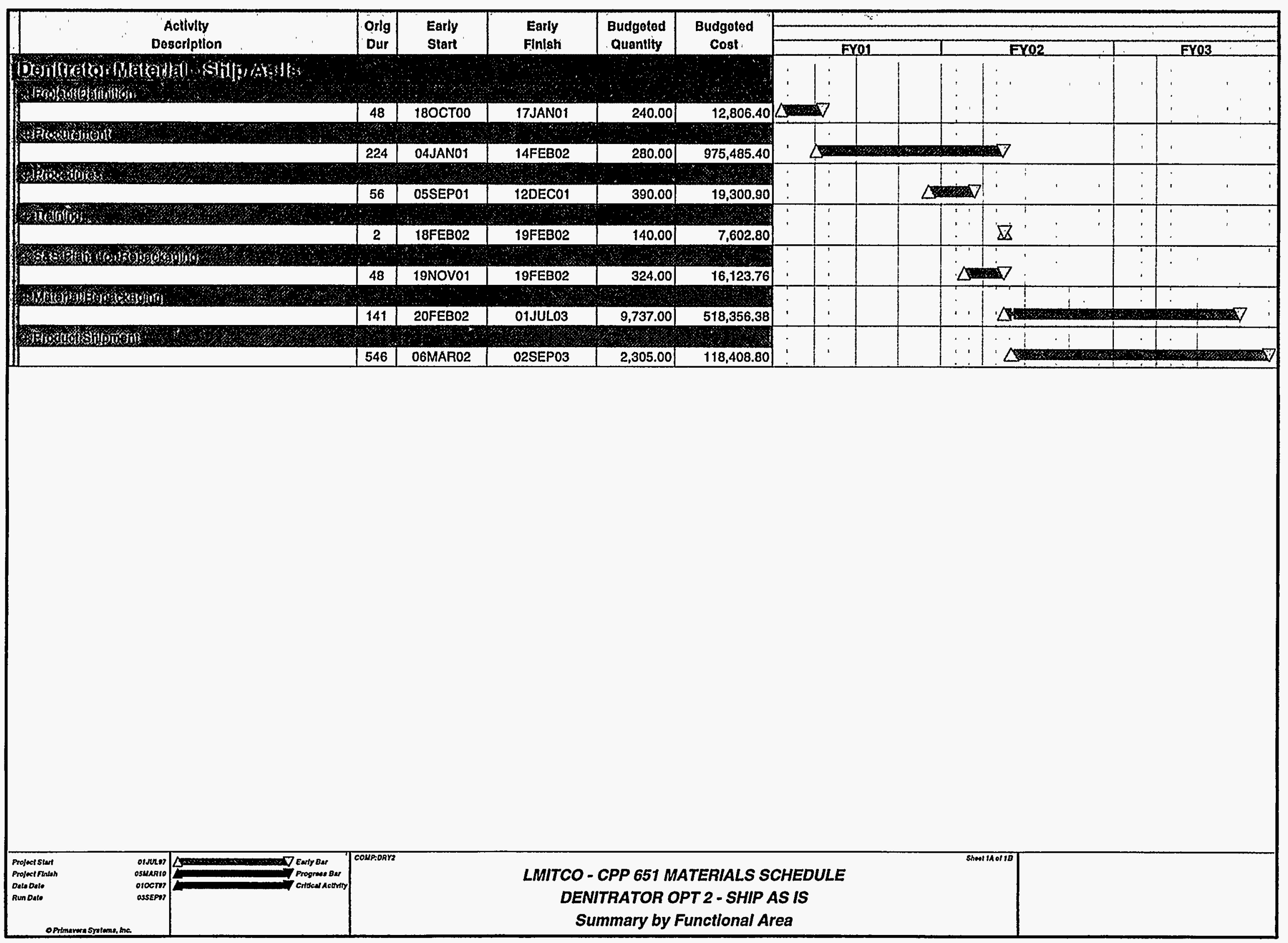




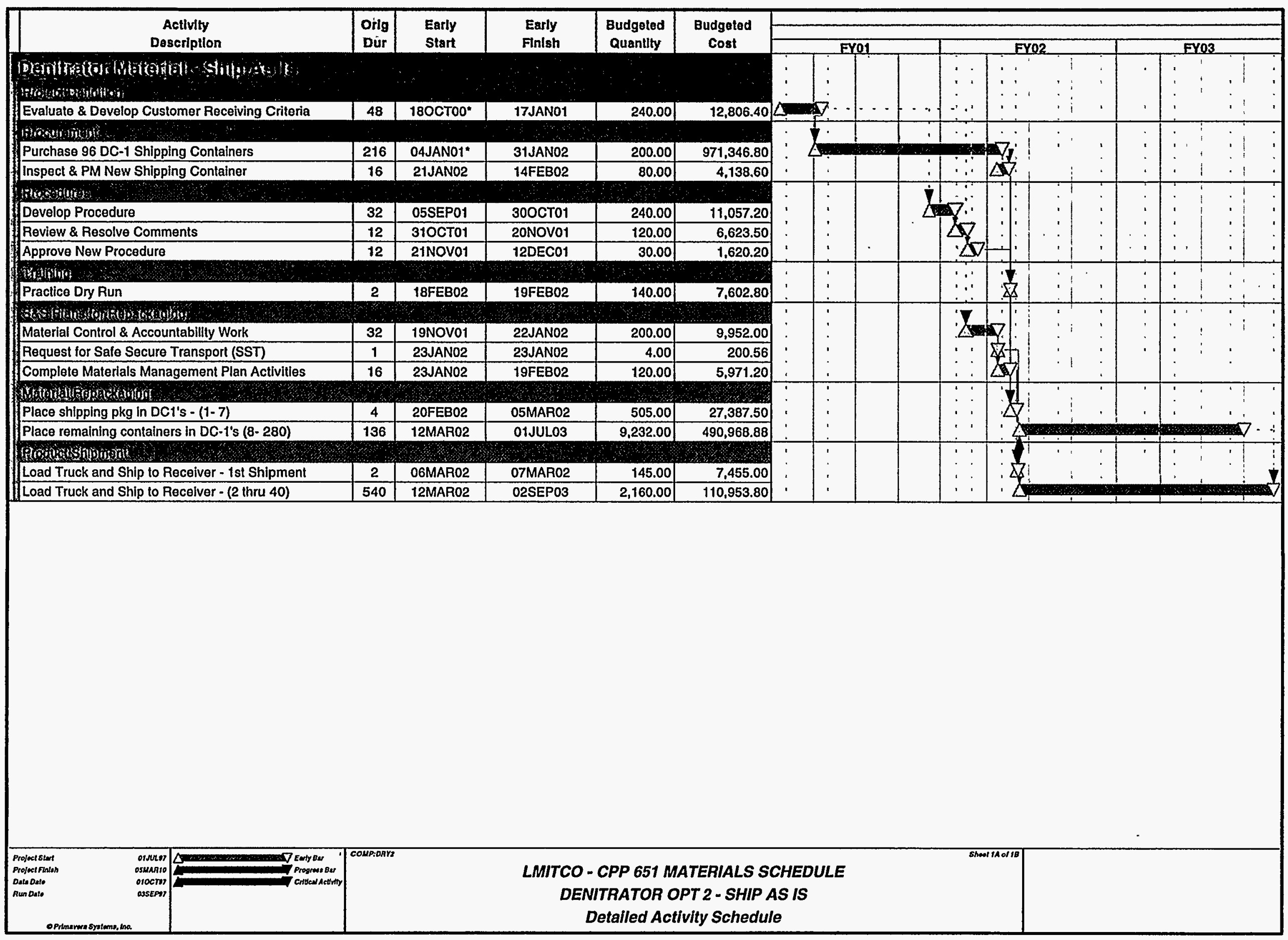


MITCO - CPP 651 MATERIAL SCHEDULE

EPORT DATE 03SEP97 RUN NO. 468 $14: 52$

Resource Estimates
PRIMAVERA PROJECT PLANNER

RESOURCE LOADING REPORT

TOTAL USAGE FOR YEAR
OPT B - SHIP AS IS \& TRANSFER TEAM

START DATE 01JUL97 FIN DATE 05MAR10

DATA DATE $010 C T 97$ PAGE NO. 1

\begin{tabular}{|c|c|c|c|c|c|c|}
\hline IESOURCE & RESOURCE DESCRIPTION & $\begin{array}{r}F Y \\
2001 \\
\end{array}$ & $\begin{array}{r}F Y \\
2002 \\
\end{array}$ & $\begin{array}{r}F Y \\
2003 \\
\end{array}$ & $\begin{array}{r}F Y \\
2004 \\
\end{array}$ & TOTAL \\
\hline 341E140 & Radiological Engineer & 40 & 74 & 46 & & 160 \\
\hline 342Т050 & Radiological Technician & 470 & 514 & 596 & & 1580 \\
\hline $420 \mathrm{E} 110$ & Quality Engineer & 56 & 54 & & & 110 \\
\hline $420 T 060$ & Quality Inspector & 24 & 71 & & & 95 \\
\hline $280 \mathrm{E} 130$ & Transportation Engineer & 1914 & 1914 & & & 3829 \\
\hline $280 P 170$ & Transporation Coordinator & 419 & 365 & 382 & & 1167 \\
\hline $110 \mathrm{E} 130$ & Other/Technical Engineer & 245 & 173 & 179 & & 597 \\
\hline $100 \mathrm{M} 6$ & Direct Purchases & & & & & \\
\hline $100 \mathrm{M} 8$ & Subcontracts & & & & & \\
\hline $110 \mathrm{M} 020$ & Fuel Manager & 1914 & 1914 & & & 3829 \\
\hline $112 \mathrm{M} 010$ & CPP 651 Operations Foreman & 710 & 685 & 765 & & 2160 \\
\hline $112 R 040$ & CPP 651 Fuel Operators & 2488 & 2437 & 2386 & & 7310 \\
\hline $113 E 080$ & Facility Fuel Engineer & 1118 & 1056 & 765 & & 2939 \\
\hline $122 E 130$ & Design Engineer & & & & & \\
\hline $130 \mathrm{P} 130$ & Trainer & 28 & 63 & & & 90 \\
\hline $152 \mathrm{P} 160$ & Procedure Writer & 153 & 235 & & & 388 \\
\hline 213R040 & CPP 602 Fuel Operators & & 203 & 337 & & 540 \\
\hline 221E010 & Technical Safety Engineer (TSE) & & 30 & & & 30 \\
\hline $432 \mathrm{E} 130$ & Plant Systems Engineer & 24 & 41 & & & 65 \\
\hline $100 \mathrm{E} 130$ & Security Operations & & 30 & & & 30 \\
\hline $120 \mathrm{P} 170$ & Safeguards \& Accountability & 4990 & 5058 & 765 & & 10814 \\
\hline $520 C 040$ & Machinist & & & & & \\
\hline $520 C 110$ & Welder & & & & & \\
\hline $520 \mathrm{M} 010$ & Craft Foreman & & 71 & 84 & & 155 \\
\hline \multirow[t]{2}{*}{ 520R080 } & Equipment Operator & 449 & 344 & 337 & & 1130 \\
\hline & REPORT TOTAL & 15041 & 15333 & 6643 & & 37016 \\
\hline
\end{tabular}


LMITCO - CPP 651 MATERIAL SCHEDULE REPORT DATE 03SEP97 RUN NO. 470
$14: 57$
PRIMAVERA PROJECT PLANNER

COST LOADING REPORT

TOTAL USAGE FOR YEAR
OPT B - SHIP AS IS \& TRANSFER TEAM

START DATE 01JUL97 FIN DATE 05MAR10

DATA DATE $010 \mathrm{CT} 97$ PAGE NO. 1

\begin{tabular}{|c|c|c|c|c|c|c|}
\hline RESOURCE & RESOURCE DESCRIPTION & $\begin{array}{r}F Y \\
2001 \\
\end{array}$ & $\begin{array}{r}F Y \\
2002 \\
\end{array}$ & $\begin{array}{r}F Y \\
2003 \\
\end{array}$ & $\begin{array}{r}F Y \\
2004 \\
\end{array}$ & TOTAL \\
\hline 1341E140 & Radiological Engineer & & 3291 & 2791 & & 6082 \\
\hline 1342 T050 & Radiological Technician & & 24370 & 29454 & & 53824 \\
\hline $1420 \mathrm{E} 110$ & Quality Engineer & 2849 & 1766 & & & 4615 \\
\hline 1420T060 & Quality Inspector & & 1538 & & & 1538 \\
\hline $3280 \mathrm{P} 170$ & Transporation Coordinator & 2006 & 16121 & 19178 & & 37304 \\
\hline $4110 \mathrm{E} 130$ & Other/Technical Engineer & & 11952 & 13974 & & 25926 \\
\hline $5100 \mathrm{M} 8$ & Subcontracts & 666667 & 293333 & & & 960000 \\
\hline $5112 \mathrm{M} 010$ & CPP 651 Operations Foreman & & 32427 & 39687 & & 72113 \\
\hline $5112 R 040$ & CPP 651 Fuel Operators & 454 & 110783 & 123780 & & 235016 \\
\hline $5113 E 080$ & Facility Fuel Engineer & 10917 & 48549 & 46181 & & 105648 \\
\hline $5130 \mathrm{P} 130$ & Trainer & 438 & 1063 & & & 1500 \\
\hline $5152 P 160$ & Procedure Writer & 2890 & 4541 & & & 7430 \\
\hline 5213R040 & CPP 602 Fuel Operators & & 10532 & 17484 & & 28015 \\
\hline $5221 E 010$ & Technical Safety Engineer (TSE) & & 709 & & & 709 \\
\hline $5432 E 130$ & Plant Systems Engineer & & 1207 & & & 1207 \\
\hline $6100 \mathrm{E} 130$ & Security Operations & & 604 & & & 604 \\
\hline $6120 \mathrm{P} 170$ & Safeguards \& Accountability & 5971 & 45781 & 38065 & & 89817 \\
\hline $6520 \mathrm{M} 010$ & Craft Foreman & & 3016 & 4182 & & 7198 \\
\hline \multirow[t]{2}{*}{ 6520R080 } & Equipment Operator & & 13482 & 16055 & & 29537 \\
\hline & REPORT TOTAL & 6921 & 625066 & 350828 & & 1668084 \\
\hline
\end{tabular}




\section{Denitrator Product}

Option 3 (Stabilize to oxide in new building, ship as liquid to SRS)

Cost:

Cost for planning and preparations (Project Definition and S\&S plans) $=\$ \mathbf{8 , 2 3 9 , 9 2 0}$

Cost for Procurement $=\$ \mathbf{1 , 6 5 6 , 0 0 0}$

Cost for Documentation (SAR, etc.) $=\$ 166,800$

Cost for Procedure Preparation and Training $=\mathbf{\$ 8 8 , 7 0 0}$

Cost to dissolve and repackage in new building and Ship $=\$ \mathbf{1 , 4 0 2 , 3 7 5}$

\section{Total Cost for Option $3=$}

$\$ 8,239,920+\$ 1,656,000+\$ 166,800+\$ 88,700+\$ 1,402,375=\underline{\underline{\mathbf{\$ 1 , 5 5 3 , 7 9 5}}}$

Schedule: 20 months for planning, procurement and preparations

12 months for documentation, procedures and training

21 months to dissolve, repackage and ship

Total Duration for Option $3=\underline{\underline{53} \text { months }}$

Comments: See attached Primavera generated detailed resources, cost data and scheduled activities for this option. 


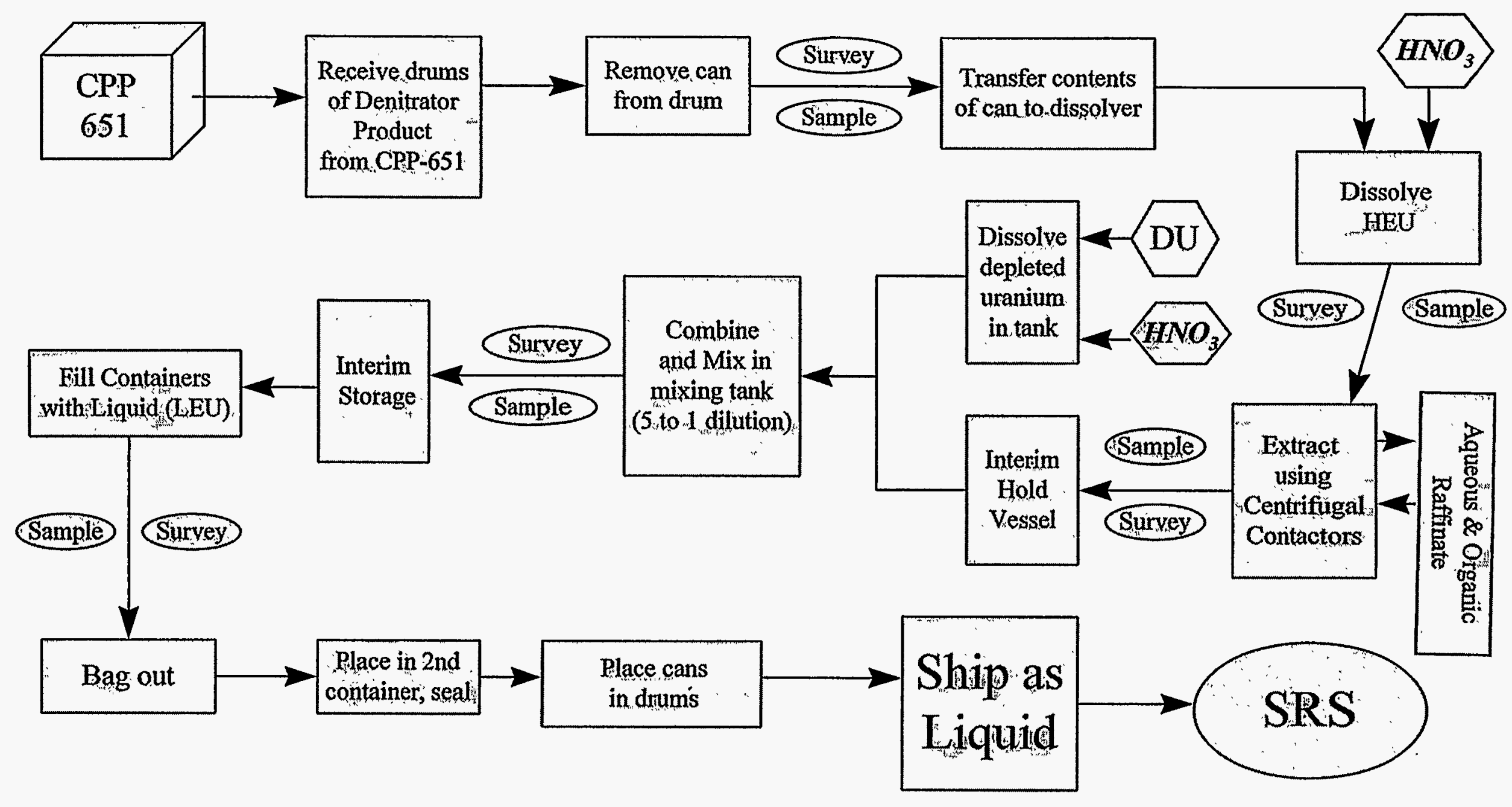

\section{DISSOLVE, EXTRACT, DILUTE, AND SEND AS LIQUID USING NEW FACILITY}




\section{Denitrator Product - Option 3}

\section{Assumptions to: \\ Dissolve, Extract, Dilute, and Send As Liquid Using a New Facility}

This process will be set up and operated in a new building at ICPP, specifically built for this process.

The building will have piping connections that tie in to current potable water, steam, condensate, treated water, nitric acid, high pressure air, service waste, and sanitary waste systems at ICPP.

The main process equipment will consist of dissolvers for both the Denitrator product and the depleted uranium, centrifugal contactors, aqueous and organic raffinate tanks, nitric acid tank, interim hold vessels in banks, and interim storage vessels in banks.

All the process equipment, except the nitric acid tank, will be critically safe.

Each day 1 container of Denitrator Product will be delivered from CPP-651 to the new building.

1 container of Denitrator Product will be dissolved per day.

Contact Rad Level reading range from $3 \mathrm{mr} / \mathrm{hr}$ to $900 \mathrm{mr} / \mathrm{hr}$. The majority on in the 100 to 200 $\mathrm{mr} / \mathrm{hr}$ range and only 14 of the bottles are at $500 \mathrm{mr} / \mathrm{hr}$ or greater.

Shielding will be incorporated into the design of the dissolution and extraction (centrifugal contactors) portion of the process.

There will be a 5 to 1 dilution of the Denitrator Product.

For every one container ( $8 \mathrm{~kg}$ 's) of highly enriched uranium (HEU) (Denitrator Product) at 350 grams per liter, there will be 138 liters of low enriched uranium (LEU) produced.

One interim storage tank will be filled with 138 liters of LEU per day.

Liquid will be placed in DOT, Type A shipping packages, such as a VPS-BXKT-003B. Each shipping package can hold 4 , one liter containers of liquid. It will take 35 packages to hold the liquid contained within one interim storage tank.

A total of approximately 38,100 liters of LEU will be produced for dilution of the 276 containers of Denitrator product.

A total of 9525 DOT, Type A shipping packages will be required. 


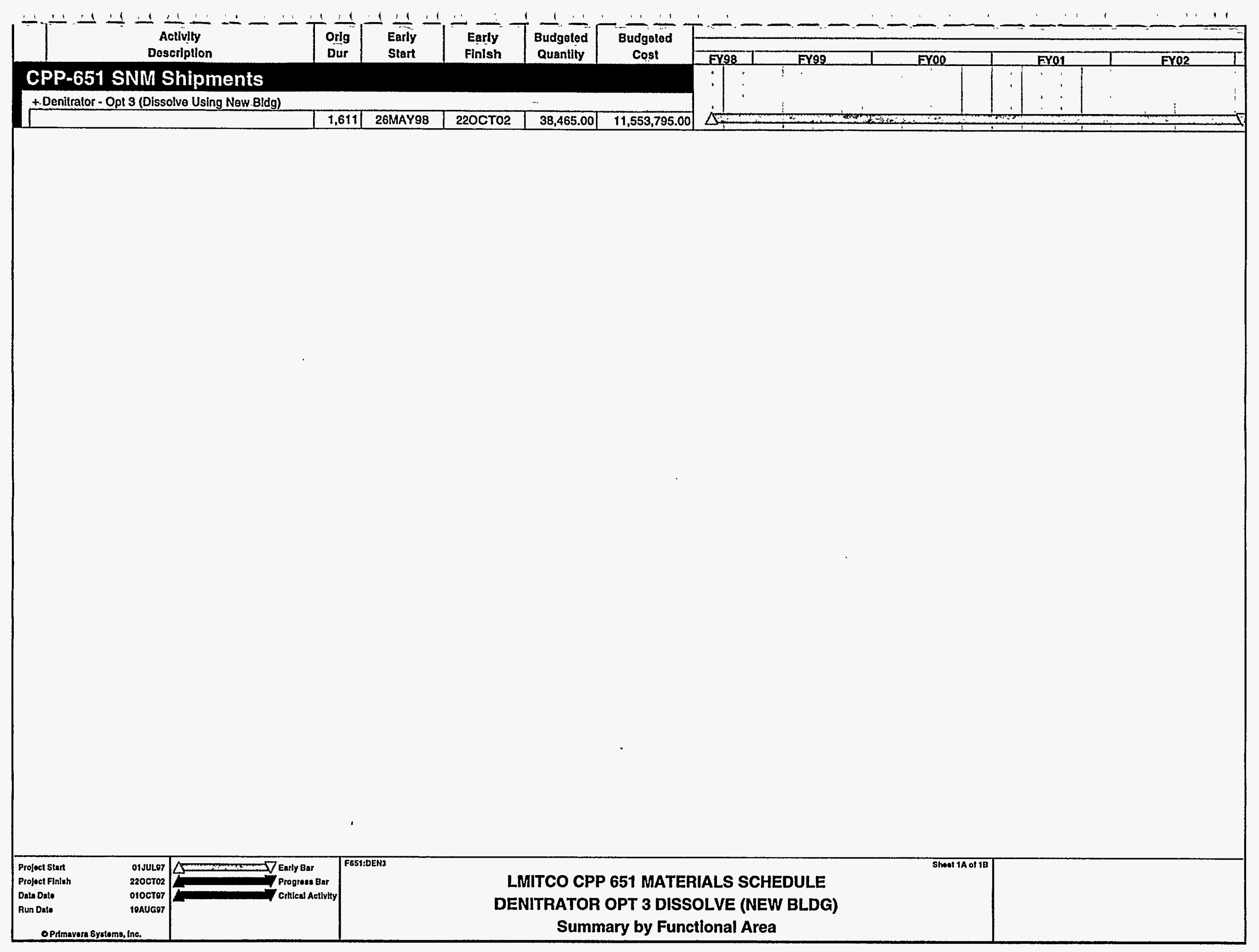




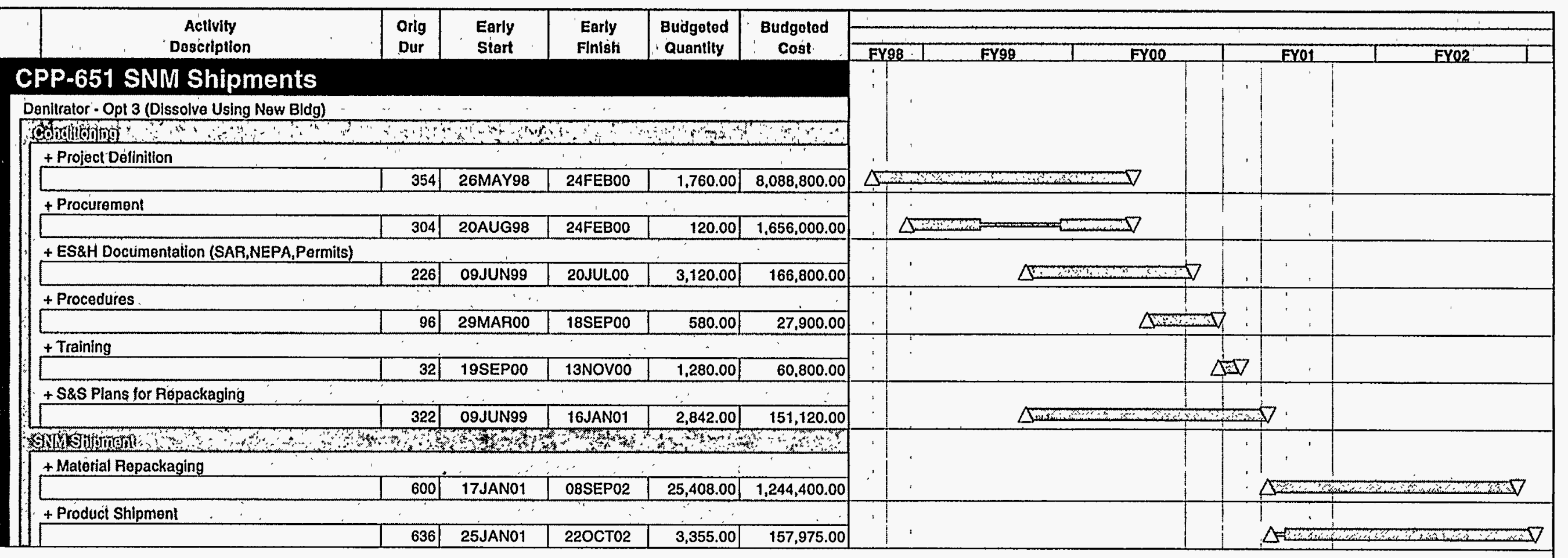

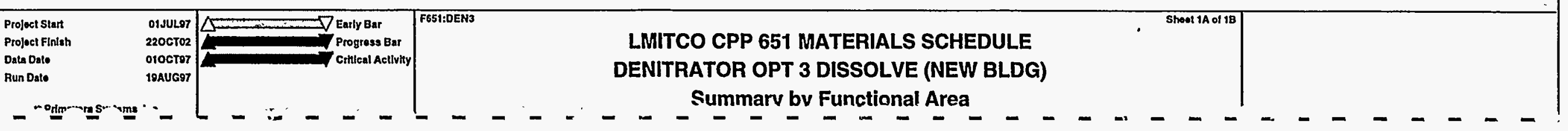




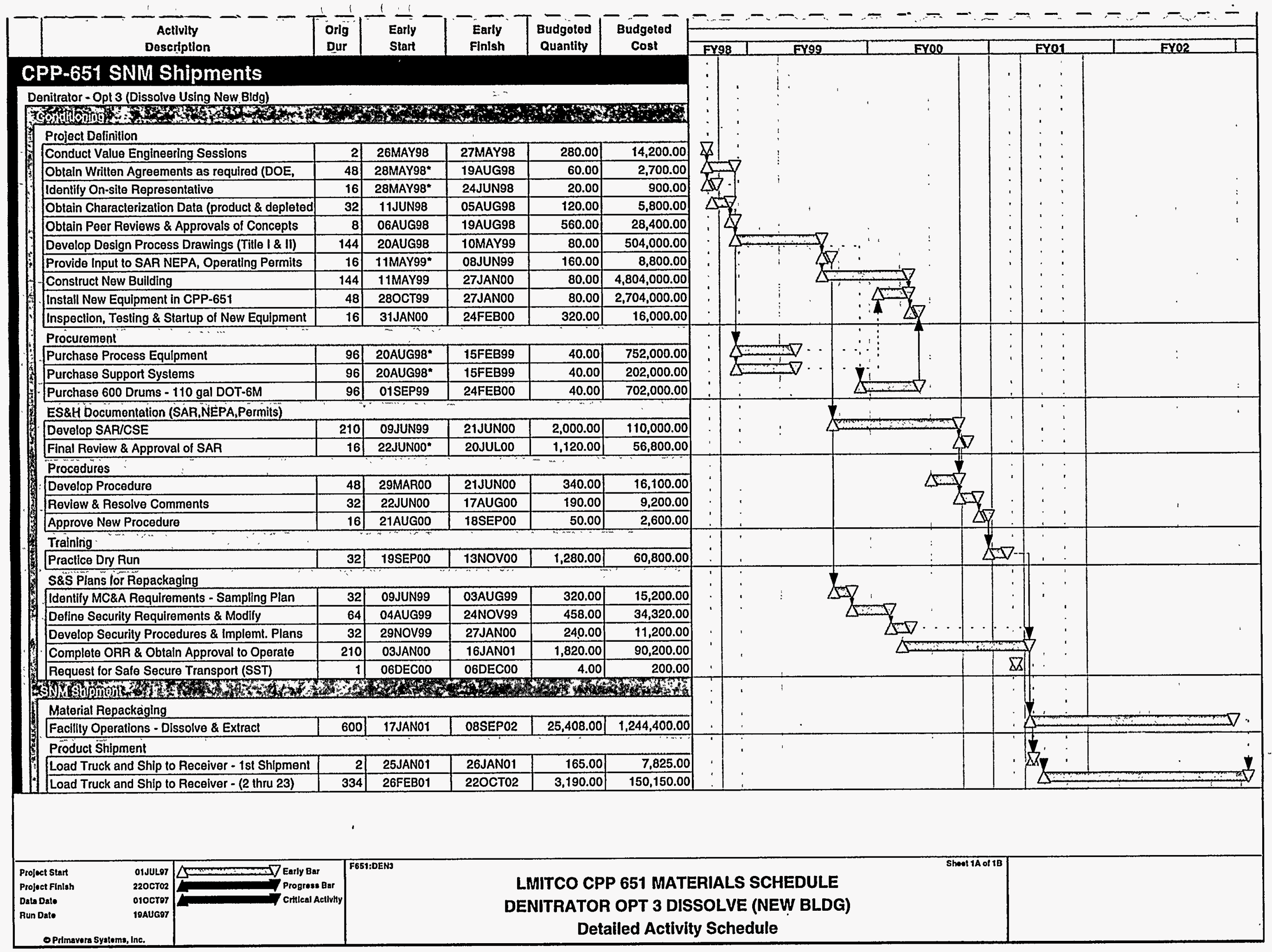




\begin{tabular}{|c|c|c|c|c|c|c|c|c|}
\hline RESOURCE & RESOURCE DESCRIPTION & $\begin{array}{r}F Y \\
1998 \\
\end{array}$ & $\begin{array}{r}F Y \\
1999 \\
\end{array}$ & $\begin{array}{r}F Y \\
2000 \\
\end{array}$ & $\begin{array}{r}F Y \\
2001 \\
\end{array}$ & $\begin{array}{r}F Y \\
2002 \\
\end{array}$ & $\begin{array}{r}F Y \\
2003 \\
\end{array}$ & TOTAL \\
\hline $1341 \mathrm{E} 140$ & Radiological Engineer & 80 & & 158 & 22 & & & 260 \\
\hline 1342 T050 & Radiological Technician & & & & 857 & 1143 & & 2000 \\
\hline 1420E 110 & Quality Engineer & 70 & 34 & 175 & 22 & & & 300 \\
\hline 1420T060 & Quality Inspector & & & 120 & & & & 120 \\
\hline $1710 \mathrm{P} 170$ & Environmental Engineer & 80 & 195 & 484 & 22 & & & 780 \\
\hline 3280E130 & Transportation Engineer & & & 58 & 22 & & & 80 \\
\hline $3280 \mathrm{P} 170$ & Transporation Coordinator & 60 & & 120 & 193 & 263 & 17 & 654 \\
\hline 4110E010 & Safety Analyst & 60 & 155 & 425 & & & & 640 \\
\hline $4110 E 120$ & Criticality Safety Engineer & 60 & 155 & 425 & & & & 640 \\
\hline 4110E130 & Other/Technical Engineer & 73 & 112 & 253 & 22 & & & 460 \\
\hline 41E1R010 & RAL Technician & 20 & & & 709 & 947 & & 1676 \\
\hline 41E1S010 & RAL Engineer & & 160 & & 236 & 316 & & 712 \\
\hline $5100 \mathrm{M} 4$ & Construction Purchases & & & & & & & \\
\hline $5100 \mathrm{M} 6$ & Direct Purchases & & & & & & & \\
\hline $5100 \mathrm{M} 8$ & Subcontracts & & & & & & & \\
\hline 5110M020 & Fuel Manager & 60 & 195 & 574 & 22 & & & 850 \\
\hline $5112 G 050$ & Administration Support & & 62 & 204 & 54 & & & 320 \\
\hline $5112 \mathrm{M} 010$ & CPP 651 Operations Foreman & & & 58 & 111 & 132 & 9 & 310 \\
\hline 5112R040 & CPP 651 Fuel Operators & 60 & & 240 & 6101 & 7844 & 34 & 14280 \\
\hline 5113E070 & Fuel Supervisor & & & 58 & 22 & & & 80 \\
\hline $5113 E 080$ & Facility Fuel Engineer & 90 & 74 & 831 & 1936 & 2093 & 17 & 5040 \\
\hline 5122E130 & Design Engineer & 60 & 61 & 99 & & & & 220 \\
\hline $5130 P 130$ & Trainer & 60 & & 170 & 250 & & & 480 \\
\hline $5152 P 160$ & Procedure Writer & & & 120 & & & & 120 \\
\hline $5213 \mathrm{M} 010$ & CPP 602 Operations Foreman & & & 58 & 22 & & & 80 \\
\hline 5213R040 & CPP 602 Fuel Operators & 20 & & 208 & 1642 & 1829 & & 3700 \\
\hline 5221E010 & Technical Safety Engineer (TSE) & & & 78 & 22 & & & 100 \\
\hline 5432E130 & Plant Systems Engineer & & & 58 & 22 & & & 80 \\
\hline $6100 E 130$ & Security Operations & 60 & 21 & 258 & 22 & & & 360 \\
\hline $6120 \mathrm{P} 170$ & Safeguards \& Accountability & 160 & 160 & 258 & 923 & 1209 & 4 & 2715 \\
\hline $6520 \mathrm{C} 020$ & Electrician & & 15 & 15 & & & & 30 \\
\hline $6520 \mathrm{M} 010$ & Craft Foreman & & 10 & 10 & 90 & 132 & 9 & 250 \\
\hline 6520R080 & Equipment Operator & & & & 359 & 527 & 34 & 920 \\
\hline \multirow[t]{2}{*}{$6520 T 070$} & Instrument Technician & & 107 & 101 & & & & 208 \\
\hline & REPORT TOTAL & 1072 & 1515 & 5617 & 13702 & 16435 & 124 & 38465 \\
\hline
\end{tabular}




\section{LMITCO}

REPORT DATE 19AUG97 RUN NO. 330 22:25

Detailed by Resource

\section{PRIMAVERA PROJECT PLANNER}

COST LOADING REPORT

TOTAL USAGE FOR YEAR
CPP 651 Denitrator Material - Opt 3

START DATE $01 J U L 97$ FIN DATE 220 CT02

DATA DATE $010 \mathrm{OCT} 97$ PAGE NO. 1

\begin{tabular}{|c|c|c|c|c|c|c|c|c|}
\hline RESOURCE & RESOURCE DESCRIPTION & $\begin{array}{r}F Y \\
1998 \\
\end{array}$ & $\begin{array}{r}F Y \\
1999 \\
\end{array}$ & $\begin{array}{r}F Y \\
2000 \\
\end{array}$ & $\begin{array}{r}F Y \\
2001 \\
\end{array}$ & $\begin{array}{r}F Y \\
2002 \\
\end{array}$ & $\begin{array}{r}F Y \\
2003 \\
\end{array}$ & TOTAL \\
\hline 1341E140 & Radiological Engineer & 4000 & & 7914 & 1086 & & & 13000 \\
\hline 1342 T050 & Radiological Technician & & & & 42833 & 57167 & & 100000 \\
\hline $1420 \mathrm{E} 110$ & Quality Engineer & 3479 & 1698 & 8737 & 1086 & & & 15000 \\
\hline $1420 T 060$ & Quality Inspector & & & 6000 & & & & 6000 \\
\hline $1710 \mathrm{P} 170$ & Environmental Engineer & 4000 & 9738 & 24176 & 1086 & & & 39000 \\
\hline $3280 \mathrm{E} 130$ & Transportation Engineer & & & 2914 & 1086 & & & 4000 \\
\hline $3280 \mathrm{P} 170$ & Transporation Coordinator & 3000 & & 6000 & 9670 & 13174 & 856 & 32700 \\
\hline $4110 E 010$ & Safety Analyst & 3000 & 7738 & 21262 & & & & 32000 \\
\hline $4110 E 120$ & Criticality Safety Engineer & 3000 & 7738 & 21262 & & & & 32000 \\
\hline $4110 E 130$ & Other/Technical Engineer & 3639 & 5611 & 12664 & 1086 & & & 23000 \\
\hline 41E1R010 & RAL Technician & 1000 & & & 35466 & 47334 & & 83800 \\
\hline 41E1S010 & RAL Engineer & & 8000 & & 11822 & 15778 & · & 35600 \\
\hline $5100 \mathrm{M} 4$ & Construction Purchases & & 2700000 & 4800000 & & & & 7500000 \\
\hline $5100 \mathrm{M} 6$ & Direct Purchases & & 7838 & 7363 & & & & 15200 \\
\hline $5100 \mathrm{M} 8$ & Subcontracts & 307465 & 1266493 & 576042 & & & & 2150000 \\
\hline $5110 \mathrm{M} 020$ & Fuel Manager & 4200 & 13633 & 38547 & 1520 & & & 57900 \\
\hline $5112 \mathrm{G} 050$ & Administration Support & & 2475 & 8154 & 2171 & & & 12800 \\
\hline $5112 \mathrm{M} 010$ & CPP 651 Operations Foreman & & & 2914 & 5571 & 6587 & 428 & 15500 \\
\hline $5112 R 040$ & CPP 651 Fuel Operators & 3000 & & 11650 & 303823 & 392214 & 1713 & 712400 \\
\hline 5113 E070 & Fuel Supervisor & & & 3497 & 1303 & & & 4800 \\
\hline $5113 \mathrm{E} 080$ & Facility Fuel Engineer & 4479 & 3698 & 41537 & 96789 & 104640 & 856 & 252000 \\
\hline $5122 E 130$ & Design Engineer & 3000 & 3031 & 4969 & & & & 11000 \\
\hline $5130 \mathrm{P} 130$ & Trainer & 3000 & & 8500 & 12500 & & & 24000 \\
\hline $5152 P 160$ & Procedure Writer & & & 5400 & & & & 5400 \\
\hline $5213 \mathrm{M} 010$ & CPP 602 Operations Foreman & & & 2914 & 1086 & & & 4000 \\
\hline $5213 R 040$ & CPP 602 Fuel Operators & 900 & & 9373 & 73907 & 82320 & & 166500 \\
\hline $5221 E 010$ & Technical Safety Engineer (TSE) & & & 3914 & 1086 & & & 5000 \\
\hline $5432 \mathrm{E} 130$ & Plant Systems Engineer & & & 2914 & 1086 & & & 4000 \\
\hline $6100 \mathrm{E} 130$ & Security Operations & 2700 & 928 & 11595 & 977 & & & 16200 \\
\hline $6120 P 170$ & Safeguards \& Accountability & 7200 & 7200 & 11623 & 41545 & 54414 & 193 & 122175 \\
\hline $6520 \mathrm{C020}$ & Electrician & & 619 & 581 & & & & 1200 \\
\hline 6520M010 & Craft Foreman & & 516 & 484 & 4485 & 6587 & 428 & 12500 \\
\hline $6520 R 080$ & Equipment Operator & & & & 14352 & 21078 & 1370 & 36800 \\
\hline \multirow[t]{2}{*}{$6520 T 070$} & Instrument Technician & & 4290 & 4030 & & & & 8320 \\
\hline & REPORT TOTAL & 361063 & 4051244 & 5666930 & 667422 & 801292 & 5844 & 11553794 \\
\hline
\end{tabular}




\section{Denitrator Product}

Option 4 (Stabilize to oxide in CPP-637 and CPP-601, ship as liquid to SRS)

Cost:

Cost for planning and preparations (Project Definition and S\&S plans) $=\$ 1,422,391$

Cost for procurement $=\$ \mathbf{6 5 6 , 0 0 0}$

Cost for Documentation $(\mathrm{SAR}$, etc. $)=\$ 166,800$

Cost for Procedure Preparation and Training $=\$ \mathbf{2 0 5 , 9 1 3}$

Cost to dissolve and repackage in CPP-651 and Ship $=\$ \mathbf{2 , 1 0 8 , 1 7 3}$

\section{Total Cost for Option $4=$}

$$
\$ 1,422,391+\$ 656,000+\$ 166,800+\$ 205,913+\$ 2,108,173=\underline{\mathbf{\$ 4 , 5 5 9 , 2 7 7}}
$$

Schedule: 24 months for planning, preparations and procurement

9 months for documentation, procedures and training

19 months to dissolve, repackage and ship

Total Duration for Option $4=\underline{\underline{52} \text { months }}$

Comments: See attached Primavera generated detailed resources, cost data and scheduled activities for this option. 

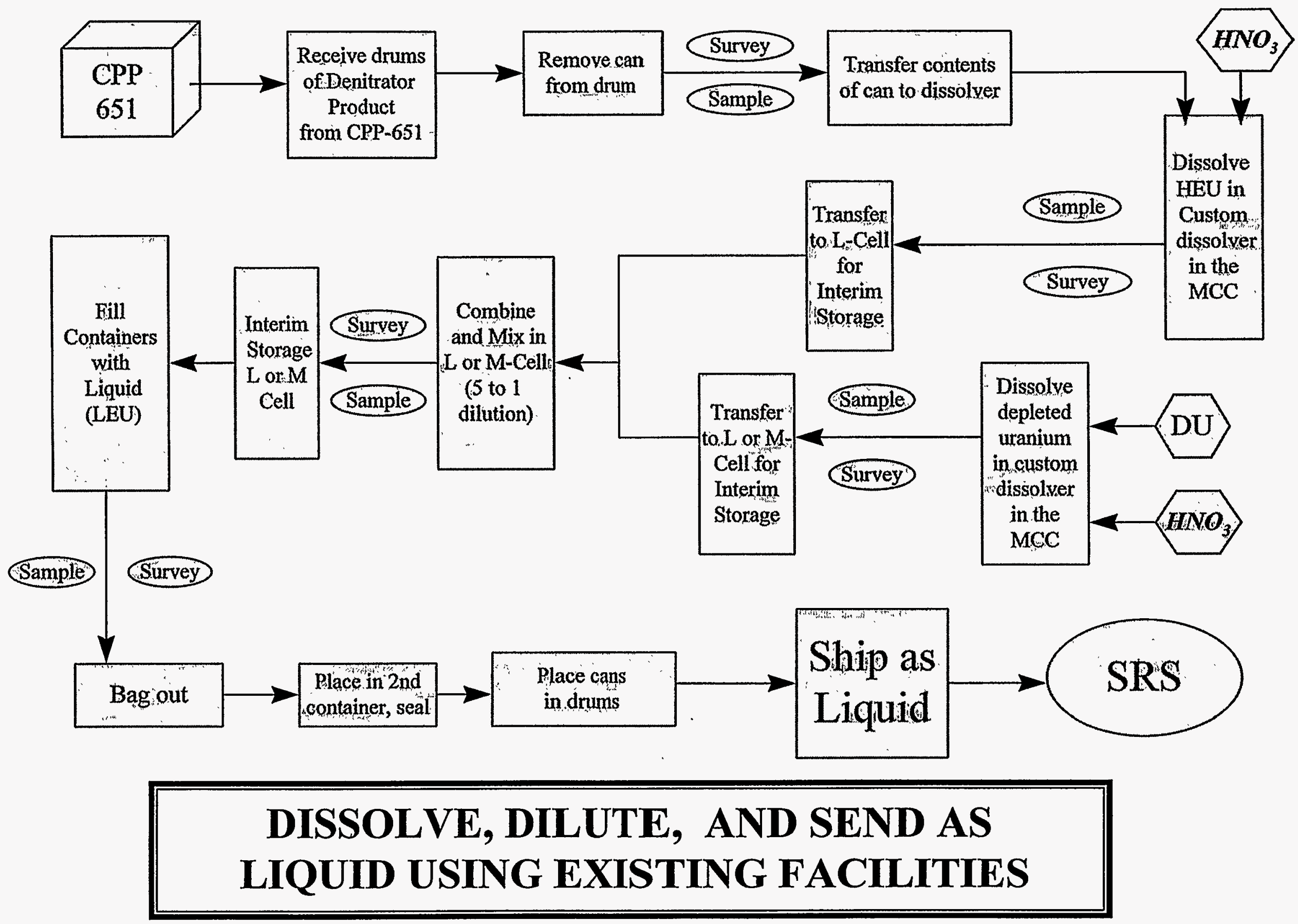


\section{Denitrator Product - Option 4}

\section{Assumption to: \\ Dissolve, Extract, Dilute, and Send as Liquid Using Existing Facilities}

CPP-601 and CPP-602, Cells P, Q, L, M, N, U, W, K, T and $Z$ will be used along with the multicurie cell and the Denitrator area and vault.

The PEW will be used to handle the waste streams.

There will be a 5 to 1 dilution of the Denitrator Product

Contact Rad Level reading range from $3 \mathrm{mr} / \mathrm{hr}$ to $900 \mathrm{mr} / \mathrm{hr}$. The majority are in the 100 to 200 $\mathrm{mr} / \mathrm{hr}$ range and only 14 of the bottles are at $500 \mathrm{mr} / \mathrm{hr}$ or greater.

Assuming a rate of one container of product being dissolved per day, the process will require about $1 \frac{1}{2}$ years.

The majority of the instrumentation and pumps will need to be refurbished.

An Operational Readiness Review (ORR) will be required. 


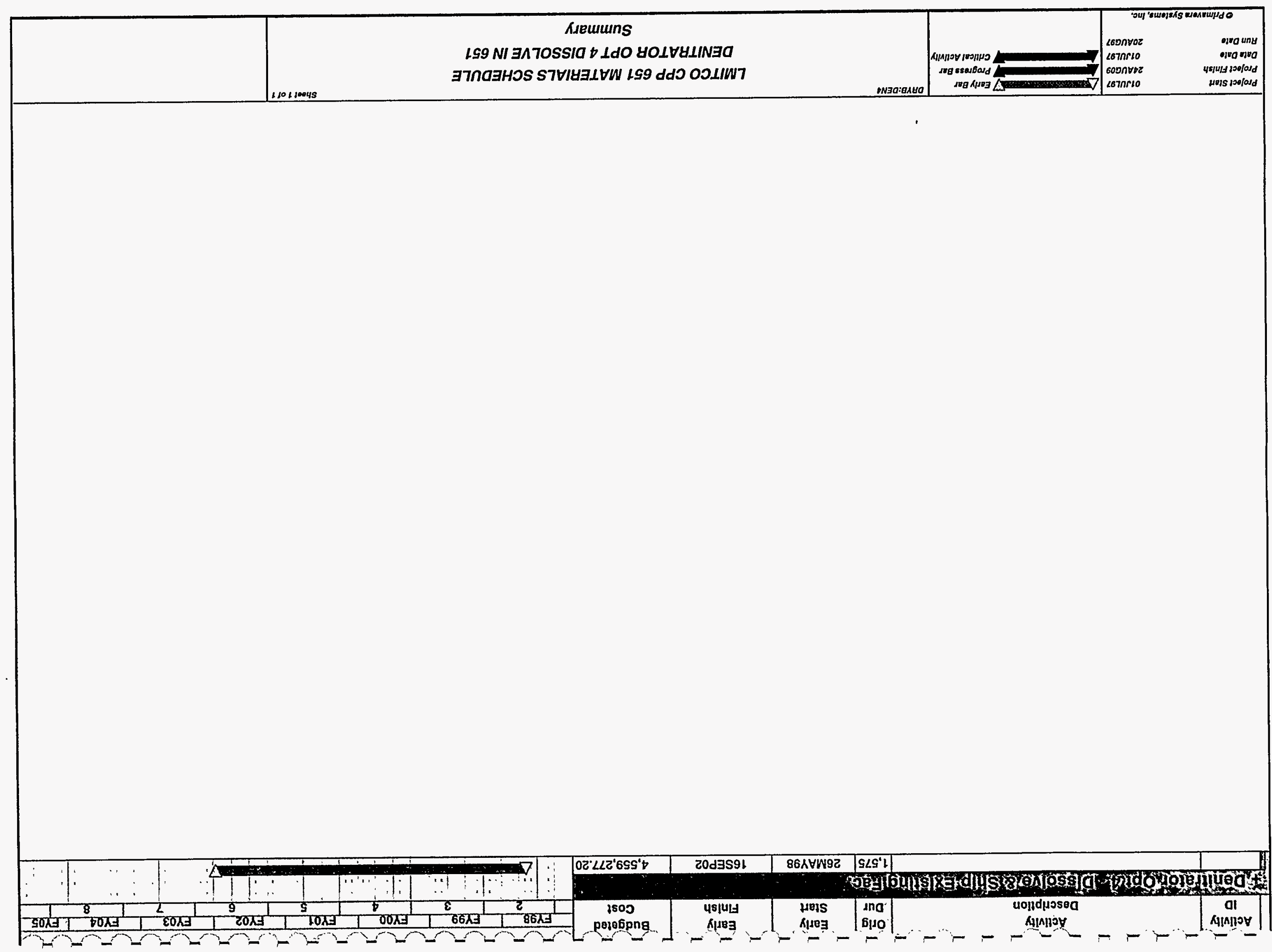




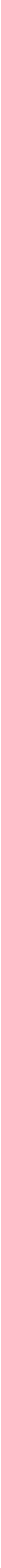




\begin{tabular}{|c|c|c|c|c|c|c|c|}
\hline RESOURCE & RESOURCE DESCRIPTION & $\begin{array}{r}F Y \\
1998 \\
\end{array}$ & $\begin{array}{r}F Y \\
1999 \\
\end{array}$ & $\begin{array}{r}F Y \\
2000 \\
\end{array}$ & $\begin{array}{r}F Y \\
2001 \\
\end{array}$ & $\begin{array}{r}F Y \\
2002 \\
\end{array}$ & TOTAL \\
\hline 1341E140 & Radiological Engineer & 3779 & 3870 & 7571 & 1429 & & 16649 \\
\hline 1342T050 & Radiological Technician & & & & 41273 & 58727 & 100000 \\
\hline $1420 \mathrm{E} 110$ & Quality Engineer & 1000 & 4000 & 8571 & 1429 & & 15000 \\
\hline 1420T060 & Quality Inspector & & & 6000 & & & 6000 \\
\hline $1710 \mathrm{P} 170$ & Environmental Engineer & 2000 & 23167 & 12405 & 37815 & 51774 & 127160 \\
\hline $3280 \mathrm{E} 130$ & Transportation Engineer & & & 2571 & 1429 & & 4000 \\
\hline $3280 \mathrm{P} 170$ & Transporation Coordinator & 1000 & 2000 & 9014 & 28937 & 48776 & 89727 \\
\hline 4110E010 & Safety Analyst & 1000 & 21167 & 9833 & & & 32000 \\
\hline $4110 \mathrm{E} 120$ & Criticality Safety Engineer & 2523 & 22768 & 9833 & & & 35124 \\
\hline 4110E130 & Other/Technical Engineer & 14705 & 27158 & 7821 & 1429 & & 51112 \\
\hline 41E1R010 & RAL Technician & 5204 & 4420 & & 34174 & 48626 & 92424 \\
\hline 41E1S010 & RAL Engineer & & & 8000 & 11391 & 16209 & 35600 \\
\hline $5100 \mathrm{M} 4$ & Construction Purchases & & 303125 & 46875 & & & 350000 \\
\hline $5100 \mathrm{M} 6$ & Direct Purchases & & & 250000 & & & 250000 \\
\hline $5100 \mathrm{M} 8$ & Subcontracts & & 650000 & 550000 & & & 1200000 \\
\hline $5110 \mathrm{M} 020$ & Fuel Manager & 1400 & 32433 & 22067 & 2000 & & 57900 \\
\hline $5112 \mathrm{G} 050$ & Administration Support & & & 9943 & 2857 & & 12800 \\
\hline $5112 \mathrm{M} 010$ & CPP 651 Operations Foreman & & & 27474 & 30317 & 50469 & 108260 \\
\hline $5112 R 040$ & CPP 651 Fuel Operators & 1000 & 2000 & 13838 & 391026 & 577730 & 985594 \\
\hline 5113E070 & Fuel Supervisor & & & 3086 & 1714 & & 4800 \\
\hline $5113 E 080$ & Facility Fuel Engineer & 2000 & 6000 & 71586 & 154534 & 211420 & 445539 \\
\hline $5122 E 130$ & Design Engineer & 1000 & 4000 & 6000 & & & 11000 \\
\hline $5130 \mathrm{P} 130$ & Trainer & 1000 & 2000 & 32500 & 12500 & & 48000 \\
\hline $5152 \mathrm{P} 160$ & Procedure Writer & & & 5928 & & & 5928 \\
\hline 5213M010 & CPP 602 Operations Foreman & & & 2571 & 1429 & & 4000 \\
\hline 5213R040 & CPP 602 Fuel Operators & 900 & & 36455 & 12536 & & 49890 \\
\hline 5221E010 & Technical Safety Engineer (TSE) & & & 3571 & 1429 & & 5000 \\
\hline 5432E 130 & Plant Systems Éngineer & & & 2571 & 1429 & & 4000 \\
\hline $6100 E 130$ & Security Operations & 900 & 1800 & 12214 & 1286 & & 16200 \\
\hline $6120 \mathrm{P} 170$ & Safeguards \& Accountability & 5400 & 1800 & 24494 & 67443 & 101261 & 200398 \\
\hline $6520 C 020$ & Electrician & & & 1200 & & & 1200 \\
\hline 6520M010 & Craft Foreman & & & 1000 & 14082 & 24145 & 39226 \\
\hline 6520R080 & Equipment Operator & & & & 53737 & 92688 & 146426 \\
\hline \multirow[t]{2}{*}{ 5520T070 } & Instrument Technician & & & 8320 & & & 8320 \\
\hline & REPORT TOTAL & 44811 & 1111707 & 1213315 & 907620 & 1281825 & 4559278 \\
\hline
\end{tabular}


LMITCO

REPORT DATE 20AUG97 RUN NO. 423 09:48

RL-09 All Resource Estimates
PRIMAVERA PROJECT PLANNER

CPP 651 Material Schedule - All Opts

RESOURCE LOADING REPORT

START DATE 01JUL97 FIN DATE 24AUG09

DATA DATE 01JUL97 PAGE NO. 1

\begin{tabular}{|c|c|c|c|c|c|c|c|}
\hline RESOURCE & RESOURCE DESCRIPTION & $\begin{array}{r}F Y \\
1998 \\
\end{array}$ & $\begin{array}{r}F Y \\
1999 \\
\end{array}$ & $\begin{array}{r}F Y \\
2000 \\
\end{array}$ & $\begin{array}{r}F Y \\
2001 \\
\end{array}$ & $\begin{array}{r}F Y \\
2002 \\
\end{array}$ & TOTAL \\
\hline 1341E140 & Radiological Engineer & 69 & 71 & 151 & 29 & & 320 \\
\hline $1342 T 050$ & Radiological Technician & & & & 825 & 1175 & 2000 \\
\hline 1420E110 & Quality Engineer & 20 & 80 & 171 & 29 & & 300 \\
\hline 1420T060 & Quality Inspector & & & 120 & & & 120 \\
\hline $1710 P 170$ & Environmental Engineer & 40 & 463 & 248 & 689 & 940 & 2380 \\
\hline $3280 E 130$ & Transportation Engineer & & & 51 & 29 & & 80 \\
\hline $3280 P 170$ & Transporation Coordinator & 20 & 40 & 180 & 577 & 973 & 1790 \\
\hline 4110E010 & Safety Analyst & 20 & 423 & 197 & & & 640 \\
\hline $4110 \mathrm{E} 120$ & Criticality Safety Engineer & 40 & 444 & 197 & & & 680 \\
\hline $4110 \mathrm{E} 130$ & Other/Technical Engineer & 196 & 440 & 156 & 29 & & 820 \\
\hline 41E1R010 & RAL Technician & 88 & 72 & & 683 & 973 & 1816 \\
\hline 41E1S010 & RAL Engineer & & & 160 & 228 & 324 & 712 \\
\hline $5100 \mathrm{M} 4$ & Construction Purchases & & & & & & \\
\hline $5100 \mathrm{M} 6$ & Direct Purchases & & & & & & \\
\hline $5100 \mathrm{M} 8$ & Subcontracts & & & & & & \\
\hline $5110 \mathrm{MO} 20$ & Fuel Manager & 20 & 463 & 338 & 29 & & 850 \\
\hline $5112 G 050$ & Administration Support & & & 249 & 71 & & 320 \\
\hline $5112 \mathrm{M} 010$ & CPP 651 Operations Foreman & & & 531 & 586 & 973 & 2090 \\
\hline $5112 R 040$ & CPP 651 Fuel Operators & 20 & 40 & 280 & 7762 & 11408 & 19510 \\
\hline 5113E070 & Fuel Supervisor & & & 51 & 29 & & 80 \\
\hline 5113E080 & Facility Fuel Engineer & 40 & 120 & 1311 & 2864 & 3825 & 8160 \\
\hline $5122 \mathrm{E} 130$ & Design Engineer & 20 & 80 & 120 & & & 220 \\
\hline $5130 P 130$ & Trainer & 20 & 40 & 650 & 250 & & 960 \\
\hline $5152 \mathrm{P} 160$ & Procedure Writer & & & 140 & & & 140 \\
\hline $5213 \mathrm{M} 010$ & CPP 602 Operations Foreman & & & 51 & 29 & & 80 \\
\hline $5213 R 040$ & CPP 602 Fuel Operators & 20 & & 721 & 279 & & 1020 \\
\hline 5221E010 & Technical Safety Engineer (TSE) & & & 71 & 29 & & 100 \\
\hline 5432E130 & Plant Systems Engineer & & & 51 & 29 & & 80 \\
\hline $6100 \mathrm{E} 130$ & Security Operations & 20 & 40 & 271 & 29 & & 360 \\
\hline $6120 P 170$ & Safeguards \& Accountability & 120 & 40 & 523 & 1435 & 2147 & 4265 \\
\hline $6520 \mathrm{C020}$ & Electrician & & & 30 & & & 30 \\
\hline 6520M010 & Craft Foreman & & & 20 & 284 & 486 & 790 \\
\hline 6520R080 & Equipment Operator & & & & 1134 & 1946 & 3080 \\
\hline \multirow[t]{2}{*}{$6520 T 070$} & Instrument Technician & & & 208 & & & 208 \\
\hline & REPORT TOTAL & 773 & 2856 & 7251 & 17953 & 25169 & 54001 \\
\hline
\end{tabular}




\section{Denitrator Product}

Option 5 (Repackage into smaller cans in CPP-651, ship to SRS)

Cost:

Cost for planning and preparations (Project Definition and S\&S plans) $=\$ \mathbf{7 4 0 , 8 5 3}$

Cost to procure drums $=\$ \mathbf{\$ 3 1 , 0 0 0}$

Cost for Documentation (SAR, etc.) $=\$ \mathbf{1 6 6 , 8 0 0}$

Cost for Procedure Preparation and Training $=\mathbf{\$ 8 8 , 7 0 0}$

Cost to Repackage in CPP-651 and Ship $=\$ 781,916$

\section{Total Cost for Option $5=$}

$$
\$ 740,853+\$ 381,000+\$ 166,800+\$ 88,700+\$ 781,916=\underline{\underline{\mathbf{2}, \mathbf{1 5 9 , 2 6 9}}}
$$

Schedule: $\quad 9$ months for planning, SAR changes and preparations

13 months for procurement

5 months to develop procedures and training

11 months to repackage and ship

Total Duration for Option $5=\underline{\underline{38} \text { months }}$

Comments: See attached Primavera generated detailed resources, cost data and scheduled activities for this option. 


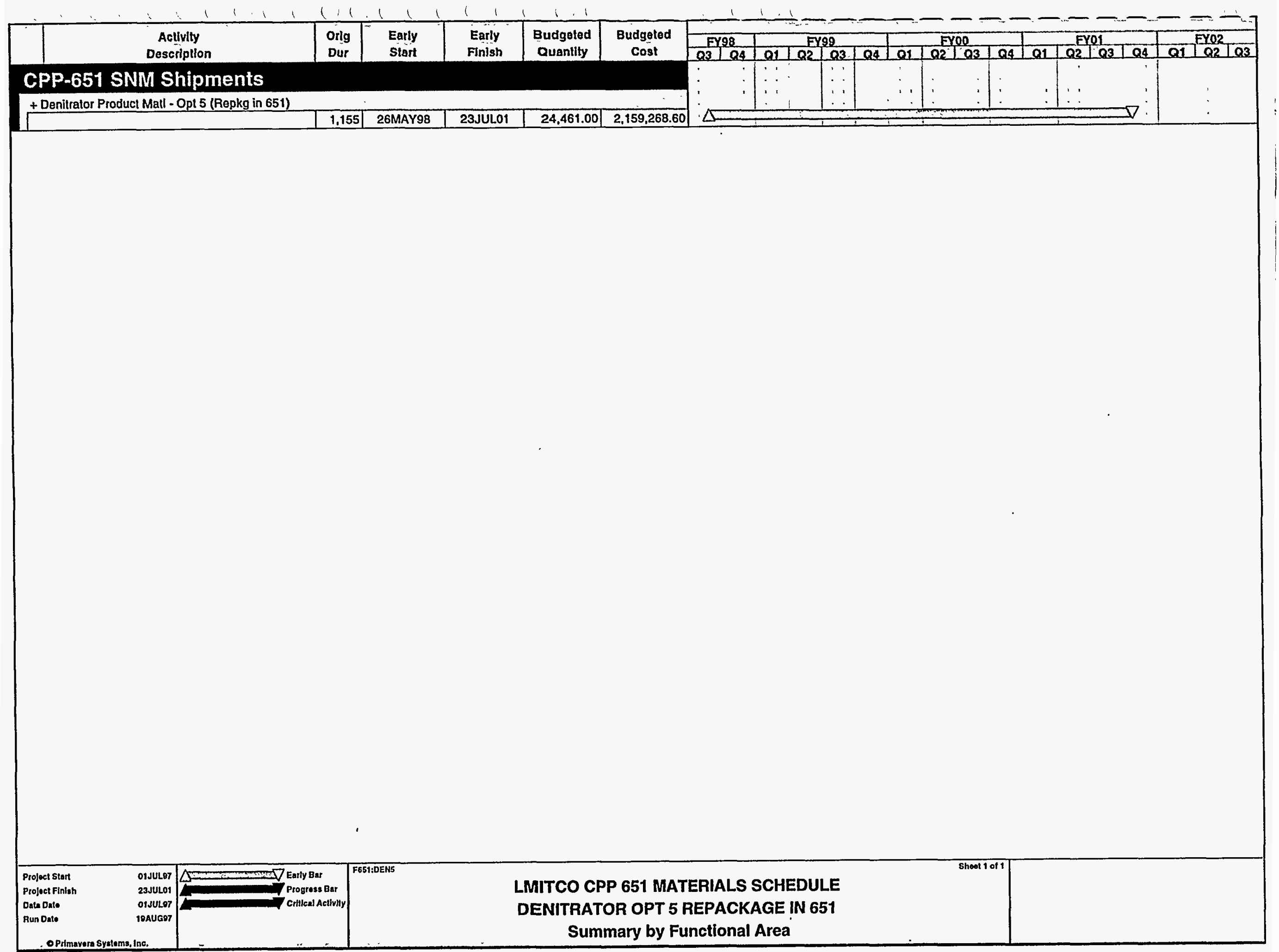




\section{CPP-651 SNM Shipments}

\section{Denitrator Product Matl - Opt 5 (Repkg in 651)}

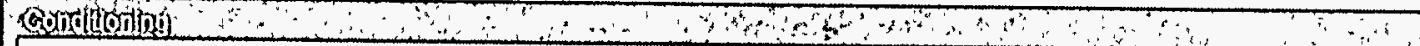
+ Project Delinillon

\begin{tabular}{|c|c|c|c|c|c|}
\hline & 144 & 26MAY98 & 10FEB99 & $1,640.00$ & $583,000.0$ \\
\hline \multicolumn{4}{|l|}{+ Procurement } & \multicolumn{2}{|l|}{$\therefore$} \\
\hline & 160 & 18AUG98 & 03.JUN99 & 200.00 & $381,000.0$ \\
\hline \multicolumn{6}{|c|}{ + ES\&̇H Documentatlón (SAR,NEPA,Permils) } \\
\hline & 217 & 18AUG98 & 14SEP99 & $3,120.00$ & $166,800.0$ \\
\hline \multicolumn{6}{|l|}{ + Procedures } \\
\hline & 96 & 17AUG99 & O9FEB00 & 580.00 & $27,900.00$ \\
\hline \multicolumn{6}{|l|}{ + Training } \\
\hline & 32 & 10FEB00 & 05APR00 & $1,280.00$ & $60,800.00$ \\
\hline \multicolumn{6}{|c|}{ + S\&S Plans for Repackaging } \\
\hline & 210 & 17AUG99 & 30AUG00 & $2,898.00$ & $157,852.60$ \\
\hline \multicolumn{6}{|l|}{ 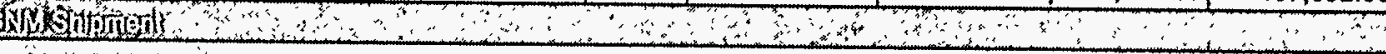 } \\
\hline \multicolumn{6}{|l|}{ + Material Repackaging } \\
\hline & 150 & 31AUG00 & 31MAY01 & $14,148.00$ & $751,118.40$ \\
\hline \multicolumn{6}{|l|}{ + Producl Shipment } \\
\hline & 272 & $250 \mathrm{CT} 00$ & 23JUL01 & 595.00 & $30,797$. \\
\hline
\end{tabular}

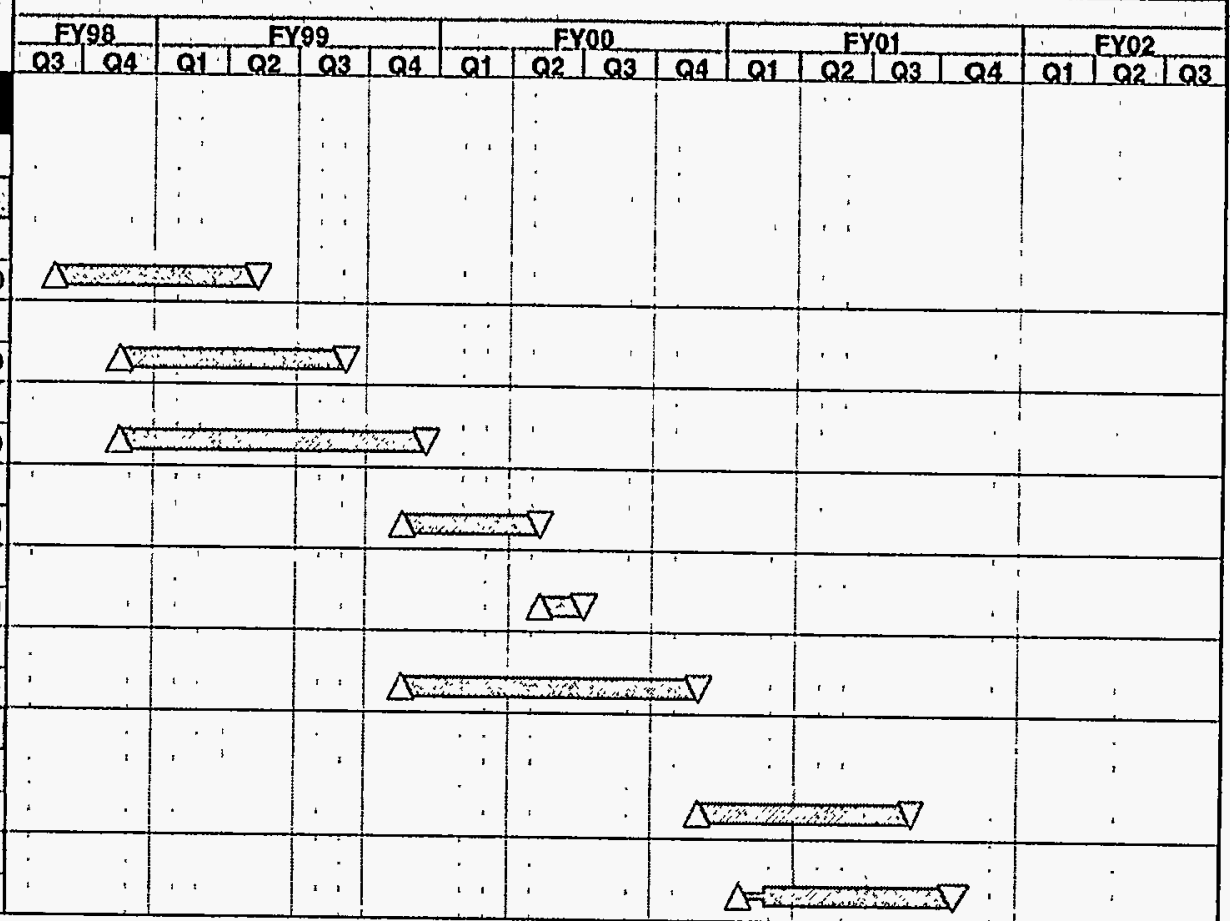

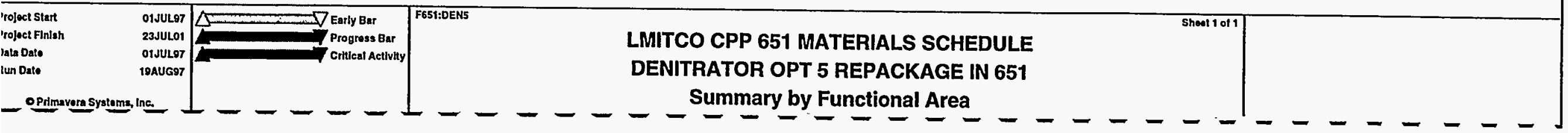




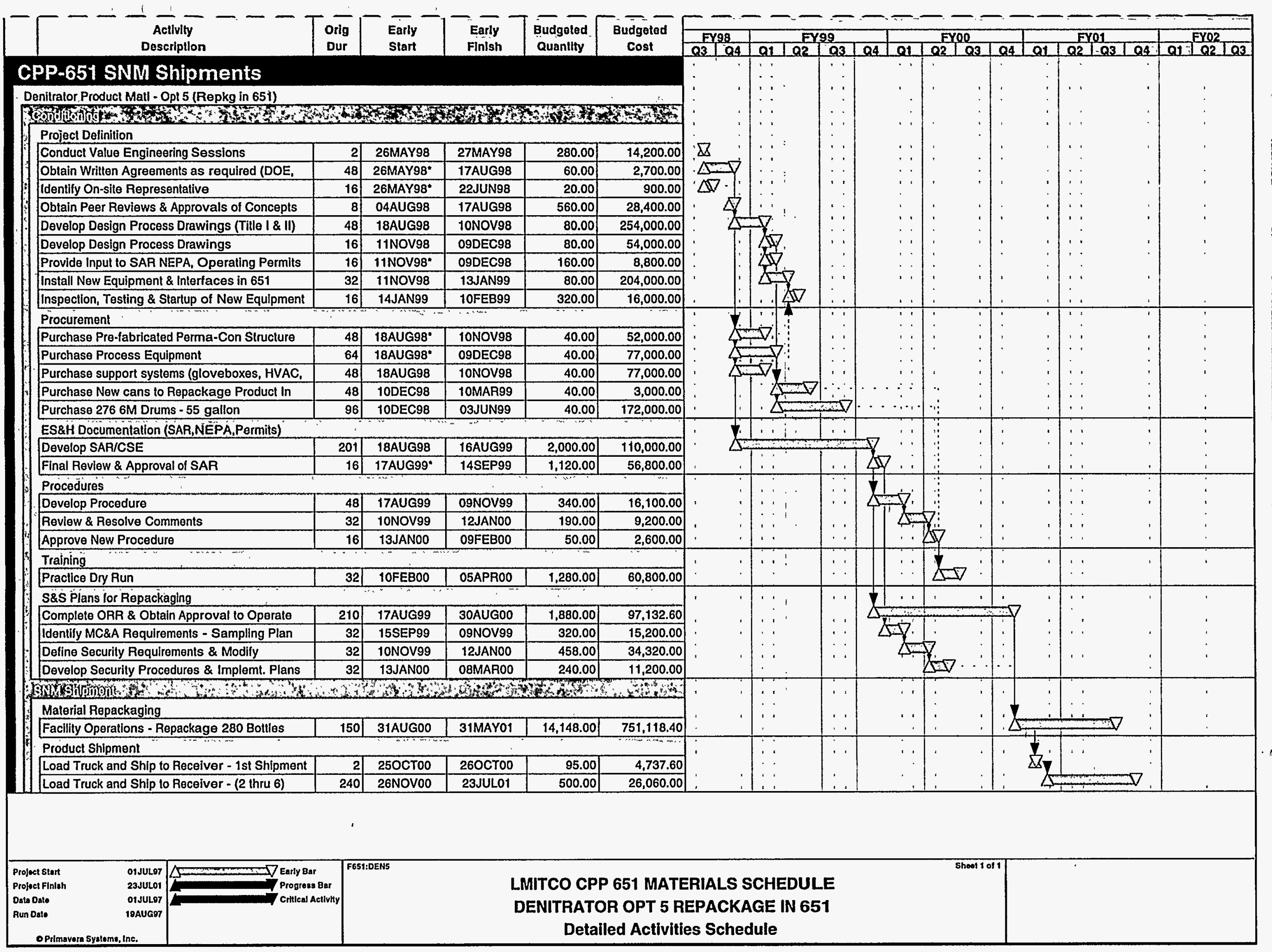


PRIMAVERA PROJECT PLANNER

COST LOADING REPORT

TOTAL USAGE FOR YEAR
CPP 651 Material Schedule - All Opts

START DATE 01JUL97 FIN DATE 23JUL01

DATA DATE 01JUL.97 PAGENO. 1

\begin{tabular}{|c|c|c|c|c|c|c|}
\hline IESOURCE & RESOURCE DESCRIPTION & $\begin{array}{r}F Y \\
1998 \\
\end{array}$ & $\begin{array}{r}F Y \\
1999 \\
\end{array}$ & $\begin{array}{r}F Y \\
2000 \\
\end{array}$ & $\begin{array}{r}F Y \\
2001 \\
\end{array}$ & TOTAL \\
\hline 41E140 & Radiological Engineer & 3000 & 4495 & 4505 & & 12000 \\
\hline $342 T 050$ & Radiological Technician & & & 7585 & 63522 & 71107 \\
\hline 20E 110 & Quality Engineer & 4432 & 8063 & 4505 & & 17000 \\
\hline 20T060 & Quality Inspector & & 6000 & & & 6000 \\
\hline $10 P 170$ & Environmental Engineer & 6109 & 28386 & 3505 & & 38000 \\
\hline $80 \mathrm{E} 130$ & Transportation Engineer & & 495 & 3505 & & 4000 \\
\hline $80 \mathrm{P} 170$ & Transporation Coordinator & 3000 & 5083 & 917 & 3008 & 12008 \\
\hline 10E010 & Safety Analyst & 6109 & 25891 & & & 32000 \\
\hline $110 \mathrm{E} 120$ & Criticality Safety Engineer & 6109 & 25891 & & & 32000 \\
\hline $110 \mathrm{E} 130$ & Other/Technical Engineer & 5083 & 15270 & 9579 & & 29933 \\
\hline E1R010 & RAL Technician & & & 5914 & 49526 & 55440 \\
\hline E1S010 & RAL Engineer & & 2500 & 7392 & 15848 & 25741 \\
\hline 100M4 & Construction Purchases & & 200000 & & & 200000 \\
\hline $100 \mathrm{M} 6$ & Direct Purchases & & & 15200 & & 15200 \\
\hline 100M8 & Subcontracts & 224609 & 446391 & & & 671000 \\
\hline 10M020 & Fuel Manager & 8553 & 43740 & 5607 & & 57900 \\
\hline $12 G 050$ & Administration Support & & 990 & 11810 & & 12800 \\
\hline $112 \mathrm{M} 010$ & CPP 651 Operations Foreman & & 495 & 3505 & 3094 & 7094 \\
\hline 12R040 & CPP 651 Fuel Operators & 3000 & 5625 & 57119 & 339918 & 405662 \\
\hline 13E070 & Fuel Supervisor & & 594 & 4206 & & 4800 \\
\hline 113E080 & Facility Fuel Engineer & 4432 & 20288 & 54553 & 84697 & 163970 \\
\hline 22E130 & Design Engineer & 3000 & 6000 & 2000 & & 11000 \\
\hline 30P130 & Trainer & 3000 & 4000 & 17000 & & 24000 \\
\hline 52P160 & Procedure Writer & & 1950 & 3450 & & 5400 \\
\hline $213 \mathrm{M} 010$ & CPP 602 Operations Foreman & & 495 & 3505 & & 4000 \\
\hline $13 R 040$ & CPP 602 Fuel Operators & & 1908 & 27661 & 66738 & 96307 \\
\hline 21E010 & Technical Safety Engineer (TSE) & & 495 & 4505 & & 5000 \\
\hline 5432E130 & Plant Systems Engineer & & 495 & 3505 & & 4000 \\
\hline $6100 \mathrm{E} 130$ & Security Operations & 2700 & 4046 & 9454 & & 16200 \\
\hline $6120 \mathrm{P} 170$ & Safeguards \& Accountability & 6300 & 7271 & 20172 & 66997 & 100740 \\
\hline $6520 \mathrm{C} 020$ & Electrician & & & 1200 & & 1200 \\
\hline $6520 \mathrm{M} 010$ & Craft Foreman & & & 1000 & 2730 & 3730 \\
\hline 6520R080 & Equipment Operator & & & & 5717 & 5717 \\
\hline \multirow[t]{2}{*}{ 6520T070 } & Instrument Technician & & & 8320 & & 8320 \\
\hline & REPORT TOTAL & 289439 & 866858 & 301175 & 701797 & 2159269 \\
\hline
\end{tabular}




\begin{tabular}{|c|c|c|c|c|c|c|}
\hline RESOURCE & RESOURCE DESCAIPTION & $\begin{array}{r}F Y \\
1998 \\
\end{array}$ & $\begin{array}{r}F Y \\
1999 \\
\end{array}$ & $\begin{array}{r}F Y \\
2000 \\
\end{array}$ & $\begin{array}{r}F Y \\
2001 \\
\end{array}$ & TOTAL \\
\hline 1341E140 & Radiological Engineer & 60 & 90 & 90 & & 240 \\
\hline 1342T050 & Radiological Technician & & & 154 & 1286 & 1440 \\
\hline 1420E110 & Quality Engineer & 89 & 161 & 90 & & 340 \\
\hline $1420 T 060$ & Quality Inspector & & 120 & & & 120 \\
\hline $1710 P 170$ & Environmental Engineer & 122 & 568 & 70 & & 760 \\
\hline $3280 E 130$ & Transportation Engineer & & 10 & 70 & & 80 \\
\hline $3280 \mathrm{P} 170$ & Transporation Coordinator & 60 & 102 & 18 & 60 & 240 \\
\hline 4110E010 & Safety Analyst & 122 & 518 & & & 640 \\
\hline $4110 E 120$ & Criticality Safety Engineer & 122 & 518 & & & 640 \\
\hline $4110 \mathrm{E} 130$ & Other/Technical Engineer & 102 & 296 & 123 & & 520 \\
\hline 41E1R010 & RAL Technician & & & 96 & 804 & 900 \\
\hline 41E1S010 & RAL Engineer & & 50 & 141 & 257 & 448 \\
\hline $5100 \mathrm{M} 4$ & Construction Purchases & & & & & \\
\hline 5100M6 & Direct Purchases & & & & & \\
\hline $5100 \mathrm{M} 8$ & Subcontracts & & & & & \\
\hline $5110 \mathrm{MO} 20$ & Fuel Manager & 122 & 648 & 80 & & 850 \\
\hline $5112 G 050$ & Administration Support & & 25 & 295 & & 320 \\
\hline $5112 \mathrm{MO} 010$ & CPP 651 Operations Foreman & & 10 & 70 & 60 & 140 \\
\hline 5112R040 & CPP 651 Fuel Operators & 60 & 113 & 1146 & 6552 & 7870 \\
\hline 5113E070 & Fuel Supervisor & & 10 & 70 & & 80 \\
\hline 5113E080 & Facility Fuel Engineer & 89 & 406 & 1059 & 1406 & 2960 \\
\hline 5122E130 & Design Engineer & 60 & 120 & 40 & & 220 \\
\hline $5130 \mathrm{P} 130$ & Trainer & 60 & 80 & 340 & & 480 \\
\hline $5152 P 160$ & Procedure Writer & & 43 & 77 & & 120 \\
\hline $5213 \mathrm{M} 010$ & CPP 602 Operations Foreman & & 10 & 70 & & 80 \\
\hline 5213R040 & CPP 602 Fuel Operators & & 42 & 591 & 1286 & 1920 \\
\hline 5221E010 & Technical Safety Engineer (TSE) & & 10 & 90 & & 100 \\
\hline 5432E130 & Plant Systems Engineer & & 10 & 70 & & 80 \\
\hline 6100E130 & Security Operations & 60 & 90 & 210 & & 360 \\
\hline $6120 P 170$ & Safeguards \& Accountability & 140 & 162 & 432 & 1346 & 2080 \\
\hline $6520 C 020$ & Electrician & & & 30 & & 30 \\
\hline $6520 \mathrm{M010}$ & Craft Foreman & & & 20 & 55 & 75 \\
\hline 6520R080 & Equipment Operator & & & & 120 & 120 \\
\hline \multirow[t]{2}{*}{ 6520T070 } & Instrument Technician & & & 208 & & 208 \\
\hline & REPORT TOTAL & 1268 & 4209 & 5750 & 13234 & 24461 \\
\hline
\end{tabular}




\title{
Appendix B
}

\author{
Dry Blending Test and Evaluation:
}

\section{Development of a $\mathrm{UO3}$ grinding/blending process using RM-2 Mill}




\title{
DEVELOPMENT OF A UO $\mathrm{AR}_{3}$ GRINDING/BLENDING PROCESS USING RM-2 MILL
}

\author{
Prepared by
}

Raj K. Rajamani

August 1997

Includes a special report on grinding/blending evaluation by Professor M. E. Wadsworth

Department of Metallurgical Engineering

University of Utah

Salt Lake City, UT 84112

Report to:

Bob Harmon

Lockheed Martin Idaho Technologies Company

Idaho Falls, ID 83415 


\section{SCOPE OF THE PROJECT}

The ultimate objective is to show that highly enriched uranium powder (HEU) can be blended with depleted uranium powder (DU) such that the final product cannot be physically separated. The feasibility of this process is demonstrated with surrogate powders instead of uranium powders for obvious reasons.

The principal requirement of the process is that HEU and DU can be dry blended in a cylindrical canister that is 5 inches in diameter and 17 inches long. The second requirement is HEU mass accountability. That is, the mass of HEU going into the grinding/blending process and coming out of the process must be accounted for within fractions of a gram. Third, the handling of HEU in open air be as minimal as possible with the least number of handling steps. Fourth, the process must be robust so that the production process can be designed to be safe, with minimal operator exposure. Finally, the blended product must be small enough in particle size and mixed well enough that it would be extremely difficult to separate the product by physical separation techniques.

Let us consider each of the mills that is available in the market for this process to review its merits and shortcomings.

Ball Mill: This is a cylindrical mill fitted with lifter bars on the shell. HEU plus DU material along with 1/4-inch steel media would be placed in the mill and tightly closed with a lid. This mill passes mass accounting requirements, minimum handling and can be made in the size of 5inch diameter by 27 -inches long. The mill would be lying on its shell surface over rollers that would spin the mill at $105 \mathrm{rpm}$. The obvious drawback is that with the mill diameter being so small, the impact forces of the ball on the HEU/DU powder is at best very little. Hence, it would take many days time to achieve some level of grinding and such small diameter mills would never grind powders to submicron (1-5 micron) sizes. Hence this mill is unsuitable for this purpose.

Vibration Mill: The ball mill described above would be vibrated back and forth about an axis such that the balls rub against the powder and the shearing action would cause grinding. In this mill also the rate of grinding is so slow that it would take a few days to achieve a reasonable level of grinding. On this account this mill is unsuitable.

Attrition Mill: The 5-inch diameter by 17-inches long cylinder would be standing upright and the canister would be filled with 3-mm steel spheres. In the interstitial space the HEU/DU powder would be filled up. Furthermore, a central shaft with radial blades would pass through the top lid and the shaft would be located within the ball and powder mix. A motor spins the 
shaft at about $600 \mathrm{rpm}$ and the resulting shearing action grinds the powder. First, the packing of powder will occur against the shell walls and corners. In these regions the powder will not be mixed at all as the powder has compacted by itself against the walls. Secondly, after the grinding is done, the lid must be opened and the stirrer shaft removed for use again. This step leads to spillage and hence mass accounting would require an extremely tedious cleaning step. Finally, the entire canister must be filled with $3-\mathrm{mm}$ steel spheres for the milling action to be efficient. This leaves only $40 \%$ of the canister volume for the powder.

The RM-2 Mill: The RM-2 mill is a ball mill operating in a very high gravitational field, for instance $100 \mathrm{G}$ on the average and the mill can be designed to withstand even higher G-fields if necessary. Here $45 \%$ of the canister volume is filled with $2-\mathrm{mm}$ steel spheres or any other heavier metal spheres. Then the HEU/DU powder, amounting to $30 \%$ of the canister volume, is added to the mill and the mill is shut tightly with a lid. Then the canister is fitted in the mill cage and allowed to experience $100 \mathrm{G}$ centrifugal field while self-rotating. In an hour or so, as demonstrated later, the particle size of the powder reaches ultrafine sizes (1-5 microns). The canister is then ready for transportation to a reprocessing facility.

During grinding, the steel media continuously scours the mill shell and, hence, there is no segregation of powder in the mill. This fact assures that mixing is complete. The processing steps are: filling the canister with a set amount of steel media and powder, closing it with a lid, fitting it in the mill cage, and grinding, and the canister is ready for shipping. At the Savannah reprocessing facility the steel balls would be dissolved in the nitric used for processing HEU. Therefore, the RM-2 mill involves minimal processing steps, full mass accountability, and the least exposure of HEU to room atmosphere. Hence, this mill is chosen for blending/grinding.

\section{Blending by Grinding}

There are a number of challenges in this blending by grinding process. First of all, grinding should take place in as small a cylinder as 5 inches in diameter. Grinding should proceed at a reasonable rate so that the mixing of a batch of HEU/DU can be done in an hour or two. The size distribution of the final powder should reach 1-5 micron size, which ensures that the particles of HEU/DU have increased several thousand fold in number. The mill should provide complete mixing without presenting corners and crevices where powder can deposit and stay unmixed. Grinding to micron sizes is not a trivial task as very high forces are needed to fracture the particles to these sizes. As the particles become small, they tend to escape the grinding action within the mill and hence the mill has to apply repeated actions to further fracture these particles. 
Blending by grinding in a mill is an attractive technique for the mixing of HEU with DU. First of all, blending could be done in a dry process. Secondly, as grinding proceeds, particles multiply in number and this fact alone brings about more blending. Finally, when numerous particles of HEU are mixed with even more numerous particles of DU, it is extremely difficult to separate without the use of conventional enrichment techniques, for example the gaseous diffusion process or the gas centrifuge enrichment process.

In the grinding/blending test described below the HEU and DU powders are mixed in a 1:5 mass ratio totaling to 100 gms. The mill canister, which is 4.75 inches in diameter and 4 inches long is first filled with 400 grams of alumina ceramic balls. These balls are 2-3 mm in diameter. Steel bearing balls of the same diameter could have been used but were unavailable at the time of the test. The powder is milled for 75 minutes. During milling the average particle size is reduced from 70 microns to less than 1.0 micron thereby increasing the number of particles by a factor of two million. The alumina or steel balls penetrate and come out of powder charge during milling many thousand times, hence, contributing to a good blending of the powders. The entire process is done dry to minimize nuclear criticality concerns.

Grinding HEU with EU is an attractive option for blending the two materials. Since size reduction of both HEU and EU particles occurs in the mill, in addition to bulk blending brought about by mill rotation, intimate mixing of the powder takes place. Suppose the bulk density of uranium powder is $0.7 \mathrm{gm} / \mathrm{cc}$ and the average particle size is 70 microns and upon grinding the particle size is 0.5 microns, which is readily possible in the RM-2 mill, then the number of particles in the feed is $9.1 \times 10^{5}$ per cc and in the product is $2.5 \times 10^{12}$ per cc. In other words, there is a two million fold increase in particles of HEU and DU. Such a numerous population of particles ensures that a grain of HEU is surrounded by many grains of DU. Furthermore, separation of these particles by known extractive techniques requires considerably more effort than from a mixture of coarser grains.

During grinding, particle fracture occurs, which raises the temperature at the fracture tip to a few thousand degrees. As a result, mechanical fusion of one material over another occurs. In this case, since DU is larger in number, it is expected to coat the surface of HEU. In fact the mechanofusion occurring in mills is exploited in mechanical alloying, for instance, in the manufacture of nickel and copper alloys. In the dry process, mechanofusion is enhanced due to the intimate contact between the grains of DU and HEU. In a wet process this would not be the case, because the intervening liquid (usually water) film would give rise to other chemical reactions in the liquid phase. Thus particle size reduction to submicron sizes and mechanofusion are two overwhelming reasons for adopting grinding mills for blending. 
$\underline{\text { RM-2 Mill }}$

The mill is based on the principle of a planetary ball mill operation. In other words, a ball mill operates in a very high gravitational field. The high gravitational field is developed by a gyration arm spinning at high speed. A ball mill situated on the gyration arm rotates on its own axis, thus experiencing the centrifugal field.

The RM-2 Concept mill, which is being patented here in the U.S., uses novel mechanical parts to effect the centrifugal field and mill rotation. This novel design enables the mill to operate at very high centrifugal fields not possible with the state-of-the-art mill. The centrifugal field and the critical speed of the mill shell can be independently varied. The concept mill is extremely quiet in operation, almost no more than the swishing sound of a fan. Due to the enormous centrifugal field, size reduction to ultrafine sizes occurs within a matter of an hour or so. Furthermore, this mill is uniquely suited for a mill shell diameter of a few inches. Even in a very small diameter, the concept mill imposes a heavy centrifugal force to effect size reduction. Finally, the mill end can be tightly sealed, as anyone would do with a canister, and is held in a protective cage during mill operation, which assures zero leakage.

The can used in the RM-2 mill is a cylindrical can of a diameter of 4.75 inches and a length of 4.0 inches. In the actual blending work using the 5 -inch by 17 -inch can, the design must take a few factors into account. First the mill wall can be made thin, as low as one-eighth of an inch, but the mill cage surrounding the can will provide the necessary mechanical strength. The internal shell must be fitted with lifters to effect more mixing. A leak-proof design of the canister lid is needed for prevention of HEU/DU leakage. The grinding media are simply metal spheres, especially small-diameter spheres. The diameter of the media is in the range of 1-6 mm and a further study would be required to optimize the process. Metallic media are preferable in view of the fact that the Savannah facility uses nitric acid to dissolve the blended powder.

The mill has two motors, one to drive the gyration arm and the other to spin the mill itself. These speeds should be chosen so that the mill operates at as high a centrifugal field as is mechanically possible. This requirement imposes a careful design of the mill shaft and bearings, in which the Principal Investigator has good experience. The whole milling process operates in the dry mode. The powder stays dry during the entire process. 


\section{EXPERIMENTAL WORK}

\section{$\underline{\text { Materials }}$}

A pair of surrogate powders was sought, which could stand in for DU and HEU in the grinding/blending experimental work. In particular, powders of different colors were sought as such a mixture could be examined under an optical microscope upon blending. Although many candidate materials such as copper oxide, copper sulfate, nickel oxide and silicon carbide are available, the choice finally came down to titanium dioxide and titanium monoxide. These oxides would be referred to as dioxide and monoxide hereinafter for the sake of brevity. The dioxide is pure white in color and the monoxide is a dark greenish-brown, and exhibit a density of $4.26 \mathrm{gm} / \mathrm{cc}$ and $4.9 \mathrm{gm} / \mathrm{cc}$ respectively. Hence, they are ideal candidates in place of DU and HEU. However, the monoxide turned out to be lot more hard (higher grinding harness index) than the dioxide because the monoxide is made by reducing dioxide with hydrogen at around $450^{\circ} \mathrm{C}$ temperature. Thus, the monoxide undergoes sintering during its manufacture and hence the hardness. This fact should be kept in mind while reviewing the results of grinding.

In the experimental tests, titanium dioxide and titanium monoxide were used as surrogate material for DU and HEU respectively. It is well known that pure powders of titanium oxides are extremely hard to grind, that is, they exhibit a very high grinding hardness index. Uranium ore has a grinding index of 14.6 and can fall anywhere in the range 10-20 depending on the source. Hence, the actual uranium oxide particles have about $10 \%$ of the strength of titanium oxide particles. Hence, it would be expected that the true mixture of HEU and DU can be ground to micron sizes in half the time it took to grind titanium oxide. In other words, the true mixture can be milled and blended in 40 minutes approximately.

The particle density of titanium dioxide is $4.26 \mathrm{gm} / \mathrm{cc}$ and that of titanium monoxide is $4.90 \mathrm{gm} / \mathrm{cc}$. It would have been preferable to have two oxides of differing color but the same density. Anyhow, this density compares well with that of compacted uranium oxide which is $3.5 \mathrm{gm} / \mathrm{cc}$.

\section{Grinding Test}

The mill canister is first filled with 20 gms of monoxide and 80 gms of dioxide. Then alumina media of size $0.6-1.0 \mathrm{~mm}$ is added to a filling level of $35 \%$. The bulk volume of alumina media used in this test is $350 \mathrm{cc}$ and the mass is $700 \mathrm{gms}$. If steel media had been used, the mass of steel balls would have been $1680 \mathrm{gms}$. The canister is then set into the cage of the RM-2 mill. A centrifugal field of $68 \mathrm{G}$ is exerted by the gyration arm and the canister speed is set at $80 \%$ of critical speed. The mixture sample is ground for exactly 75 minutes after 
which the canister is opened. The contents are sieved on a 150 mesh screen to separate the powder from the alumina grinding media. Then the powder is riffled to take four representative samples. One portion of a sample is used for size analysis and all four samples are then analyzed in an X-ray diffractometer.

\section{RESULTS}

Analysis

The size analysis of fresh samples as well as the ground mixture is done with the Microtrac SPA particle analyzer. This analyzer is based on the optical laser diffraction principle. The Xray work is done on a Siemens $X$-ray diffraction machine.

The RM-2 mill is capable of reducing even submicron powder to an ultrafine size powder. The following table gives the feed and product size distribution of the monoxide and dioxide mixture. The average size of the feed is one micron and the maximum size is 75 microns, whereas in the product, the average size is 0.5 microns. The size distribution of feed and product mixture is shown in the attached figure. The figure shows percentage by weight below a given particle size which is termed "cumulative percent passing." The feed size distribution is a bimodal distribution because part of it is made up of fine titanium dioxide and part of it is made up of coarse monoxide. The starting powder size distribution spans the range 1 to 75 microns with $15 \%$ over 10 microns in size. The product is $100 \%$ finer than 1.69 microns as seen in Table 1. Hence a large degree of size reduction has been brought about in about an hour. Simply the $68 \mathrm{G}$ centrifugal field imposes very high stresses on the particles, and hence the fast kinetics. Under visual observation, the powder is a light-gray powder showing intimate mixing. Even under an optical microscope the white grains of dioxide cannot be distinguished from the dark-grayish grains of monoxide. Rather agglomerated clumps of dioxide are seen.

Visual inspection of the blended powder shows no apparent streaks of dark color anywhere within the powder mass. Even when the powder is spread out on a piece of paper, no streaks could be seen. The blended powder is a very light-gray color as contrasted with the stark white of dioxide and dark gray. Professor Milton Wadsworth's evaluation of blending with X-ray is detailed in his memo-report, which is attached. Professor Wadsworth concludes that "if the mixed $U^{235} / U^{238}$ oxides are of uniform composition, density, and size distribution in the final blended (ground) product ... the separation of the isotope by physical means will not be possible." 


\section{Blending/grinding criteria met in RM-2 mill:}

(1) Only one step of loading the mill with surrogate powders and grinding media.

(2). There was no leakage out of the mill in any of the tests conducted here.

(3) The product particle size meets the 1-5 micron size criterion established.

(4) The process uses mill shell and grinding media readily dissolvable in nitric acid. (Although actual tests here used an alumina can and media, it could have been readily done in aluminum or steel cans).

(5) The material did not stick to the corners or mill shell wall, thus ensuring complete mixing.

\section{CONCLUSIONS}

(1) The RM-2 mill exerts a very high centrifugal field on the mill and hence an extremely fast grinding rate of the monoxide-dioxide mixture is observed.

(2) During 75 minutes of grinding, the starting mixture of an average size of one micron and a maximum size of 75 microns is reduced to an average size of 0.5 micron and the maximum size in the product is only 1.69 microns.

(3) Under an optical microscope, individual grains of dioxide and monoxide could not be readily identified.

(4) It would have been ideal to have two powders of identical hardness (grinding index) to conduct the surrogate mixture grinding experiments. The readily available choice was titanium monoxide and titanium dioxide. The monoxide being a sintered powder is much harder than dioxide when it comes to grinding. This difficulty would not arise when dealing with DU and HEU as they are mineral particles of nearly the same hardness. Hence, they would grind down to nearly the same size distribution producing an even greater degree of mixing.

(5) The grind time chosen in this study is 75 minutes. This time could be doubled to produce an even greater degree of mixing.

(6) The operating conditions of the mill can be optimized to produce a high degree of mixing. 
Table 1. Feed and Product Size Distributions of Dioxide-Monoxide Mixture Grinding

\begin{tabular}{ccc}
\hline $\begin{array}{c}\text { Size } \\
\text { microns }\end{array}$ & $\begin{array}{c}\text { Cumulative } \\
\text { Feed }\end{array}$ & $\begin{array}{c}\text { Percent passing } \\
\text { 75-minute product }\end{array}$ \\
\hline 75 & 100 & 100 \\
53 & 98.74 & 100 \\
38 & 95.08 & 100 \\
27 & 91.62 & 100 \\
19 & 89.30 & 100 \\
13 & 85.76 & 100 \\
9.4 & 84.88 & 100 \\
6.6 & 83.50 & 100 \\
4.7 & 79.94 & 100 \\
3.73 & 79.80 & 100 \\
2.63 & 77.96 & 100 \\
1.69 & 70.52 & 100 \\
1.01 & 51.72 & 95.7 \\
0.66 & 31.44 & 69.4 \\
0.43 & 14.24 & 38.5 \\
0.34 & 4.24 & 11.8 \\
0.24 & .80 & 4.0 \\
0.17 & .24 & 2.0 \\
& & \\
\hline
\end{tabular}


Feed and ground product size distribution of dioxide-monoxide mixture.

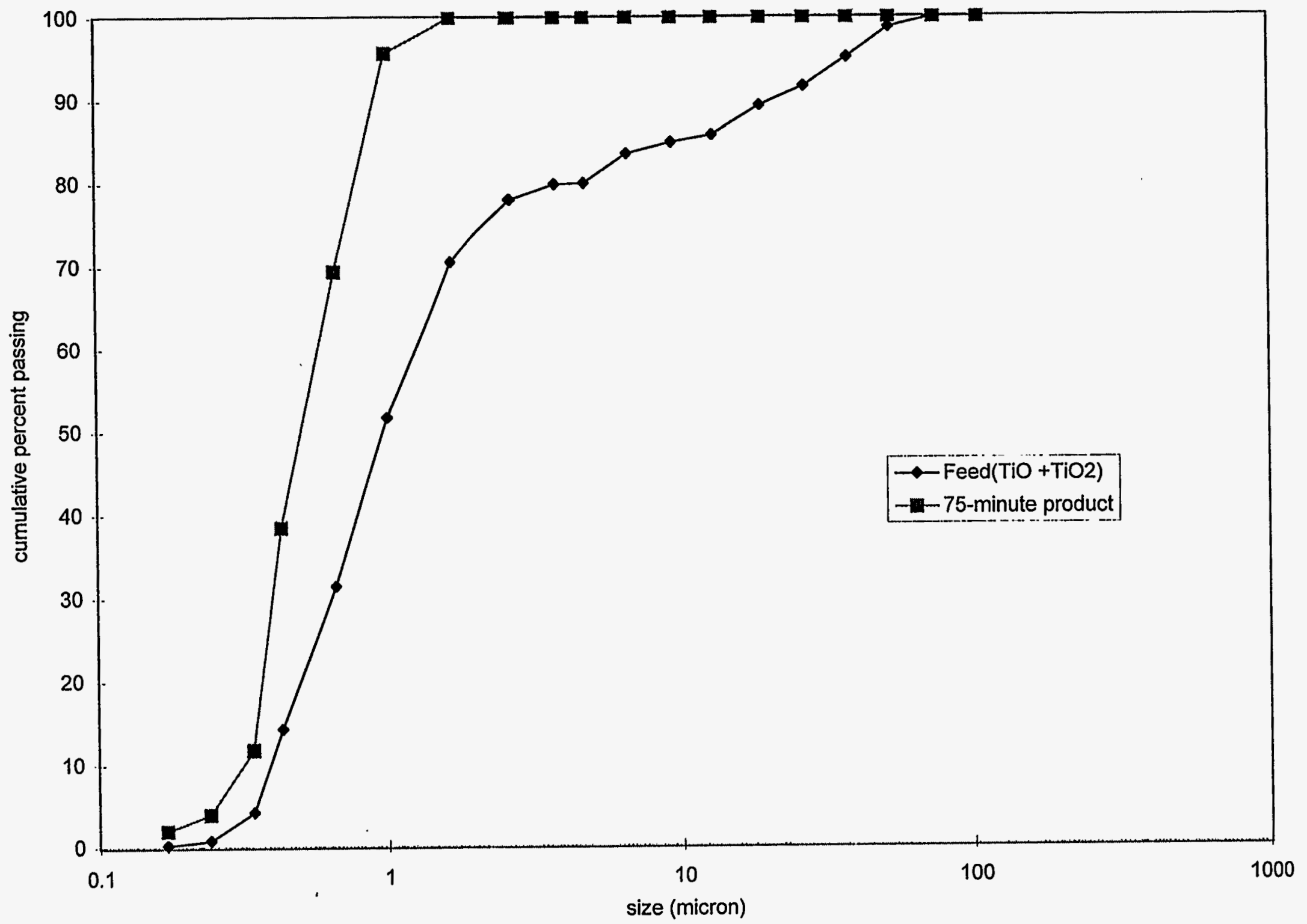




\section{Memo}

To: $\quad$ Dr. Raj K. Rajamani

From:

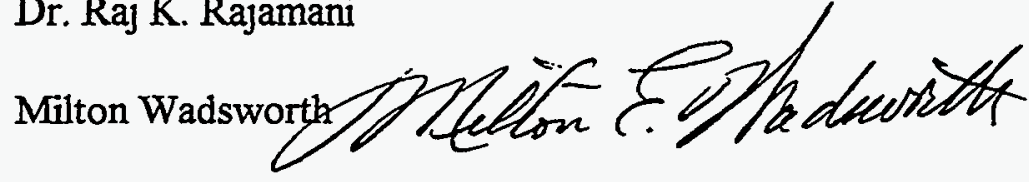

Subject: $\quad$ Separation of Mixed Isotope Powders

Date: $\quad$ August 26, 1997

The effectiveness of mixing oxides of uranium for the purpose of diluting enriched uranium $\left(U^{235}\right)$ for safe shipment consists of two parts: 1) the ability to mix the enriched oxide to extensive dilution by your new grinding process; and, 2) once mixed, the denial of any possibility of recovering enriched $U^{235}$ selectively by conventional chemical separation technology or by conventional mineral separation processes.

To address the first of these questions, you have simulated the effectiveness of grind-mixing to blend two oxides of titanium, $\mathrm{TiO}$ and $\mathrm{TiO}_{2}$. The selection of these oxides places a special burden on the test because of the great difference in hardness, TiO being much harder than $\mathrm{TiO}_{2}$. The x-ray results demonstrated effective blending using your equipment. Clearly grindmixing for the blending of oxides of essentially the same hardness and density will be even more effective. I am convinced results obtained for your tests assure even more effective results for mixed oxides of the same hardness and density.

$X$-ray results for the mixed oxides you have provided, indicate extensive blending of the two titanium oxides to a degree of uniformity to support the use of this technique for the blending of mixed oxides of uranium. To assure that the mixed oxides of uranium cannot be treated by some readily available mineral process technology, such as gravity separation or centrifuging, it is essential that the mixed oxide each be of the same chemical composition and density before the grind-blending treatment. Further, it is essential that in the ground product each oxide have the same size distribution. The latter is important so that separation techniques based on size or on size and density cannot be used separate the isotope selectively.

To address the second issue, $I$ assume the mixed $U^{235} / \mathrm{U}^{238}$ oxides meet the above conditions; namely thorough, uniform blending and oxides of identical composition, density and size distribution in the final product. If these conditions are met, I concur with you that separation of the isotope by physical means will not be possible. Similarly we can conclude, because of the identical chemical properties of each of the mixed oxides, that chemical separations by conventional dissolution, extraction and recovery using aqueous processes as well as high 
Dr. Raj K Rajamani

Page 2

August 26, 1997

temperature processes such as molten phase separations will be ineffective as a means to separate the isotope.

The above conclusions do not, however, eliminate any of the recognized techniques used for isotope separation used or proposed historically. The attached table lists proposed as well as developed isotope separation processes and the principles upon which each is based. These methods require a major national effort with extensive cost implications. The attached figure illustrates some comparative costs. Converting these costs to constant dollars illustrates the financial commitment required. 


\title{
SOME URANIUM ISOTOPE SEPARATION PROCESSES
}

\author{
BASED ON \\ EXAMPLES \\ DIFFUSION PRINCIPLES \\ GASEOUS DIFFUSION \\ MASS DIFFUSION \\ THERMAL DIFFUSION \\ CARRIER DIFFUSION \\ CENTRIFUGE PRINCIPLES \\ GAS CENTRIFUGE \\ AERODYNAMIC PRINCIPLES \\ SEPARATION NOZZLE \\ UCOR PROCESS \\ PHASE EQUILIBRIUM PRINCIPLES \\ FRACTIONAL DISTILLATION \\ CHEMICAL PRINCIPLES \\ CHEMICAL EXCHANGE \\ ION EXCHANGE \\ PHOTOEXCITATION PRINCIPLES \\ LASER ISOTOPE SEPARATION \\ ELECTROMAGNETIC PRINCIPLES \\ PLASMA SEPARATION \\ CALUTRON \\ CHEMI-IONIZATION WITH \\ QUADRUPOLE MASS FILTER
}


- EARLY 1940'S:

- RESEARCH CONDUCTED ON ELECTROMAGNETIC SEPARATION, GASEOUS DIFFUSION, THERMAL DIFFUSION, GAS CENTRIFUGATION, PHOTOCHEMICAL METHODS.

- THREE PRODUCTION-SCALE PLANTS BUILT IN OAK RIDGE:

- THERMAL DIFFUSION

- ELECTROMAGNETIC

- GASEOUS DIFFUSION

- IN VIEW OF GASEOUS DIFFUSION ECONOMICS, THERMAL DIFFUSION AND ELECTROMAGNETIC PLANTS WERE SHUT DOWN.

- EARLY 1950'S:

- OAK RIDGE GASEOUS DIFFUSION PLANT EXPANDED

- NEW GASEOUS DIFFUSION PLANTS BUILT AT PADUCAH, KY, AND PORTSMOUTH, OH. 


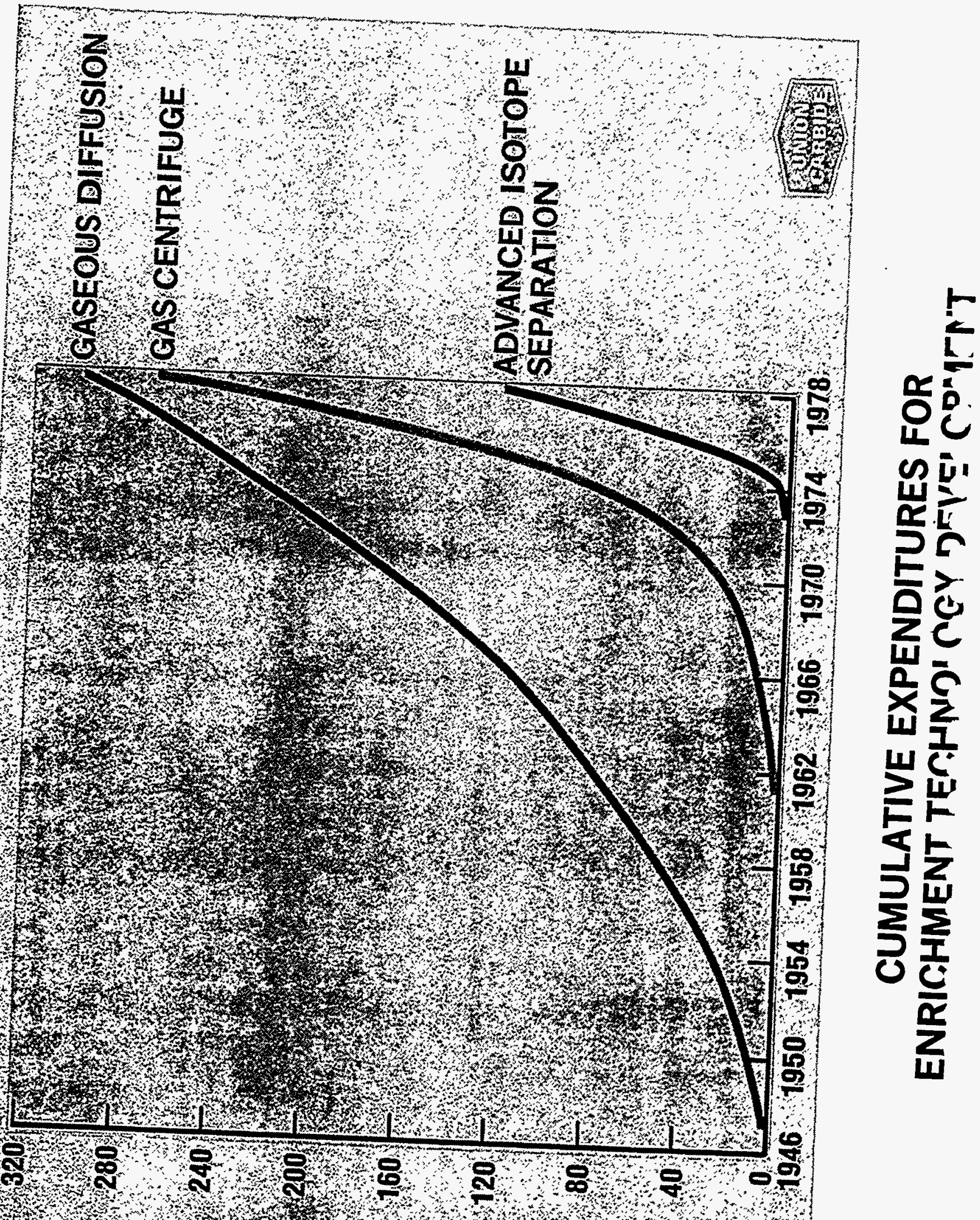




\title{
Appendix C
}

\section{Detailed cost and schedule activities}

\author{
for
}

current budget, base case, and options A, B, C, and D 


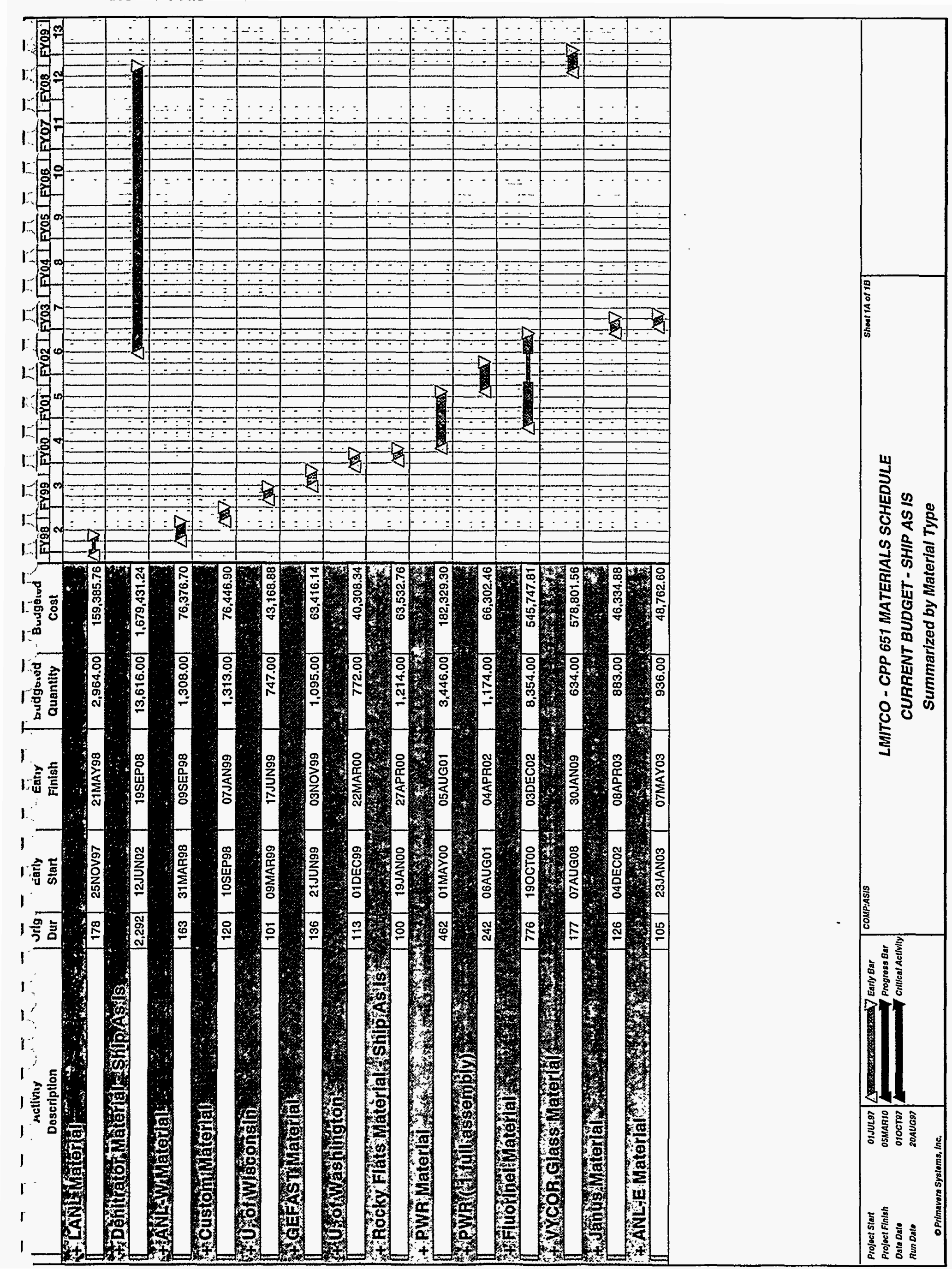


存展

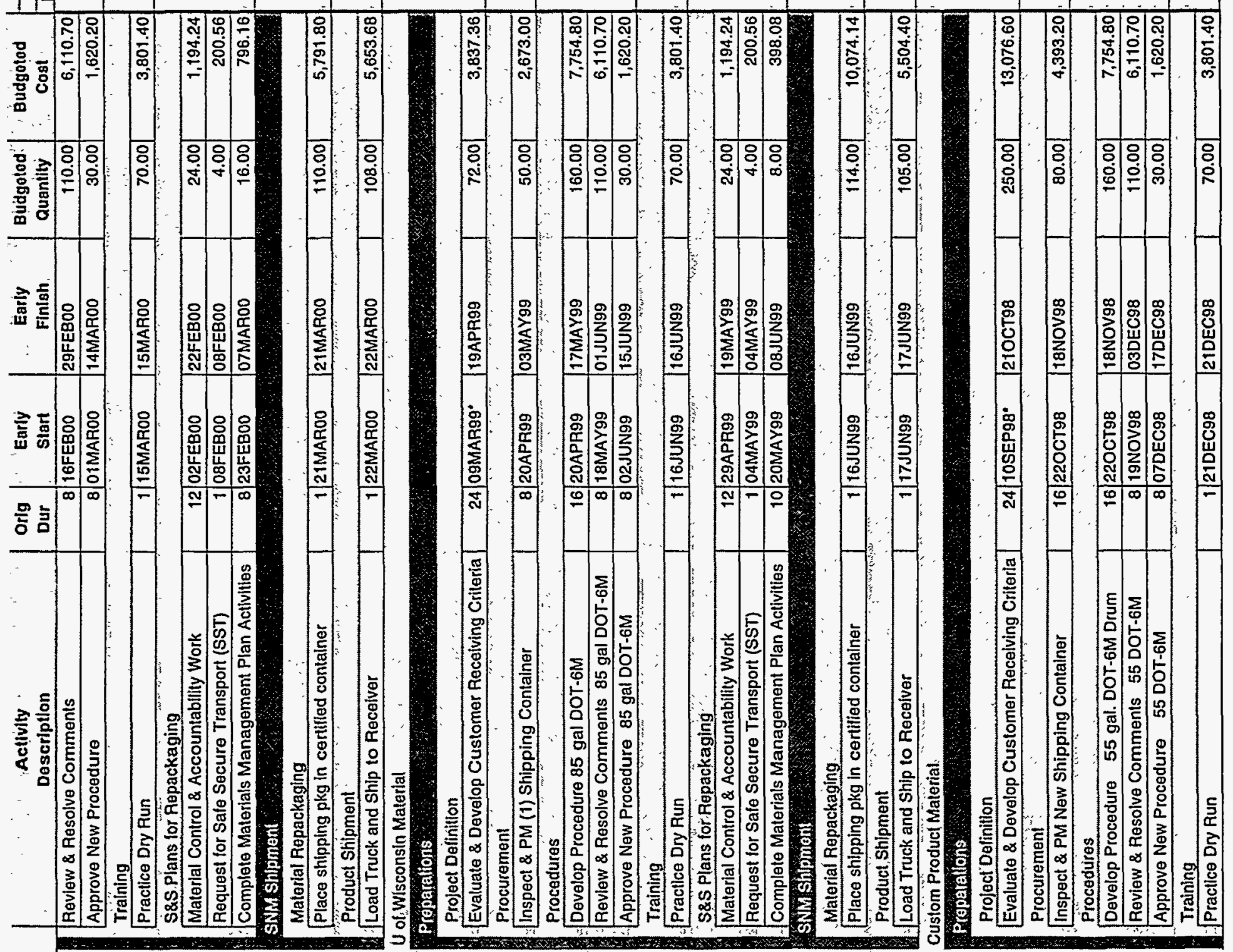




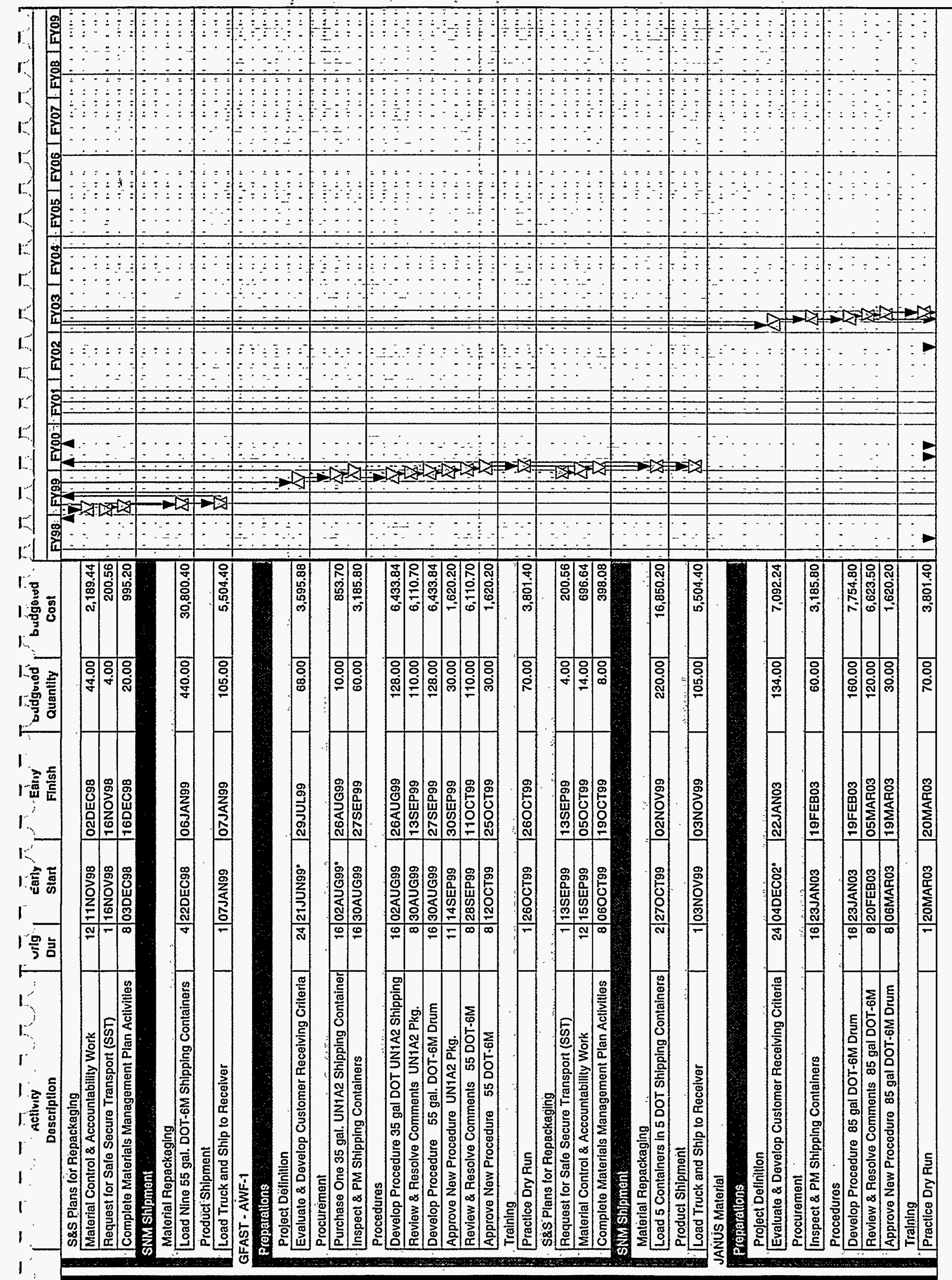




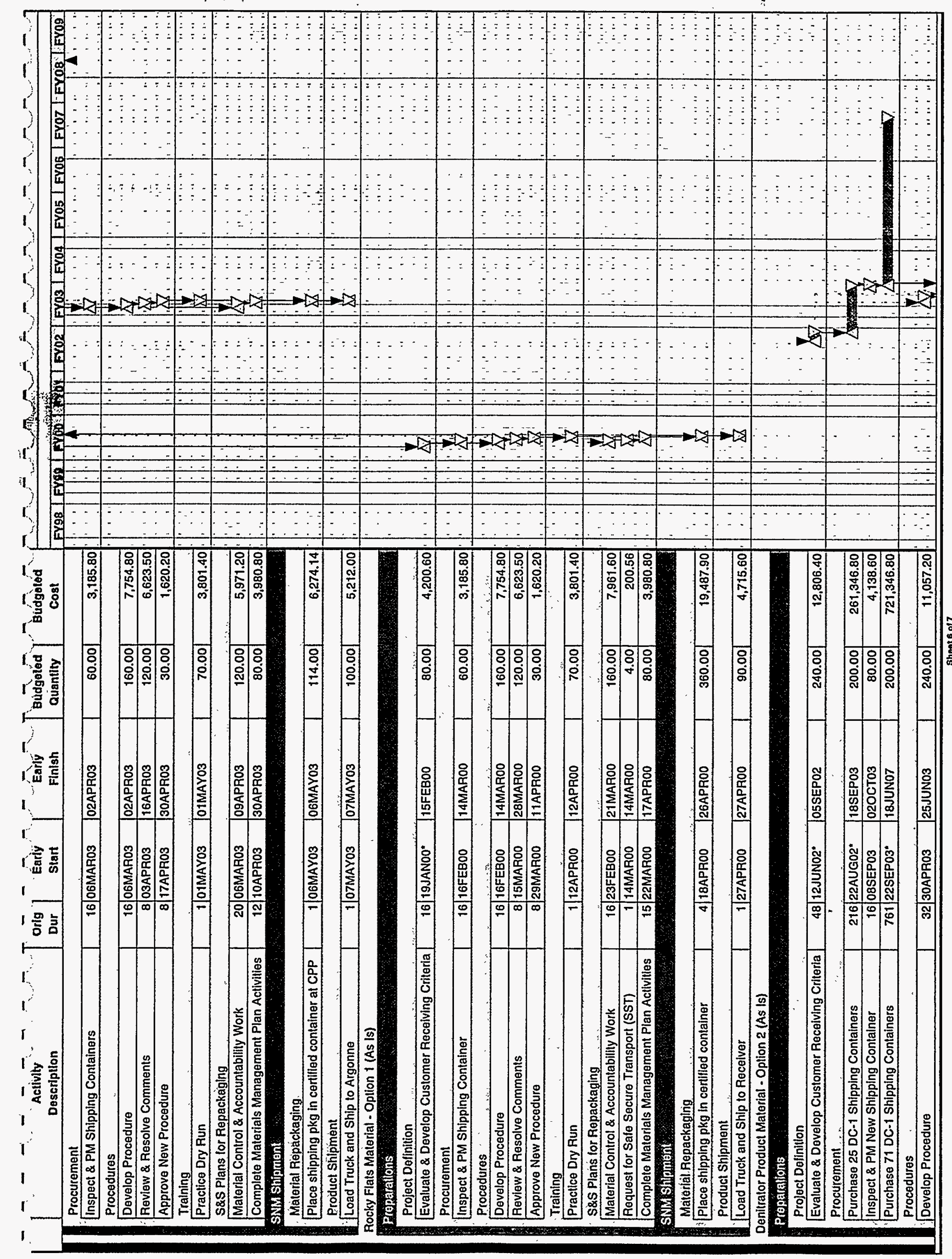


Tralning

Practice Dry Run

12 17JULO3 16JUL03 O6AUG03

S\&S Plans for Repackaging

Material Control \& Accountability Work 210600 T03

10700 T03 120.00

Request for Sale Secure Transport (SST)

SNM shifomiont

Materlal Repackaging.

\begin{tabular}{|l|l|}
\hline Place shipping pkg in DC1's - (1-7) & 4 OO8OCTO3
\end{tabular}

\begin{tabular}{|l|r|r|}
\hline Place remaining containers in DC-1's (8- 280) & 494 & $280 \mathrm{OTO} 3$ \\
\hline
\end{tabular}

Próduct Shipment

Load Truck and Ship to Receiver - 1st Shipment

2 220CTO3
\begin{tabular}{|l|l|}
\hline 10SEP03 & $070 C T 03$ \\
\hline
\end{tabular} 107OCTO3 1 10SEP03

Load Truck and Ship to Recelver - (2 thru 40) \begin{tabular}{r|r}
1,789 & $280 \mathrm{CTO} 3$
\end{tabular}

210CTO3 06AUG0B

$230 \mathrm{CTO} 3$ 230CTO3 $490,968.88$ $7,455.00$ $110,953.80$

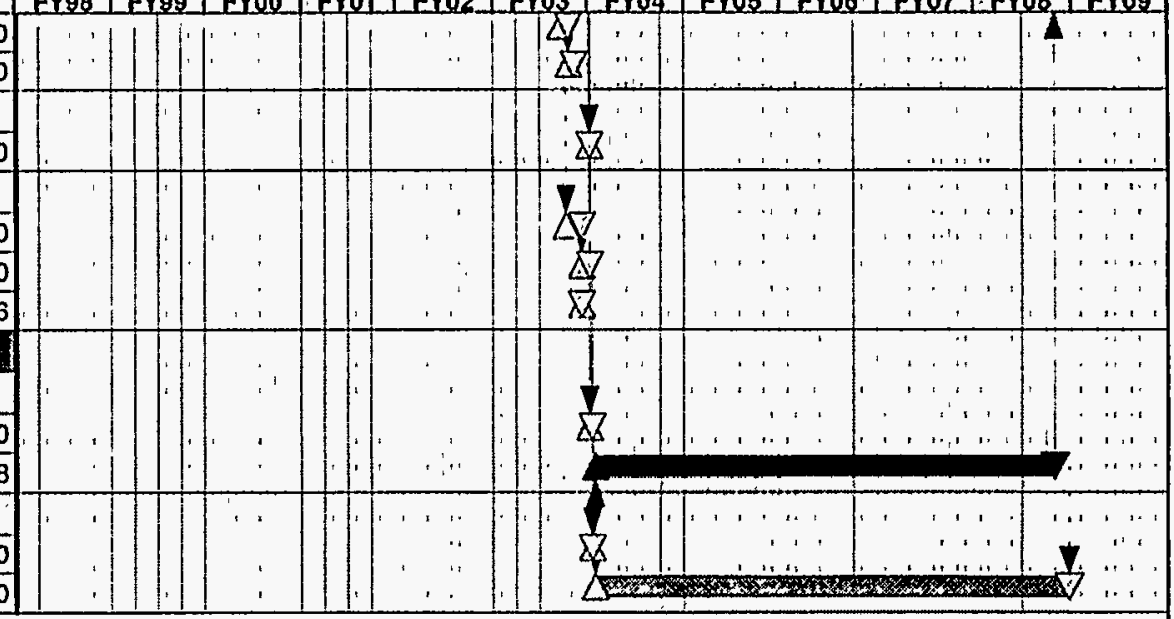




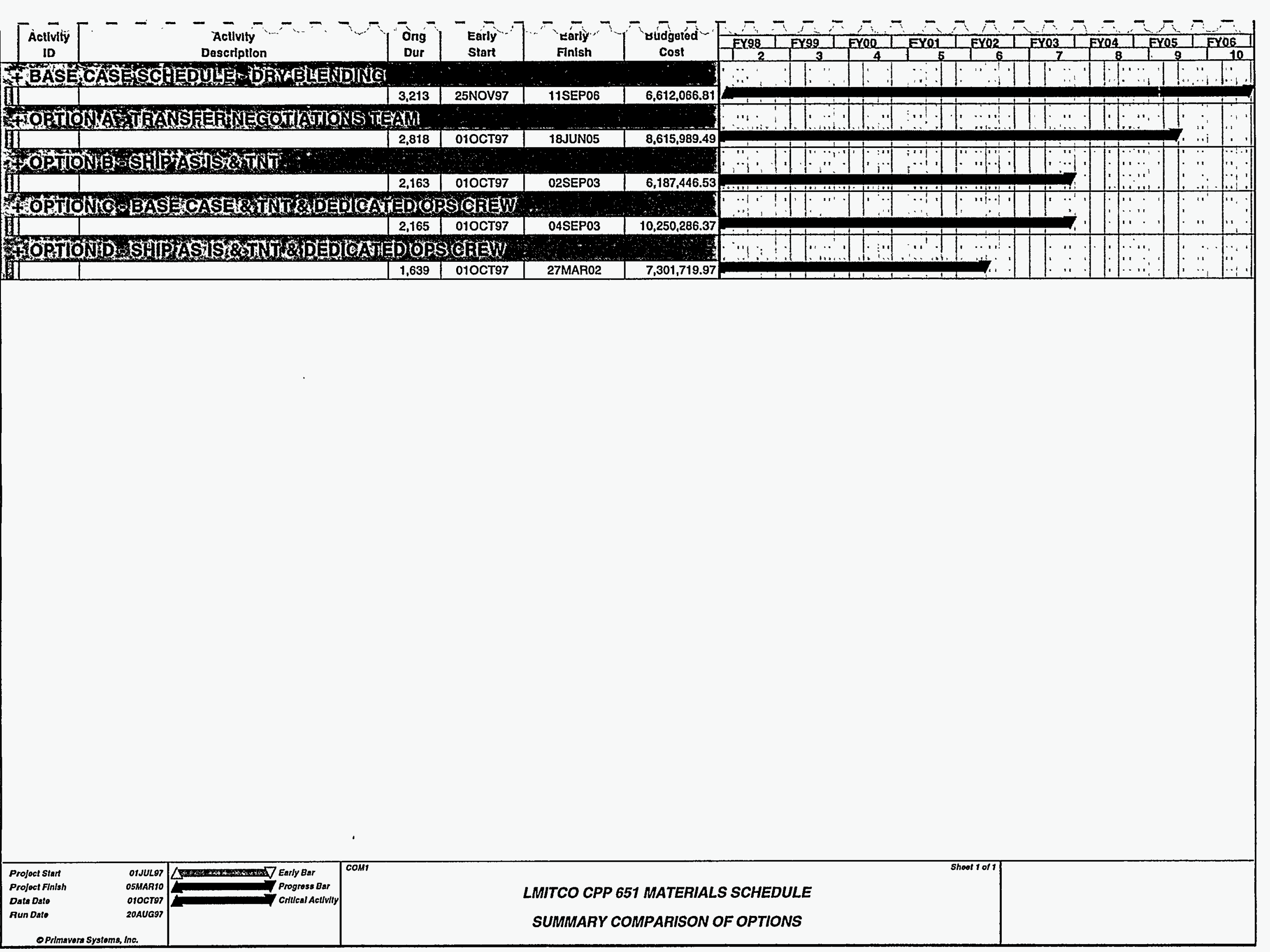




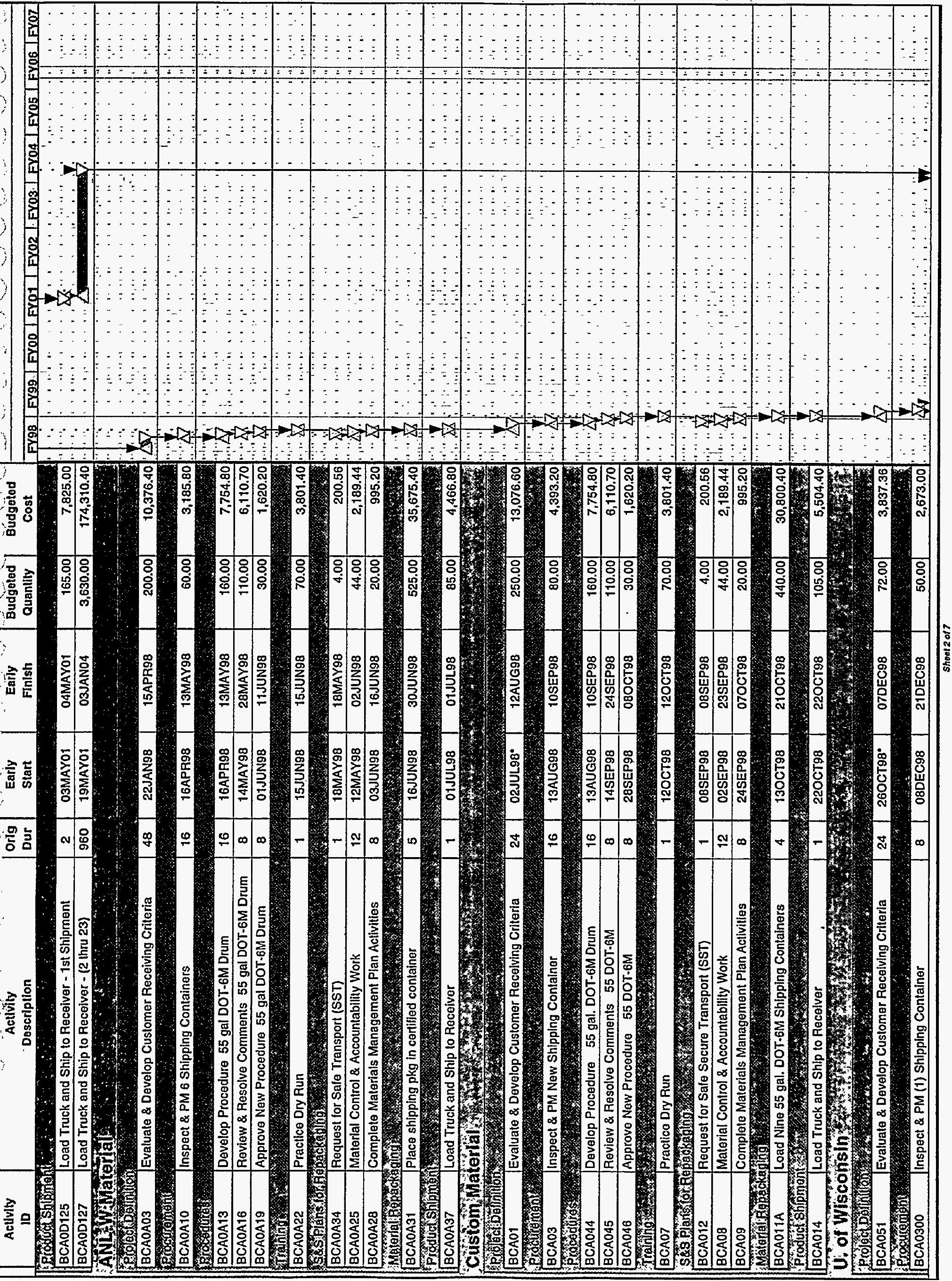




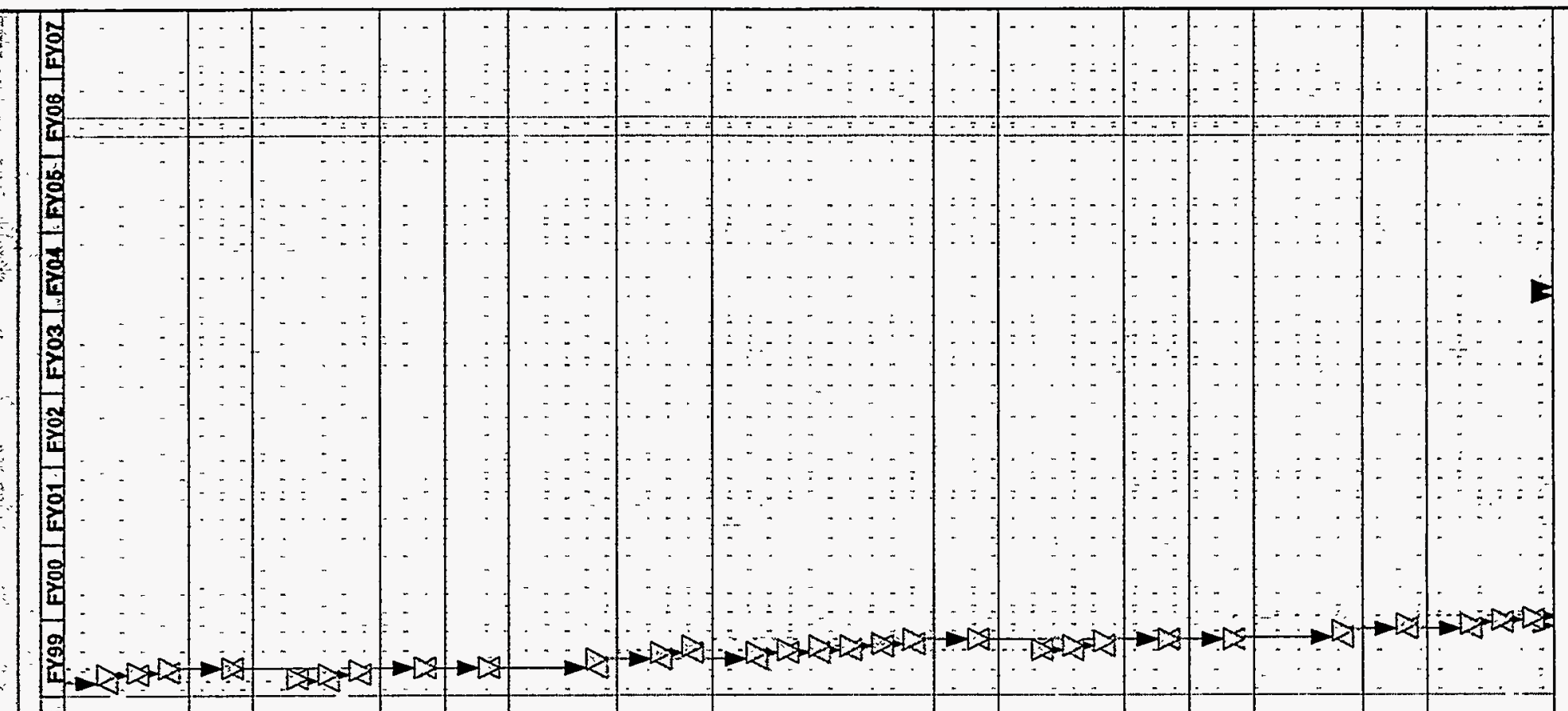

薯 Z

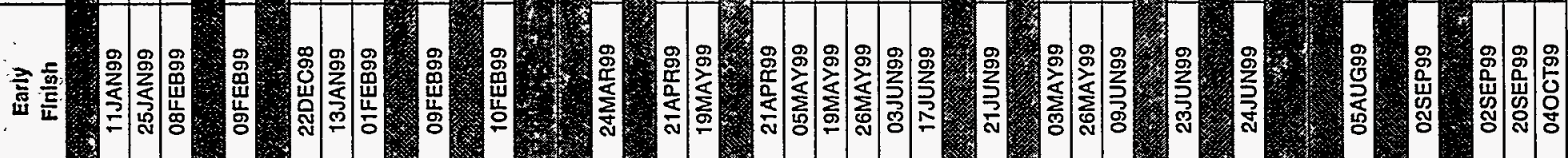

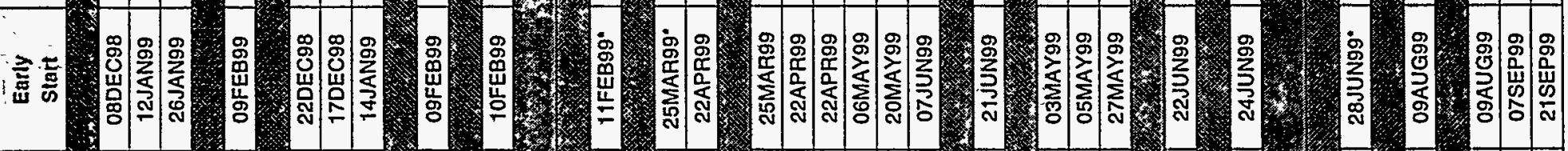
뮴 놈

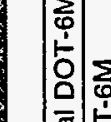
$\Sigma_{0}^{0}$ W

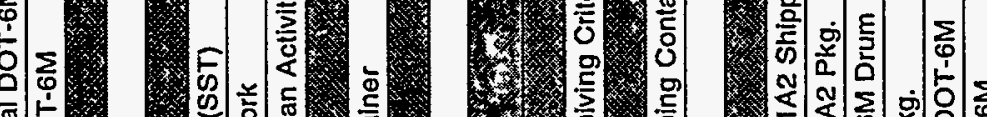

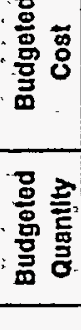

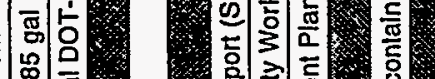

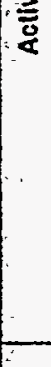

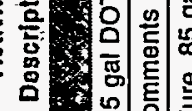

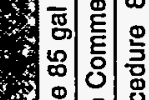

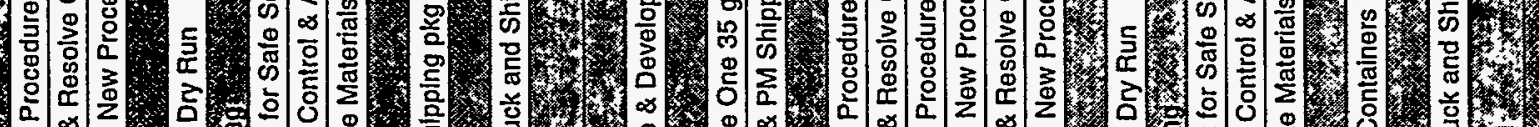
至

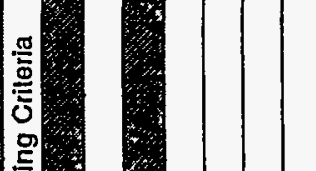
- 


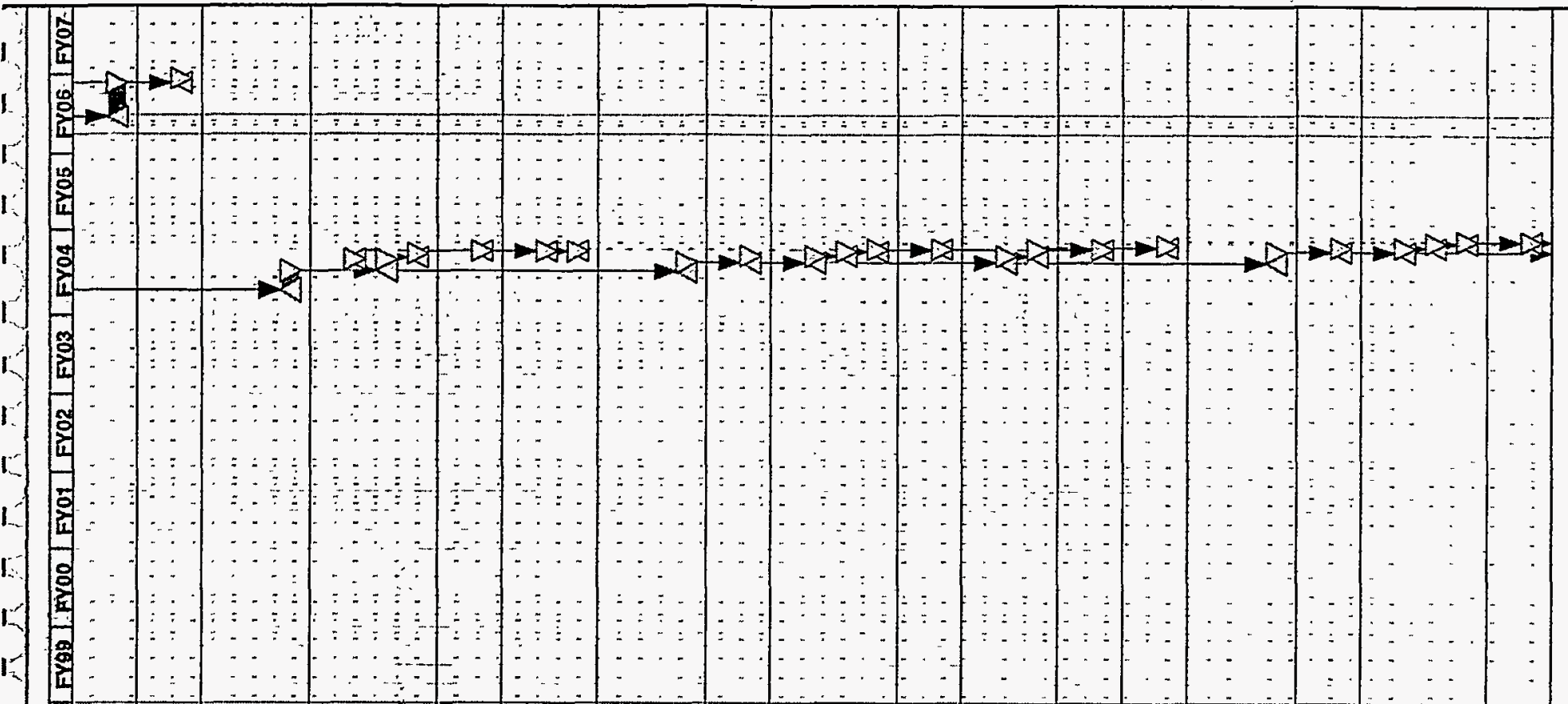

II)

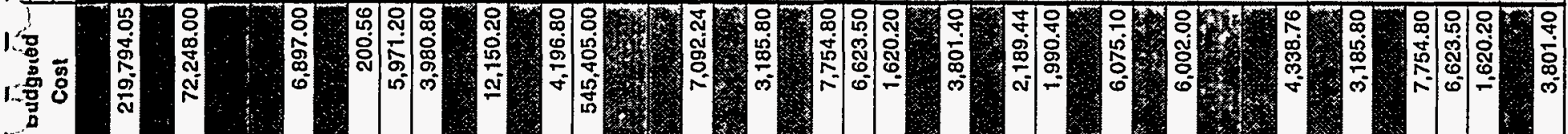

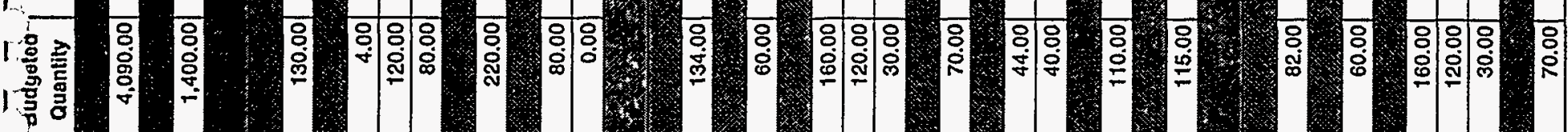

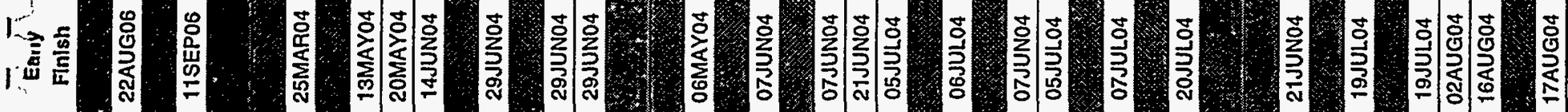
第言置 翌

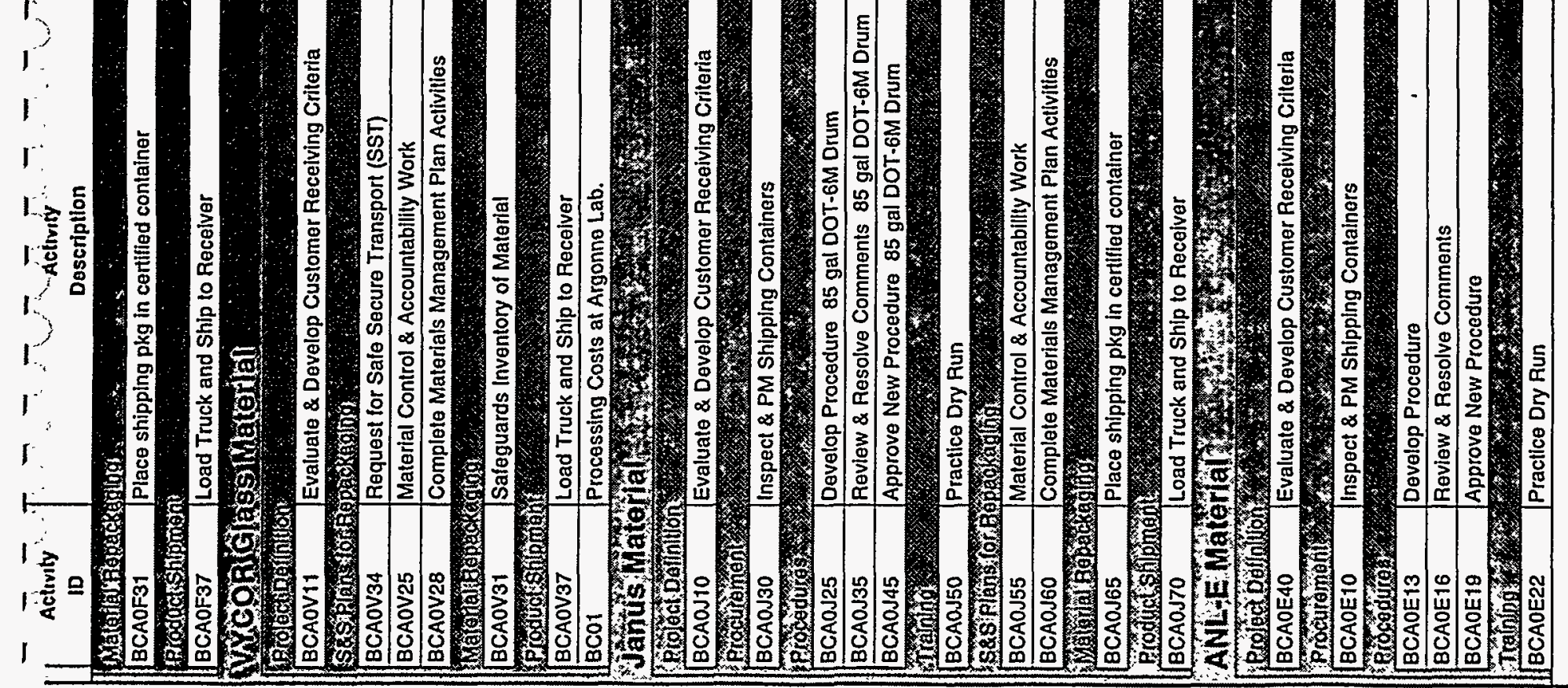




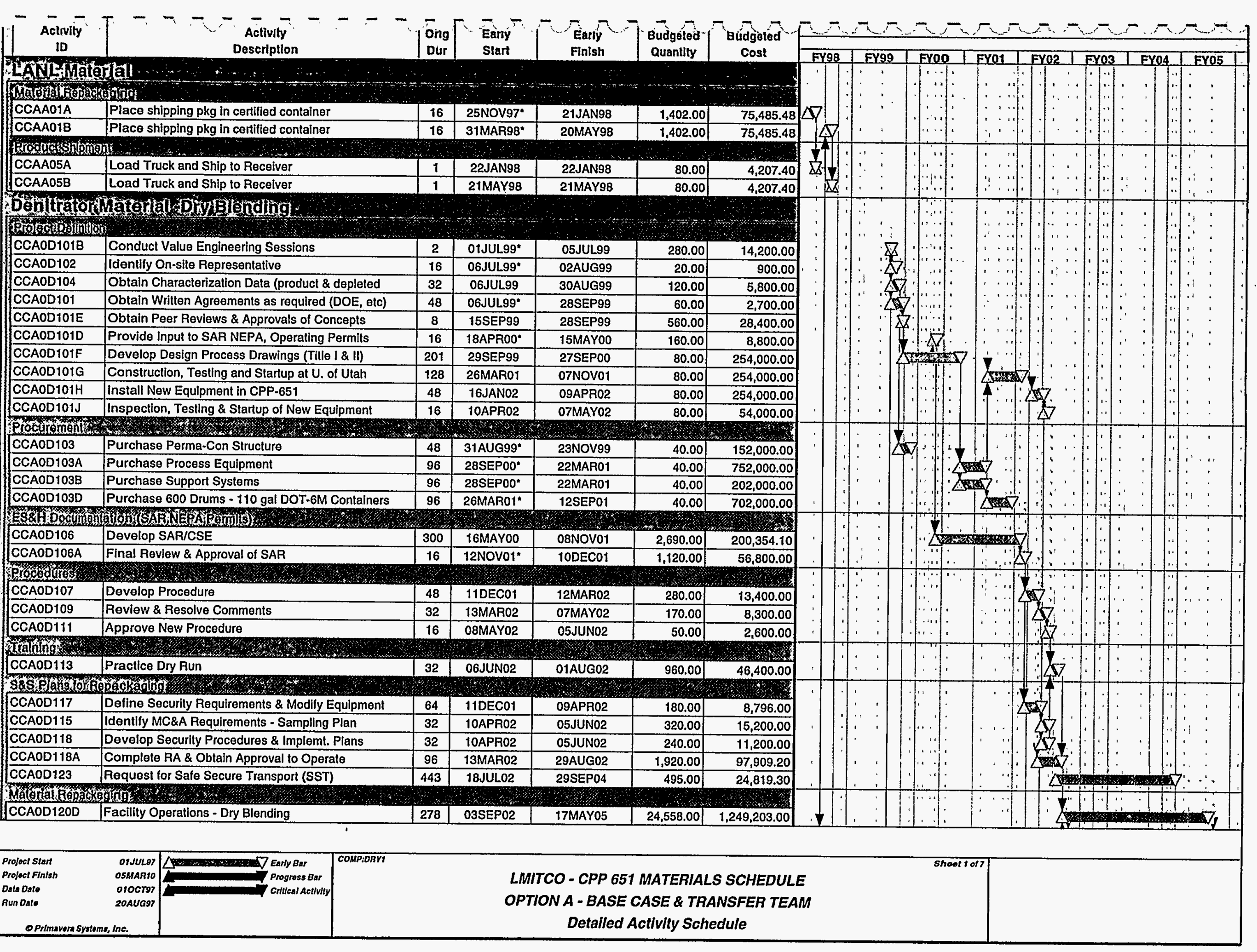




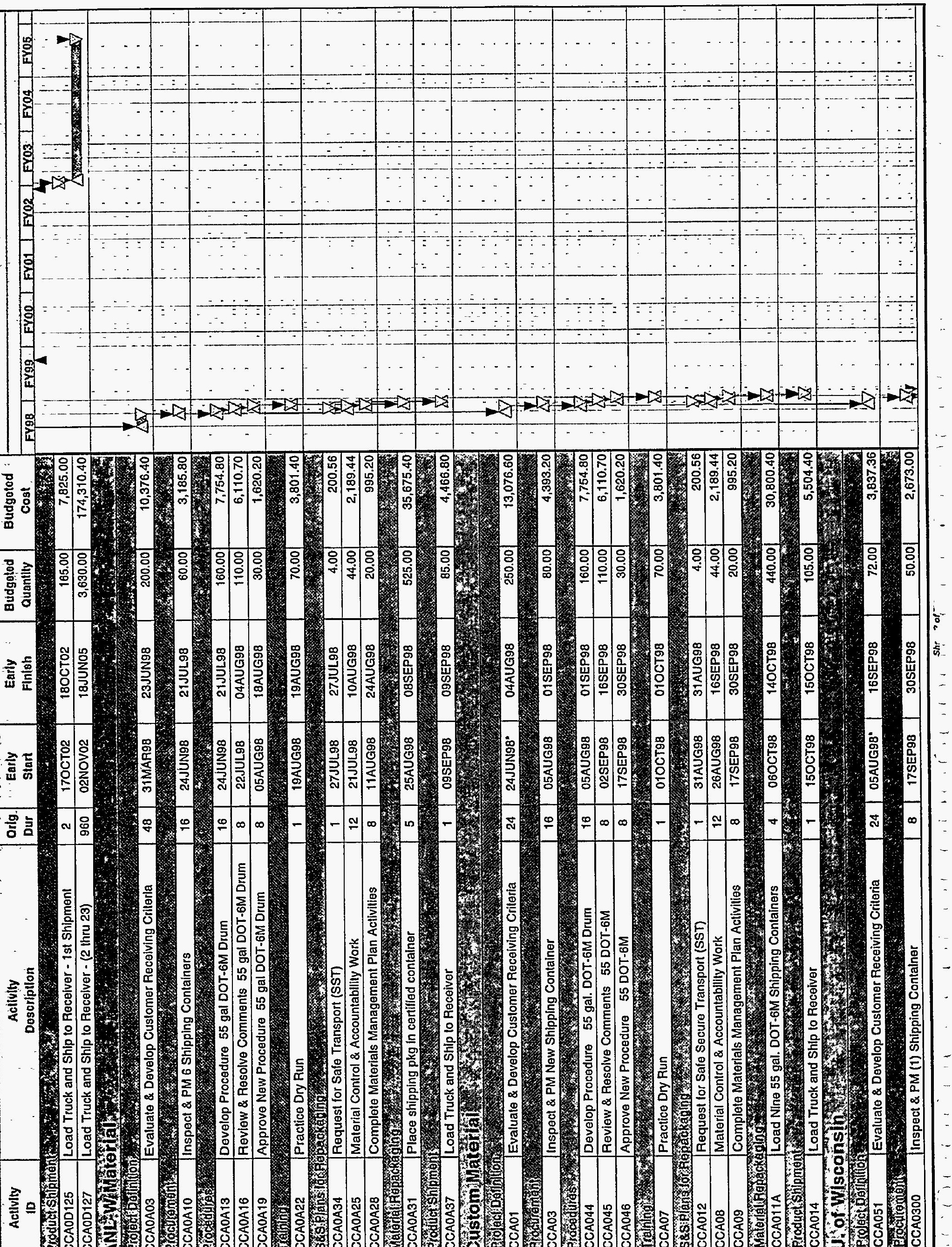




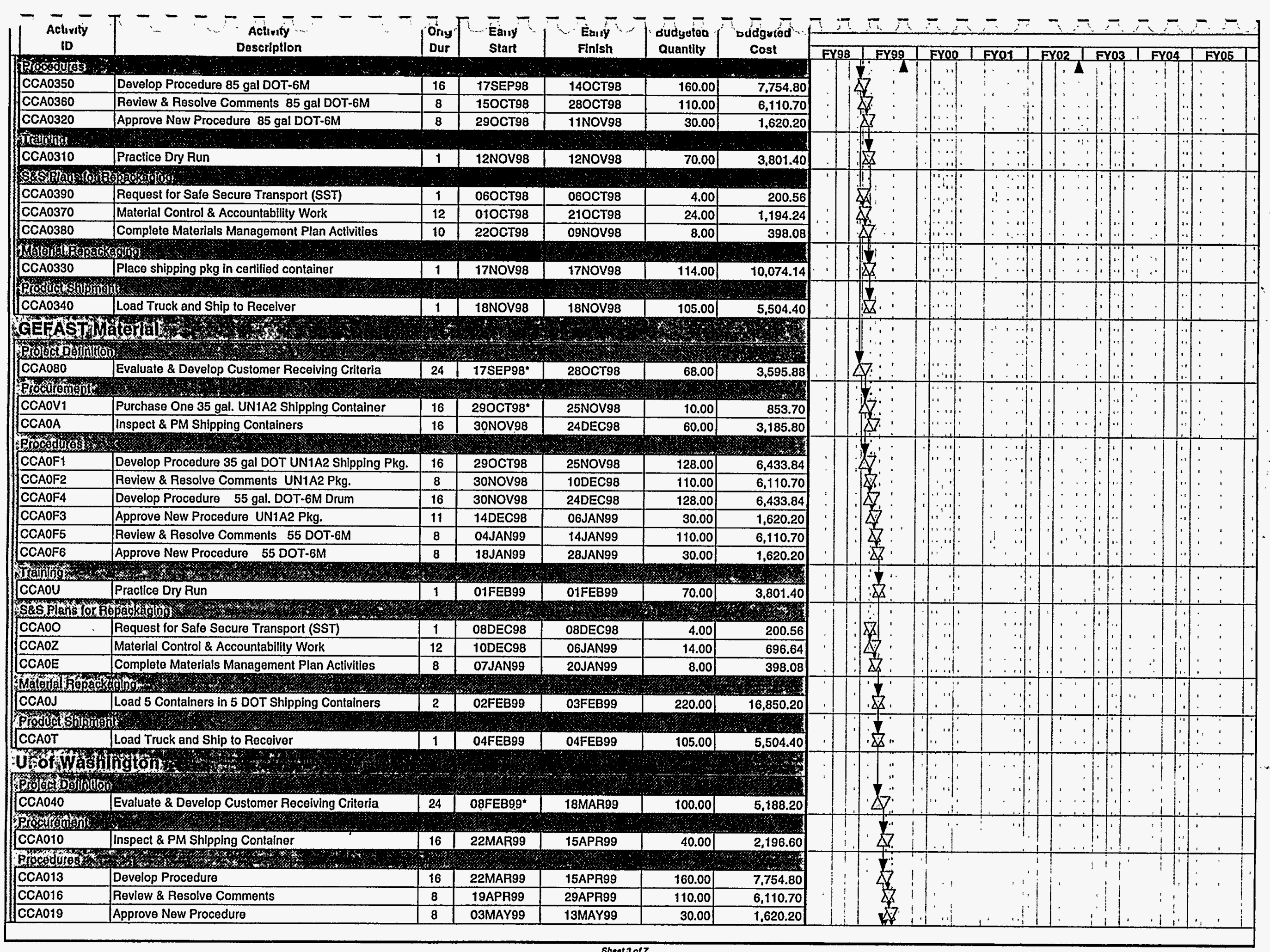




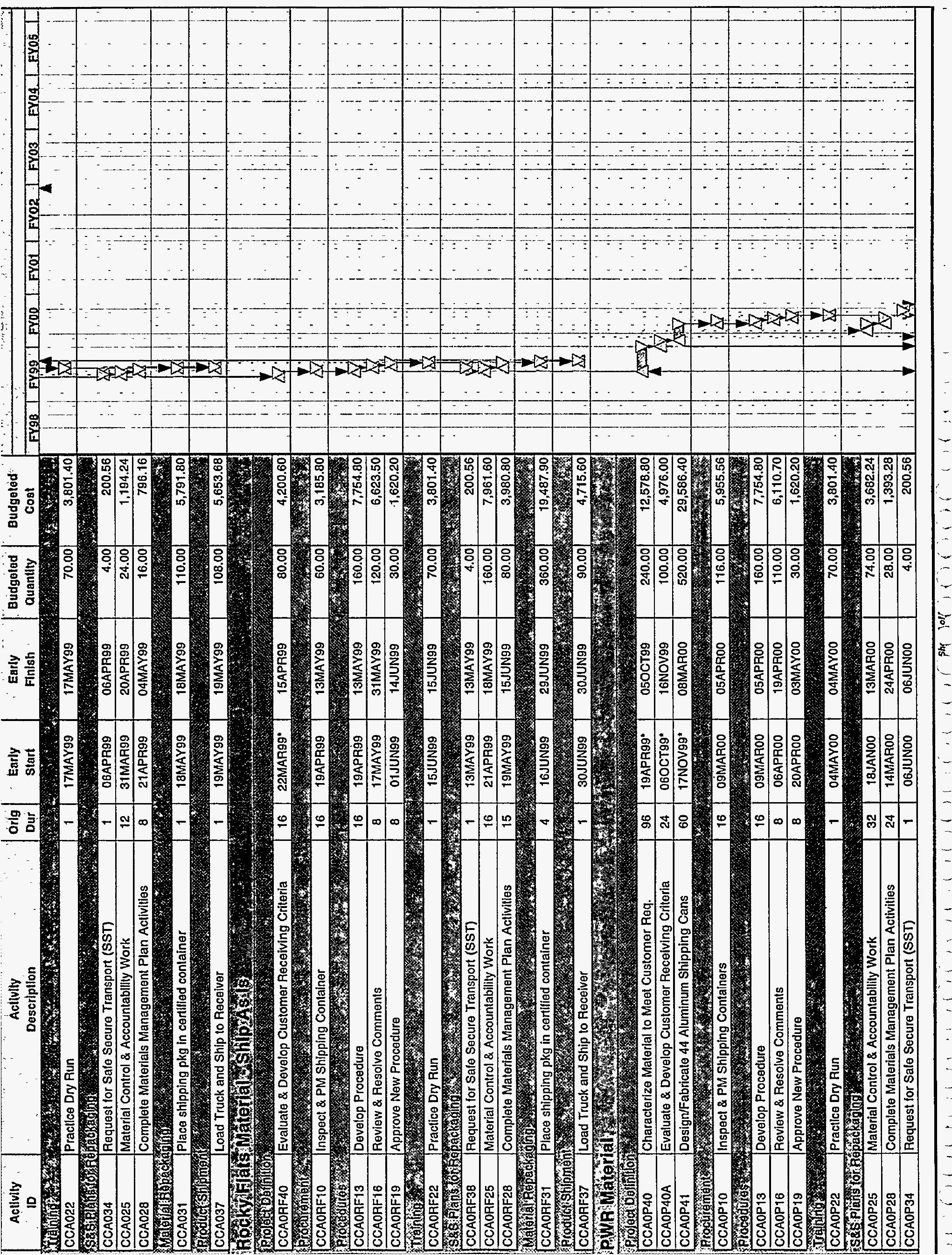




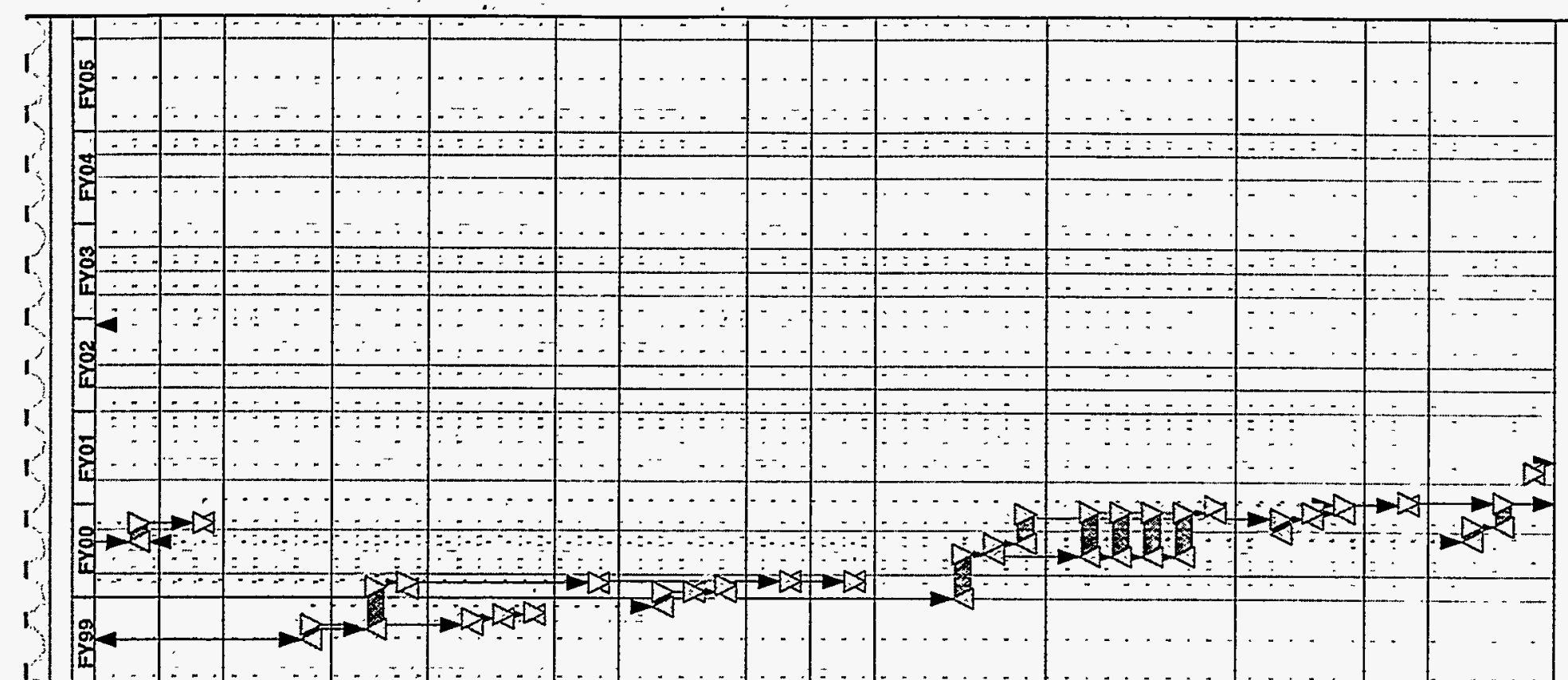

i)

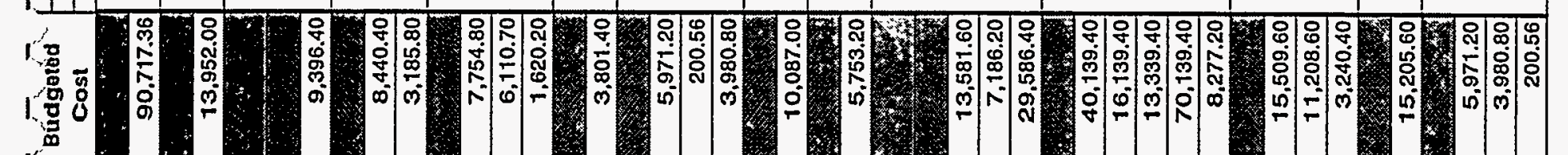

I'

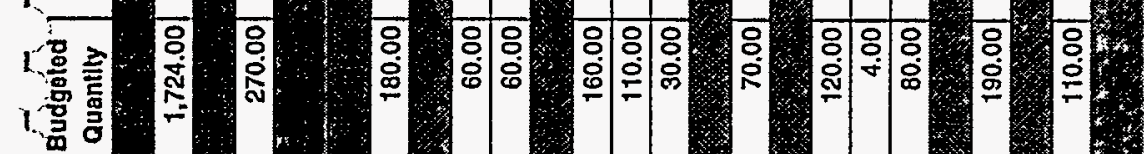

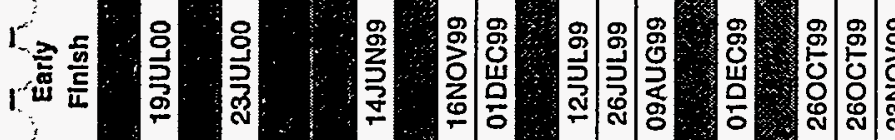

1)

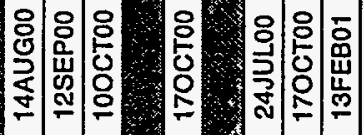

简

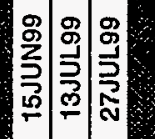

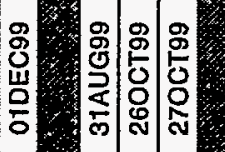

喅

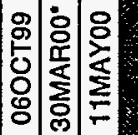

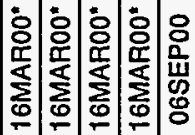

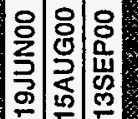

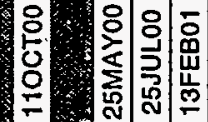

$s-\infty$

\% 니용

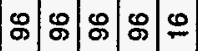

लै ๒

$\checkmark$ 임

.




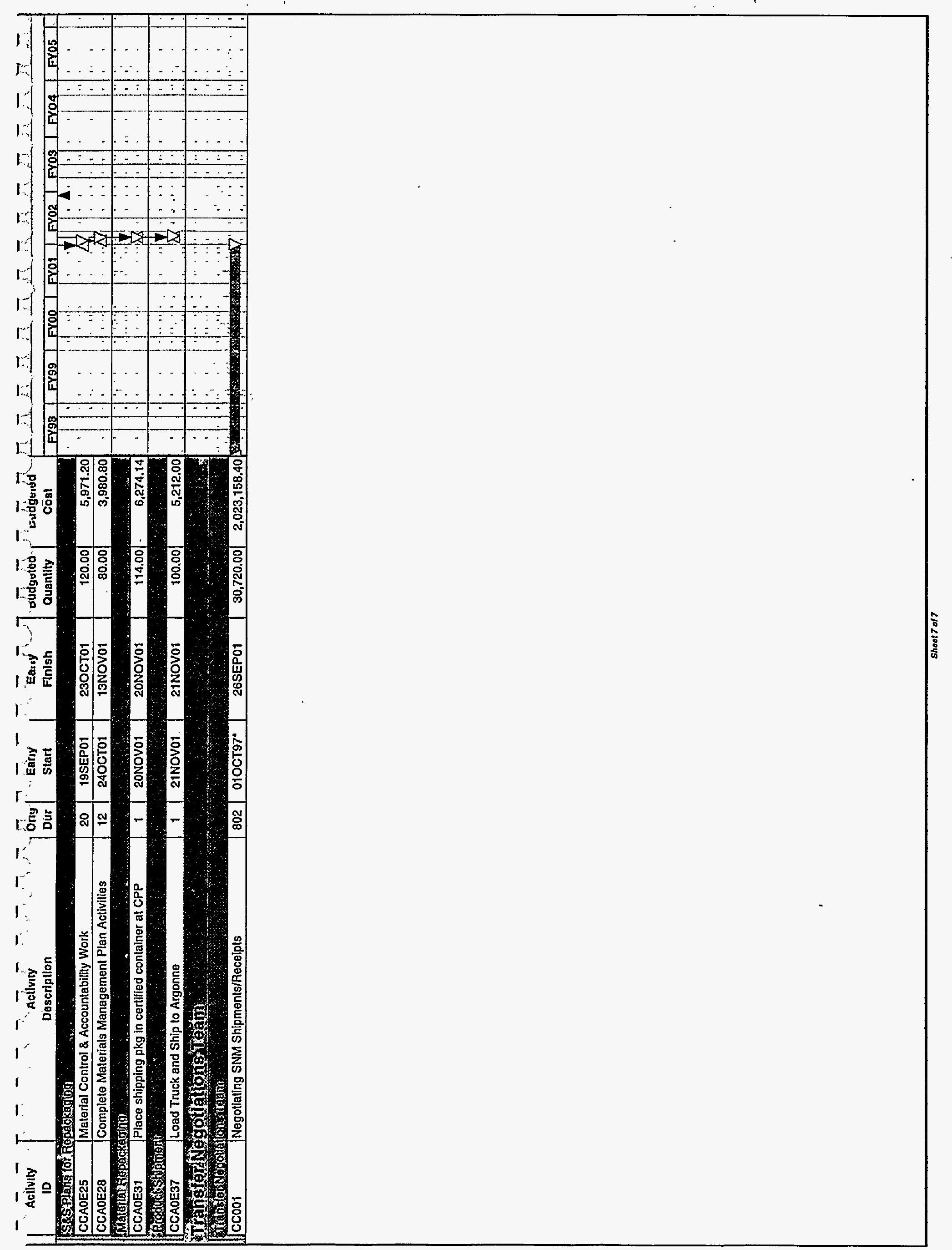









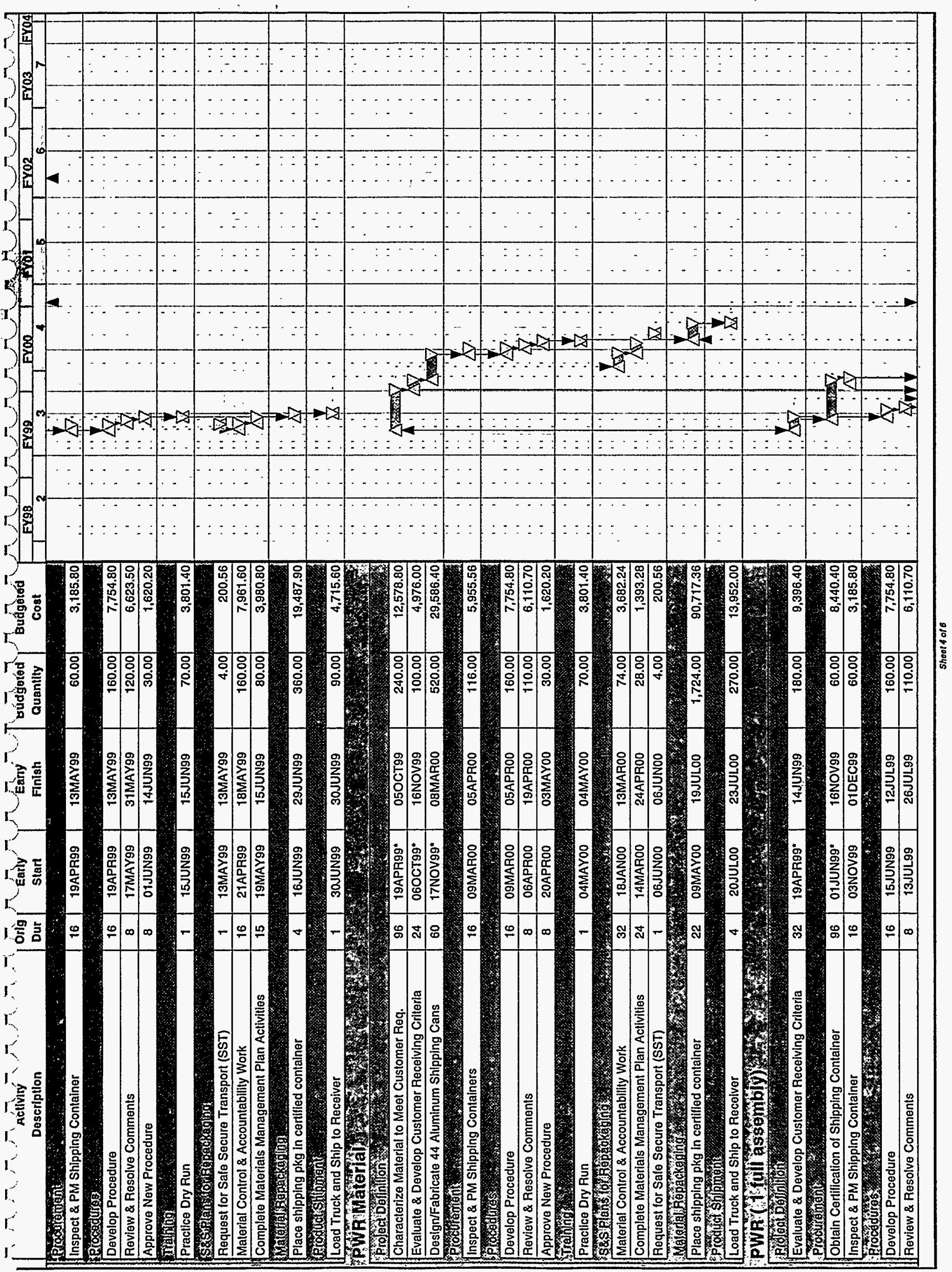




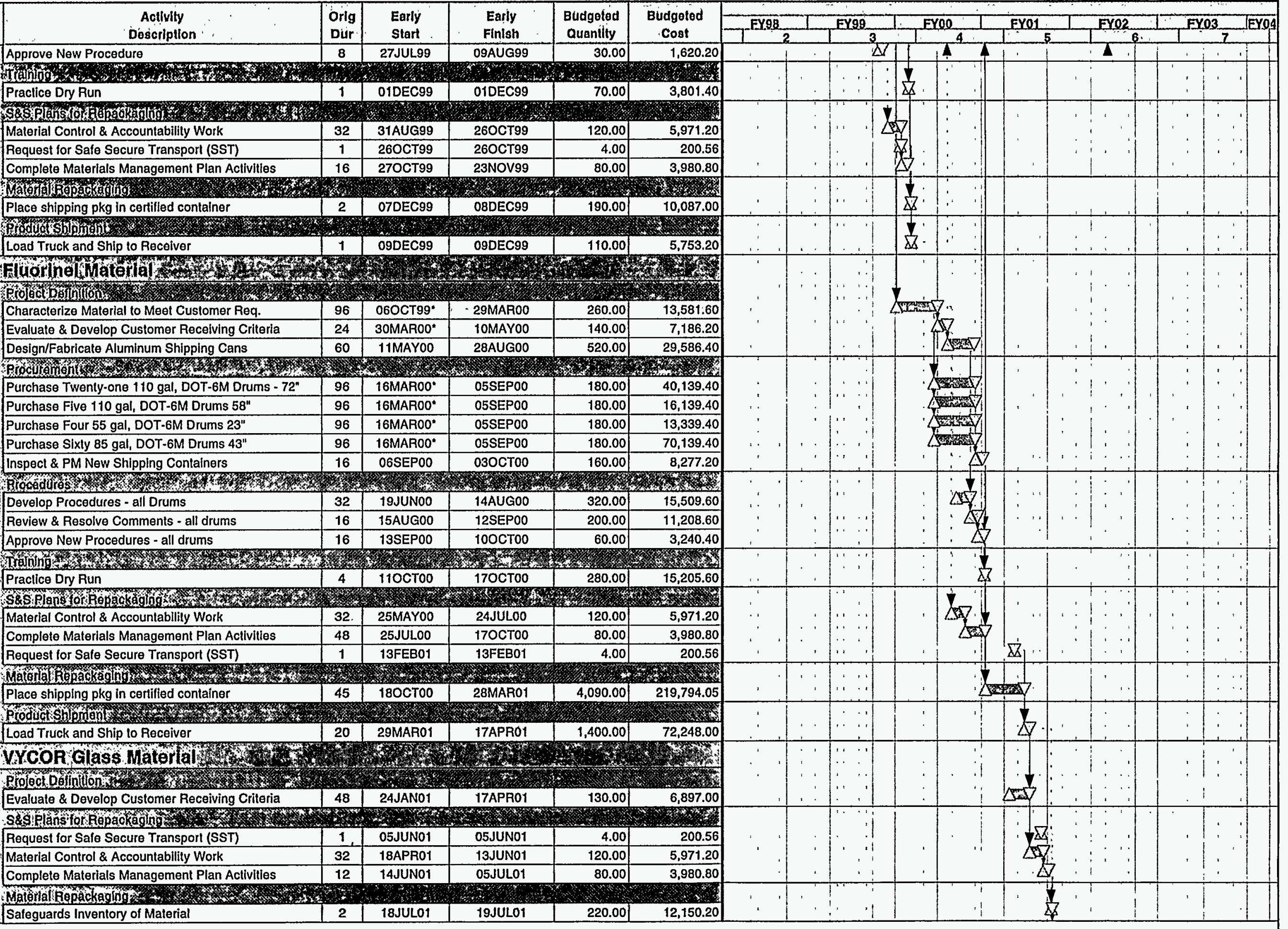


Ty

(3)

$1)$

i

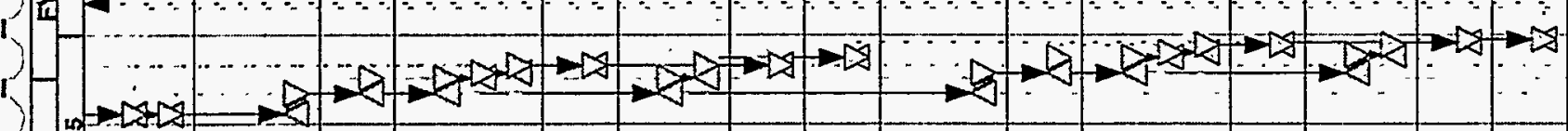

1.5

)

1.

i)

)

5

\%

1

i.

1 尔

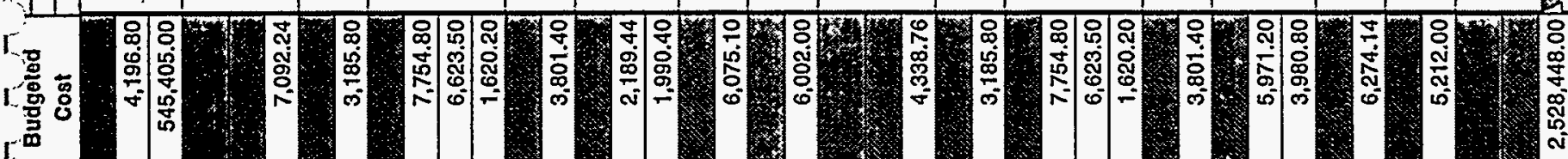

ro

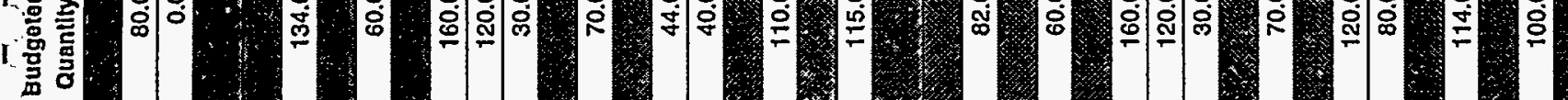

r

5

5

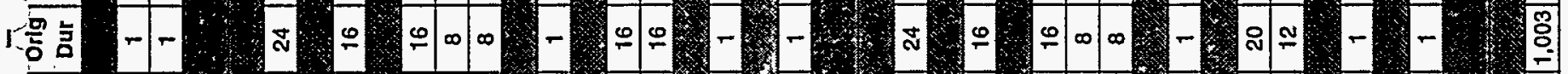




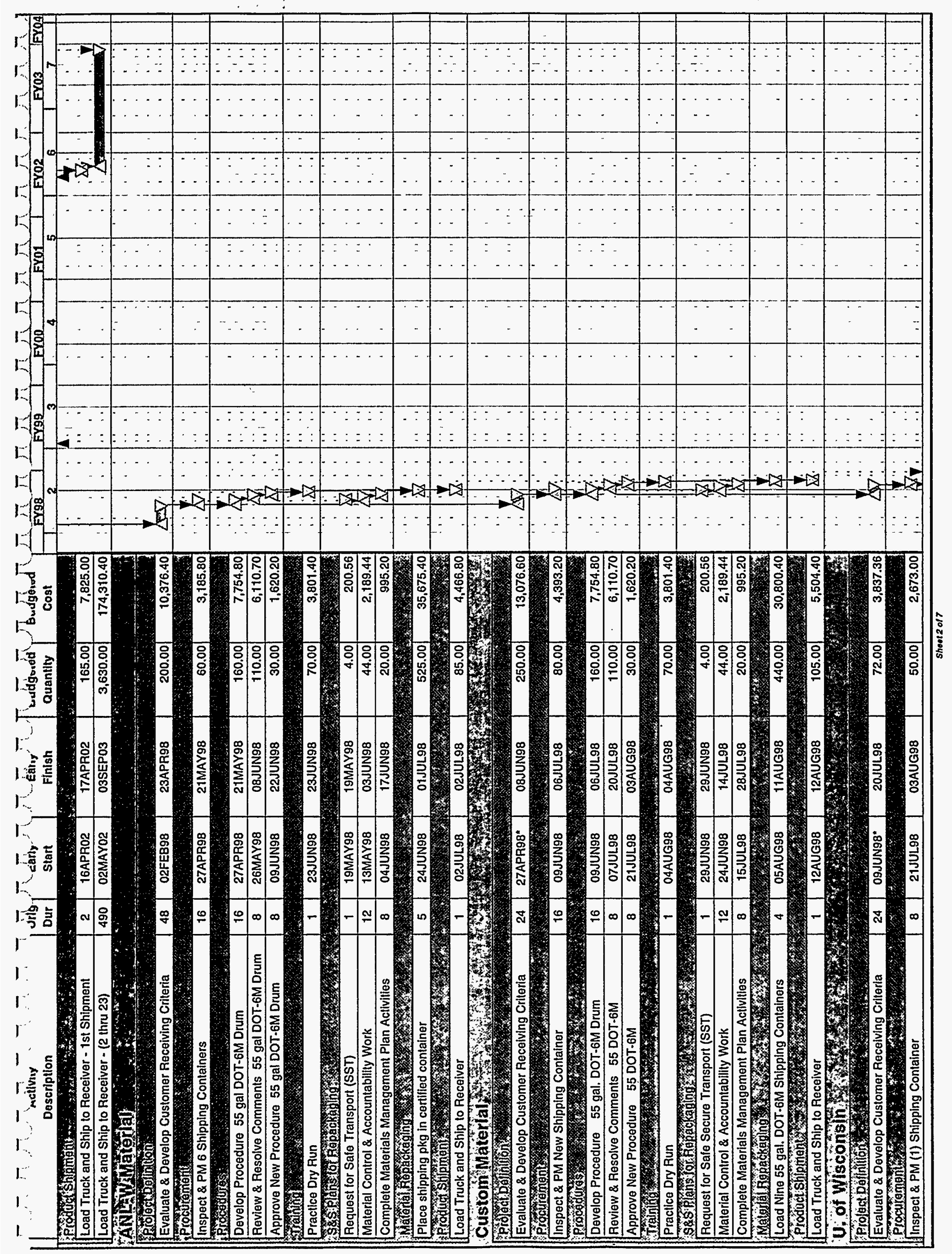




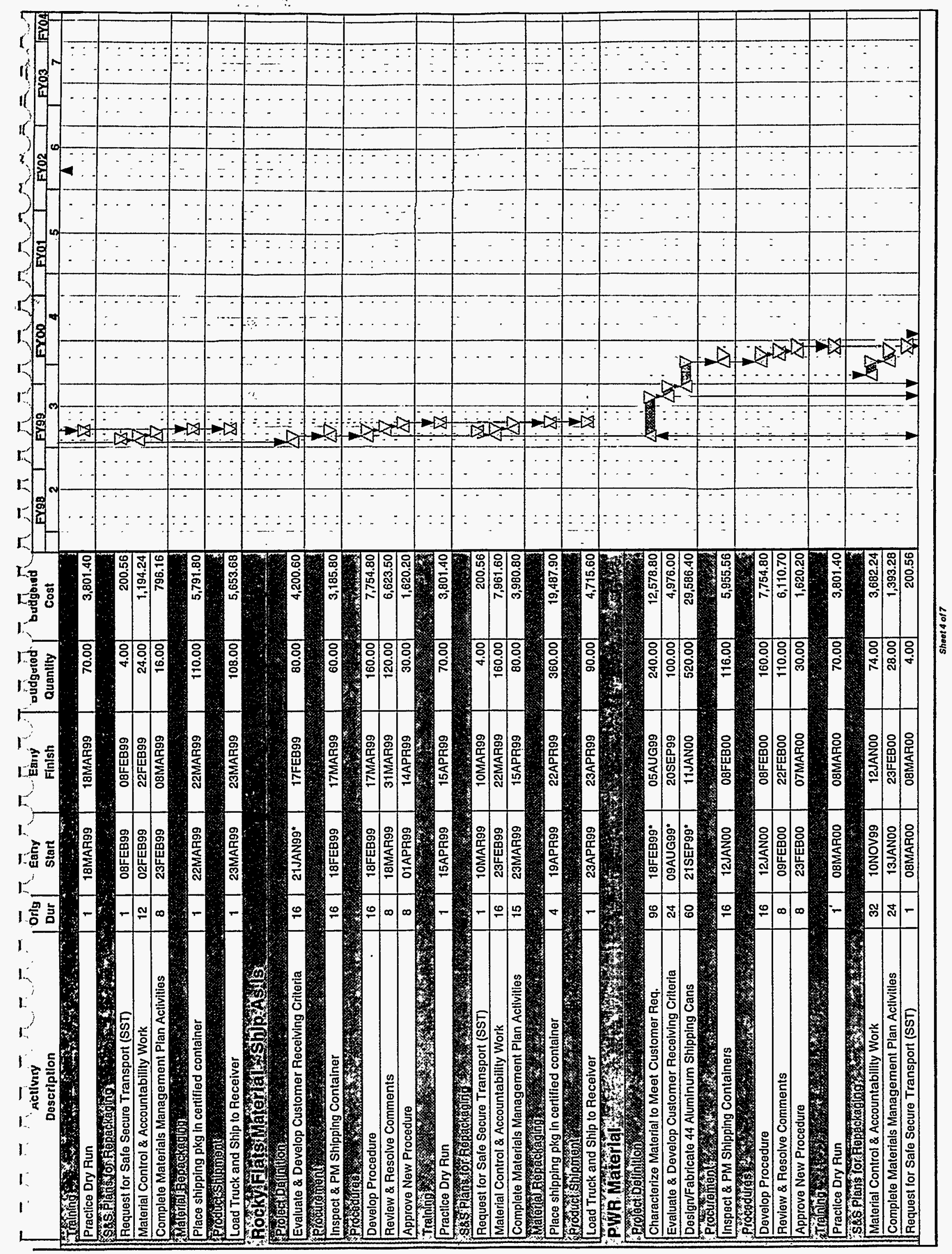




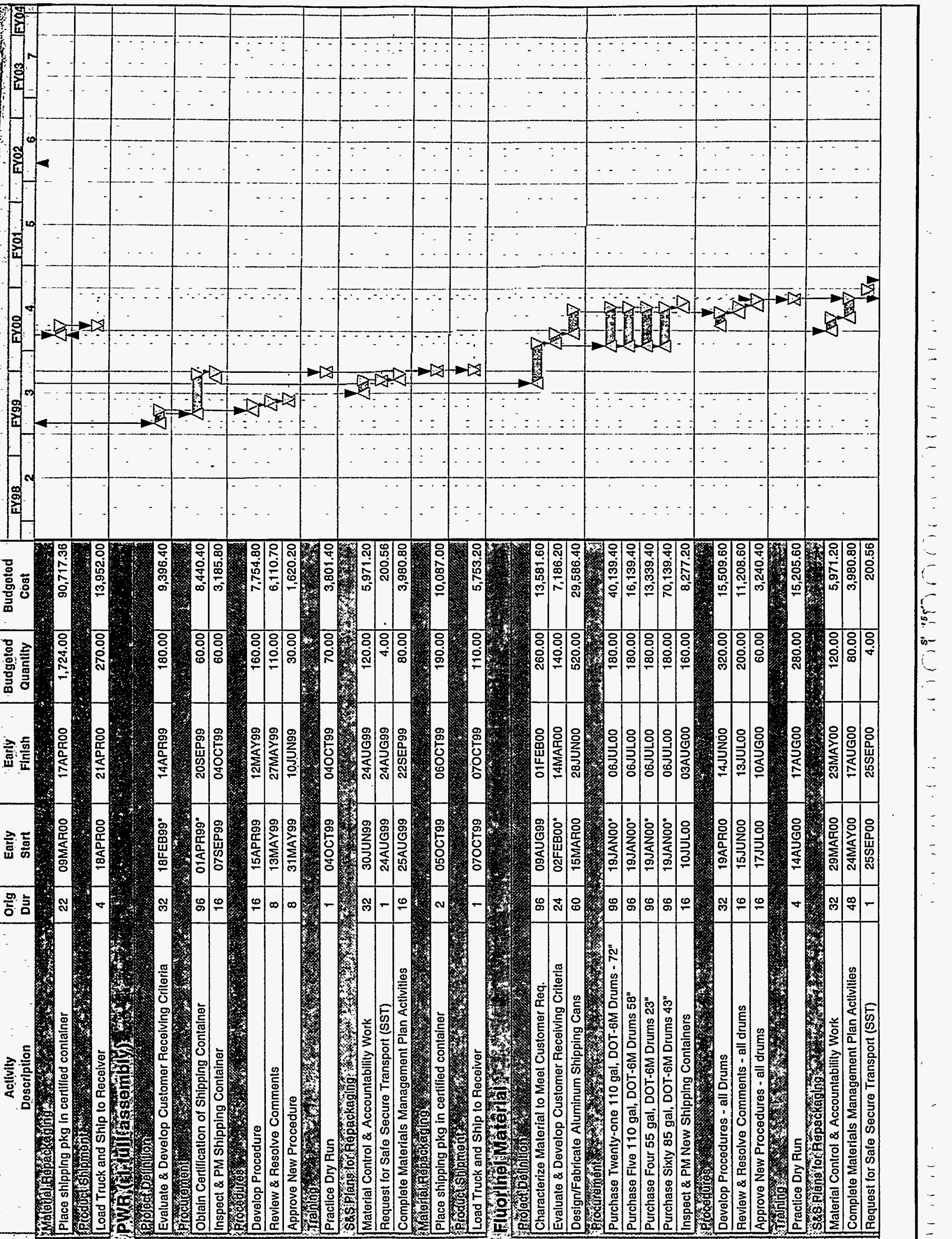




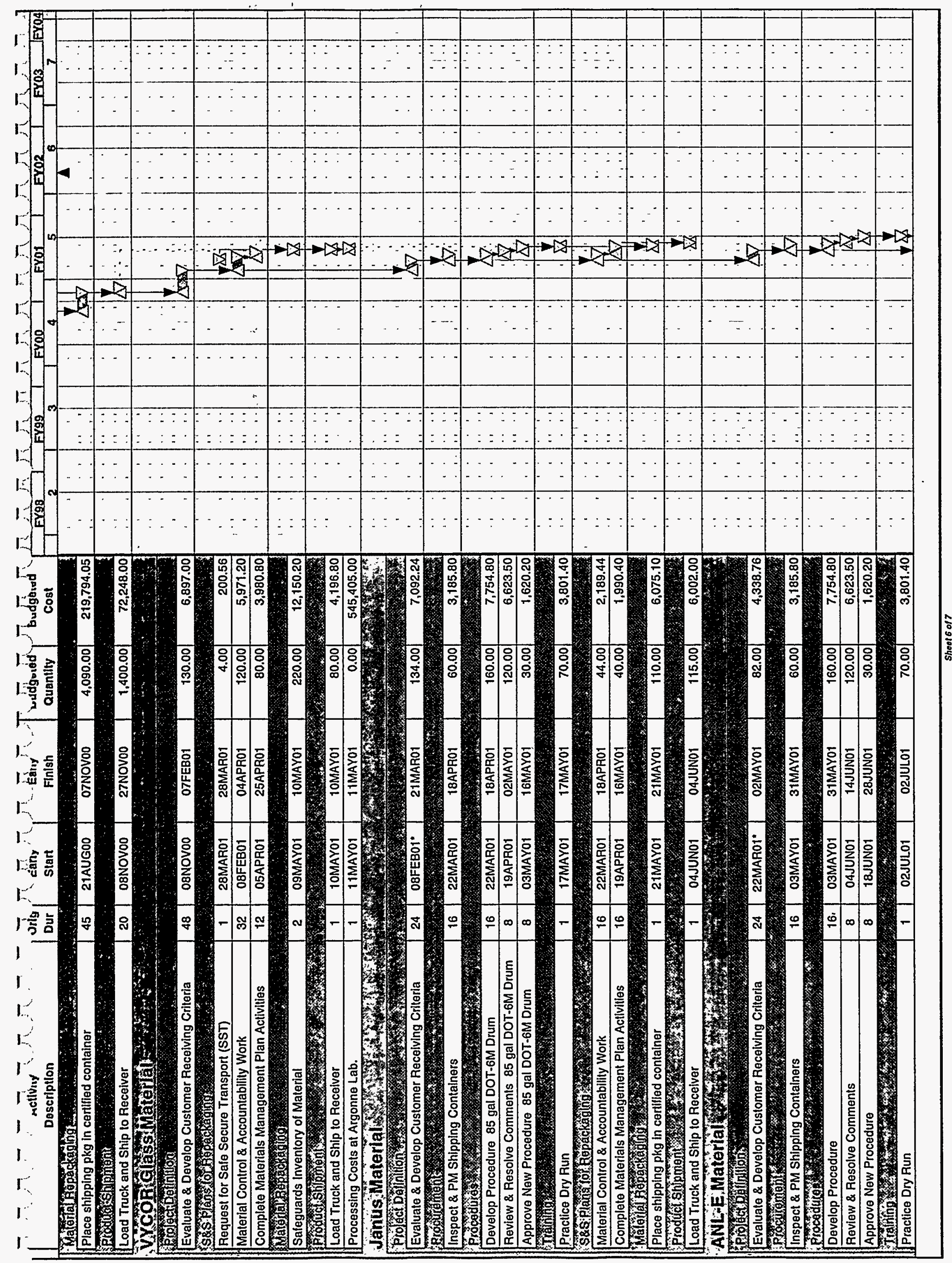




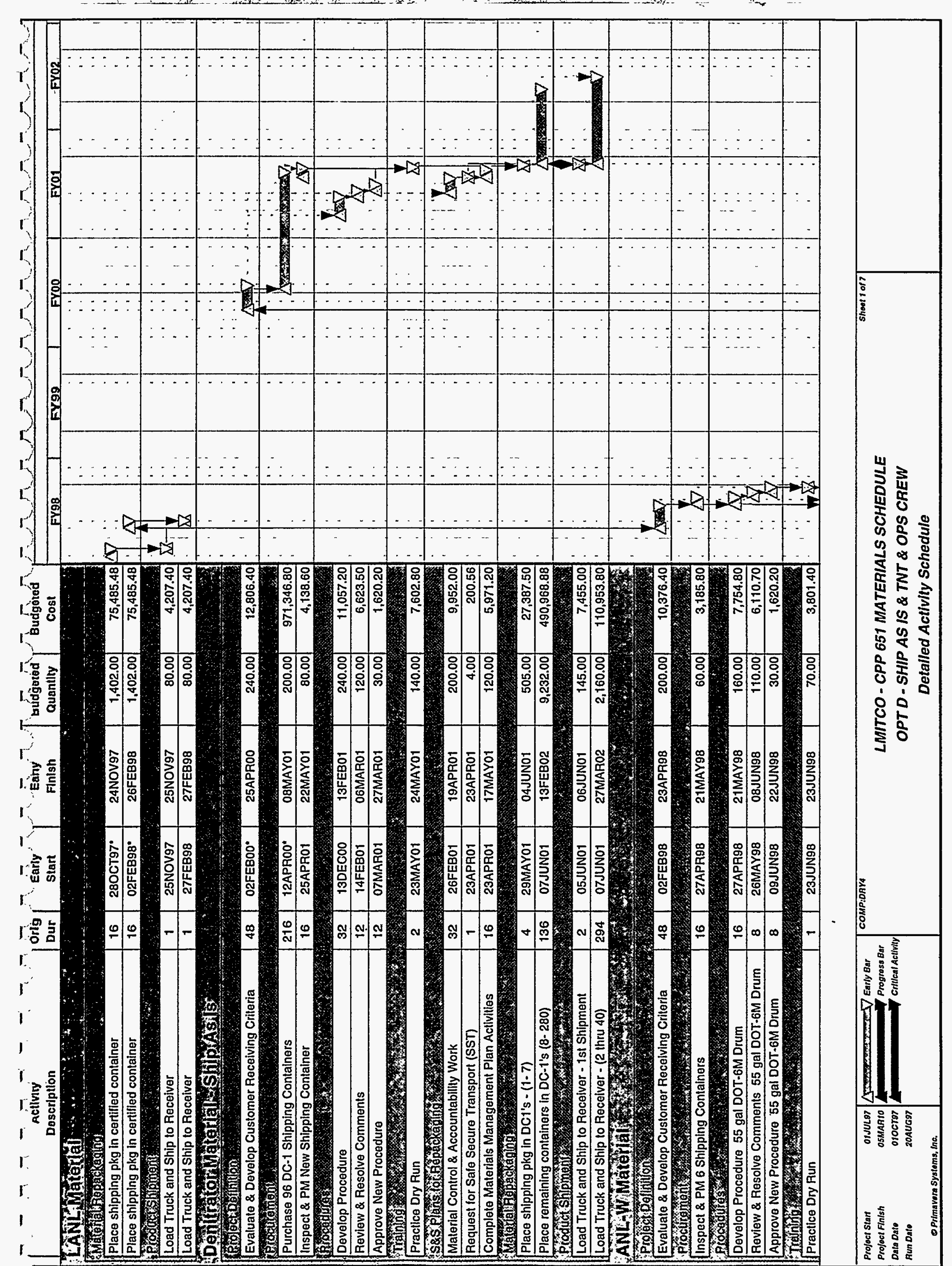




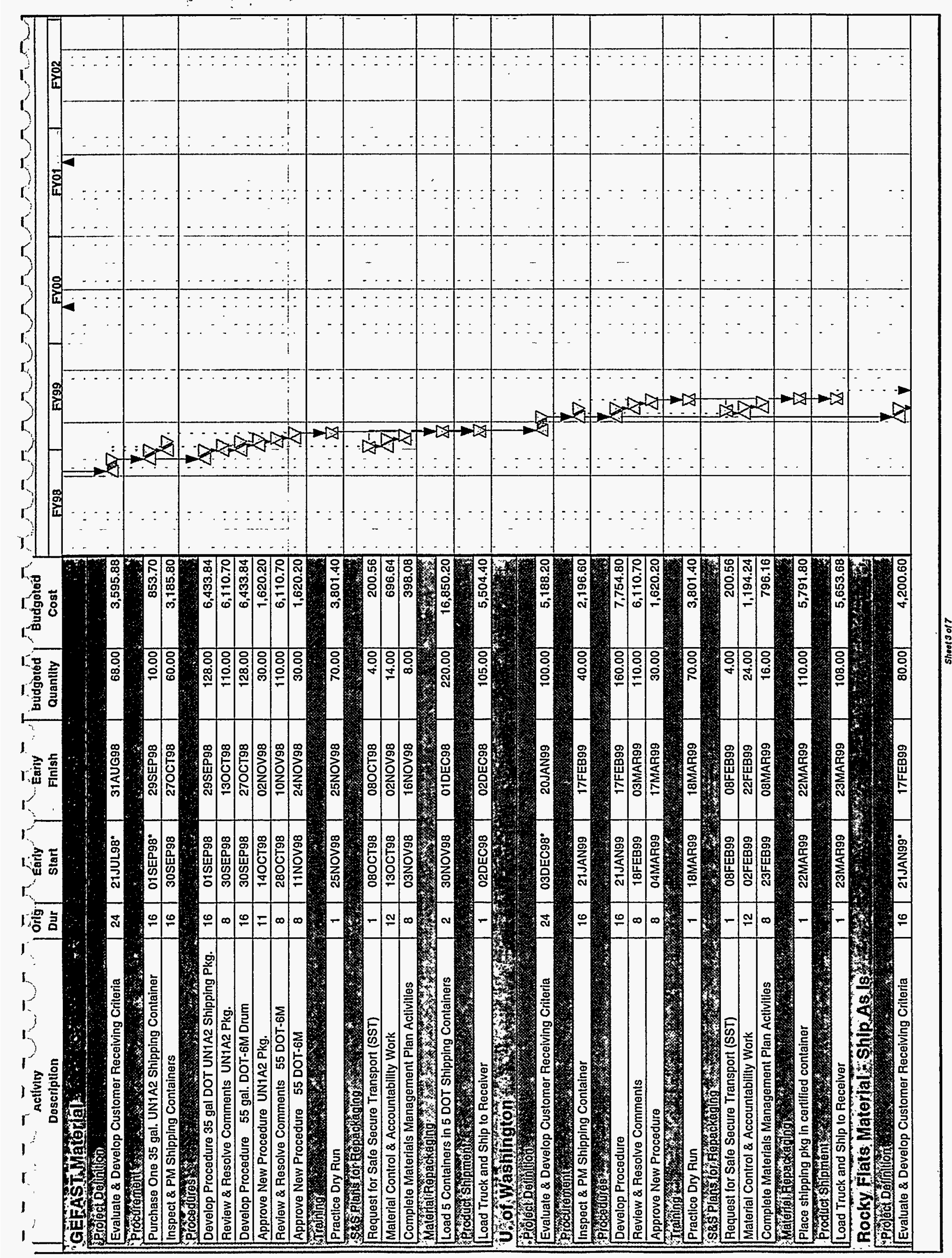




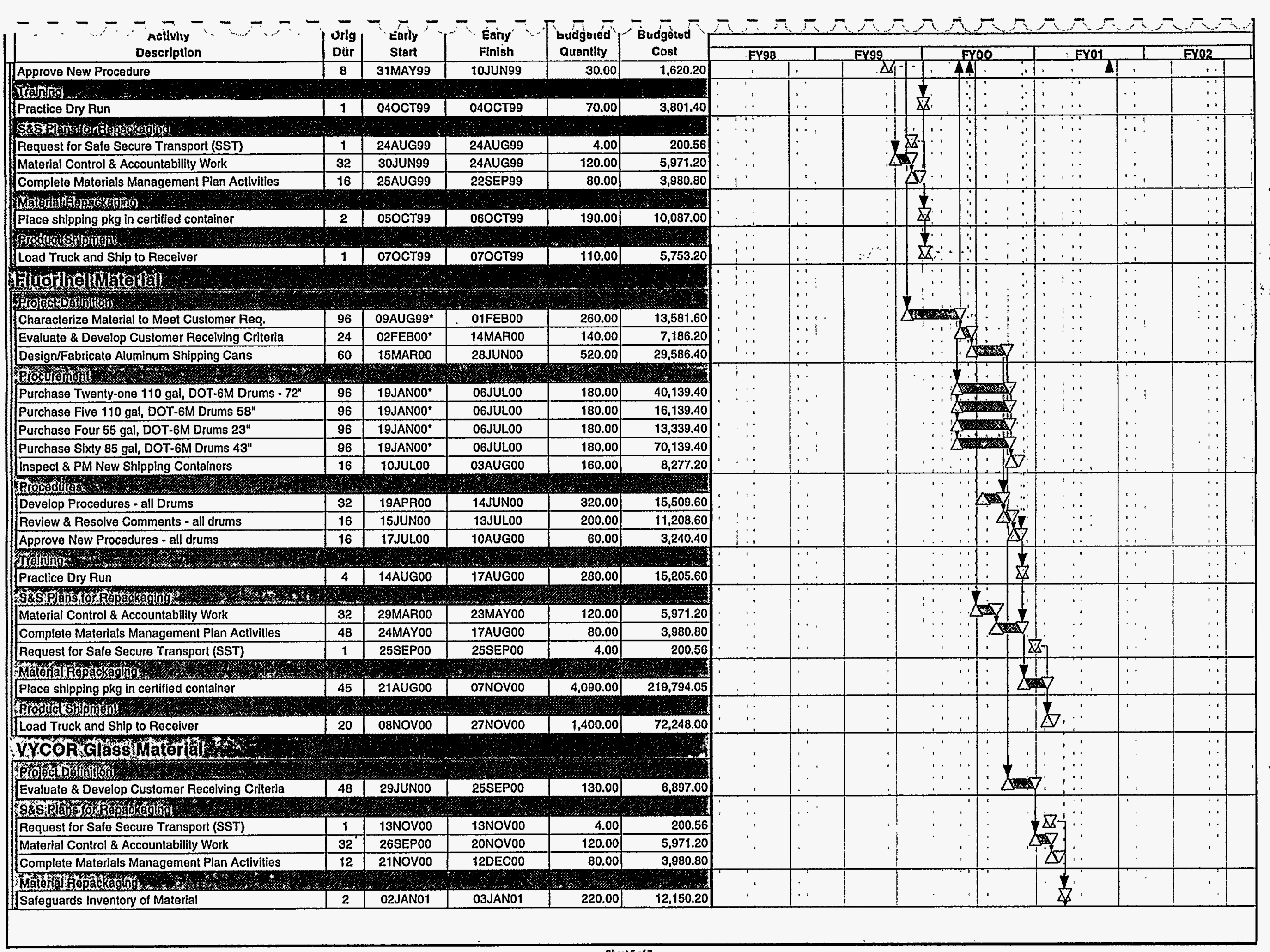




\section{Acivily \\ Descripition}

\begin{tabular}{|c|c|c|} 
Orig & Early & Early \\
Dur & Start & Finish
\end{tabular}

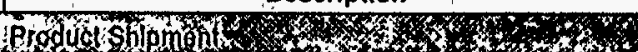

ad Truck and Ship to Recelver

Processing Costs at Argonne Lab.

Janus Material

(2)

Evaluale \& Develop Customer Recelving Criteria

Proof

Inspect \& PM Shipping Containers

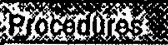

Develop Procedure 85 gal DOT-6M Drum

Review \& Resolve Comments 85 gal DOT-6M Drum

Approve New Procedure 85 gal DOT-6M Drum

Trânion

Practice Dry Rur

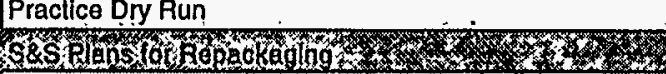

Material Control \& Accountability Work

Complete Materials Management Plan Activities

Mán

Place shipping pkg in certified container

Load Truck and Ship to Receiver

\begin{tabular}{ll|l|l|}
1 26APR01 - 26APR01 & 115.00 & $6,002.00$ \\
\hline
\end{tabular}

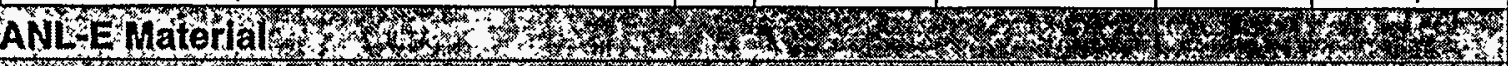

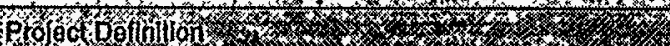

Evaluate \& Develop Customer Receiving Criteria Piocuteno inspect \& PM Shipping Containers

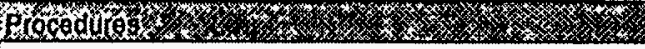

Develop Procedure

Review \& Resolve Comments

Approve New Procedure

\begin{tabular}{l|l|l}
16 & 29MARO1 & 25APR01 \\
\hline
\end{tabular}

60.00

160.00 8 10 MAYO1 23MAYO1

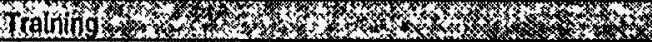

Practice Dry Run

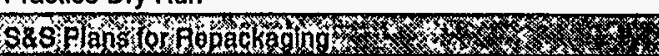

Material Control \& Accountability Work

Complete Materials Management Plan Activities

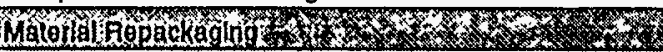

Place shipping pkg in certifited container at CPP

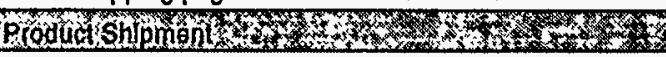

Load Truck and Ship to Argonne

Transfêr Negotiations Team $\mathrm{m} / \mathrm{k}$

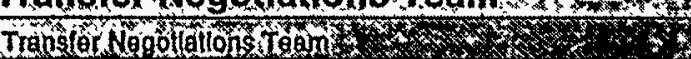

Negoliating SNM Shipments/Receipis

Added Cost 5 Dedicated Oneration

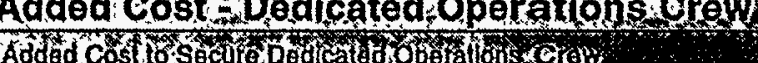

Training

SNM Fuel Handling Operations \begin{tabular}{|l|l|l|}
\hline 16 & 29MAR01 & 25APRO1 \\
\hline
\end{tabular}

\begin{tabular}{|c|c|c}
\hline 8 & 26APR01 & 09MAY01 \\
\hline 8 & 10MAY01 & 23MAY01 \\
\hline
\end{tabular}

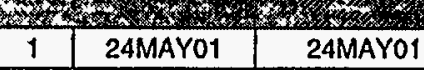

\begin{tabular}{|l|l|l}
\hline 96 & O1APR99* \\
\hline
\end{tabular}

O1APR99

20SEP99 26SEP00

\begin{tabular}{|r|r|}
\hline 160.00 & $7,754.80$ \\
\hline 120.00 & $6,623.50$ \\
\hline 30.00 & $1,620.20$ \\
\hline
\end{tabular}

(3.00)

\begin{tabular}{rr|r|}
70.00 & $3,801.40$ \\
\hline
\end{tabular} \begin{tabular}{|l|l|l|r|r|}
\hline 20 & $29 M A R 01$ & $02 M A Y 01$ & 120.00 & $5,971.20$ \\
\hline
\end{tabular} 12 O3MAY01 23MAY01

\begin{tabular}{l|l|l}
\hline 1 & $29 M A Y 01$ & $29 M A Y 01$ \\
\hline
\end{tabular}

\begin{tabular}{|r|r|}
\hline 120.00 & $5,971.20$ \\
\hline 80.00 & $3,980.80$ \\
\hline
\end{tabular}

\begin{tabular}{|r|r|}
\hline 114.00 & $6,274.14$ \\
\hline
\end{tabular}

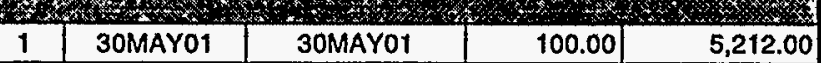
H. 26SEP01

\begin{tabular}{|l|l|}
\hline $30,720.00$ & $2,023,158.40$ \\
\hline
\end{tabular} \begin{tabular}{|r|r|}
\hline & \\
\hline & \\
\hline $5,760.00$ & $298,828.80$ \\
\hline $9,022.00$ & $464,761.36$ \\
\hline
\end{tabular}

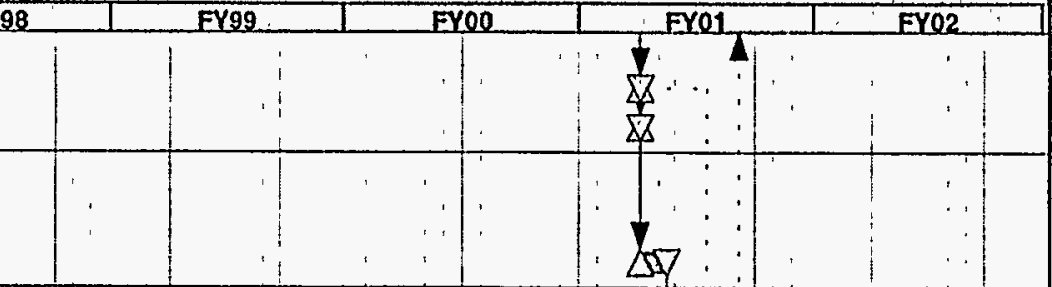
.

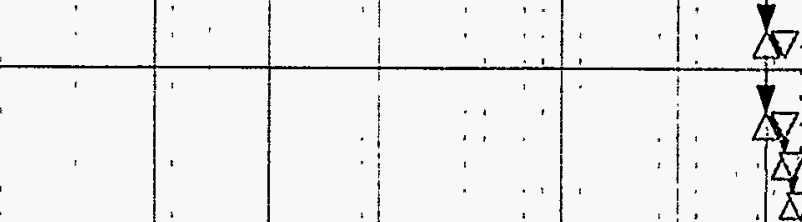

离
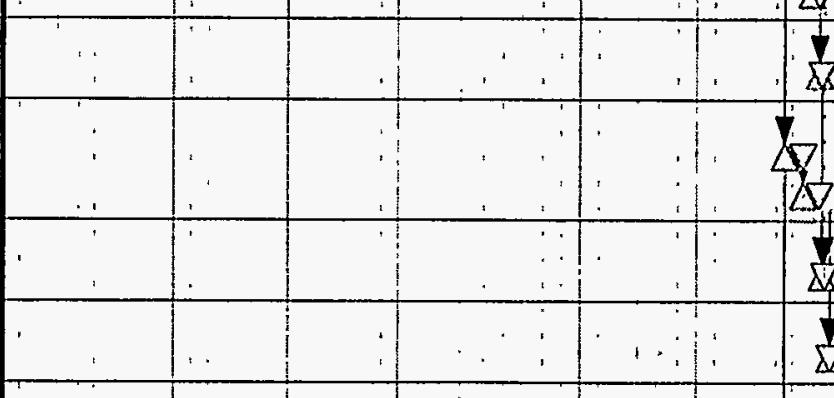

这

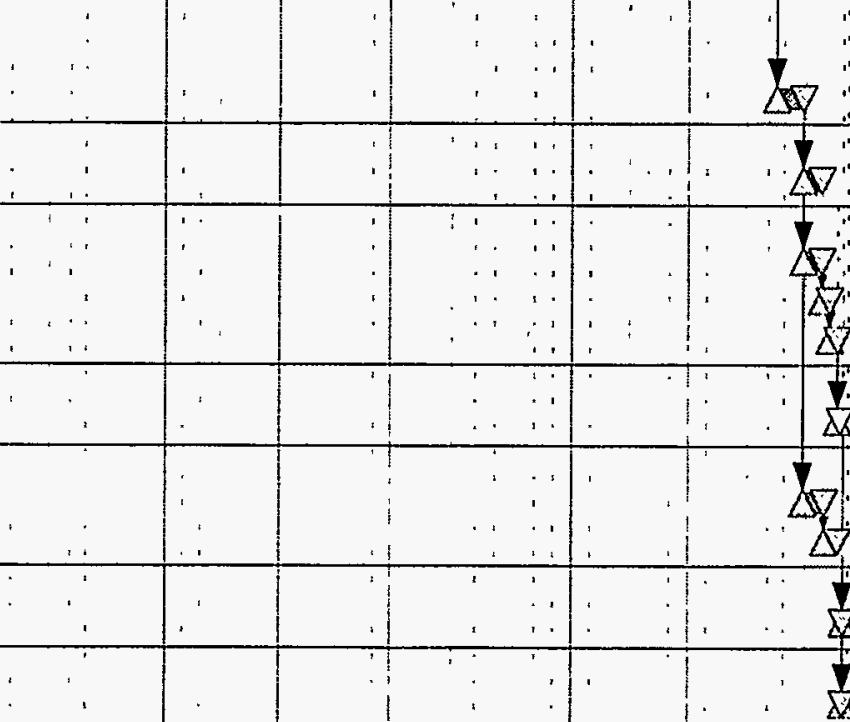

Q

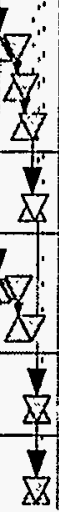
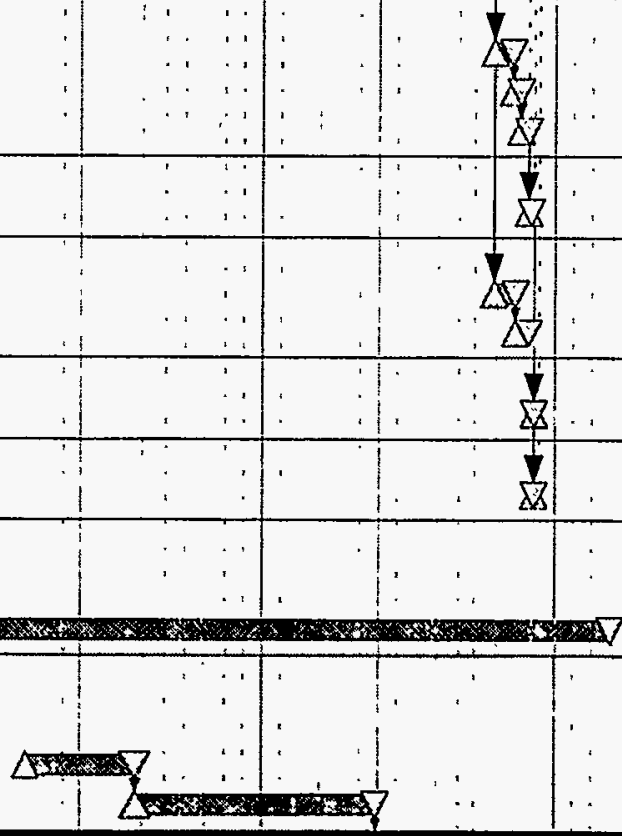


\section{Appendix D}

\section{Detailed resource and cost reports}

for

current budget, base case, and options A, B, C, and D 


\section{LMITCO - CPP 651 MATERIAL SCHEDULE}

\section{PRIMAVERA PROJECT PLANNER}

COST LOADING REPORT

CURRENT FUNDING -SHIP AS IS SCENARIO

START DATE 01JUL97 FIN DATE O5MAR10

DATA DATE 010 OT97 PAGE NO. 1

Cost Loading - Summary by Cost Account

TOTAL USAGE FOR YEAR

\begin{tabular}{|c|c|c|c|c|c|c|c|c|c|c|c|c|c|c|}
\hline ACCOUNT & ACCOUNT TITLE & $\begin{array}{r}F Y \\
1998 \\
\end{array}$ & $\begin{array}{r}F Y \\
1999 \\
\end{array}$ & $\begin{array}{r}F Y \\
2000 \\
\end{array}$ & $\begin{array}{r}F Y \\
2001 \\
\end{array}$ & $\begin{array}{r}F Y \\
2002 \\
\end{array}$ & $\begin{array}{r}F Y \\
2003 \\
\end{array}$ & $\begin{array}{r}F Y \\
2004 \\
\end{array}$ & $\begin{array}{r}F \bar{Y} \\
2005 \\
\end{array}$ & $\begin{array}{r}F Y \\
2006 \\
\end{array}$ & $\begin{array}{r}F Y \\
2007 \\
\end{array}$ & $\begin{array}{r}F Y \\
2008 \\
\end{array}$ & $\begin{array}{r}F Y \\
2009 \\
\end{array}$ & TOTAL \\
\hline $\begin{array}{l}12100 \\
12101 \\
121010 \\
121011 \\
121012 \\
121013 \\
121017 \\
12103 \\
12104 \\
12105 \\
12106 \\
12107 \\
12108 \\
12109\end{array}$ & $\begin{array}{l}\text { LANL Material } \\
\text { Fluorinel Material } \\
\text { VYCOR Glass Material } \\
\text { ANL-W Material } \\
\text { ANL-E Material } \\
\text { Rocky Flats Option } 1 \text { (As Is) } \\
\text { Denitrator Option } 1 \text { (As Is) } \\
\text { PWR (6 SPERT Boxes) } \\
\text { PWR (1 full assembly) } \\
\text { U of Washington } \\
\text { U of Wisconsin } \\
\text { Custom Product Material } \\
\text { GFAST - AWF-1 } \\
\text { JANUS Material }\end{array}$ & $\begin{array}{r}159386 \\
76377\end{array}$ & $\begin{array}{l}43169 \\
69909 \\
31307\end{array}$ & $\begin{array}{l}63533 \\
11137 \\
40308 \\
32110\end{array}$ & $\begin{array}{r}171192 \\
9718\end{array}$ & $\begin{array}{l}38215 \\
56584\end{array}$ & $\begin{array}{r}140829 \\
48763 \\
279179 \\
\\
46335 \\
\end{array}$ & 352366 & 314538 & 316434 & 267235 & $\begin{array}{r}4454 \\
111465\end{array}$ & 574347 & $\begin{array}{r}159386 \\
545748 \\
578802 \\
76377 \\
48763 \\
63533 \\
1679431 \\
182329 \\
66302 \\
40308 \\
43169 \\
76447 \\
63416 \\
46335 \\
\end{array}$ \\
\hline & AEPORT TOTAL & 242301 & 144384 & 147088 & 408905 & 271723 & 515105 & 352366 & 314538 & 316434 & 267235 & 115919 & 574347 & 3670345 \\
\hline
\end{tabular}




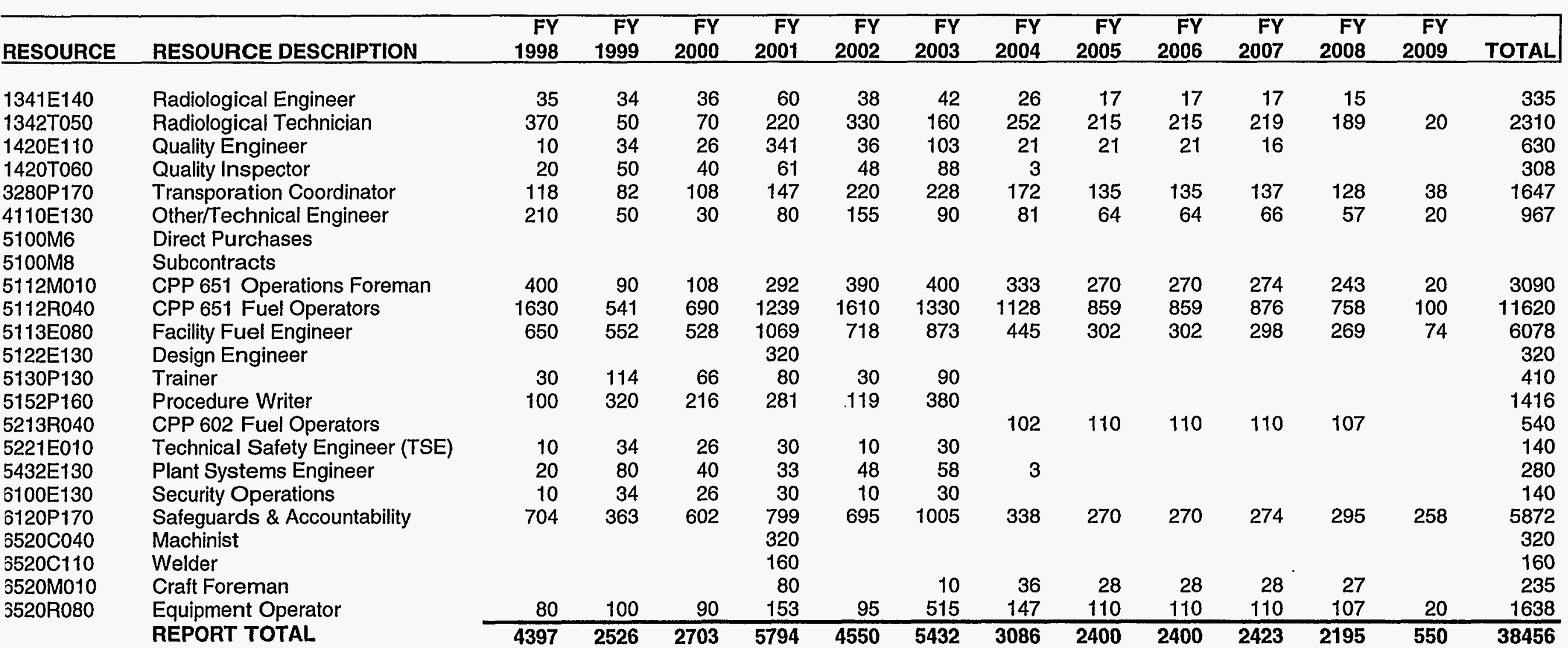


LMITCO - CPP 651 MATERIAL SCHEDULE

REPORT DATE 05AUG97 RUN NO. 483

$$
\text { 13:02 }
$$

Cost load by resource type
PRIMAVERA PROJECT PLANNER

BASE CASE SCHEDULE - DRY BLENDING

COST LOADING REPOAT

START DATE 01JUL97 FIN DATE 11SEP06

DATA DATE $010 \mathrm{OCT} 97$ PAGENO. 1

\begin{tabular}{|c|c|c|c|c|c|c|c|c|c|c|c|}
\hline HESOURCE & RESOURCE DESCRIPTION & $\begin{array}{r}F Y \\
1998 \\
\end{array}$ & $\begin{array}{r}F Y \\
1999 \\
\end{array}$ & $\begin{array}{r}F Y \\
2000 \\
\end{array}$ & $\begin{array}{r}\text { FY } \\
2001\end{array}$ & $\begin{array}{r}F Y \\
2002 \\
\end{array}$ & $\begin{array}{r}F Y \\
2003 \\
\end{array}$ & $\begin{array}{r}F Y \\
2004 \\
\end{array}$ & $\begin{array}{r}F Y \\
2005\end{array}$ & $\begin{array}{r}F Y \\
2006 \\
\end{array}$ & TOTAL \\
\hline 1341E140 & Radiological Engineer & 6737 & 2433 & 5798 & 14748 & 6099 & 6280 & 2319 & 2965 & 3649 & 51027 \\
\hline 1342 T050 & Radiological Technician & 18271 & 3457 & 2469 & 27799 & 50137 & 51626 & 10414 & 11851 & 22221 & 198244 \\
\hline 1420E110 & Quality Engineer & 5026 & 3989 & 5867 & 4708 & & & 1357 & 6677 & 11965 & 39589 \\
\hline $1420 T 060$ & Quality Inspector & 2051 & 2051 & 1538 & & & & 3077 & 3487 & 2051 & 14256 \\
\hline $1710 \mathrm{P} 170$ & Environmental Engineer & 4000 & 11257 & 11440 & 3833 & & & & & & 30530 \\
\hline $3280 \mathrm{E} 130$ & Transportation Engineer & & & 167 & 3833 & & & & & & 4000 \\
\hline $3280 \mathrm{P} 170$ & Transporation Coordinator & 9117 & 5616 & 9710 & 12700 & 22451 & 20985 & 9994 & 6493 & 16621 & 113688 \\
\hline $4110 \mathrm{E} 010$ & Salety Analyst & 3000 & 78277 & 65504 & & & & & & & 146781 \\
\hline $4110 E 120$ & Criticality Safely Enginẹer & 3000 & 13119 & 14308 & & & & & & & 30427 \\
\hline $4110 E 130$ & Other/Technical Engineer & 21230 & 7635 & 11948 & 8833 & & & 5675 & 573 & 20694 & 76587 \\
\hline 41E1R010 & RAL Technician & 1000 & & & 16679 & 30082 & 30976 & 5063 & & & 83800 \\
\hline 41E1S010 & RAL Engineer & & & & 13560 & 10027 & 10325 & 1688 & & & 35600 \\
\hline $5100 \mathrm{M} 4$ & Constructlon Purchases & & & 437500 & 112500 & & & & & & 550000 \\
\hline $5100 \mathrm{M} 6$ & Direct Purchases & & & & & & & 1302 & 3698 & & 5000 \\
\hline $5100 \mathrm{M} 8$ & Subcontracts & 270928 & 1071135 & 729688 & & & & 545405 & 29967 & 69233 & 2716355 \\
\hline $5110 \mathrm{M} 020$ & Fuel Manager & 4200 & 14345 & 14904 & 6067 & & & & & & 39516 \\
\hline $5112 G 050$ & Administralion Support & & & 2019 & 8056 & & & & & & 10075 \\
\hline $5112 \mathrm{M} 010$ & CPP 651 Operations Foreman & 20752 & 6744 & 2761 & 34724 & 56204 & 57749 & 15033 & 17120 & 35797 & 246885 \\
\hline $5112 R 040$ & CPP 651 Fuel Operators & 90158 & 37354 & $\begin{array}{r}27383 \\
200\end{array}$ & $\begin{array}{r}143750 \\
4600\end{array}$ & 229785 & 235966 & 67844 & 68287 & 127625 & $\begin{array}{r}1028152 \\
4800\end{array}$ \\
\hline $\begin{array}{l}5113 E 070 \\
5113 E 080\end{array}$ & $\begin{array}{l}\text { Fuel Supervisor } \\
\text { Facility Fuel Engineer }\end{array}$ & 50127 & 44023 & 26284 & 77726 & 58501 & 59990 & 47416 & 41821 & 73148 & 479037 \\
\hline 5122E130 & Design Engineer & 3000 & 2000 & 5625 & 375 & & & 8680 & 1949 & 10629 & 32258 \\
\hline $5130 \mathrm{P} 130$ & Trainer & 6000 & 6000 & 5625 & 16875 & & & 4063 & 1938 & 2500 & 43000 \\
\hline $5152 P 160$ & Procedure Wriler & 7998 & 14076 & 7892 & 1688 & & & 11610 & 4902 & 8256 & 56422 \\
\hline 5213R040 & CPP 602 Fuel Operators & 900 & & 113 & 15188 & & & & & & 16200 \\
\hline $5221 E 010$ & Technical Safety Engineer (TSE) & 1419 & 2838 & 1001 & 4708 & & & 1507 & 1330 & 1419 & 14222 \\
\hline $5432 E 130$ & Plant Systems Engineer & 3622 & 3622 & 1374 & 3833 & & & 2415 & 2415 & 2415 & 19696 \\
\hline $6100 E 130$ & Securily Operations & 3907 & 2415 & 5929 & 8175 & & & 1283 & 1132 & 1207 & 24048 \\
\hline $6120 P 170$ & Saleguards \& Accountability & 49645 & 18361 & 23546 & 47016 & 51778 & 53260 & 62878 & 31822 & 37942 & 376248 \\
\hline $6520 C 020$ & Electrician & & & 422 & 97 & & & & & & 519 \\
\hline $6520 C 040$ & Machinis! & & & & & & & 6225 & 1397 & 7622 & 15245 \\
\hline $6520 C 110$ & Welder & & & & & & & 3112 & 699 & 3811 & 7622 \\
\hline $6520 \mathrm{M} 010$ & Craft Foreman & & & 403 & 2140 & 4182 & 4182 & 3207 & 364 & 1986 & 16464 \\
\hline \multirow{3}{*}{$\begin{array}{l}\text { 6520R080 } \\
6520 T 070\end{array}$} & Equipment Operator & 4764 & 5240 & 2858 & 6550 & 13383 & 13383 & 8247 & 8004 & 22867 & 85298 \\
\hline & Instrument Technician & & & 387 & 89 & & & & & & 476 \\
\hline & REPORT TOTAL & 590852 & 1355987 & 1424661 & 600851 & 532630 & 544723 & 829813 & 248890 & 483660 & 6612067 \\
\hline
\end{tabular}




\begin{tabular}{|c|c|c|c|c|c|c|c|c|c|c|c|}
\hline IESOURCE & RESOURCE DESCRIPTION & $\begin{array}{r}F Y \\
1998 \\
\end{array}$ & $\begin{array}{r}F Y \\
1999 \\
\end{array}$ & $\begin{array}{r}F Y \\
2000 \\
\end{array}$ & $\begin{array}{r}F Y \\
2001 \\
\end{array}$ & $\begin{array}{r}F Y \\
2002 \\
\end{array}$ & $\begin{array}{r}F Y \\
2003 \\
\end{array}$ & $\begin{array}{r}F Y \\
2004 \\
\end{array}$ & $\begin{array}{r}F Y \\
2005 \\
\end{array}$ & $\begin{array}{r}F Y \\
2006 \\
\end{array}$ & TOTAL \\
\hline $341 E 140$ & Radiological Engineer & 125 & 40 & 110 & 246 & 100 & 103 & 38 & 49 & 60 & 871 \\
\hline 342T050 & Radiological Technician & 370 & 70 & 50 & 556 & 1003 & 1033 & 209 & 240 & 450 & 3980 \\
\hline $420 E 110$ & Quality Engineer & 100 & 79 & 117 & 94 & & & 26 & 130 & 233 & 780 \\
\hline 420T060 & Quality Inspector & 40 & 40 & 30 & & & & 60 & 68 & 40 & 278 \\
\hline $710 \mathrm{P} 170$ & Environmental Engineer & 80 & 208 & 215 & 77 & & & & & & 580 \\
\hline $280 E 130$ & Transportation Engineer & & & 3 & 77 & & & & & & 80 \\
\hline $280 P 170$ & Transporation Coordinator & 182 & 112 & 194 & 253 & 448 & 419 & 199 & 130 & 332 & 2268 \\
\hline $110 E 010$ & Safety Analyst & 60 & 1002 & 868 & & & & & & & 1930 \\
\hline 110E120 & Criticality Safety Engineer & 60 & 168 & 212 & & & & & & & 440 \\
\hline $110 E 130$ & Other/Technical Engineer & 307 & 113 & 233 & 177 & & & 73 & 7 & 265 & 1175 \\
\hline 1E1R010 & AAL Technician & 20 & & & 334 & 602 & 620 & 101 & & & 1676 \\
\hline & RAL Engineer & & & & 271 & 201 & 207 & 34 & & & 712 \\
\hline $\begin{array}{l}100 M 4 \\
100 M 6\end{array}$ & $\begin{array}{l}\text { Construction Purchases } \\
\text { Direct Purchases }\end{array}$ & & & & & & & & & & \\
\hline $100 \mathrm{M} 8$ & Subcontracts & & & & & & & & & & \\
\hline $110 \mathrm{MO} 20$ & Fuel Manager & 60 & 208 & 215 & 87 & & & & & & 570 \\
\hline $112 \mathrm{G} 050$ & Administration Support & & & 41 & 199 & & & & & & 240 \\
\hline $112 \mathrm{M} 010$ & CPP 651 Operations Foreman & 400 & 130 & 53 & 674 & 1086 & 1116 & 291 & 330 & 690 & 4770 \\
\hline $112 \mathrm{R040}$ & CPP 651 Fuel Operators & 1740 & 720 & 533 & 2825 & 4429 & 4548 & 1308 & 1316 & 2460 & 19880 \\
\hline $113 E 070$ & Fuel Supervisor & & & 3 & 77 & & & & & & 80 \\
\hline $113 E 080$ & Facility Fuel Engineer & 848 & 743 & 467 & 1555 & 1170 & 1200 & 822 & 693 & 1212 & 8708 \\
\hline 122E130 & Design Engineer & 60 & 40 & 113 & 8 & & & 131 & 29 & 160 & 540 \\
\hline $130 \mathrm{P} 130$ & Trainer & 120 & 120 & 113 & 338 & & & 81 & 39 & 50 & 860 \\
\hline $152 \mathrm{P} 160$ & Procedure Writer & 194 & 341 & 184 & 38 & & & 281 & 119 & 200 & 1356 \\
\hline $213 \mathrm{R} 040$ & CPP 602 Fuel Operators & 20 & & 3 & 338 & & & & & & 360 \\
\hline 221E010 & Technical Safety Engineer (TSE) & 20 & 40 & 16 & 94 & & & 21 & 19 & 20 & 230 \\
\hline $432 \mathrm{E} 130$ & Plant Systems Engineer & 60 & 60 & 23 & 77 & & & 40 & 40 & 40 & 340 \\
\hline $100 \mathrm{E} 130$ & Security Operations & 80 & 40 & 128 & 182 & & & 21 & 19 & 20 & 490 \\
\hline $120 P 170$ & Safeguards \& Accountability & 1013 & 369 & 485 & 970 & 1045 & 1074 & 1265 & 640 & 763 & 7622 \\
\hline $520 C 020$ & Electrician & & & 8 & 2 & & & & & & 10 \\
\hline $520 C 040$ & Machinist & & & & & & & 131 & 29 & 160 & 320 \\
\hline $520 C 110$ & Welder & & & & & & & 65 & 15 & 80 & 160 \\
\hline $520 \mathrm{M} 010$ & Craft Foreman & & & 8 & 43 & 84 & 84 & 64 & 7 & 40 & 330 \\
\hline \multirow{3}{*}{$\begin{array}{l}520 \mathrm{R} 080 \\
520 T 070\end{array}$} & Equipment Operator & 100 & 110 & 60 & 164 & 335 & 335 & 187 & 168 & 480 & 1938 \\
\hline & Instrument Technician & & & 8 & 2 & & & & & & 10 \\
\hline & REPORT TOTAL & 6058 & 4753 & 4494 & 9752 & 10501 & 10737 & 5448 & 4086 & 7754 & 63584 \\
\hline
\end{tabular}


TOTAL USAGE FOR YEAR

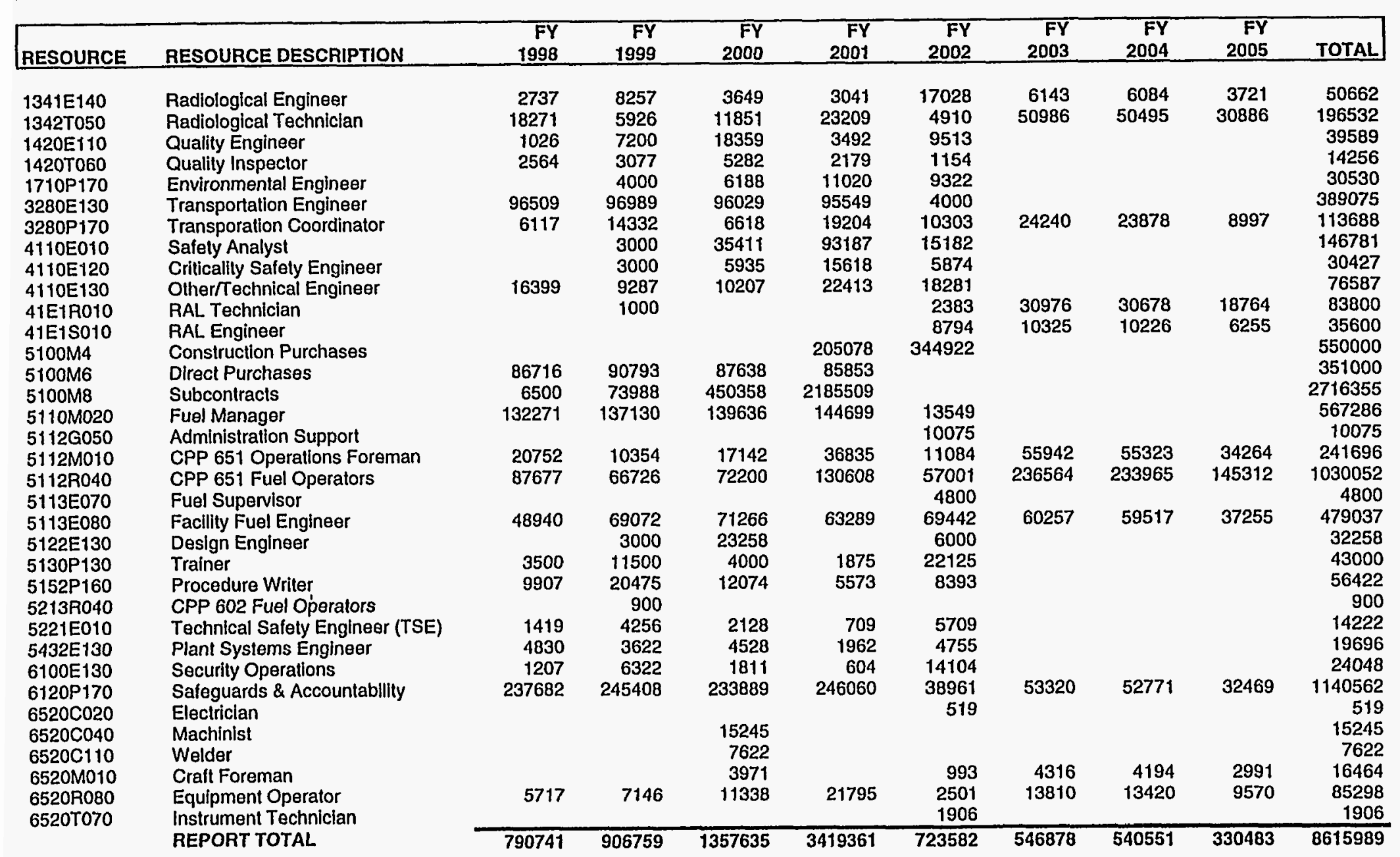


TOTAL USAGE FOR YEAR

\begin{tabular}{|c|c|c|c|c|c|c|c|c|c|c|}
\hline RESOURCE & RESOURCE DESCRIPTION & $\begin{array}{r}F Y \\
1998 \\
\end{array}$ & $\begin{array}{r}F Y \\
1999 \\
\end{array}$ & $\begin{array}{r}F Y \\
2000 \\
\end{array}$ & $\begin{array}{r}F Y \\
2001 \\
\end{array}$ & $\begin{array}{r}F Y \\
2002 \\
\end{array}$ & $\begin{array}{r}F Y \\
2003 \\
\end{array}$ & $\begin{array}{r}F Y \\
2004 \\
\end{array}$ & $\begin{array}{r}F Y \\
2005 \\
\end{array}$ & TOTAL \\
\hline $41 E 140$ & Radiological Engineer & 45 & 150 & 60 & 50 & 298 & 101 & 100 & 61 & 865 \\
\hline $1342 T 050$ & Radiological Technician & 370 & 120 & 240 & 470 & 99 & 1033 & 1023 & 625 & 3980 \\
\hline $420 \mathrm{E} 110$ & Quality Engineer & 20 & 142 & 358 & 70 & 190 & & & & 780 \\
\hline 420T060 & Quality Inspector & 50 & 60 & 103 & 43 & 23 & & & & 278 \\
\hline $710 P 170$ & Environmental Engineer & & 80 & 116 & 200 & 184 & & & & 580 \\
\hline 280E130 & Transportation Engineer & 1925 & 1934 & 1915 & 1906 & 80 & & & & 7760 \\
\hline $280 P 170$ & Transporation Coordinator & 122 & 286 & 132 & 383 & 206 & 484 & 476 & 179 & 2268 \\
\hline $110 \mathrm{E} 010$ & Safety Analyst & & 60 & 453 & 1193 & 223 & & & & 1930 \\
\hline $4110 \mathrm{E} 120$ & Criticality Safety Engineer & & 60 & 76 & 200 & 104 & & & & 440 \\
\hline $10 E 130$ & Other/Technical Engineer & 210 & 141 & 159 & 311 & 354 & & & & 1175 \\
\hline E1R010 & RAL Technician & & 20 & & & 48 & 620 & 614 & 375 & 1676 \\
\hline E1S010 & RAL Engineer & & & & & 176 & 207 & 205 & 125 & 712 \\
\hline $100 \mathrm{M} 4$ & Construction Purchases & & & & & & & & & \\
\hline $100 \mathrm{M} 6$ & Direct Purchases & & & & & & & & & \\
\hline OOM8 & Subcontracts & & & & & & & & & \\
\hline $110 \mathrm{M} 020$ & Fuel Manager & 1925 & 1994 & 2031 & 2106 & 194 & & & & 8250 \\
\hline $5112 \mathrm{G} 050$ & Administration Support & & & & & 240 & & & & 240 \\
\hline $12 \mathrm{M} 010$ & CPP 651 Operations Foreman & 400 & 200 & 330 & 710 & 219 & 1119 & 1106 & 685 & 4770 \\
\hline $12 R 040$ & CPP 651 Fuel Operators & 1690 & 1288 & 1392 & 2518 & 1150 & 4562 & 4510 & 2801 & 19910 \\
\hline $113 E 070$ & Fuel Supervisor & & & & & 80 & & & & 80 \\
\hline 5113E080 & Facility Fuel Engineer & 811 & 1159 & 1190 & 1059 & 1349 & 1205 & 1190 & 745 & 8708 \\
\hline 22E130 & Design Engineer & & 60 & 360 & & 120 & & & & 540 \\
\hline $30 P 130$ & Trainer & 70 & 230 & 80 & 38 & 443 & & & & 860 \\
\hline $52 P 160$ & Procedure Writer & 240 & 496 & 293 & 135 & 193 & & & & 1356 \\
\hline 13R040 & CPP 602 Fuel Operators & & 20 & & & & & & & 20 \\
\hline 21E010 & Technical Safety Engineer (TSE) & 20 & 60 & 30 & 10 & 110 & & & & 230 \\
\hline B2E130 & Plant Systems Engineer & 80 & 60 & 75 & 33 & 93 & & & & 340 \\
\hline 00E130 & Security Operations & 20 & 120 & 30 & 10 & 310 & & & & 490 \\
\hline $6120 P 170$ & Safeguards \& Accountability & 4777 & 4947 & 4700 & 4945 & 817 & 1076 & 1065 & 655 & 22982 \\
\hline 200020 & Electrician & & & & & 10 & & & & 10 \\
\hline 200040 & Machinist & & & 320 & & & & & & 320 \\
\hline $20 C 110$ & Welder & & & 160 & & & & & & 160 \\
\hline $20 M 010$ & Craft Foreman & & & 80 & & 20 & 86 & 84 & 60 & 330 \\
\hline \multirow{3}{*}{$\begin{array}{l}6520 \text { R080 } \\
6520 T 070\end{array}$} & Equipment Operator & 120 & 150 & 238 & 458 & 53 & 345 & 336 & 239 & 1938 \\
\hline & Instrument Technician & & & & & 40 & & & & 40 \\
\hline & REPORT TOTAL & $\overline{12894}$ & 13838 & 14922 & $\overline{16844}$ & 7425 & 10836 & 10707 & 6552 & 94018 \\
\hline
\end{tabular}


-MITCO - CPP 651 MATERIAL SCHEDULE

PEPORT DATE 05AUG97 RUN NO. 463

12:32

\section{PRIMAVERA PROJECT PLANNER}

COST LOADING REPORT

TOTAL USAGE FOR YEAR
OPT B - SHIP AS IS \& TRANSFER TEAM

START DATE 01JUL97 FIN DATE $02 S E P 03$

DATA DATE 010CT97 PAGE NO. 1

Cost load by resource type

\begin{tabular}{|c|c|c|c|c|c|c|c|c|}
\hline RESOURCE & RESOURCE DESCRIPTION & $\begin{array}{r}F Y \\
1998 \\
\end{array}$ & $\begin{array}{r}F Y \\
1999 \\
\end{array}$ & $\begin{array}{r}F Y \\
2000 \\
\end{array}$ & $\begin{array}{r}F Y \\
2001 \\
\end{array}$ & $\begin{array}{r}F Y \\
2002 \\
\end{array}$ & $\begin{array}{r}F Y \\
2003 \\
\end{array}$ & TOTAL \\
\hline 1341E140 & Radiological Engineer & 2737 & 4257 & 3649 & 2433 & 4508 & 2791 & 20375 \\
\hline 1342T050 & Radiological Technician & 18271 & 5926 & 11851 & 23209 & 25358 & 29454 & 114068 \\
\hline 1420E110 & Quality Éngineer' & 1026 & 3825 & 17713 & 2849 & 2792 & & 28204 \\
\hline 1420T060 & Quality Inspector & 2564 & 3077 & 5282 & 1218 & 3654 & & 15794 \\
\hline $3280 \mathrm{E} 130$ & Transportation Engineer & 96461 & 96941 & 95981 & 95981 & 95981 & & 481344 \\
\hline $3280 \mathrm{P} 170$ & Transporation Coordinator & 6117 & 11332 & 6618 & 21021 & 18314 & 19178 & 82581 \\
\hline $4110 E 130$ & Other/Technical Engineer & 16399 & 6247 & 6247 & 19132 & 13514 & 13974 & 75513 \\
\hline $5100 \mathrm{M} 6$ & Direct Purchases & 86572 & 90649 & 87496 & 86142 & 86142 & & 437000 \\
\hline $5100 \mathrm{M} 8$ & Subcontracts & 6500 & 15250 & 99200 & 1212072 & 293333 & & 1626355 \\
\hline $5110 \mathrm{M} 020$ & Fuel Manager & 132206 & 132863 & 131548 & 131548 & 131548 & & 659712 \\
\hline $5112 \mathrm{M} 010$ & CPP 651 Operations Foreman & 20752 & 10354 & 17142 & 36835 & 35539 & 39687 & 160309 \\
\hline $5112 R 040$ & CPP 651 Fuel Operators & 87677 & 63726 & 72200 & 129052 & 126412 & 123780 & 602846 \\
\hline 5113E080 & Facillity Fuel Engineer & 48940 & 64697 & 68621 & 67514 & 63732 & 46181 & 359684 \\
\hline 5122E130 & Design Engineer & & & 21258 & & & & 21258 \\
\hline $5130 P 130$ & Trainer & 3500 & 8500 & 4000 & 1375 & 3125 & & 20500 \\
\hline 5152P160 & Procedure Writer & 9907 & 20475 & 12074 & 6295 & 9701 & & 58452 \\
\hline 5213R040 & CPP 602 Fuel Operators & & & & & 10532 & 17484 & 28015 \\
\hline 5221E010 & Technlcal Safoty Engineer (TSE) & 1419 & 4256 & 2128 & & 2128 & & 9932 \\
\hline 5432E130 & Plant Systems Ėngineer & 4830 & 3622 & 4528 & 1434 & 2490 & & 16904 \\
\hline $6100 E 130$ & Security Operations & 1207 & 3622 & 1811 & & 1811 & & 8452 \\
\hline $6120 P 170$ & Safeguards \& Accountability & 237587 & 238112 & 233794 & 248324 & 251701 & 38065 & 1247583 \\
\hline $6520 C 040$ & Machinist & & & 15245 & & & & 15245 \\
\hline $6520 C 110$ & Wolder & & & 7622 & & & & 7622 \\
\hline $6520 \mathrm{M} 010$ & Craft Foreman & & & 3971 & & 3512 & 4182 & 11665 \\
\hline \multirow[t]{2}{*}{$6520 \mathrm{R} 080$} & Equipment Operator & 5717 & 7146 & 11338 & 21378 & 16400 & 16055 & 78034 \\
\hline & REPORT TOTAL & 790388 & 794877 & 941317 & 2107810 & 1202227 & 350828 & 6187447 \\
\hline
\end{tabular}




\section{MITCO - CPP 651 MATERIAL SCHEDULE}

EPORT DATE 05AUG97 RUN NO. 464

12:34

II Resource Estimates

\section{PRIMAVERA PROJECT PLANNER}

RESOURCE LOADING REPORT

TOTAL USAGE FOR YEAR
OPT B - SHIP AS IS \& TRANSFER TEAM

START DATE 01JUL97 FIN DATE 02 SEP03

DATA DATE $010 C T 97$ PAGE NO. 1

\begin{tabular}{|c|c|c|c|c|c|c|c|c|}
\hline ESOURCE & RESOURCE DESCRIPTION & $\begin{array}{r}F Y \\
1998 \\
\end{array}$ & $\begin{array}{r}F Y \\
1999 \\
\end{array}$ & $\begin{array}{r}F Y \\
2000 \\
\end{array}$ & $\begin{array}{r}F Y \\
2001 \\
\end{array}$ & $\begin{array}{r}F Y \\
2002 \\
\end{array}$ & $\begin{array}{r}F Y \\
2003 \\
\end{array}$ & TOTAL \\
\hline $341 \mathrm{E} 140$ & Radiological Engineer & 45 & 70 & 60 & 40 & 74 & 46 & 335 \\
\hline 342 T050 & Radiological Technician & 370 & 120 & 240 & 470 & 514 & 596 & 2310 \\
\hline $420 E 110$ & Quality Engineer & 20 & 75 & 345 & 56 & 54 & & 550 \\
\hline 420T060 & Quality Inspector & 50 & 60 & 103 & 24 & 71 & & 308 \\
\hline $80 \mathrm{E} 130$ & Transportation Engineer & 1924 & 1933 & 1914 & 1914 & 1914 & & 9600 \\
\hline $80 \mathrm{P} 170$ & Transporation Coordinator & 122 & 226 & 132 & 419 & 365 & 382 & 1647 \\
\hline 110E130 & Other/Technical Engineer & 210 & 80 & 80 & 245 & 173 & 179 & 967 \\
\hline $\begin{array}{l}\text { 00M6 } \\
\text { O0M8 }\end{array}$ & $\begin{array}{l}\text { Direct Purchases } \\
\text { Subcontracts }\end{array}$ & & & & & \\
\hline $10 \mathrm{MO} 20$ & Fuel Manager & 1924 & 1933 & 1914 & 1914 & 1914 & & 9600 \\
\hline $12 \mathrm{M} 010$ & CPP 651 Operations Foreman & 400 & 200 & 330 & 710 & 685 & 765 & 3090 \\
\hline $12 R 040$ & CPP 651 Fuel Operators & 1690 & 1228 & 1392 & 2488 & 2437 & 2386 & 11620 \\
\hline 13E080 & Facility Fuel Engineer & 811 & 1072 & 1137 & 1118 & 1056 & 765 & 5958 \\
\hline 122E130 & Design Engineer & & & 320 & & & & 320 \\
\hline $30 \mathrm{P} 130$ & Trainer & 70 & 170 & 80 & 28 & 63 & & 410 \\
\hline $152 P 160$ & Procedure Writer & 240 & 496 & 293 & 153 & 235 & & 1416 \\
\hline $13 R 040$ & CPP 602 Fuel Operators & & & & & 203 & 337 & 540 \\
\hline 21E010 & Technical Safety Engineer (TSE) & 20 & 60 & 30 & & 30 & & 140 \\
\hline $432 E 130$ & Plant Systems Engineer & 80 & 60 & 75 & 24 & 41 & & 280 \\
\hline OOE130 & Security Operations & 20 & 60 & 30 & & 30 & & 140 \\
\hline $120 \mathrm{P} 170$ & Safeguards \& Accountability & 4775 & 4785 & 4698 & 4990 & 5058 & 765 & 25072 \\
\hline $520 C 040$ & Machinist & & & 320 & & & & 320 \\
\hline $520 C 110$ & Welder & & & 160 & & & & 160 \\
\hline $520 \mathrm{M010}$ & Craft Foreman & & & 80 & & 71 & 84 & 235 \\
\hline $520 R 080$ & Equipment Operator & 120 & 150 & 238 & 449 & 344 & 337 & 1638 \\
\hline & REPORT TOTAL & 12890 & 12778 & 13972 & 15041 & 15333 & 6643 & 76656 \\
\hline
\end{tabular}


MITCO - CPP 651 MATERIAL SCHEDULE

EPORT DATE 05AUG97 RUN NO. 506

13:12

;ost load by resource type

\section{PRIMAVERA PROJECT PLANNER}

COST LOADING REPORT

TOTAL USAGE FOR YEAR
OPT C - BASE CASE \& TNT \& DED. CREW

START DATE 01JUL97 FIN DATE 04SEP03

DATA DATE 010CT97 PAGE NO. 1

\begin{tabular}{|c|c|c|c|c|c|c|c|c|}
\hline RESOURCE & RESOURCE DESCRIPTION & $\begin{array}{r}F \bar{Y} \\
1998 \\
\end{array}$ & $\begin{array}{r}F Y \\
1999 \\
\end{array}$ & $\begin{array}{r}F Y \\
2000 \\
\end{array}$ & $\begin{array}{r}F Y \\
2001 \\
\end{array}$ & $\begin{array}{r}F Y \\
2002 \\
\end{array}$ & $\begin{array}{r}F Y \\
2003 \\
\end{array}$ & TOTAL \\
\hline $1341 E 140$ & Radiological Engineer & 3421 & 7573 & 4893 & 6842 & 17832 & 10101 & 50662 \\
\hline 1342 T050 & Radiological Technician & 20740 & 3457 & 88766 & 88014 & 88226 & 88554 & 377757 \\
\hline 1420E 110 & Quality Engineer & 1603 & 7526 & 19352 & 6328 & 4781 & & 39589 \\
\hline $1420 T 060$ & Quality Inspector & 2628 & 3974 & 4577 & 3077 & & & 14256 \\
\hline $1710 \mathrm{P} 170$ & Environmental Engineer & & 4000 & 11202 & 11453 & 3875 & & 30530 \\
\hline $3280 E 130$ & Transportation Engineer & 96509 & 96989 & 96029 & 95674 & 3875 & & 389075 \\
\hline $3280 \mathrm{P} 170$ & Transporation Coordinator & 9827 & 11146 & 12061 & 21243 & 24870 & 34542 & 113688 \\
\hline 4110 E010 & Safely Analyst & & 3000 & 77811 & 65970 & & & 146781 \\
\hline $4110 \mathrm{E} 120$ & Criticalily Safety Enginoer & & 3000 & 13041 & 14386 & & & 30427 \\
\hline $4110 \mathrm{E} 130$ & Other/Technical Engineer & 20303 & 7558 & 17012 & 22755 & 8958 & & 76587 \\
\hline 41E1R010 & AAL Technician & & 1000 & & & 31869 & 50931 & 83800 \\
\hline 41E1S010 & RAL Engineer & & & & & 18623 & 16977 & 35600 \\
\hline $5100 \mathrm{M} 4$ & Construction Purchases & & & & 432292 & 117708 & & 550000 \\
\hline 5100M6 & Direct Purchases & 86716 & 92147 & 86284 & 85853 & & & 351000 \\
\hline $5100 \mathrm{M} 8$ & Subcontracts & 17050 & 270372 & 1143945 & 1284988 & & & 2716355 \\
\hline $5110 \mathrm{MO} 20$ & Fuel Manager & 132271 & 137130 & 145890 & 145870 & 6125 & & 567286 \\
\hline $5112 G 050$ & Administration Support & & & & 1904 & 8172 & & 10075 \\
\hline $5112 M 010$ & CPP 651 Operations Foreman & 25421 & 25964 & 123056 & 92502 & 90430 & 92620 & 449994 \\
\hline $5112 R 040$ & CPP 651 Fuel Operators & 109726 & 145713 & 276218 & $95462^{\circ}$ & 260286 & 391672 & 1279076 \\
\hline $5113 E 070$ & Fuel Supervisor & & & & 150 & 4650 & & 4800 \\
\hline $5113 E 080$ & Facility Fuel Engineer & 67554 & 52848 & 90392 & 61118 & 107065 & 100060 & 479037 \\
\hline $5122 \mathrm{E} 130$ & Design Engineer & & 4240 & 22018 & 5594 & 406 & & 32258 \\
\hline $5130 \mathrm{P} 130$ & Trainer & 5625 & 9375 & 4000 & 7094 & 16906 & & 43000 \\
\hline $5152 \mathrm{P} 160$ & Procedure Writer & 14541 & 15841 & 12384 & 11940 & 1716 & & 56422 \\
\hline $5213 R 040$ & CPP 602 Fuel Operators & & 900 & 339365 & 366774 & 200551 & 73635 & 981225 \\
\hline 5221E010 & Technical Safely Engineer (TSE) & 2217 & 3458 & 2128 & 1638 & 4781 & & 14222 \\
\hline $5432 E 130$ & Plant Systems Éngineer & 4905 & 4679 & 3698 & 2540 & 3875 & & 19696 \\
\hline $6100 E 130$ & Security Operalions & 1887 & 5643 & 1811 & 6439 & 8269 & & 24048 \\
\hline $6120 P 170$ & Safeguards \& Accountability & 244052 & 252319 & 232883 & 250282 & 87690 & 88761 & 1155987 \\
\hline $6520 \mathrm{C0} 20$ & Electrician & & & & 413 & 105 & & 519 \\
\hline $6520 C 040$ & Machinist & & 889 & 14356 & & & & 15245 \\
\hline $6520 C 110$ & Welder & & 445 & 7178 & & & & 7622 \\
\hline $6520 \mathrm{M} 010$ & Craft Foreman & & 232 & 3740 & 892 & 4013 & 7588 & 16464 \\
\hline \multirow{3}{*}{$\begin{array}{l}\text { 6520R080 } \\
\text { 6520T070 }\end{array}$} & Equipment Operator & 7682 & 6074 & 10921 & 23820 & 12519 & 24281 & 85298 \\
\hline & Instrument Technician & & & & 1519 & 387 & & 1906 \\
\hline & REPORT TOTAL & 874678 & 1177490 & 2865010 & 3214823 & 1138565 & 979721 & 50286 \\
\hline
\end{tabular}


TOTAL USAGE FOR YEAR

DATA DATE 010CT97 PAGE NO. 1

\begin{tabular}{|c|c|c|c|c|c|c|c|c|}
\hline ESOURCE & RESOURCE DESCRIPTION & $\begin{array}{r}F Y \\
1998 \\
\end{array}$ & $\begin{array}{r}F Y \\
1999 \\
\end{array}$ & $\begin{array}{r}F Y \\
2000 \\
\end{array}$ & $\begin{array}{r}\text { FY } \\
2001 \\
\end{array}$ & $\begin{array}{r}F Y \\
2002 \\
\end{array}$ & $\begin{array}{r}F Y \\
2003 \\
\end{array}$ & TOTAL \\
\hline $41 E 140$ & Radiological Engineer & 56 & 139 & 80 & 127 & 296 & 166 & 865 \\
\hline $42 T 050$ & Radiological Technician & 420 & 70 & 1798 & 1782 & 1787 & 1793 & 7650 \\
\hline 420E110 & Quality Engineer & 31 & 149 & 378 & 126 & 96 & & 780 \\
\hline 1420T060 & Quality Inspector & 51 & 78 & 89 & 60 & & & 278 \\
\hline $710 P 170$ & Environmental Engineer & & 80 & 207 & 216 & 78 & & 580 \\
\hline 280E130 & Transportation Engineer & 1925 & 1934 & 1915 & 1908 & 78 & & 7760 \\
\hline $280 P 170$ & Transporation Coordinator & 196 & 222 & 241 & 424 & 496 & 689 & 2268 \\
\hline $10 E 010$ & Safety Analyst & & 60 & 996 & 874 & & & 1930 \\
\hline $10 E 120$ & Criticality Safety Engineer & & 60 & 167 & 213 & & & 440 \\
\hline $110 E 130$ & Other/Technical Engineer & 260 & 132 & 233 & 371 & 179 & & 1175 \\
\hline 1E1R010 & RAL Technician & & 20 & & & 637 & 1019 & 1676 \\
\hline 1E1S010 & RAL Engineer & & & & & 372 & 340 & 712 \\
\hline 100M4 & Construction Purchases & & & & & & & \\
\hline 100M6 & Direct Purchases & & & & & & & \\
\hline 100M8 & Subcontracts & & & & & & & \\
\hline $10 \mathrm{MO20}$ & Fuel Manager & 1925 & 1994 & 2122 & 2121 & 88 & & 8250 \\
\hline $112 \mathrm{G} 050$ & Administration Support & & & & 38 & 202 & & 240 \\
\hline $12 \mathrm{M010}$ & CPP 651 Operations Foreman & 490 & 500 & 2372 & 1783 & 1787 & 1852 & 8785 \\
\hline $112 R 040$ & CPP 651 Fuel Operators & 2115 & 2811 & 5324 & 1845 & 5065 & 7550 & 24710 \\
\hline $113 E 070$ & Fuel Supervisor & & & & 3 & 78 & & 80 \\
\hline $113 E 080$ & Facility Fuel Engineer & 1119 & 893 & 1511 & 1043 & 2141 & 2001 & 8708 \\
\hline $122 \mathrm{E} 130$ & Design Engineer & & 79 & 341 & 112 & 8 & & 540 \\
\hline $130 P 130$ & Trainer & 113 & 188 & 80 & 142 & 338 & & 860 \\
\hline $152 P 160$ & Procedure Writer & 352 & 384 & 300 & 282 & 38 & & 1356 \\
\hline 213R040 & CPP 602 Fuel Operators & & 20 & 6541 & 7070 & 3866 & 1419 & 18916 \\
\hline $221 E 010$ & Technical Safety Engineer (TSE) & 31 & 49 & 30 & 24 & 96 & & 230 \\
\hline 54.3?E130 & Plant Systems Engineer & 81 & 78 & 61 & 43 & 78 & & 340 \\
\hline 6100)E130 & Security Operations & 31 & 109 & 30 & 136 & 184 & & 490 \\
\hline $6120 P \cdot 170$ & Saleguards \& Accountability & 4905 & 5086 & 4680 & 5041 & 1789 & 1791 & 2329\%: \\
\hline $65: 300020$ & Electrician & & & & 8 & 2 & & 10 \\
\hline 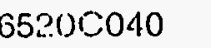 & Machinisst & & 19 & 301 & & & & 320 \\
\hline 65200110 & Wolder & & 9 & 151 & & & & 160 \\
\hline $65: 20 \mathrm{M010}$ & Cralt Forellian & & 5 & 75 & 18 & 80 & 152 & 330 \\
\hline $65:) 1717080$. & I:(uірmи:n) iperator & 161 & 128 & 229 & 500 & 313 & 607 & 1938 \\
\hline \multirow[t]{2}{*}{$65: ? 111070$} & Insilrumt1:nl rechnician & & & & 32. & 8 & & 40 \\
\hline & HE:POFH TOTAL & 14263 & 16293 & 30255 & 26341 & 20179 & 19379 & 125709 \\
\hline
\end{tabular}


MITCO - CPP 651 MATERIAL SCHEDULE

EPORT DATE 05AUG97 RUN NO. 466

13:16

ost load by resource type
PRIMAVERA PROJECT PLANNER

COST LOADING REPORT

TOTAL USAGE FOR YEAR
OPT D - SHIP AS IS \& TNT \& DED. CREW

START DATE 01JUL97 FIN DATE 27MAR02

DATA DATE $010 \mathrm{CT} 97$ PAGENO. 1

\begin{tabular}{|c|c|c|c|c|c|c|c|}
\hline RESOURCE & RESOURCE DESCRIPTION & $\begin{array}{r}F \bar{Y} \\
1998 \\
\end{array}$ & $\begin{array}{r}F Y \\
1999 \\
\end{array}$ & $\begin{array}{r}F Y \\
2000 \\
\end{array}$ & $\begin{array}{r}F Y \\
2001 \\
\end{array}$ & $\begin{array}{r}F Y \\
2002 \\
\end{array}$ & TOTAL \\
\hline 1341E140 & Radiological Engineer & 3421 & 3573 & 4893 & 5876 & 2612 & 20375 \\
\hline 1342T050 & Radiological Technician & 20740 & 5682 & 86655 & 88522 & 87768 & 289367 \\
\hline 1420E110 & Quality Engineer & 1603 & 3526 & 19239 & 3837 & & 28204 \\
\hline 1420T060 & Quality Inspector & 2628 & 3974 & 4577 & 4615 & & 15794 \\
\hline $3280 \mathrm{E} 130$ & Transportation Engineer & 96509 & 96989 & 96029 & 95549 & & 385075 \\
\hline $3280 \mathrm{P} 170$ & Transporation Coordinator & 9827 & 8146 & 14568 & 31947 & 18093 & 82581 \\
\hline $4110 E 130$ & Other/Technical Engineer & 20303 & 2707 & 14863 & 24562 & 13078 & 75513 \\
\hline $5100 \mathrm{M} 6$ & Direct Purchases & 86716 & 92147 & 86284 & 85853 & & 351000 \\
\hline $5100 \mathrm{MB}$ & Subcontracts & 17050 & 4700 & 521422 & 1082778 & & 1625950 \\
\hline $5110 \mathrm{M} 020$ & Fuel Manager & 132271 & 132930 & 131613 & 130955 & & 527770 \\
\hline 5112M010 & CPP 651 Operations Foreman & 25421 & 57965 & 91044 & 93137 & 92273 & 359840 \\
\hline $5112 R 040$ & CPP 651 Fuel Operators & 109726 & 292128 & 126803 & 207367 & 115845 & 851870 \\
\hline 5113E080 & Facillty Fuel Engineer & 67554 & 47848 & 96906 & 103807 & 43569 & 359684 \\
\hline $5122 E 130$ & Design Engineer & & 1240 & 20018 & & & 21258 \\
\hline 5130P130 & Trainer & 5625 & 6375 & 4000 & 4500 & & 20500 \\
\hline $5152 P 160$ & Procedure Writer & 14541 & 15841 & 12384 & 15686 & & 58452 \\
\hline $5213 R 040$ & CPP 602 Fuel Operators & & 11525 & 328563 & 269088 & 361810 & 970986 \\
\hline 5221E010 & Technical Safety Engineer (TSE) & 2217 & 3458 & 2128 & 2128 & & 9932 \\
\hline $5432 E 130$ & Plant Systems Engineer & 4905 & 4679 & 3698 & 3622 & & 16904 \\
\hline $6100 E 130$ & Security Operations & 1887 & 2943 & 1811 & 1811 & & 8452 \\
\hline $6120 P 170$ & Safeguards \& Accountability & 244052 & 245119 & 243395 & 288580 & 88502 & 1109648 \\
\hline 65200040 & Machinist & & 889 & 14356 & & & 15245 \\
\hline $6520 C 110$ & Welder & & 445 & 7178 & & & 7622 \\
\hline $6520 \mathrm{M} 010$ & Craft Foreman & & 232 & 3740 & 3637 & 4057 & 11665 \\
\hline \multirow{2}{*}{$6520 R 080$} & Equipment Operator & 7682 & 6074 & 10921 & 37781 & 15575 & 78034 \\
\hline & REPORT TOTAL & 874678 & 1051135 & 1947087 & 2585639 & 843182 & 7301720 \\
\hline
\end{tabular}




\begin{tabular}{|c|c|c|c|c|c|c|c|}
\hline RESOURCE & RESOURCE DESCRIPTION & $\begin{array}{r}F Y \\
1998 \\
\end{array}$ & $\begin{array}{r}F Y \\
1999\end{array}$ & $\begin{array}{r}F Y \\
2000 \\
\end{array}$ & $\begin{array}{r}F Y \\
2001 \\
\end{array}$ & $\begin{array}{r}F Y \\
2002 \\
\end{array}$ & TOTAL \\
\hline 41E140 & Radiological Engineer & 56 & 59 & 80 & 97 & 43 & 335 \\
\hline $342 T 050$ & Radiological Technician & 420 & 115 & 1755 & 1793 & 1777 & 5860 \\
\hline $420 E 110$ & Quality Engineer & 31 & 69 & 375 & 75 & & 550 \\
\hline $420 T 060$ & Quality Inspector & 51 & 78 & 89 & 90 & & 308 \\
\hline $280 E 130$ & Transportation Engineer & 1925 & 1934 & 1915 & 1906 & & 7680 \\
\hline $280 P 170$ & Transporation Coordinator & 196 & 162 & 291 & 637 & 361 & 1647 \\
\hline $\begin{array}{l}1110 \mathrm{E} 130 \\
100 \mathrm{M} 6\end{array}$ & $\begin{array}{l}\text { Other/Technical Engineer } \\
\text { Direct Purchases }\end{array}$ & 260 & 35 & 190 & 315 & 167 & 967 \\
\hline 100M8 & Subcontracts & & & & & & \\
\hline $10 \mathrm{M020}$ & Fuel Manager & 1925 & 1934 & 1915 & 1906 & & 7680 \\
\hline $112 \mathrm{M010}$ & CPP 651 Operations Foreman & 490 & 1117 & 1755 & 1795 & 1779 & 6936 \\
\hline $112 R 040$ & CPP 651 Fuel Operators & 2115 & 5631 & 2444 & 3997 & 2233 & 16420 \\
\hline 113E080 & Facility Fuel Engineer & 1119 & 793 & 1605 & 1720 & 722 & 5958 \\
\hline 122E130 & Design Engineer & & 19 & 301 & & & 320 \\
\hline $30 \mathrm{P} 130$ & Trainer & 113 & 128 & 80 & 90 & & 410 \\
\hline $152 \mathrm{P} 160$ & Procedure Writer & 352 & 384 & 300 & 380 & & 1416 \\
\hline 213R040 & CPP 602 Fuel Operators & & 222 & 6333 & 5187 & 6974 & 18716 \\
\hline 21E010 & Technical Safety Engineer (TSE) & 31 & 49 & 30 & 30 & & 140 \\
\hline 5432E 130 & Plant Systems Engineer & 81 & 78 & 61 & 60 & & 280 \\
\hline $100 \mathrm{E} 130$ & Security Operations & 31 & 49 & 30 & 30 & & 140 \\
\hline $120 P 170$ & Safeguards \& Accountability & 4905 & 4926 & 4891 & 5799 & 1779 & 22300 \\
\hline $520 C 040$ & Machinist & & 19 & 301 & & & 320 \\
\hline $520 C 110$ & Welder & & 9 & $\cdot 151$ & & & 160 \\
\hline $520 \mathrm{M} 010$ & Craft Foreman & & 5 & 75 & 73 & 82 & 235 \\
\hline \multirow[t]{2}{*}{$520 \mathrm{R} 080$} & Equipment Operator & 161 & 128 & 229 & 793 & 327 & 1638 \\
\hline & REPORT TOTAL & 14263 & 17940 & 25199 & 26771 & 16243 & 100416 \\
\hline
\end{tabular}

